\title{
GEOTECHNICAL SUPPORT AND TOPICAL STUDIES \\ FOR NUCLEAR WASTE GEOLOGIC REPOSITORIES
}
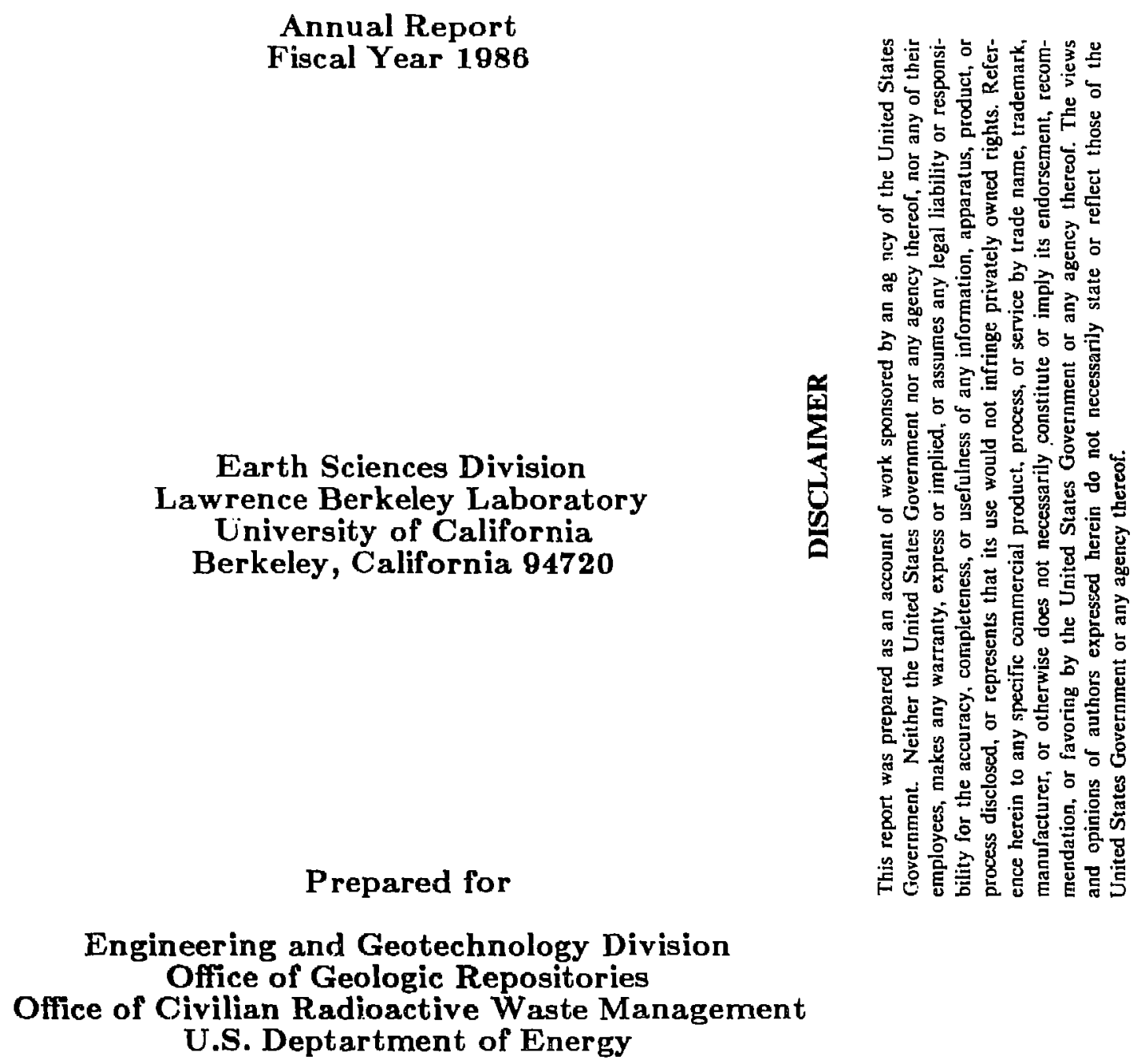

November 1986

This work was prepared for the U.S. Department of Energy under Contract Nom DE-AC03-76SF00098.

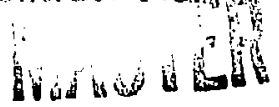




\section{Table of Contents}

EXECUTIVE SUMMARY, C.F. Tsang …................................................. 1

GEOSCIENCE TECHNICAL SUPPORT FOR NUCLEAR WASTE

GEOLOGIC REPOSITORIES, D.C. Mangold, F. V. Hale,

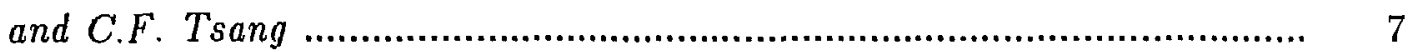

POSTCLOSURE MONITORING, H.F. Morrison and E.L. Majer ................ 15

FRACTURE STUDIES

Geochemical-mineralogical and Geomechanical Investigations of

Fractured, Heated Rock, H.A. Wollenberg, S. Flexser,

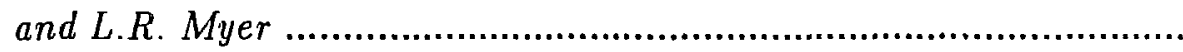

Deformation of Fractures Under Normal Stress, L.R. Myer,

L.J. Pyrak-Nolte, and N.G.W. Cook

Fracture Permeability Under Normal Stress, L.J. Pyrak-Nolte,

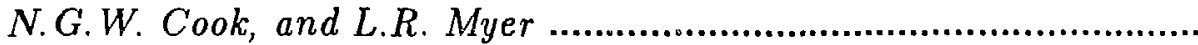

Channel Model of Flow Through Fractured Media, Y.W. Tsang

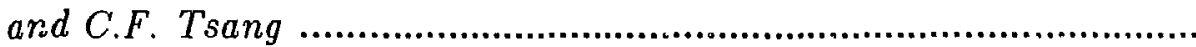

Solution of Navier-St,okes Equations in Fractures

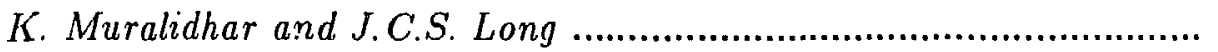

Pressure Solution Geochemistry, I.A.Apps

Seismic Wave Properties of Idealized Fractures, D.L. Hopkins, L.R. Myer, and N.G.W. Cook

Modeling the Seismic Response of Fractured Media, E.L. Majer

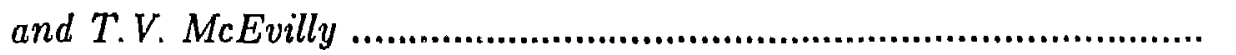

Borehole Breakout Analysis, N.G.W. Cook and Z. Zheng

Frictional Stability of Fractures and Faults in Rock, J.M. Kemeny and N.G.W. Cook 


\title{
LBL Geologic Repository Project (FY 1986)
}

\author{
Executive Summary
}

Chin-Fu Tsang

The multidisciplinary project was initiated in fiscal year 1986. It comprises two major interrelated parts:

(1) Technical Assistance. This part of the project includes: (a) review of the progress of major projects in the DOE Office of Civilian Radioactive Waste Management Program and advise the Engineering and Geotechnology Division on significant technical issues facing each project; (b) analyze geotechnical data, reports, tests, surveys and plans for the different projects; (c) review and somment on major technical reports and other program documents such as site characterization plans and area characterization plans and (d) provide scientific and technical input at technical meetings.

(2) Topical Studies. This activity comprises studies on scientific and technical topics, and issues of significance to in-situ testing, test analysis methods, and performance assessment of nuclear waste geologic repositories. The subjects of study were selected based on discussions with DOE staff. For fiscal year 1986, one minor and one major area of investigation were undertaken. The minor topic is a preliminary consideration and planning exercise for postclosure monitoring studies. The major topic, with subtasks involving various geoscience disciplines, is on the mechanical, hydraulic, geophysical and geochemical properties of fractures in geologic rock masses. 
The main LBL personnel that are responsible for the formulation and performance of both parts of the project are:

$\begin{array}{ll}\text { John A. Apps } & \text { Geochemistry } \\ \text { Harold A. Wollenberg } & \text { Geology } \\ \text { Neville G. W. Cook } & \text { Geomechanics } \\ \text { Larry R. Myer } & \text { Geomechanics } \\ \text { Ernest L. Majer } & \text { Geophysics } \\ \text { Thomas V. McEvilly } & \text { Geophysics } \\ \text { H. Frank Morrison } & \text { Geophysics } \\ \text { Marcelo J. Lippmann } & \text { Hydrogeology } \\ \text { Chin-Fu Tsang } & \text { Hydrogeology } \\ \text { Paul A. Witherspoon } & \text { Hydrogeology }\end{array}$

Additional LBL personnel are involved in the topical studies part of the project, and some also assist in the technical review.

Two important and rather special features of this project should be pointed out here. First, this project is truly multi-disciplinary. As seen by the LBL personnel listed above, all major geoscience disciplines are represented, with many years of combined experience in the nuclear waste geologic isolation problem. Many meetings and discussions among LBL personnel were held. Whenever time allowed, major issues and results presented to DOE have undergone multidisciplinary discussions and scrutiny.

The second feature that is of crucial importance is that both parts of the project, the technical assistance and the topical studies, were mainly performed by the same personnel. This ensured the participation of highly-respected researchers working at the forefront of the state-of-the-art, in providing DOE with comments and results relevant to the geotechnical aspects of nucleal waste 
geologic repositories. Often, technical reviews influenced the direction and emphasis of topical studies and topical studies provided inputs to the reviews.

The present report lists the technical reviews and comments made during the fiscal year and summarizes the technical progress of the topical studies.

In the area of technical assistance, during FY86, a total of 48 reviews were made, including reviews of five Environmental Assessment (EA) reports, 11 Site Characterization Plans (SCP) chapters, four DOE technical papers, five NRC Generic Technical Position (GTP) papers, six unsolicited proposals to DOE, 17 trips to meetings and trip reports, as well as one mineralogical and petrological analysis of well cuttings. These activities are described in a Table on pages 1214.

The objective of the post-closure monitoring studies is to give a preliminary evaluation of key parameters and issues, and to prepare appropriate plans and proposals for detailed investigations. A number of in-house meetings were held and many ideas were discussed. A preliminary proposed plan of using geophysical (electrical) methods for monitoring the behavior of underground nuclear waste repositories after their closure has been prepared for the DOE. A brief summary is included in this annual report. One key point that emerges from these two studies is that it is important to begin post-closure monitoring planning and execution at an early stage of repository design and consiruction. Some of the monitoring methods may require special built-in features for the repository and all the monitoring methods require a properly established data baseline.

Fracture studies form the main part of the topical studies. We approached the problem from many directions: 


\section{Solid Mechanies, \\ Fluid Dynamics, \\ Geology, \\ Geophysics, and \\ Geochemistry.}

Ten articles on the progress of our fracture studies are included in this report. The article titles and their authors are listed in the Table of Contents. This multi-disciplinary program was carried out through laboratory experiments, theoretical analyses as well as numerical simulation. Part of the studies are of a fundamental nature, based on which we expect important practical geotechnical issues to be addressed, clarified or restlved in the next two or three years. Other studies, on the other hand, have already yielded results that provide new insights and analysis techniques for understanding the physics and chemistry of fracture systems.

The major accomplishments of the first year may be summarized as follows:

(1) Careful radiographic measurements were made of core samples of granitic rocks which had been exposed to elevated temperatures for more than a year during heater experiments conducted at Stripa, Sweden (Chan et al., 1080). It was found that in response to elevated temperatures radioelements were absorbed to the linings of open fractures by water and/or vapor.

(2) Fracture deformation measurements as a function of normal stress were completed for three natural fractures in granitic rock masses. Results from all three fractures illustrate the critical importance of the size and distribution of asperities and voids on mechanical behavior.

(3) The effect of uniaxial effective stress on fluid flow through a natural fracture in a low permeability granite rock was studied. Flow measurements in 
conjunction with fracture displacement measurements were used to develop an empirical relationship between fluid flow and fracture closure.

(4) A channel model was proposed to describe and calculate transport through fractured media in terms of flow through a system of tortuous and variableaperture channels. Based on this new model, we are able to analyze and correlate several sets of laboratory and field data on tracer transport and pressure measurements, and to suggest new measurements to validate the model's predictions.

(5) A fundamental analysis based on the Navier Stokes equation is made of the fluid flow in a variable-aperture fracture having a number of contact areas. Flow patterns around a square or circular obstacle have been obtained, displaying features that may lead to a departure from the conventional Darcy's law of flow.

(6) Theoretical, experimental and field investigations of pressure solution phenomena were reviewed in relation to the seismic stability of fractures. All evidence supports a novel interpretation that pressure solution results from the enhanced aqueous solubility of minerals due to stress induced defects in their crystal structures. An experiment to measure this phenomenon in quartz has been designed using information from a survey of the kinetics of quartz dissolution and precipitation under hydrostatic conditions.

(7) A series of controlled experiments have been performed in which seismic waves were propagated across idealized fracture surfaces. Furthermore, a new analytic model has been developed and implemented numerically to calculate the specific stiffness of a fracture.

(8) The development of a computer model to predict how seismic waves travel through a fracture network has been completed. This will be used to 
analyze seismic data for the detection and characterization of fracture zones between boreholes and/or subsurface workings.

(9) A methodology has been developed to generate wellbore breakout in elastic brittle rocks using numerical simulation. A number of significant conclusions are found by studying the predicted breakout cross-sections.

(10) A theory was developed for the mechanical behavior of a slip plane containing asperities. It was applied to understand the shear deformation and stability of fractures and faults. This has important implications for the stability of rock masses. 


\section{Geoscience Technical Support \\ for Nuclear Waste Geologic Repositories}

D. C. Mangold, F. V. Hale and C. F. Tsang

The Geoscience Technical Support activities in the Geologic Repository Project (GRP) covered a broad range of reports and reviews, particularly the Environmental Assessment (EA) and Site Characterizaiton Program (SCP) reviews, during FY86. The accompanying table, "Geotechnical Support Activities: Fiscal Year 1986," gives the type of review or other activity, the date when a report was sent to DOE, and a brief description of the material or meeting that was reviewed.

The reviews were performed by a pool of highly knowledgeable and respected research scientists, who represent a broad range of disciplines in the earth sciences. The individuals an their specialities are listed below:

$\begin{array}{ll}\text { Numes } & \text { Principal Expertise } \\ \text { John A. Apps } & \text { Geochemistry } \\ \text { Chalon L. Carnahan } & \text { Geochemistry } \\ \text { Steven Flexser } & \text { Geology } \\ \text { Harold A. Wollenberg } & \text { Geology } \\ \text { Neville G. W. Cook } & \text { Geomechanics } \\ \text { Larry R. Myer } & \text { Geomechanics } \\ \text { Ernest L. Majer } & \text { Geophysics } \\ \text { Thomas V. McEvilly } & \text { Geophysics } \\ \text { H. Frank Morrison } & \text { Geophysics } \\ \text { Marcelo J. Lippmann } & \text { Hydrogeology } \\ \text { Chin-Fu Tsang } & \text { Hydrogeology } \\ \text { Paul A. Witherspoon } & \text { Hydrogeology }\end{array}$

The diversity of backgrounds of the participating scientists is representative of the multidisciplinary teamwork that has characterized LBL's effort in this project. They have developed a close working relationship in carrying out the topical studies (reported in subsequent parts of this report) and based on this, they are able to perform the many 
different technical support tasks given by DOE in a timely and effective manner.

In total, there were 48 reviews, including reviews of 5 EA Rคrorts, $11 \mathrm{SCP}$ Chapters, 4 DOE technical papers, 5 NRC Generic Technical Position (GTP) papers, 6 unsolicited proposals to DOE, 17 trips to meetings and their reports, as well as 1 mineralogical and petrological analysis of well cuttings. A briel summary of the activities for each of these categories is given below.

\section{Environmental Assessments}

The draft Environmental Assessment reports for the five sites proposed by DOE for a nuclear waste repository were reviewed by LBL scientists. The sites were Hanford, Yucca Mountain, Richton Dome, Davis Canyon, and Deal Smith. Each site had chapters on the site selection process, the present conditions of the site with regard to its geology, hydrology, etc., the expected effects of site characterization activities, the regional and local effects of locating a repository at the site, and an evaluation of the suitability of the site for site characterization and for development as a repository. These reviews were performed within a very short time frame as required by DOE.

\section{Site Characterization Program Reviews}

The chapters for the Site Characterization Program Reviews of Hanford or BWIP (Basalt Waste Isolation Project), and the NNWSI (Nevada Nuclear Waste Storage Investigations Project) sites were reviewed by LBL scientists in the areas of geology, geomechanics, hydrology, geochemistry, the repository, and the site programs in these areas. In general, reviews were done by a few specialists in each area in order to cover the many aspects in each chapter. The comments on these chlapters were also provided to DOE in a timely way. 


\section{DOE Technical Papers}

There were reviews from time to time on papers that treated particular points related to nuclear waste isolation where LBL had expertise to provide helpful comments. The issues dealt with included 9 tandem accelerator mass spectrometry facility (used for age-dating of ground water, for example), a NNWSI position paper on seismic/tectonic definitions, a rock mechanics laboratory program plan, and the tentative program for Phase 3 of the international collaboration at the Stripa project in Sweden. In past years LBL had a leading role in the Swedish-American Cooperative Program at Stripa for experimental work related to nuclear waste isolation.

\section{NRC Generic Terhnical Position Papers}

The reviews also covered the Generic Technical Position papers of the US Nuclear Regulatory Commission. These documents establish generic guidelines on topics of technical interest related to nuclear waste storage. The topics were concerning the extent of the disturbed zone around a repository, in situ testing during site characterization, ground water travel time, radionuclide sorption for a repository, and procedures for qualifying existing data as part of the QA program for potential sites of repositories. To provide comments on these documents LBL personnel from several different fields often read the same paper, bringing different perspectives together to prepare the review report.

\section{Unsolicited Proposals to DOE}

From time to time DOE received proposals from researchers to conduct research on various aspects of the potential sites (such as the geology, geochemistry, etc.) or the methodology used to evaluate the technical aspects of the sites. These proposals were sent to LBL and reviewed by LBL scientists familiar witi, the particular area of proposed research. The topics for the site-related studies included salt basins as repositories of 
nuclear waste, the deep structure and evolution of the northern Delaware basin, and dissolution features in playa lake basins. For the methodology investigations the topics covered were characterization of geologic fractures using fractal and graph theory, seismic studies for safe disposal of nuclear waste, and the use of chemical models in assessing salt repository performance.

\section{Meetings Attended and Trip Reports}

Throughout the fiscal year members of the LBL staff, upon the request from $\mathrm{DOE} / \mathrm{HQ}$, attended meetings related to the GRP Project and prepared comments on significant points from the meetings. In November 1985, scientists attended a workshop on the structure and tectonics of the Palo Duro basin, and a seismic/tectonic workshop sponsored by NNWSI. In December, there were trips to Richland, Washington for a DOE/NRC pre-test consultation ineeting and a meeting on the BWIP site hydrochemistry. Also, LBL scientists attended the American Nuclear Society 1985 winter meeting in San Francisco.

During April 1986, LBL scientists attended a seminar on recent developments in evaporite deformation studies and a workshop on calcite-silica deposits. They participated in budget reviews for the SRP (Salt Repository Project), BWIP, and NNWSI for FY88 in April and May. The month of May was also the time that LBL staff went to an sliP geochemistry review, NNWSI geology and hydrology reviews, and a joint ONWI (Battelle Office of Nuclear Waste Isolation) Engineering Review Group and Geology Review Group meeting on hydrogeology of the potential site at Deaf Smith county. In July, scientists attended an ONWI site characterization geochemistry budget meeting, and a BWIP SCP Chapter 6 (repository) comments resolution workshop.

In these meetings and reviews, members of LBL provided the expertise and knowledge from many disciplines to focus on the many different aspects of nuclear waste isolation where DOE needed comments and suggestions. 


\section{Mineralogical and Petrological Analysis}

At the request of DOE, well cuttings from the Rolesville pluton were examined and analyzed for their mineralogy and petrology. The volumetric percentage of the constituent minerals, the degree of alteration, and the extent of fracturing were reported.

\section{Conclusion}

LBL has been very active in meeting DOE's need for review work as part of the geoscience technical support for nuclear waste repositories. The ability of scientists from many disciplines to work together at LBL was an important part of the effort to provide DOE with timely, helpful and balanced review comments to meet its requirements. 


\section{GEOTECHNICAL SUPPORT ACTIVITIES}

FISCAL YEAR 1986

\begin{tabular}{|c|c|c|}
\hline Activity & Delivery & Description \\
\hline EA Review & $10 / 18 / 85$ & $\begin{array}{l}\text { Draft Environmental Assessment report for the } \\
\text { Hanford sile }\end{array}$ \\
\hline EA Review & $10 / 18 / 85$ & $\begin{array}{l}\text { Draft Environmental Assessment report for the } \\
\text { Yucca Mountain site }\end{array}$ \\
\hline EA Review & $10 / 18 / 85$ & $\begin{array}{l}\text { Draft Environmental Assessment report for the } \\
\text { Richton Dome site }\end{array}$ \\
\hline EA Review & $10 / 18 / 85$ & $\begin{array}{l}\text { Draft Environmental Assessment report for the } \\
\text { Davis Canyon site }\end{array}$ \\
\hline EA Review & $10 / 18 / 85$ & $\begin{array}{l}\text { Draft Environmental Assessment report for the } \\
\text { Deaf Smith site }\end{array}$ \\
\hline Review & $10 / 25 / 85$ & $\begin{array}{l}\text { DOE "Fact Sheet: Availability of a Tandem } \\
\text { Accelerator Mass Spectrometry Facility" }\end{array}$ \\
\hline Review & $11 / 85$ & $\begin{array}{l}\text { NNWSI "Seismic/Tectonic Definitions," section } \\
3.2 .2 \text { of the seismic/tectonic position paper. }\end{array}$ \\
\hline Review & $11 / 22 / 85$ & $\begin{array}{l}\text { "Rock Mechanics Laboratory Program Plan (Revi- } \\
\text { sion 1)" (O/TM-69), an Internal Technical } \\
\text { Memorandum by Oschman, et al., ONWI/Battelle }\end{array}$ \\
\hline Trip Report & $12 / 12 / 85$ & $\begin{array}{l}\text { NRC/SRP workshop on structure and tectonics of } \\
\text { the Palo Duro Basin, Columbus, OH, Nov. 19-21 }\end{array}$ \\
\hline Trip Report & $12 / 15 / 85$ & $\begin{array}{l}\text { NNWSI Se ismic/tectonic workshop, Las Vegas, NV, } \\
\text { Nov. 11-13 }\end{array}$ \\
\hline Trip Report & $1 / 3 / 86$ & $\begin{array}{l}\text { DOE/NRC Pre-test consultation meeting, Richland, } \\
\text { WA, Dec. 9-10 }\end{array}$ \\
\hline Trip Report & $2 / 21 / 86$ & $\begin{array}{l}\text { DOE-RL/USGS meeting on site hydrochemistry, } \\
\text { Richland, WA, Dec. 10-12 }\end{array}$ \\
\hline Review & $3 / 5 / 86$ & $\begin{array}{l}\text { NRC Generic Technical Position (GTP) "Interpre- } \\
\text { tation and Identification of the Extent of the Dis- } \\
\text { turbed Zone with High-Level Waste Rule (10 CFR } \\
60 \text { )" }\end{array}$ \\
\hline Review & $3 / 5 / 86$ & $\begin{array}{l}\text { NRC GTP "In Situ Testing During Site Characteri- } \\
\text { zation for Hligh-Level Nuclear Waste Repositories" }\end{array}$ \\
\hline Review & $3 / 5 / 86$ & NRC GTP "Ground Water Travel Time" \\
\hline
\end{tabular}




\begin{tabular}{|c|c|c|}
\hline \multicolumn{3}{|c|}{$\begin{array}{l}\text { GEOTECHNICAL SUPPORT ACTIVTTIES } \\
\text { FISCAL YEAR } 1986 \text { (Continued) }\end{array}$} \\
\hline Activity & Delivery & Description \\
\hline Review & $3 / 17 / 86$ & $\begin{array}{l}\text { NRC GTP "Determination of Radion uclide Sorp- } \\
\text { tion for High-Level Nuclear Waste Repositories" }\end{array}$ \\
\hline Trip & $3 / 26 / 86$ & $\begin{array}{l}\text { ANS } 1985 \text { winter meeting, San Francisco, CA (no } \\
\text { trip report required; recorded in monthly report) }\end{array}$ \\
\hline Review & $3 / 27 / 86$ & $\begin{array}{l}\text { Unsolicited proposal to DOE by Sheppard and Lid- } \\
\text { dell, "Characterization of Geologic Fractures Using } \\
\text { Fractals and Graph Theory" }\end{array}$ \\
\hline Review & $5 / 9 / 86$ & $\begin{array}{l}\text { Unsolicited proposal to DOE by Sonnenfeld, "Salt } \\
\text { Basins as Repositories of Nuclear W'aste" }\end{array}$ \\
\hline Trip Report & $5 / 13 / 86$ & $\begin{array}{l}\text { TBEG seminar on recent developments in evaporite } \\
\text { deformation studies, Austin, TX, April 23-24 }\end{array}$ \\
\hline Trip Report & $5 / 13 / 86$ & $\begin{array}{l}\text { SAIC workshop on calcite-silica deposits, Las } \\
\text { Vegas, NV, April } 28\end{array}$ \\
\hline Trip Report & $5 / 23 / 86$ & $\begin{array}{l}\text { SRP FY88 budget review, Washington, DC, April } \\
28-29\end{array}$ \\
\hline $\begin{array}{cc}\text { Trip Report } \\
\vdots \quad: \quad \\
\end{array}$ & $5 / 23 / 86$ & $\begin{array}{l}\text { BWIP FY } 88 \text { budget review, Washington, DC, April } \\
\text { 30-May } 1\end{array}$ \\
\hline Trip Report & $5 / 23 / 86$ & $\begin{array}{l}\text { NNWSI FY88 budget review, Washington, DC, } \\
\text { May 12-15 }\end{array}$ \\
\hline Review. & $6 / 12 / 86$ & $\begin{array}{l}\text { Unsolicited proposal to DOE by Mithal, et al., "A } \\
\text { Preliminary Proposal: Seismic Studies for Safe } \\
\text { Disposal of Radioactive Waste" }\end{array}$ \\
\hline Trip Report & $6 / 17 / 86$ & $\begin{array}{l}\text { SRP geochemistry review, Columbus, OH, May 19- } \\
21\end{array}$ \\
\hline Trip Report & $6 / 17 / 86$ & $\begin{array}{l}\text { NNWSI SCP chapter } 3 \text { (hydrology) review, Las } \\
\text { Vegas, NV, May 29-30 }\end{array}$ \\
\hline Analysis & $6 / 30 / 86$ & $\begin{array}{l}\text { Mineralogical and petrological analysis of well cut- } \\
\text { tings from Rolesville pluton }\end{array}$ \\
\hline Trip Report & $7 / 7 / 86$ & $\begin{array}{l}\text { NNWSI SCP chapter } 1 \text { (geology) review, Las Vegas, } \\
\text { NV, May } 27-29\end{array}$ \\
\hline Trip Report & $7 / 21 / 86$ & $\begin{array}{l}\text { ONWI joint ERG-GRG review meeting on hydro- } \\
\text { geology of the potential site at Deaf Smith Courty, } \\
\text { Texas, held in Columbus, OH, May } 14-16 \\
\end{array}$ \\
\hline
\end{tabular}




\section{GEOTECHNICAL SUPPORT ACTIVTTIES}

\section{FISCAL YEAR 1986 (Continued)}

\begin{tabular}{|c|c|c|}
\hline Activity & Delivery & Description \\
\hline Trip Report & $7 / 22 / 86$ & $\begin{array}{l}\text { ONWI site characterization geochemistry budget } \\
\text { presentation, Washington, DC, July } 7\end{array}$ \\
\hline Trip Report & $7 / 30 / 86$ & $\begin{array}{l}\text { BWIP SCP chapter } 6 \text { (repository) comment resolu- } \\
\text { tion meeting, Richland, WA, July } 28-30 \text { (comments } \\
\text { delivered at meeting) }\end{array}$ \\
\hline Trip Report & $8 / 1 / 86$ & $\begin{array}{l}\text { Further comments on the ONWI joint ERG-GRG } \\
\text { review meetiug on the hydrogeology of the poten- } \\
\text { tial site at Deal Smith County, Texas }\end{array}$ \\
\hline SCP Review & $8 / 1 / 86$ & PIRC chapter 2 (geomechanics) \\
\hline SCP Review & $8 / 4 / 86$ & PIRC chapter 4 (geochemistry) \\
\hline SCP Review & $8 / 7 / 86$ & BWiP chapter 4 (geochemistry) \\
\hline SCP Review & $8 / 7 / 86$ & PIRC chapte 6 , part 1 (repository) \\
\hline SCP Rcview & $8 / 11 / 80$ & BWIP chapter 2 (geomechanics) \\
\hline SCP Review & $8 / 13 / 86$ & PIRC chapter 1 (geology) \\
\hline SCP Review & $8 / 19 / 86$ & PIRC chapter 3 (hydrology) \\
\hline SCP Review & $8 / 20 / 86$ & PIRC chapter 6, part 2 (repcsitory) \\
\hline Review & $8 / 22 / 86$ & $\begin{array}{l}\text { NRC GTP "Qualification of Existing Data for } \\
\text { High-Level Nuclear Waste Repositories" }\end{array}$ \\
\hline Review & $9 / 9 / 86$ & $\begin{array}{l}\text { Unsolicited proposal to DOE by Dickerson, "Inves- } \\
\text { tigation of the Deep Structure and Evolution of the } \\
\text { Northern Delaware Basin" }\end{array}$ \\
\hline Review & $9 / 9 / 86$ & $\begin{array}{l}\text { From DOE for comments: Tentative program for } \\
\text { the Stripa project phase } 3,1986-1991\end{array}$ \\
\hline Review & $9 / 11 / 86$ & $\begin{array}{l}\text { Unsolicited proposal to DOE by Reeves, "Investiga- } \\
\text { tion of Dissolution Features in Playa Lake Basins, } \\
\text { Proposed Nuclear Waste Repository Site, Deaf } \\
\text { Smith County, Texas" }\end{array}$ \\
\hline Review & $9 / 12 / 86$ & $\begin{array}{l}\text { Unsolicited proposal to DOE by Weare, et al., "Use } \\
\text { of Chemical Models in Assessing Salt Repository } \\
\text { Performance" }\end{array}$ \\
\hline SCP Review & $9 / 26 / 86$ & BWIP section 8.3.1.4 (site geochemistry program) \\
\hline SCP Review & $9 / 29 / 86$ & BWIP chapter 1 (geology) \\
\hline SCP Review & $9 / 29 / 86$ & BWIP section 8.3.1.1 (site geology program) \\
\hline
\end{tabular}




\title{
Postclosure Monitoring
}

\author{
H.F. Morrison and E.L. Majer
}

The future integrity of nuclear waste repositories relies on the assessment and prediction of changes in the groundwater regime in the vicinity of the site. Without water as a transport medium there would be little concern about the long term stability of suitably engineered repositories. However, even in so called unsaturated zones, there is $80 \%$ saturation of the pore spaces and uncertain amounts of water in the fractures of the rock. We have also come to realize that the fluid flow in a formation is largely controlled by the fracture permeability and certain geophysical and geochemical properties are also highly influenced by the fracture system and the fluid saturation of the fractures.

In general, small changes in stress state, and saturation are likely to be represented by relatively larger changes in the geometry and saturation in the fractures themselves. Thus, as stress states change, open fractures close rather easily in one direction and open in another. A nearly saturated rock will hold all the water in the matrix porosity and manifest a rather small fluid permeability; a small amount of water will then fill the fractures and change the bulk permeability dramatically. That the fractures can act to amplify such small changes in state is fortuitous because we have identified several geophysical and geochemical methods which are sensitive to the fracture systems and hence will provide excellent methods for monitoring changes in them.

Monitoring methods must be sensitive to changes in permeability and saturation in the vicinity of the repository and must also be non invasive. The monitoring is especially important in the early stages after emplacement since it is in this period 
that major changes in stresss state caused by heating or the excavation itself would be expected. It is also important to realize that there must be a background against which to see the changes: any measurements must therefore commence before excavation so that such a baseline can be established. The measurements must also be robust in the sense that they can be continued over the long term without worrying about component or system failure on a scale hundreds of years. This long term monitoring is very important to ensure that major changes in stress (tectonics) or climate (water saturation) do not occur which would invalidate the predictions of the integrity of the site.

In the topical studies reported in this annual report, we have devoted considerable effort to understanding the role of fractures in fluid flow, seismic wave propagation and mechanical properties of rocks in the repository. These studies have shed new light on mechanisms of fluid flow in fractured rock and how individual fractures influence seismic waves. A method has also been developed for calculating seismic velocities and attenuation through the same system of fractures used to study hydrological flow. This approach promises to allow seismic methods to be used to predict fluid flow in regions inaccessible to hydrological measurements. These studies have revealed that the seismic methods are also sensitive to changes in the fracture system and are consequently excellent tools for monitoring.

We have also looked into other monitoring methods and we have identified two very promising techniques, one of which is complementary to the seismic methods. We will discuss each of these monitoring methods in more detail below.

\section{Post-Closure Monitoring of Thermohydrological Perturbations}

The heat released by the radioactive wastes will remain in the rock formations for thousands of years and will distort the hydrological conditions between the repository and the accessible environment. The most obvious natural analog of thermally 
induced perturbations is the occurances of geysers and hot springs above a magina intrusion or a geothermal anomaly. Although we do not expect the buried radioactive wastes will generate such drastic thermohydrological changes, preliminary estimates indicated that the thermally induced perturbations cannot be ignored for the current designs of repositories.

The thermohydrological perturbations will depend on the ambient conditions of the host rock formations. If the repository is below the watertable in a saturated system, the dominant changes are the introduction of convective movement of liquid flow which moves the water in the repository upward by the buoyancy forces. If the formation is fractured, the liquid movements will be mainly through the fracture network. Temperature sensors, pressure gauges placed on the surfaces near fractures and fault zones would detect heat flow changes, pressure changes, and the flow direction changes. Durability or ease of replacement of the sensors is a crucial issue to fully assess the impact of long-term evolutions of buoyance distortions.

If the repository is above the watertable in a thick unsaturated system, the gaseous flow should also be considered together with liquid flow changes. For fractured, porous formations, The capillary forces are likely to hold liquid water in the rock matrix and kcep the fractures dry. The fracture network will be the main conduits for the gaseous flow. If the fracture network is very conductive, The gaseous velocities can be very high and the presence of thermally induced gas flow can be easily detected. Gaseous tracers would enhance the capabilities to detect thermally induced changes in flow conditions.

The monitoring network for detecting thermohydrological changes in gas, liquid flows and tracers will be mainly on the ground surfaces and in shallow borcholes. A few deep monitoring boreholes away from the repository can also enhance the monitoring of the three-dimensional changes induced by the repository. Whenever possible, the hydrological monitoring network should coordinate with other remote sensing 
electromagnetic and seismic devices. A coordinated effort among thermohydrological, geochemical, and geophysical studies should be valuable for the success of postclosure monitoring of repository performance. 


\section{Seismic Methods}

The seismic methods can be divided into the active and passive methods. The passive methods involve "listening" to seismic energy being created by stress changes or natural seismicity such as microearthquakes or acoustic emissions (AE) near the undeground openings. Active methods involve introducing energy into the ground and observing how the seismic waveforms change due to inhomogenieties in the rock. Both the direct and reflected arrivals can be used for this imaging process. Seismic reflection methods are of course used extensivly in the petroleum industry for reservoir delineation. For this discussion we will confine ourselves to mainly the active methods, although the passive listening may play a very inportant role in monitoring the long term integrity and stability of a repository. The utility of the passive as well as the active techniques will depend upon the resolution obtainable in any given rock Lype. For this reason the discussion will be mainly directed towards the seismic methods that have the highest resolution. These methods are the Vertical Seismic Profiling techniques. The VSP techniques are superior in this sense because the sensor is located below the weathered rock layers that usually strip the high frequency information for the data. In the seismic methods it is important to remember the effect that water plavs in the propagation of seismic waves. As a rock is saturated, or dried, velocity changes of 20 to 30 percent are seen in relatively unconfined samples. Also, water plays a crucial role in the generation of pore pressure changes which will significantly effect the rate and generation of AE/Microseismic events, especially in the presence of thermal loading. In monitoring a repository it is the water content and behavior that will determine if the repository is performing as designed. Therefore, we have selected the methods that have the highest potential for monitoring the parameters that will control these factors. 
Vertical seismic profiling (VSP) techniques are becoming increasingly popular for defining detailed subsurface structure. In addition tr the more conventional uses of VSP, we have been investigating the use of three component VSP's for fracture detection and characterization in addition to using VSP for detailed structural definition. Fracture detection using $P$ and $S$ waves in VSP studies is not a new idea, (Stewart et al., 1981). It is becoming increasingly apparent, however, that to utilize the full potential of VSP, 3-component data should be acquired. Crampin has pointed out the importance of using 3-component data in VSP work, particularly for fracture detection (Crampin, 1978, 1981, 1984a, 1984b, 1985). These authors and others have pointed out the phenomenon of shear wave splitting and the anisotropy effects of $S H$ versus the $S V$ waves in addition to $P$ versus $S$ wave anisotropy (Leary and Henyey, 1985). In addition to Crampin's theoretical work on shear wave spiitting (1978, 1985) there has been some recent laboratory (Myer et al., 1985) and theoretical work Schoenberg $(1980,1983)$ which explains shear wave anisotropy in terms of fracture stiffress. The fracture stiffness theory differs from Crampin's theory in that at a fracture, or a non-welded interface, the displacement across the surface is not required to be continuous as a seismic wave passes, only the stress must remain continuous. This displacement discontinuity is taken to be linearly related to the stress through the stiffness of the discontinuity.

The implication of the fracture stiffness theory is that for very thin discontinuities, for example fractures, there can b: significant effect upon the propagation of a wave. Usually one thinks of seismic resolation in terms of wavelength as compared to the thickness and lateral extent of a bed or other feature. In the stiffness theory the lateral extent is still important, but if the fracture stiffness is adequate, the thickness of the feature can be much much less than the seismic wavelength. This stiffness theory is also attractive from several other points of vicw. Schocnuerg $(1980,1983)$ shows that the ratio of the velocity of a seismic wave perpendicular and parallel to a 
set of stiffness discontinuities is a function of the spacing of the discontinuities as well as the stiffness. Thus, given the stiffness and the velocity anisoptropy, one could determine the average fracture spacing or density. Or, altematively, given independent information on fracture density, one could determine the fracture stiffness and hopefully relate this stiffness to actual fracture properties such as discriminating between filled atid open fractures or hopefully hydraulic conductivity. In any case, there is sufficient reason to expect fracture content and properties to be reflected in the velocity, amplitude, and polarization of the shear waves. For the purpose of postclosure monitoring the concept of fracture stiffness and its effect upon the propagation of seismic waves is very important. In a monitoring mode one would look for changes in wave propagation characteristics as a function of time rather than absolute values. Depending upon travel paths and rock types a change of just a few percent change in the velocity of a 50 meter zone would be detectable. Thus if the fracture and/or water content of the repository horizion cahnges due to infiooding or thermal loading (i.e. either drying or saturation) this would be detectable.

In addition to describing structure and fracture content we are also hoping to relate the seismic response of the rock mass to the hydrologic response. The idea is to tomographically map the variation in the P-, SV-, and SH-wave properties and relate the resulting anomalies to the actual fracture density, orientation, and spacing. An example of this approach is shown in figure 1. Shown are ray paths through a model of fractured rock. This fracture model was actually generated by modifying code that is used to model the hydrologic respone of fractured media. In this way we can compare the seismic response to the hydrologic response. In a conventional approach to ray tracing, the fractures, due to their very small width, would have little or no effect on the ray parameters. In the programs that we have developed we have incorporated the effect of fracture stiffness (Myer et al. 1985) in addition to the effect of the bulk rock properties. The fractures in figure 1 are zero thickness but have finite stiffness. 
The area modeled in figure 1 is $1 \mathrm{~km}$ by $1 \mathrm{~km}$. Figures 2 and 3 show the resulting waveforms from $4 \mathrm{hz}$ and $40 \mathrm{hz}$ wavelets, respectively. As can be seen the stiffness has a significant effect on the seismic energy. Shown in these figures are P-waves. We also have the capability to model SV- and SH-waves as well. The aim is to use the times, amplitudes and polarizations of the P-, SV-, and SH-waves to map fracture properties.

A significant question that remains to be answered is the scale effect of stiffness. If we use stiffnesses of fractures that have been measured in the laboratory in our kilometer size model, we see no effect on the seismic waves. To see an effect we must assume that stiffness scales as the square of the length of the fracture. We have observed in field cases effects of fractures at kilometer size scales, (Majer et al 1986). Therefore we assume that there must be a scale effect.

In another VSP: field study at the Salton Sea deep hole we observed another interesting effect of fractures. Shown in figures 4 and 5 are the P-wave VSP's from a near offset $(300 \mathrm{ft})$ and a far offset $(4000 \mathrm{ft})$, respectively. The depth covered in detail in the well was from 5600 to $2000 \mathrm{ft}$. In the near offset data (figure 4) we see a clean waveform with good first arrivals and no secondary arrivals until the converted S-waves appear over a second later. In the far offset this is not the case. The data in figure 5 has been dipfiltered slightly, but there is still significantly more energy directly after the first arrival i the far offset than in the near offset. One explaination for this may be due to fractures. From available core and well log data in this section of the well, it appears that this is where there are significant vertical fractures. In the near offset case the waves will be almost at vertical incidence. Therefore, vertical fractures would have little effect on the fractures. In the far offset case, the waves were propagating in a more horizontal orientation than vertical. Thus, if they intersect a vertical feature there would be an effect on the wave, which is what we observe. In the far offset we are probably observing diffraction from the vertical fracture sets. 
This is probably the reason for the secondary arrivals traveling away from the fracture zone up and down the well. The shear-wave data are very complicated also indicating significant fracture content.

In a field study in a less complicated environment we performed a multioffset/multi-source VSP. As in the case of the Salton Sea we used P- and S-wave vibrators. The zone covered in the well was from 300 feet to 1800 feet. At each offset (each being 300 feet from the well) we turned the S-wave vibrator parallel and perpendicular to the ray path connecting the well and the vibrator. In effect we had a compressional wave (P-wave vibrator), a SH-wave (shear-wave vibrator perpendicular to the well), and a SV-wave source (shear-wave vibrator parallel to the well). The well that we used was in granite about 30 miles east of the San Andreas Fault near Lancaster, Califomia. It was a very tight granite and relatively unfractured formation. Hydyofracturing had been carried out in the well to determine the stress information. There were some fractured regions at the bottom of the well, but we were mostly in unfractured rock, especially compared to a geothermal environment. The plan of the experiment was to vibrate at 0,45 , and 90 degrees to the fracture direction inferred from the hydrofracture data. We knew that we were unlikley to detect the short fractures from the hydrofracture, but we were interested in determining if we could detect a preferred fabric or overall microfracturing of the rock. Differences were detected in the SH- and SV-components from the different shear wave sources as a function of azimuth. The differences are subtle and difficult to demonstrate at the scale available in this report, but were on the order of 5 to 10 percent velocity anisotropy. Shown in figures 6,7 , and 8 are the 3 component data from the SH source at 0,45 , and 90 degrees, respectivly, to the fracture direction that have been rotated into the plane of propagation of the P-wave. That is, channel 2 is the paiticle motion component along the ray path $(\mathrm{P}), 3$ is vertical (SV), and 4 is horizonta: (SH) to the ray path. From these figures on can at least see the relative amount of energy arriving at the different 
positions of the source and receiver. Even in this relatively isotropic environment we do see effects of fractures.

The active methods have been stressed in this discussion, however we feel that the passive methods will also play an important role in postclosure monitoring due to the simplicity of their implimentation. Seismic sensors mounted in realtively shallow holes above the repository (100 meter deep holes) at spacings of a few hundred meters would detect near AE size events. AE events will undoubtably be created as the thermal pulse travels outward from the repository. If the events are confined to AE size events (Magnitude less than -3) then the size of the source disturbances are probably not significant to cause a break in the integrity of the sealing system. However, detection of activity from the repository horizion, would probably indicate a problem. In this sense AE/Microseismic monitoring would be useful as a first alert. Resolution on the order of a few tens of meters could be obtained given a dense enough borehole array. This would give sufficient guidence for any remedial action to be taken, i.e. grouting or sealing.

In conclusion, we have been carrying out field and modeling studies to determine the effect of fractures on the propagation of seismic waves. The goal is to be able to map the orientation, density, and spacing of fracture sets in the field and to be able to give the hydrolcgist/reservoir engineer useful information. To date we have seen that firactures do have a significant effect on seismic waves. In a monitoring sense these methods hold great promise for detecting water content changes and fracture changes due to thermal loading and/or stress redistributions from the closure or readjustment of underground openings. The key to the seismic, as well as the other geophysical techniques, is detecting changes from a known baseline. A few percent change in rock properties is easily detectable. Given the time framc of the monitoring scheme involved, instumentation capable of much better resolution will undoubtably be availabic. Therefore, the seismic methods scem very well suitcd for monitoring 
the fracture and water content change in a rock mass, especially if used in conjuction with the with the electrical methods. 


\section{Electrical Methods}

Electrical methods seem particularly promising in monitoring the groundwater regime since the electrical conductivity of rocks depends almost entirely on the pore water content and yet they seem to have received little notice either in site characterization or as effective monitoring of performance.

We have completed a review of the role of electrical conductivity measurements in repository monitoring (Morrison et al. 1986) and the major observations are repeated here. The bulk resistivity of a rock depends on the porosity (including fracture porosity), saturation, dissolved solids in the pore water, and temperature. Electrical methods can be used to detect zones of varying water content and, most importantly for this study, to monitor time changes in the rocks associated with changing saturation, temperature, etc.

Electrical methods are ideally suited to the detection of major fractures in site characterization, but another equally important application is the relationships between large scale resistivity and fracture systems in rock. There has been very little work done on this central issue. Empirical relations between resistivity and porosity have been derived on the basis of laboratory samples or from well logging, but there are no comparable 'laws' for rock masses with major fracture or joint patterns. Hydrologic models for such rocks have recently been derived but the corresponding resistivity models have not been attempted. Resistivity due to fracture distributions with preferred orientation could be determined with such models, as could quantitative interpretation of changes as fracture aperture varies with load. This study is not only important for the assessment and monitoring of a repository site, but has far ranging implications in rescrvoir studies for oil, gas, and geothermal resources.

The clectrical conductivity can be measured in two ways. Current can bc injected into the ground through pairs of electrodes and corresponding voltage drops can be measured in the vicinity with other pairs of electrodes. In general, clectrodes 
can be used in the subsurface although traditionally the arrays have been employed on the surface. Measurements of voltage and current for different electrode geometries are then used to infer the subsurface distribution of conductivity. These methods are indirect but ideally suited to measure the properties of a region to which it is impossible to gain direct access. The resulting interpretation of the conductivity distribution is not unique, nor does it provide high resolution of subsurface features. In many applications this latter property is to our advantage since the measurements yield bulk average values of the conductivity which often includes features that are not included in hand sample or borehole logging measurements (e.g. fracture porosity).

The uniqueness property of the interpretation is only now yielding to quantitative analysis. Recently we have attempted to quantify this process by using rigorous generalized least squares inversion techniques and this promises to greatly speed up interpretation and at the same time quantify the uniqueness question.

The electrical conductivity can also be measured inductively. Instead of injecting current into the ground as described in the dc resistivity method above, currents can be induced to flow by a changing magnetic field. The source of the changing magnetic field could be a loop of wire carrying alternating current, or, again, a wire grounded with electrodes in which alternating rather than direct current is used. The currents induced in the ground are measured either by detecting the magnetic fields they produce or by measuring the voltage drops in pairs of electrodes. Sources and receivers can be on the surface, in the ground, or combinations of both.

In these inductive or electromagnetic (em) methods the interpretation depends both on transmitter-receiver geometry and frequency of opcration. In principle the interpretation should be more definitive than with the dc resistivity methods. Rigorotis confirmation of this statement in inhomogeneous media awaits the development of gencralized inversion techniques for em methods. 
The em methods offer some proven advantages over the dc methods. Measurements can be made without contacting the ground; measurements are insensitive to high resistivity zones; depth of investigation can be controlled by the frequency of operation so that large transmitter-receiver spacings are not required; and because of the transmitter source field fall-off, the methods are not sensitive to conductivity inhomogeneities far from the zone of interest.

Both electrical and em methods are applicable in mapping and monitoring waste repository sites. Recent developments in mathematical modelling, generalized inversion, and field techniques and instrumentation, have combined to offer a quantitative approach to such monitoring that is not only non-invasive but highly diagnostic of the properties of the site and its post-emplacement changes. To be effective electrical and electromagnetic methods must be applied in two stages:

I. Mapping the subsurface resistivity distribution prior to and during the excavation and preparation of the site. This will include determining the general resistivity distribution which will be the starting point for the long term monitoring and will also include measurements to locate specific fractures or fracture zones which may be in the vicinity of the site but not detected in drilling or excavation.

I1. Monitoring the subsurface resistivity changes associated with site excavation and preparation and long term changes after waste emplacement and repository closure.

There must also be a a parallel and integral study of the basic relationship between fractures and resistivity in rock. The results of this study will then be used in the design of the experiments to map and monitor the in situ resistivity. 


\section{Electrical Conductivity}

The electrical conductivity of rocks and unconsolidated sediments in the upper few $\mathrm{km}$ of the earth's crust is govemed by the water content and the nature of the waier paths through the rock. Electrical current is carried by ions in the water and so the bulk resistivity will depend on the ionic concentration and ionic mobility as well as the saturation and nature of the porosity. The dependence of the conductivity on temperature and pressure is due to the change in ion mobility with temperature and the effect of pressure on the apertures of the pore paths respectively. The presence of clays in a rock has a large effect on the conductivity because of the increased ion concentration in the diffuse layer adjacent to the clay mineral surface. In fact, such a phenomenon occurs at all mineral surfaces but to a lesser extent than with highly surface active minerals like clay. The surface conduction mechanism is important in understanding the behavior of partially saturated rocks and also in setting limits on the extent to which electrical conductivity can be linked to hydraulic conductivity.

Most studies on the electrical conductivity of rocks have been on sedimentary rocks because of their importance in petroleum exploration and well logging. Archie (1942, 1947) established an empirical relationship between the formation resistivity $\left(p_{0}\right)$ the pore fluid resistivity $\left(\rho_{w}\right)$ and the porosity $\phi$ which is now referred to as Archie's Law :

$$
\rho_{0}=a \rho_{w} \phi^{-m}
$$

where $\mathrm{a}$ and $\mathrm{m}$ are constants for a given rock. For a very wide range of sedimentary rocks and for some volcanic and intrusive rocks as well, the constant, a, is close to unity and $\mathrm{m}$ is close to 2.0 (Keller and Frischknecht, 1966). Surprisingly there has not yet been a theoretical model advanced to explain this inverse dependence of resistivity on the square of porosity. 
An important and little studied aspect of rock conductivity is the role of fractures on the resultant bulk properties. Laboratory studies concentrate on small samples which almost by definition do not include fractures or joints. Field studies using surface resistivity measuring arrays are usually too strongly influenced by the inhomogeneous nature of a particular rock unit to allow fracture and pore porosity to be separated. With the increased measurement accuracy and resolution provided with subsurface techniques and the interest in monitoring time changes in resistivity, it is essential to investigate more closely the role of fracture porosity on the electrical conductivity of large rock masses.

It is well known that the hydraulic conductivity or permeability is strongly influenced by the fracture distribution : excellent numerical models are now available for characterizing fluid flow in fractured rock (e.g. Long and Witherspoon, 1985). It is also known that seismic velocities are also strongly affected by fractures in the rock. It remains to develop expressions for the electrical conductivity of such rocks and to take advantage of this valuable physical property for characterizing and monitoring large subsurface volumes of rock. In the following paragraphs we will summarize what little work has been done on the role of fractures in rock conductivity.

The simplest model of a fractured or jointed rock is one in which the fractures are plane parallel thin layers of conductivity $\sigma_{1}$ in a rock mass of conductivity $\sigma_{2}$.

Analysis of this model reveals that a very small fracture porosity can have a dramatic effect on the conductivity of the rock. For example if the fracture porosity is 0.005 and the rock matrix porosity is 0.05 the conductivity in the direction of the fractures is 3 times the rock matrix conductivity.

Keller and Frischknecht (1966) derived an expression for the resistivity of a rock with a totally random pattem of fractures with a volume fraction of $\mathrm{p}$ as :

$$
\rho_{0}=2.46 \rho_{w} p^{-1}
$$


or

$$
\sigma_{0}=\sigma_{w} \frac{p}{2.46}
$$

where it was assumed that the fractures were the only porosity. The random pattem of fractures reduces the conductivity by a factor of 2.46 over the model in which all the fractures are parallel.

Fractures clearly introduce anisotropy in a rock and in some situations even small fracture porosity can greatly alter the rock resistivity. There apparently has been no work to develop resistivity expressions for the hydraulic conductivity models in which fracture distribution size, aperture and interconnectedness are all taken into account.

That fractures do play an important role in rock resistivity is practically demonstrated in the work by Brace and Orange (1966, 1968a, 1968b). Their work on the effects of confining pressure on the resistivity of a water saturated granitie showed that at low pressures the resistivity increases as the confining pressure increases and they attribute this effect to the closure of fracture porosity. A resistivity increase of a factor of 10 as the pressure increases could easily be explained by the disappearance of only $0.1 \%$ fracture porosity in a granite of $1.0 \%$ pore porosity.

\section{Resistivity Methods}

Surface current and potential electrode arrays have been used for many years to determine the subsurface resistivity. The most important recent development in surface schemes is the use of two and three dimensional numerical models to represent the ground in interpreting the data.

Resistivity mapping using subsurface electrodes permits far grcater accuracy and resolution than can be obtained with surface-only arrays. 
An important step in this study has been the introduction of subsurface sources in the numerical models. We have modified the 2-D and 3-D code of Dey and Morrison (1976 and 1979 respectively) so that hole-to-surface and hole-to-hole electrode arrays can be studied. The programs have already been used in a subsurface contaminant study and a powerful differencing technique has been discovered which greatly assists the interpretation. (Morrison et al. 1986)

The subsurface arrays also hold great promise for eliminating or reducing nearsurface effects. The results of a surface dipole-dipole survey over the repository model with two small conductive bodies on the surface show that If the apparent resistivities are all referenced or normalized by the the resistivities observed with the current source at 650 meters depth adjacent to the repository the effects due to the surface conductors are alrıost entirely eliminated.

In summary, dc resistivity mapping with combinations of surface and subsurface clectrodes appear to have great potential. Much work remains to be done in selecting the best array geometries for sensitivity in mapping features of interest in site studies.

Hydrologic and thermal heating models could be combined to yield the resistivity changes that could be expected for various scenarios such as water re-entry, heating, or even vaporization.

The resistivity methods discussed above, and the electromagnetic methods to be described are all strongly influenced by the presence of steel casing in the bore holes. In one electromagnetic method the conductivity outside the casing can be measured if the source is a large loop on the surface and the sensor is inside the casing. For most of the methods, however, the metal casing will effectively short the source.

For dc methods there are some possibilities for surveys which use the casing itself, or insulated sections of it, as current or measuring electrodes. The current is connected to the casing at a point and the resulting potentials in the medium are governed by the conductivity and cross-section of the casing and the conductivity of 
the surroundings. There are two limiting cases for the potential distribution: If the casing is very thin and resistive, the field will be close to that of a point source; If the casing is thick and conductive (or perfectly conducting), it will be close to a line source.

Further studies are being conducted to compare the potentials of the semiinfinite pipe to a semi-infinite and finite length line source. From the comparisons, it is hoped that an "effective" length of the semi-infinite pipe can be determined so that the line source approximation can be used effectively. The current density in the surrounding medium is being calculated so as to obtain an understanding of the current pattem from a highly conductive pipe in a half space. Also, a solution for the potential field from a finite length of pipe in a layered half space, or for insulated segments of pipe, should be obtained for applications in an actual field experiment.

In experiments being designed for mapping and monitoring in the vicinity of waste repositories it probably will be necessary to use non-metallic casing. Metal segments can easily be inserted as electrodes and the magnetic dipole electromagnetic methods would see no casing effect whatsoever.

\section{Electromagnetic Methods}

Electromagnetic methods have been used traditionally to locate conductivity inhomogeneities from surface transmitter-receiver configurations. Recently they have been used successfully to map subsurface conductivity in situations where the earth can be modelled with horizontal layers. EM has great advantages over de resistivity in these situations since the sounding can be carried out with small transmitterreceiver separations (zero in the limit when the receiver is located within a horizontal loop transmitter) by varying the frequency or measuring the transient field after current in the transmitter is turned off. 
A new and promising application is in subsurface or subsurface to surface methods. We have developed numerical methods to deal with the following three configurations that would be useful in subsurface mapping and, in particular, in the detection of fracture zones.

i) Surface to bore hole. In this configuration the transmitter is a horizontal loop on the surface coaxial with a bore hole, and the receiver (only vertical component of the field so far) is located in the hole. Results show that:

a) The configuration has greater sensitivity to conductivity structure beyond the hole than surface or conventional well log methods.

b) The conductivity can be sensed through casing.

c) In layered media the currents (for any magnetic dipole source) flow parallel to layer boundaries so only horizontal conductivity is sensed. These mear'jrements are complementary to dc resistivity since the latter senses both horizurital and vertical condectivity.

ii) Subsurface magnetic dipole source. We have developed the general solution for magnetic dipoles within a layered medium and have applied the solution to the general induction logging problem in an inclined or deviated bore hole (Kennedy et al., 1986). The program is well suited to an analysis of cross hole em measurements in layered media.

We have also developed the solution for scattered fields on the surface from a subsurface planar conductor (Zhou and Becker, 1986) in the presence of a subsurface magnetic dipole. This study clearly showed that planar conductors representing fracture zoncs could be detected with such an array. This program is also easily moditied for cross hole or in-hole reflectance studies of such features. These studies assume uncased or plastic-cased holes. 
iii) Subsurface vertical electric dipole source. This is one of the most promising sources for subsurface em since there are no magnetic fields or the surface if the source is located in a horizontally layered medium. Inhomogeneities, such as the planar conductors, do produce anomalous magnetic fields on the surface so that this is an ideal configuration for location and detection of fracture zones. Preliminary results (Morrison et al. 1986) show anomalies for shcet-like conductors to be as distinct for the vertical electric dipole source as for the magnetic dipole source. Further, the em results seem more diagnostic of the parameters of the fracture than the dc results. As the frequency is increased this solution extends to the use of radar methods. At low frequencies grounded electrodes are necessary. Thus an uncased hole or plastic-cased hole fitted with metal electrodes would be required.

Much research needs to be done to determine which of these configurations is best suited to the needs of characterizing and monitoring the repository site. It is likely that a combination of dc electrical and em inethods will prove best for detecting fracture zones from a bore hole or excavation while others will be best for monitoring the site before, during, and after waste emplacement. The basic numerical programs are available for this study but they must be modified to deal with the particular features of the waste repository studies.

\section{Monitoring Changes in Subsurface Conduc tivity}

All of the electrical and electromagnetic methods discussed above for mapping the coinductivity distribution can, in principle, be used to monitor changes in the conductivity. In practice, there will be constraints imposed either by site requirements, geological features, or nature of contaminating noise that will probably eliminate ccrtain of the methods. Radar for example will have a relatively short range, $\approx 100 \mathrm{~m}$, and requires considerable power and instrumentation : it is unlikely that it would be either permitted or convenient to use within the repository for long term monitoring, 
post emplacement. DC resistivity on the other hand is known to be very sensitive to large volume changes in conductivity and we have seen from our preliminary modelling that all the electrodes can be completely outside the repository. EM models are sensitive to both volume changes in conductivity and to individual fracture zones. For one configuration, the VED, the method is only sensitive to the inhomogeneities in a layered section.

For all these methods the fundamental question of signal to noise will dictate the final accuracy with which time changes can be monitored. Source moment and signal averaging have been the only two parameters that can be increased to improve signal to noise. Recently we have completed field studies of a techrique to use remote station noise cancellation to dramatically improve signal to noise. The concept is very simple. The natural electromagnetic field noise in which signals from dc or em methods are to be detected is remarkably coherent for many kilometers over the surface. Thus the fields at a remote site can be used to predict field at a local measurement site and the noise can be subtracted from the data. In a magnetic proppant injection experiment at a test site at Mounds Oklahoma we achieved noise reductions of $60 \mathrm{db}$ in magnetic field with a remote site $1.5 \mathrm{~km}$ away.

The impact of this is greatest on subsurface source ccnfigurations where it may be difficult to emplace transmitters with adequate moment. For a magnetic dipole source the moment is the product of the number of tums, the area, and the current (and the effective permeability of the core if the coil is wound solonoidally). To obtain adequate signal with reasonable stacking this source must yield secondary ficlds at least equal to the natural noise ficld. With $60 \mathrm{db}$ of noise reduction it is clear that momenis or signal levels prcviously thought to be unachievable are now possible. This obviously will have a major impact on the application of these methods. 
Finally the success of any of these methods will depend on the accuracy and confidence that can be expected of the interpretation. This will depend on the development of objective criteria based on inverse methods and to be practical such schemes must use fast efficient focused model calculations. An integral and important part of research on the use of electrical and EM methods is the development of faster numerical algorithms for these forward calculations. 


\section{References}

Archie, G.E., 1942, The Electrical Resistivity Log as an Aid in Determining some Reservoir Characteristics. AIME Transaction, vol. 146, 54-62.

Archie, G.E., 1947, Electrical Resistivity as an Aid in Core-analysis Interpretation. Am. Assoc. Petroleum Gcologists Bull., vol. 31, no. 2., 350-366.

Brace, W.F. and Orange, A.S., 1968a, Electrical Resistivity Changes in Saturated Rocks during Fracture and Frictional Sliding. J.G.R., vol. 73, no. 4, 14331445.

Brace, W.F. and Orange, A.S., 1968b, Further Studies of the Effects of Pressure on Electrical Resistivity of Rocks. J.G.R., vol. 73, no. 16, 5407-5420.

Crampin, S., 1978, Seismic-wave propagation through a cracked solid: polarization as a possible dilatancy diagnostic: "Geophys. J. Roy. Astron. Soc.," v. 53, pp. 467-496.

1981, A review of wave motion in anisotropic and cracked elastic-media:

"Wave Motion," v. 3, pp. 343-391.

1984a, Effective anisotropic propagation through a cracked solid: In Crampin, S., Hipkin, R.G., and Chesnokov, E.M., eds., Proc. of the First Internat. Workshop on Seismic Anisotropy, "Geophys. J. Roy. Astron. Soc.," v. 76, pp. 135-145. 
1984b, Anisotropy in exploration seismics: "First Break," v. 2, pp. 19-21.

1985, Evaluation of anisotropy by shear wave splitting: "Geophysics", v. 50, no. 1 , pp. 142-152.

Dey, A. and Morrison, H.F., 1976, Resistivity Modelling for Arbitrarily Twodimensional Structures, Part I: Theoretical Formulation. LBL-5223, Lawrence Berkeley Laboratory, University of Califomia, Berkcley.

Dey, A., 1976, Resistivity Modelling for Arbitrarily Two- Dimensional Structures, Part II: User's Guide to the FORTRAN Algorithm RESIS 2D. LBL-5283, Lawrence Berkeley Laboratory, University of Califomia, Berkeley.

Dey, A., and Morrison, H.F., 1979, Resistivity Modelling for Arbitrarily Shaped Three-dimensional Structures. Geophysics, vol. 44, no. 4.

Keller, G.V. and FRischknecht, F.C., 1966, Electrical Methods in Geophysical Prospecting. Pergamon Press, New York.

Kennedy, W.D., Corry, S.M., All. S.P. and Morrison, H.F., 1986, Induction Log Response in Deviated Boreholes. SOWLA, 27th Annual Logging Symposium, June 9-13, 1986, Atlanta.

Leary, P.C. and T.L. Henyey, 1985, Anisotropy and fracture zones about a geothermal well from $P$-wave velocity profiles: "Gcophysics", v. 50, no. 1, pp. 25-36.

Long, J.C.S. and Witherspoon, P.A., 1965, The Relationship of the Degrec of 
Interconnection to Permeability in Fracture Networks. Joumal of Geophysical Research, vol. 90, no. B4, 3087-3098.

Majer, E. L., T. V. Mcevilly, F.S. Eastwood, and L.R. Mycr, 1986, Fracture Detection Using P- and S-wave VSP's at The Geyers Geothermal Ficld: Geophysics (in press)

Mclaughlin, R.J., 1981, Tectonic setting of pre-Tertiary rock and its relation to geothermal resources in The Geyers-Clear Lake area: U.S. Geol, Survey "Prof. Paper 1141," pp. 3-23.

Morrison, H.F., Becker, A., Lee K.H., 1986, Measunements of Electrical Conductivity for Characterizing and Monitoring Nuclear Waste Repositories, LBL-1986, Lawrence Berkeley Laboratory, University of Califormia, Berkeley.

Myer, L.R., D.L. Hopkins, and N.G.W. Cook, 1985, Effects of an interface in partial contact on attenuation of acoustic waves: Geophysics (in press).

Schoenberg, M., 1980, Elastic wave behavior across linear slip interfaces: "J. Acoust. Soc. Am.," v. 68, no. 5, pp. 1516-1521.

Schoenberg, M., 1983, Reflection of elastic waves from periodically stratified media with interfacial slip: "Geophys. Prosp.," v. 31, pp. 265-292.

Stewart, R.R., R.M. Turpening, and M.N. Toksoz, 1981, Study of a subsurface fracture zone by vertical seismic profiling: "Geophys. Res. Lett.," v. 8, pp. 1132 1135. 
Zhou, Q., and Becker, A., 1985, Distortion of Electromagnetic Waves by Geological Structure, Interim Report, Enginccring Gcoscience, Contract \#LLNL-7174105, Submitted to LLNL Dec. 1985. 


\section{Figure Captions}

Figure 1. FMGRAY model showing fracture pattern and ray paths.

Figure 2. The synthetic seismograms from the model in figure 1 using a 4 hz wavelet.

Figure 3. The synthetic seismograms from the model in figure 1 using a $40 \mathrm{hz}$ wavelet.

Figure 4. P-wave data from the near offset (300 feet) at the Salton Sea well. The depth ranges from 7000 feet to $500 \mathrm{ft}$.

Figure 5. P-wave data from the far offset (4000 feet) at the Salton Sea well. The depth ranges from 7100 feet to $1500 \mathrm{ft}$. Compare to figure 4 and notice the complexity of the first arrivals compared to the near offset.

Figure 6. Three component data that have been rotated. Channel 2 is the P-wave component , 3 the SV component, and 4 the SH component. The data are from a shear wave vibrator oriented such that the base plate motion is perpendicular to the inferred fracture direction.

Figure 7. Three component data that have been rotated. Channel 2 is the P-wave component, 3 the SV component, and 4 the SH. 
component. The data are from a shear wave vibrator oriented such that the base plate motion is 45 degrees to the inferred fracture direction.

Figure 8. Three component data that have been rotated. Channel 2 is the P-wave component , 3 the SV component, and 4 the SH component. The data are from a shear wave vibrator oriented such that the base plate motion is parallel to the inferred fracture direction. 


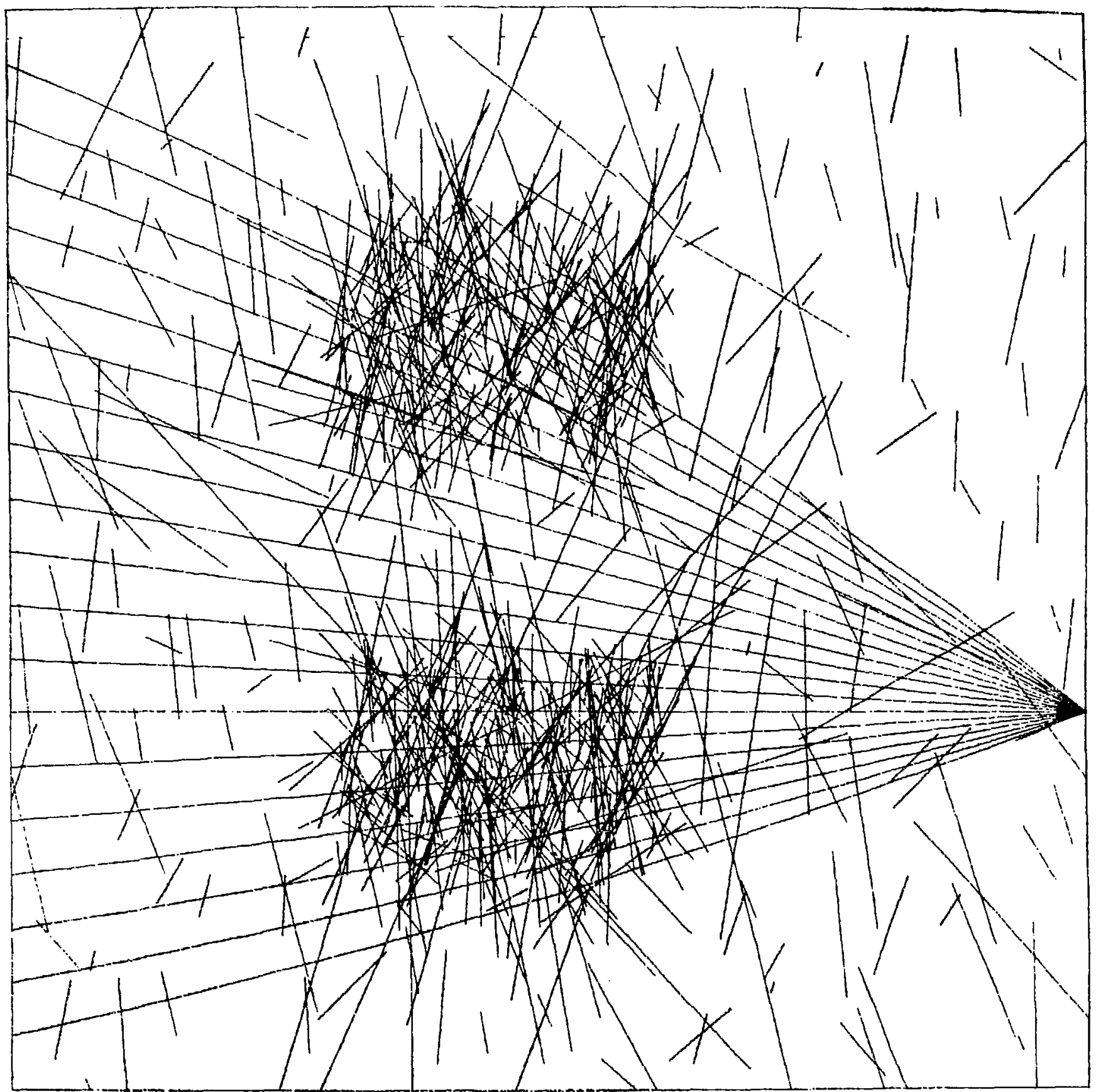

Figure 1. FMGRAY model showing fracture pattem and ray paths. 


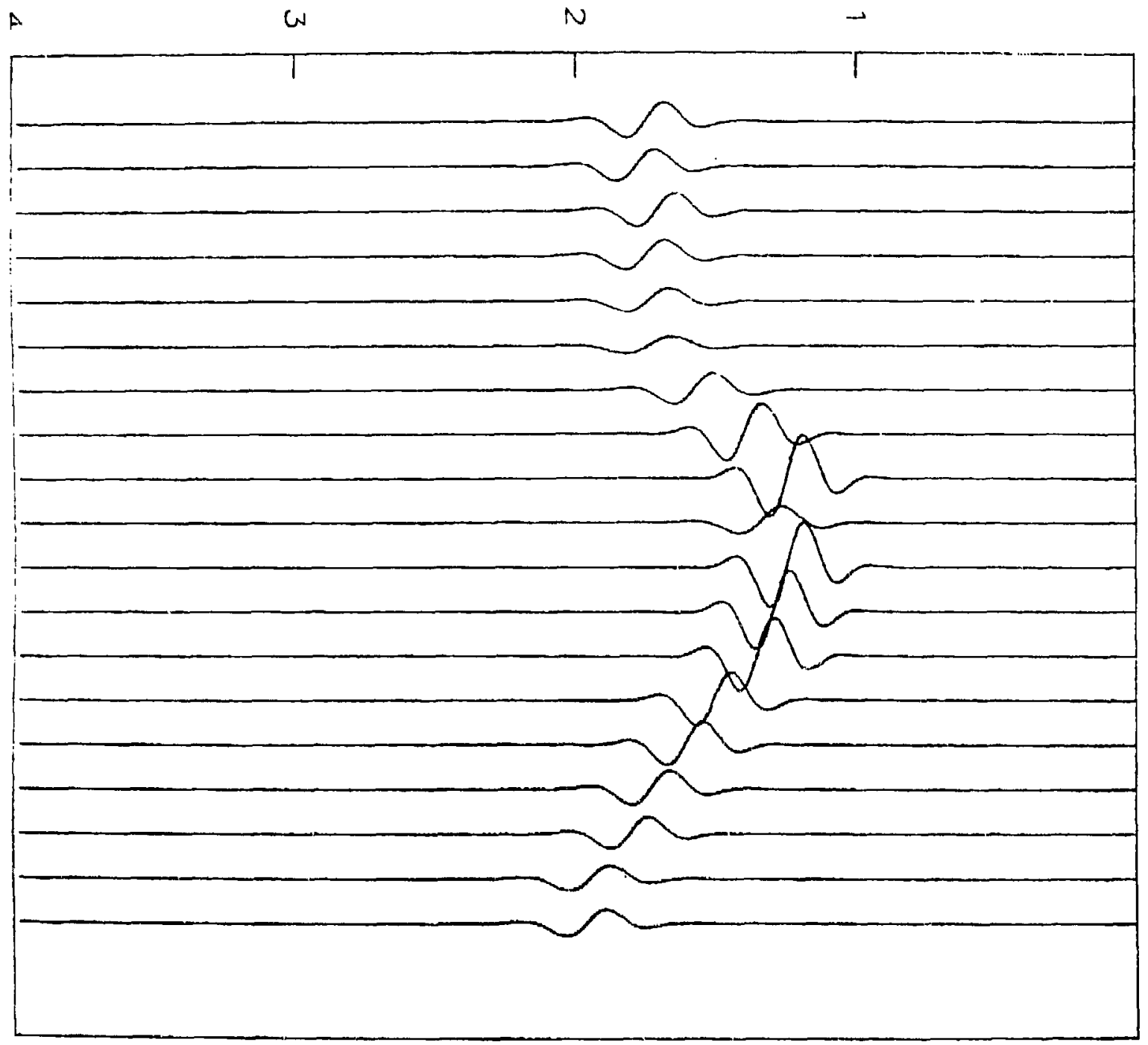

101

102

103

104

105

106

107

108

109

110

111

112

113

114

115

115

117

178

119

Figure 2. The synthetic seismograms from the model in figure 1 using a 4 hz wavelet. 


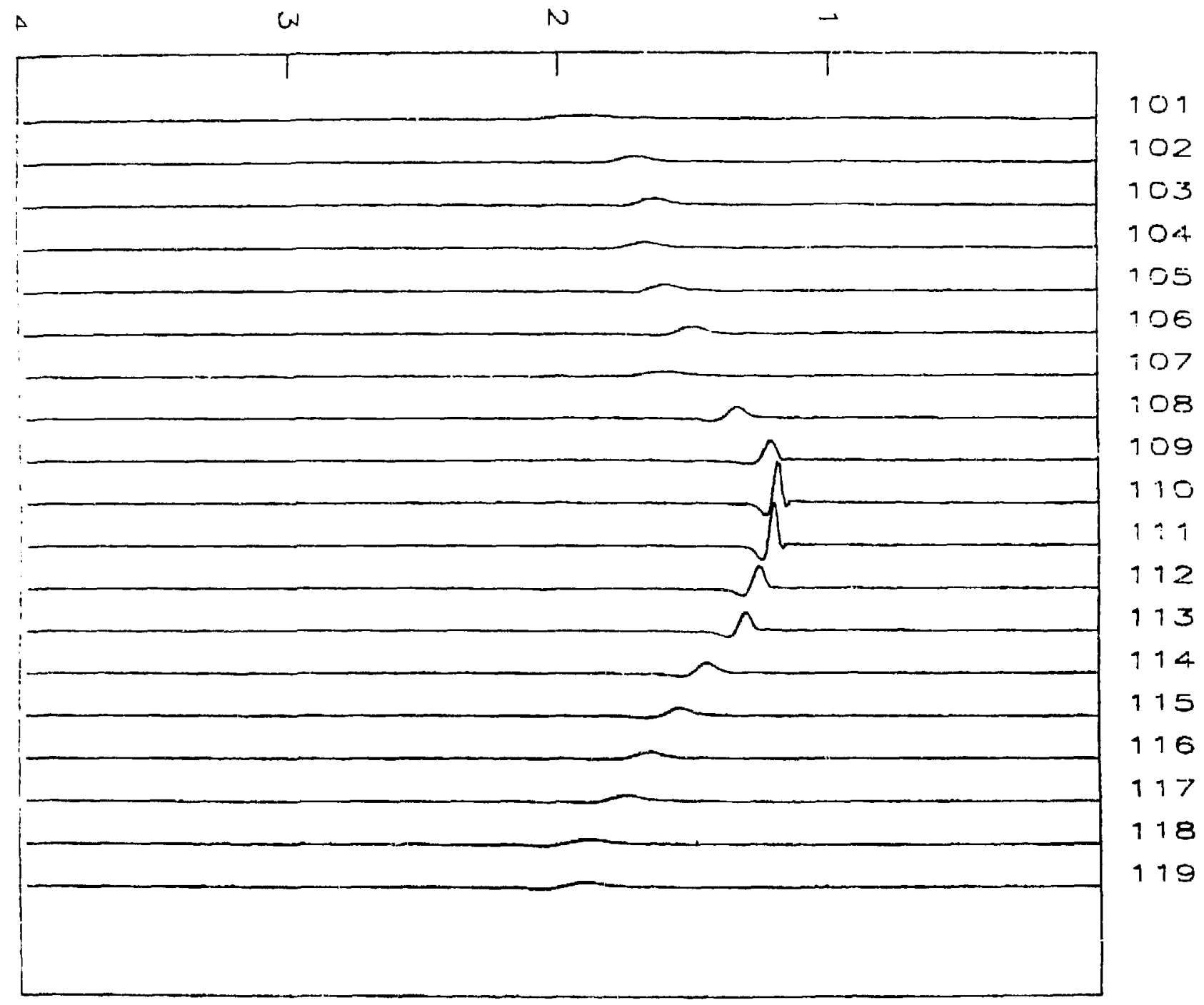

Figure 3. The synthetic seismograms from the model in figure 1 using a $40 \mathrm{hz}$ wavelet. 
NEAR OFFSET P SOURCE ROTATED RADIAL COMPONENT

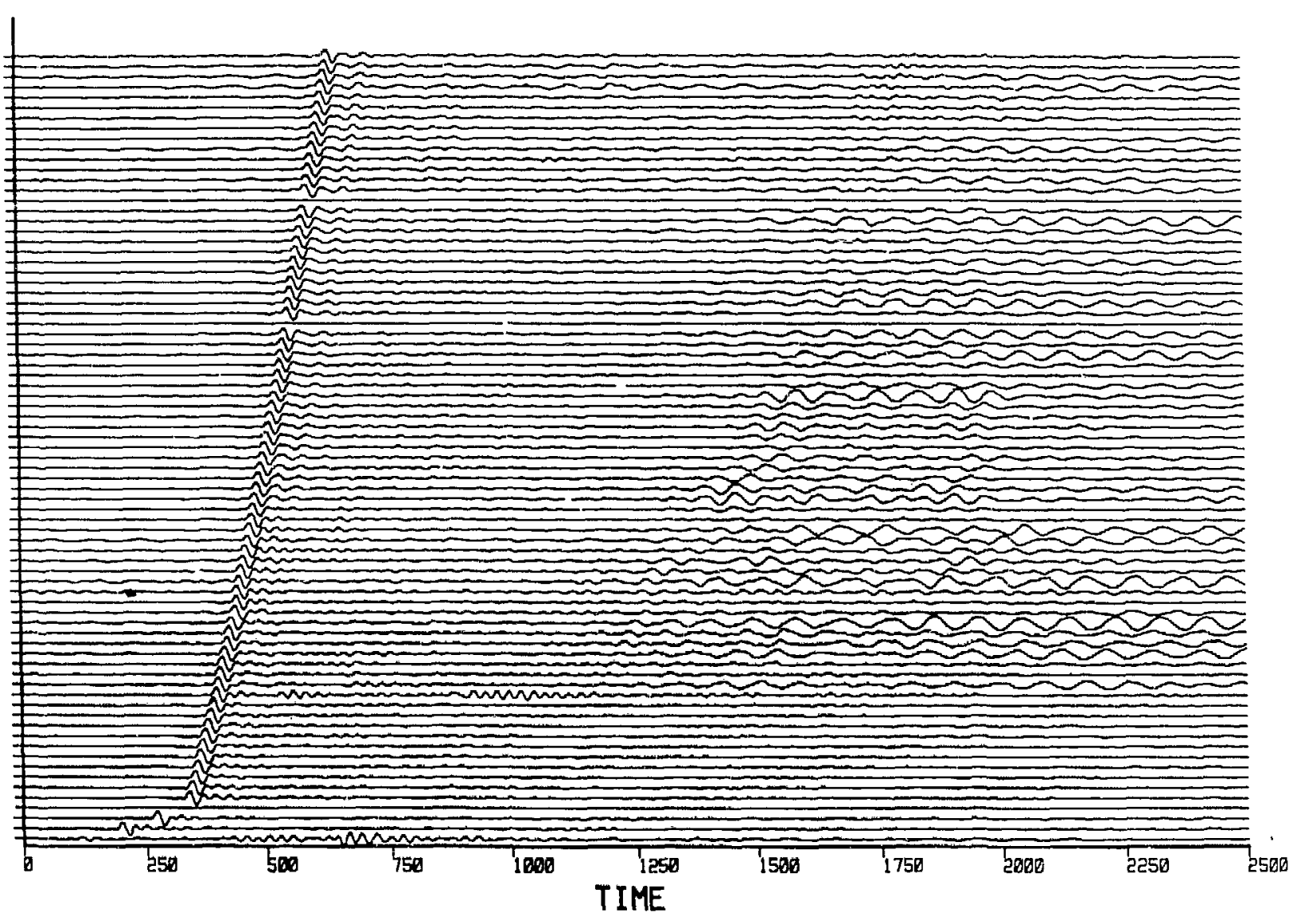

Figure 4. P-wave data from the near offset (300 feet) at the Salton Sea well. The depth ranges from 7000 feet to $500 \mathrm{ft}$. 


\section{FAR OFFSET P SOURCE VERT PHONE DIPFILTER}

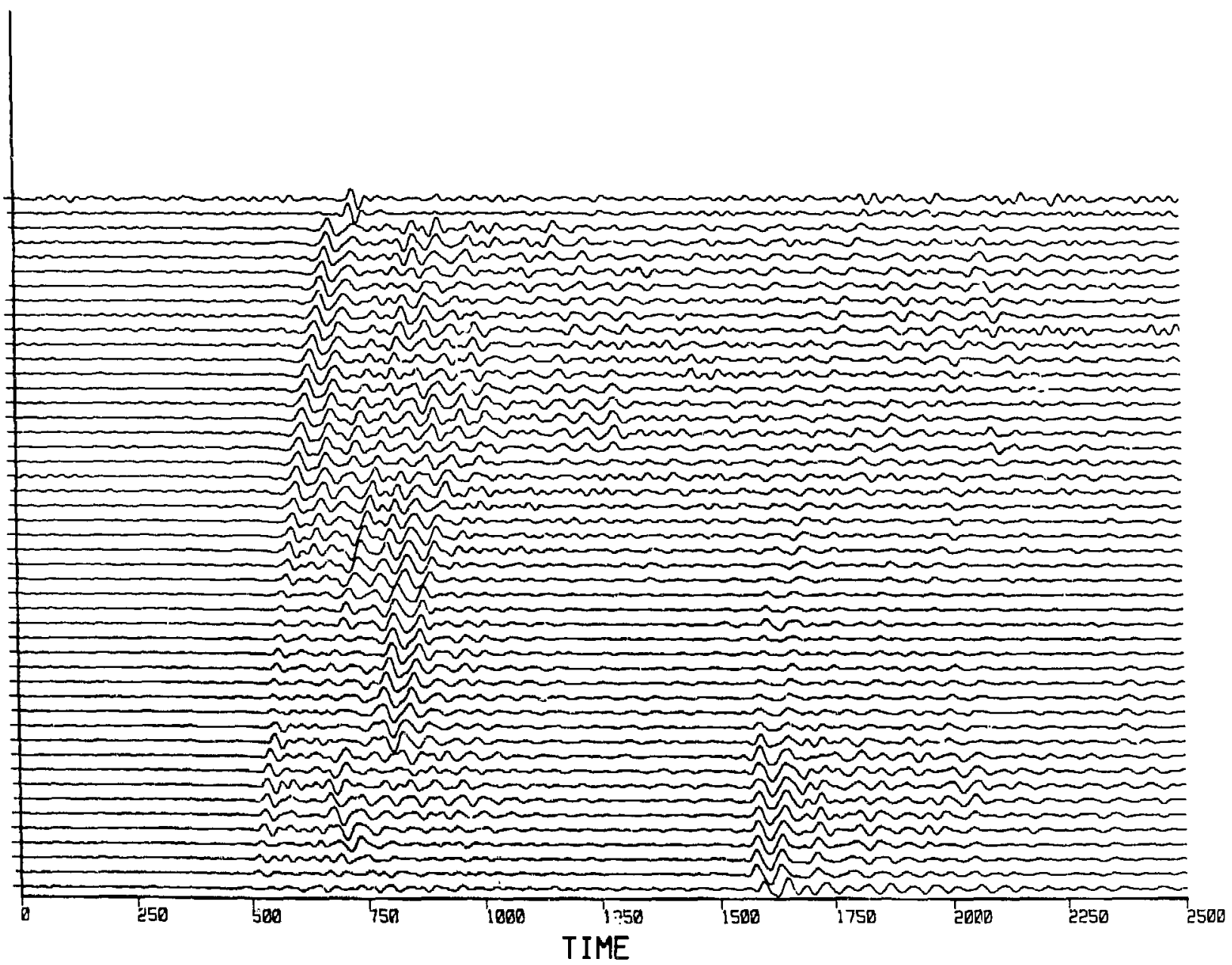

Figure 5. P-wave data from the far offset (4000 fect) at the Salton Sea

well. The depth ranges from 7100 feet to $1500 \mathrm{ft}$. Compare to

figure 4 and notice the complexity of the first arrivals compared

to the near offset. 
Figure 6. Three component data that have been rotated. Channel 2 is the P-wave component, 3 the SV component, and 4 the SH component. The data are from a shear wave vibrator oriented such that the base plate riotion is perpendicular to the inferred fracture direction.

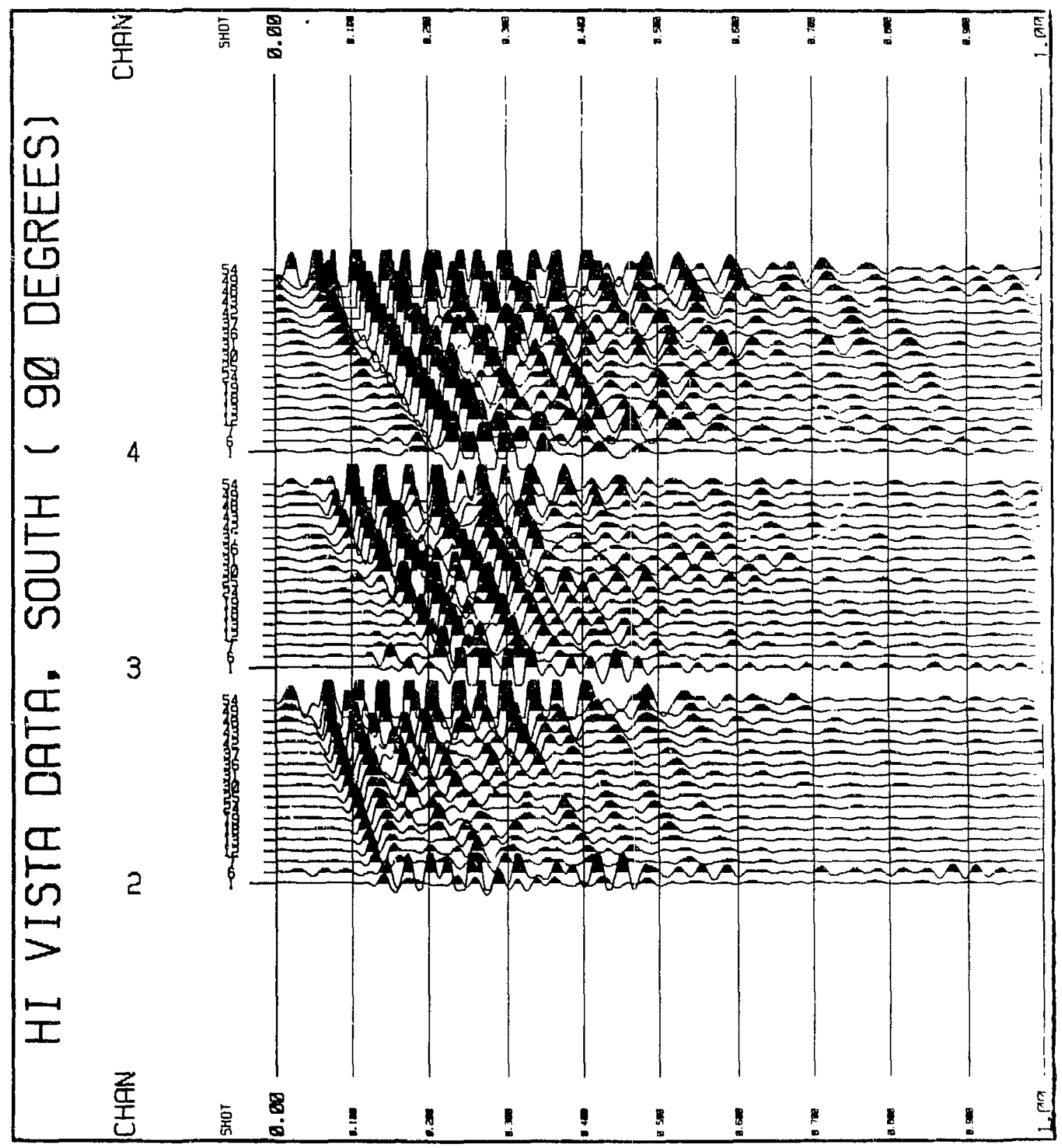


Figure 7. Three component data that have beer: rotated. Charnel 2 is the P-wave component , 3 the SV component, and 4 thi SH component. The data are from a shear wave vibrator oriented such that the base plate motion is 45 degrees to the inferred fracture direction.

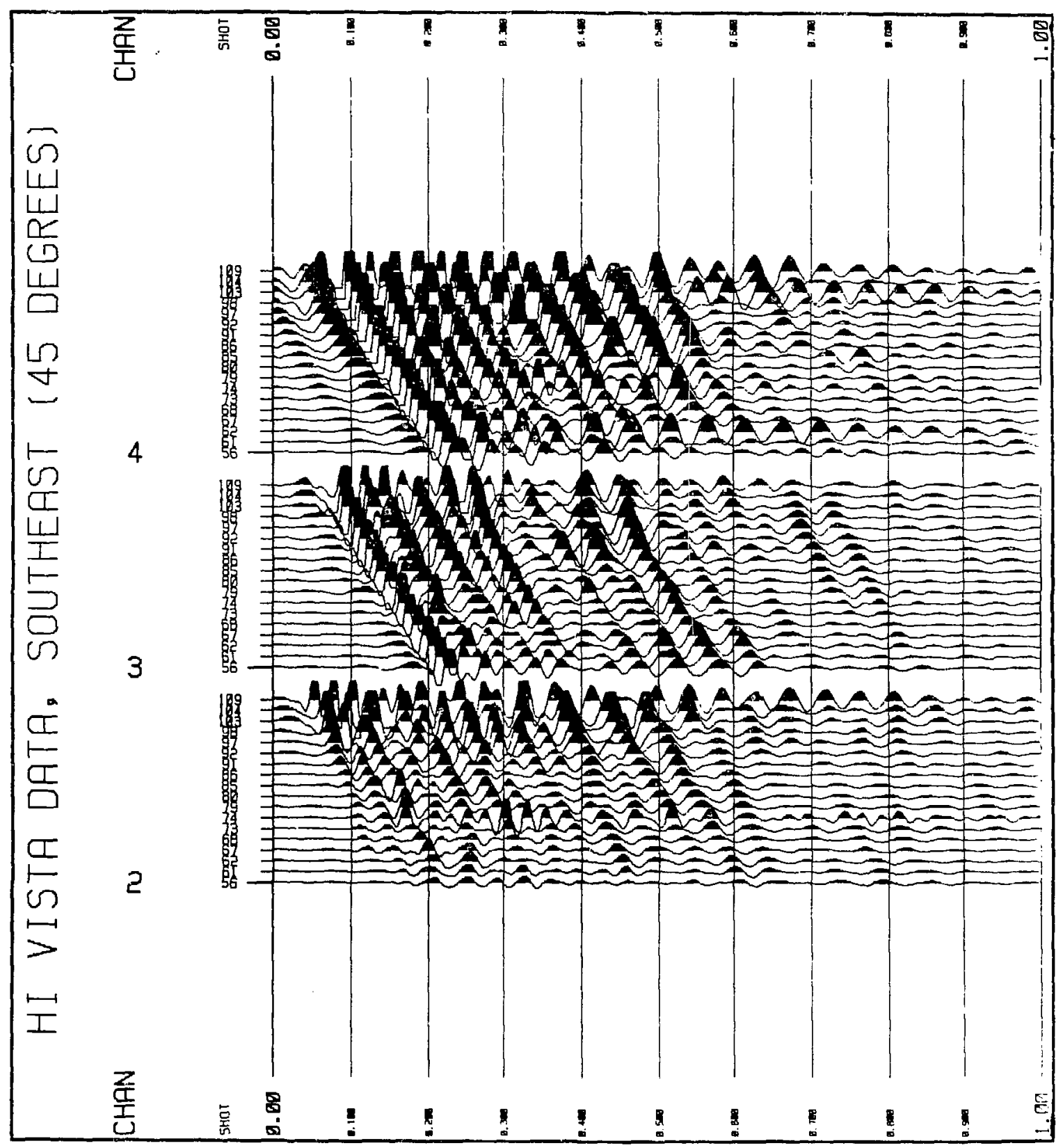


Figure 8. Three component data that have been rotated. Channel 2 is the P-wave component, 3 the SV component, and 4 the SH component. The data are from a shear wave vibrator oriented such that the base plate motion is paraliel to the inferred fracture direction.

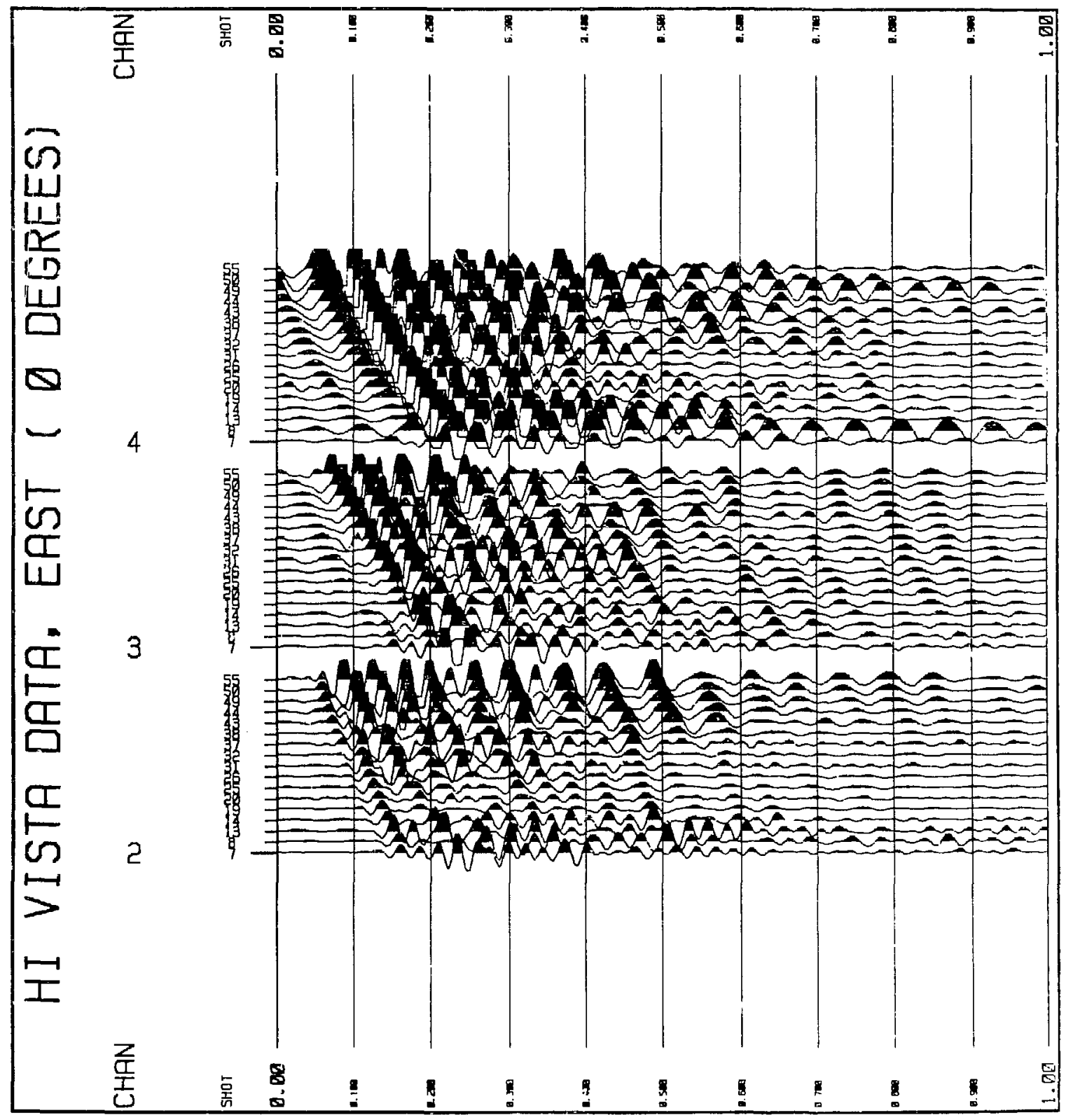




\title{
GEOCH EMICAL - MINERALOGICAL AND GEOMECH ANICAL INVESTIGATIONS OF FRACTURED, HEATED ROCK
}

\author{
H. A. Wollenberg, S. Flexser, and L. Myer
}

\section{INTROD UCTION}

Elevated temperatures in the very near field of a waste canister result in geochemical hydrologic and mechanical processes which are as complex, if not more complex than anywhere else in the repository. These processes must be understood, however, to model the transport of radionuclides in the event of a breached canister. The objective of this study is to develop an understanding of two of these processes: 1) the interaction of radionuclides with fracture-lining materials; and 2) effects of long term heating on mechanical properties of rock. The approach is to study core samples of rock which had been exposed to elevated temperatures for more than a year during the heater experiments conducted at Stripa, Sweden (Chan et. al., i980). Properties of these samples are compared with those of samples from regions in which temperature increases were small.

Past investigations of the Stripa quartz monzonite have disclosed large-scale distributions of uranium, its daughter products and thorium in groundwater and their relationships to fracture-filling and alteration minerals (Wollenberg and Flexser, 1985). The present work follows with detailed examination of the distribution of these elements in rock obviously affected by -1 year heater tests, in comparison with unaffected rock. It was shown by Wollenberg and Flexser that there were significant changes in the mineralogy of the quartz monzonite in the vicinity of the heater hole, 
accompanied by changes in uranium concentration (Fig. 1), perhaps caused by its migration in groundwater in response to the heater test. The aim of the present investigation, then is to see if the whole-rock trends observed in uranium and thorium arc upheld in cletailed exam ination of rock matrix and fractures, and if there are definite mineral associations of these elements. in a companion study, mechanical propertics of the heated rock are compared with fracture characteristics and alteration mincralogy.

\section{DESCRIP'TION OF ACTIVITIES}

Project activities emphasized determination of the mobility of radionuclides in and away from fractures in rock subjected to a full-scale heater test. L.ocations of core segments examined are shown in Fig. 2. Alpha-track exposures were made for uranium plus thorium in these selected core intervals, and resulting track densities were compared with fracture and $m$ atrix mineralogy. Alpha radiographs were obtained by placing cellulose nitrate detectors on flat, polished surfaces of the core. Exposures were for three to four weeks.

Initial examination of the detectors indicated that track densities in low-angle (with respect to core axis), predominantly chlorite-filled fractures generally match variations in whole-rock uranium determined by gamma spectrometry (Fig. 1); that is, there is a significant increase in track densities over the $-2 m$ interval adjacent to the heater hole (Table 1). Track densities associated with an open, high-angle fracture, lined with epidote and altered sphene, located within 5 to $7 \mathrm{~cm}$ of the edge of the heater hole, decrease away from the open portion of the fracture over a $0.2 \mathrm{~mm}$ span (Fig. 3A). This suggests addition of radioelements to the lining of the open fracture 
Table 1

RADIOELEMENT CONCENTRATIONS AND TRACK DENSITIES, LOW ANGLE, CHLORITE FILLED FRACTURES

\begin{tabular}{|c|c|c|c|c|}
\hline $\begin{array}{c}\text { DISTANCE FROM } \\
\text { EDGE OF HEATER } \\
(\mathrm{m}) \\
\end{array}$ & $\begin{array}{l}\text { URANIUM } \\
(\mathrm{ppm}) \\
\end{array}$ & $\begin{array}{c}\text { THOR IUM } \\
(\mathrm{ppm}) \\
\end{array}$ & $\begin{array}{l}\mathrm{U}+\mathrm{Th} \\
(\mathrm{ppm}) \\
\end{array}$ & $\begin{array}{c}\text { ALPHA TRACK } \\
\text { DENSITY } \\
\left(\mathrm{T} / \mathrm{mm}^{2}\right) \\
\end{array}$ \\
\hline 0.39 & 42 & 31 & 73 & $574 \pm 16$ \\
\hline 1.40 & 36 & 30 & 66 & $562 \pm 20$ \\
\hline 1.68 & 34 & 27 & 61 & $501 \pm 20$ \\
\hline
\end{tabular}


by water and/or vapor in response to the heater experiment. It was noted during the heater experiment that there was an appreciable flow of water into the heater hole during the first few weeks following turn-on of the heater (private communication, $\mathrm{H}$. Carlsson, 1981). The bleached zone in the first $\sim 20 \mathrm{~cm}$ of rock adjacent to the heater hole, evident in the drill-back core (Fig. 4), attests to the presence of vapor-phase hydrothermal alteration. These radioelement gradients associated with the open fracture contrast with a relatively even distribution of track densities across a nearby closed fracture of similar orientation and filling mineralogy (Fig. 3B).

In continuing activities, core slabs with fission-track detectors will be exposed to a thermal neutron flux at the TRIGA reactor. Resulting fission-track densities, specific only to uranium-235, will provide accurate determination of uranium concentrations and their spatial variations. Coupled with the alpha-track data and results of exposures of appropriate standards, the fission-track data will also permit determination of the concentration and variation of thorium.

To provide an independent ascessment of the mobilities of uranium and its daughter products, selected core specimens will also be analyzed for equilibrium - disequilibrium conditions in the uranium decay series.

To exam ine physical properties of rock that has been subjected to heating, acoustic velocities, wave attenuation characteristics and mechanical properties of selected core intervals from varying distances from the heater hole will be investigated. These properties will be compared with fracture and matrix mineralogy and alteration due to heating, as well as with the intensity of fracturing and the openness of fractures. Core intervals have been selected, specimens prepared, and compressional and shear-wave velocities are being measured under simulated in situ conditions. 


\section{CONCLUSIONS}

Preliminary results have shown the additions of radioelements to the lining of open fractures by water and/or vapor in response to elevated temperatures in a granitic rock mass. While open fractures form conduits for transport of radionuclides from a breached canister, these results suggest that such fractures may also retard transport by interaction of the radionuclides with fracture-lining materials.

\section{References}

Chan, T., Littlestone, N. and Wan, O., 1980, Thermomechanical modeling and data an alysis for heating experiments at Stripa, Sweden; Proc. 21st Rock Mechanics Sym posium.

Wollenberg, H. A., and Flexser, S., 1985, The distribution of uranium and thorium in the Stripa quartz monzonite, Sweden; Uranium, 2, $155-167$. 


\section{Figure Captions}

Figure 1. Variation of $\mathrm{U}, \mathrm{Th}$, and $\mathrm{K}$ with distance from the $\mathrm{H}-10$ heater and comparison with analyses of unheated Stripa rock.

Figure 2. Vertical cross-section through the H-10 heater hole and the heater and extensometer drifts, showing the location of drillback holes. Blocks show zones of present investigation.

Figure 3. Alpha-Track densities from $U+T h$ adjaceni to an open fracture(A) and across a filled fracture(B), near the $\mathrm{H}-10$ heater hole, Stripa.

Figure 4. Stripa drillback core, (2x reduction) showing bleached (altered) zone (at left end) within $15 \mathrm{~cm}$ of edge of heater hole. 


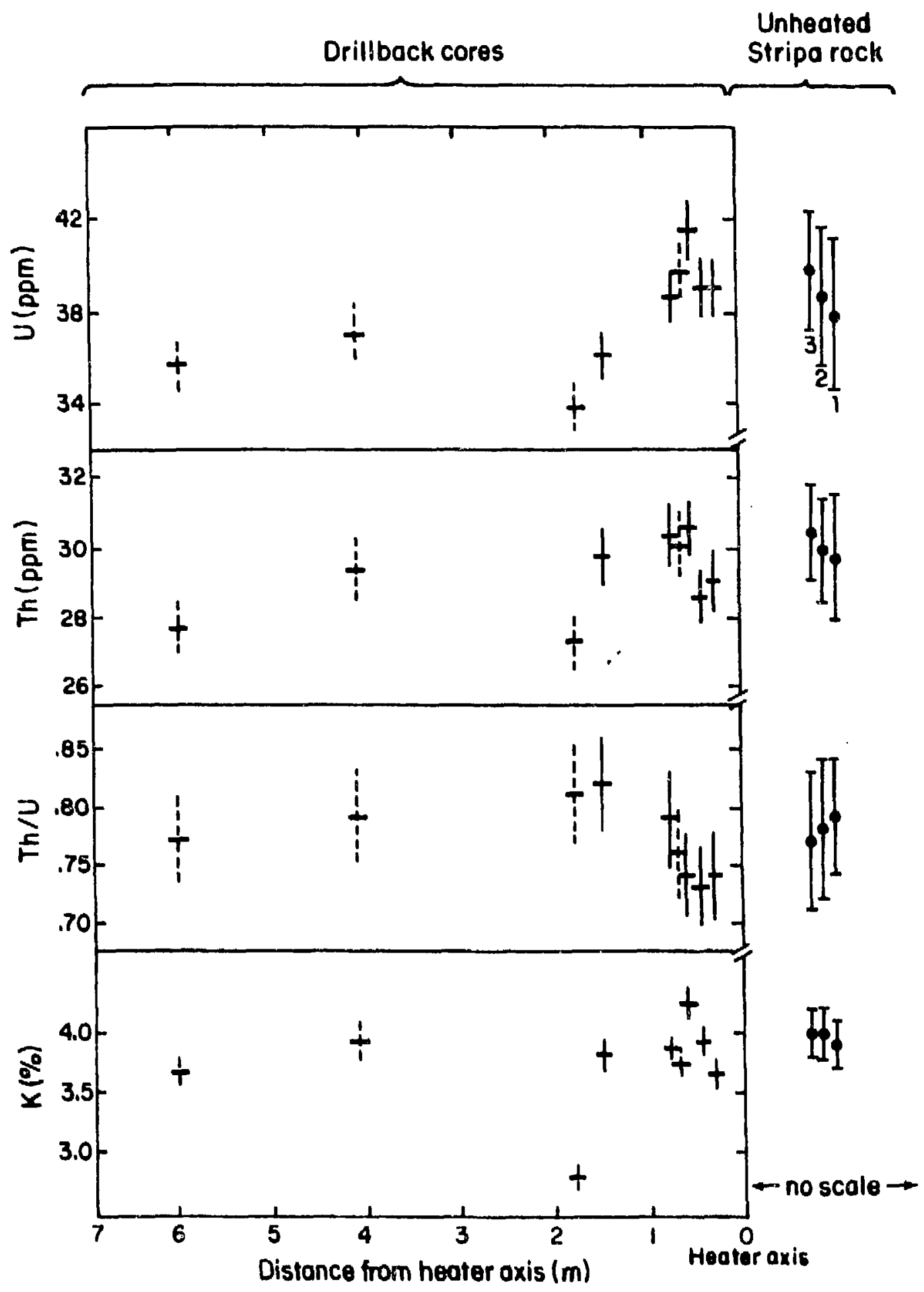

XBL 829- 2388

Figure 1. Variation of $U, T h$, and $K$ with distance from the $H-10$ heater and comparison with analyses of unheated Stripa rock. 


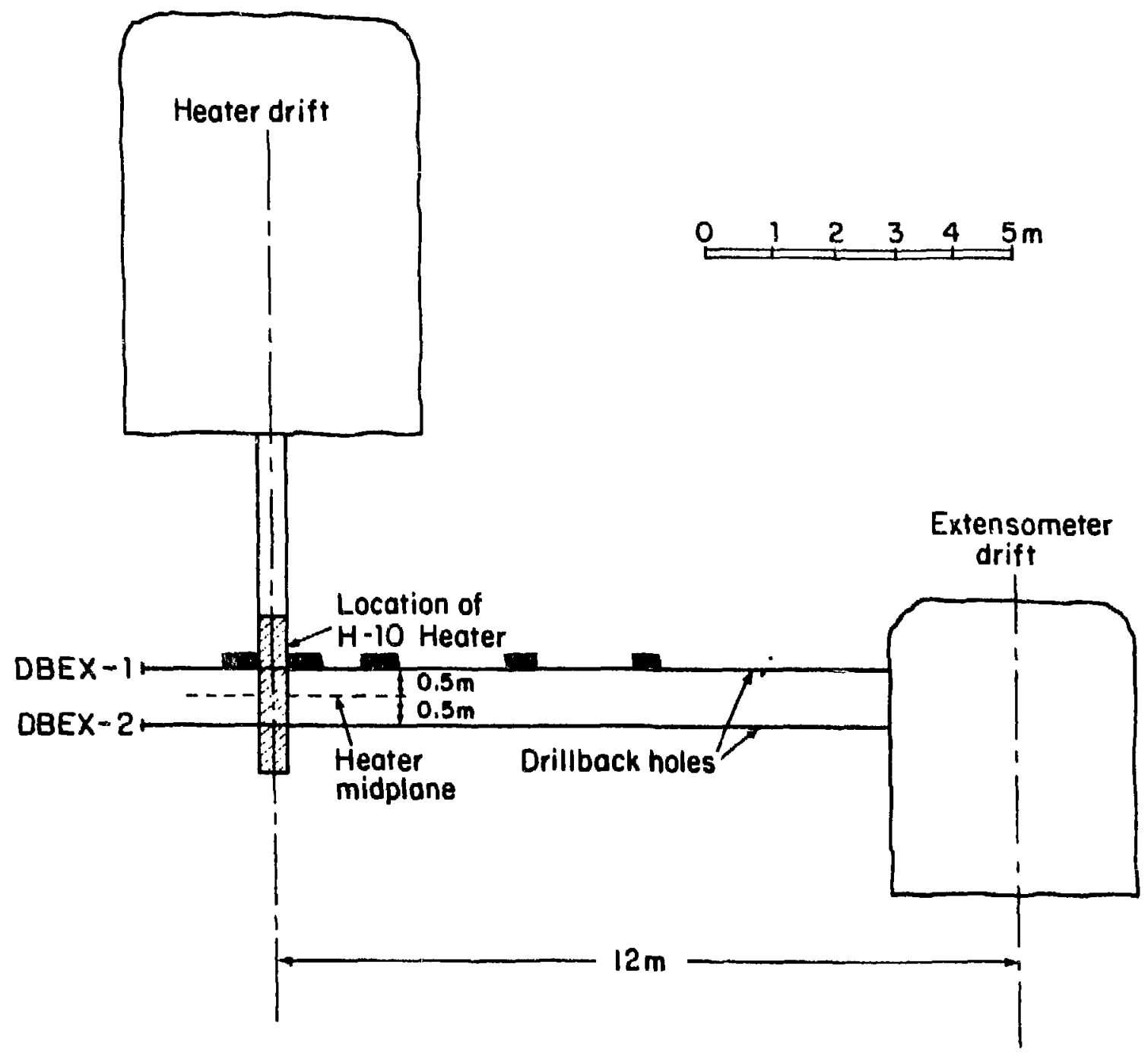

XBL B29-239I

Figure 2. Vertical cross-section through the $H-10$ heater hole and the heater and extensometer drifts, showing the location of drillback holes. Blocks show zones of present investigation. 
A. Open Fracture

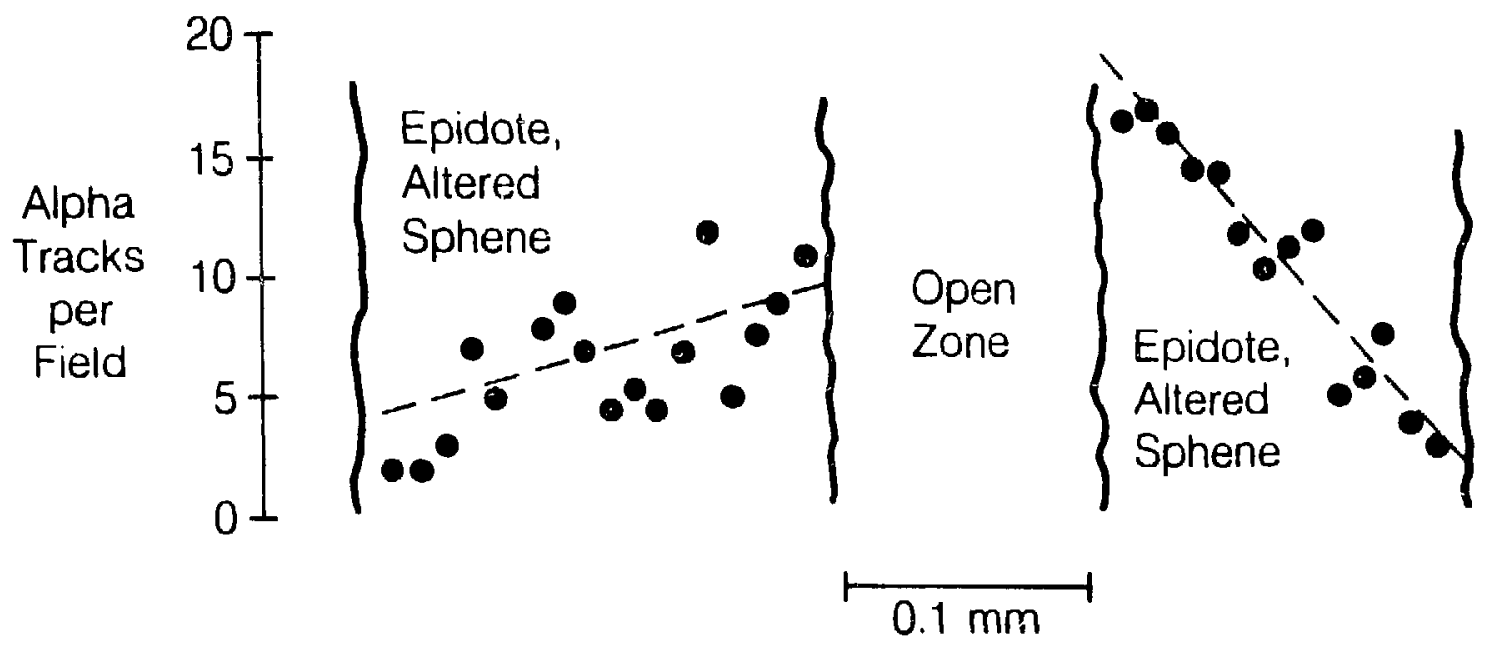

B. Closed Fracture

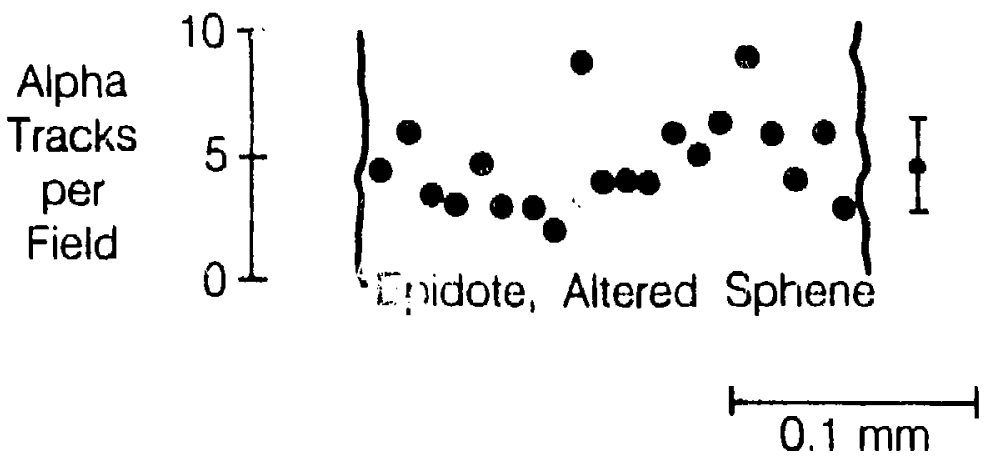

XBL $8610 \cdot 12606$

Figure 3. Alpha-Track densities from $U+T h$ adjacent 10 an open fracture(A) and across a filled fracture(B), near the $\mathrm{H}-10$ heater hole, Stripa. 


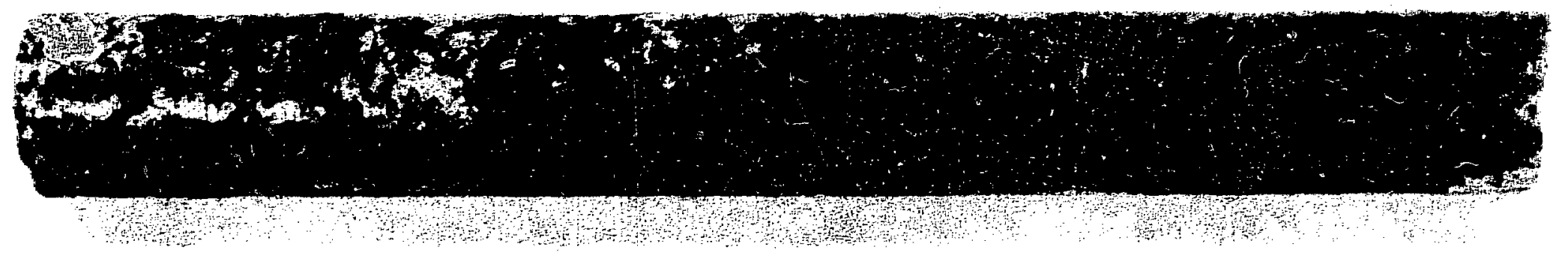

Figure 4. Stripa drillback core, $(2 x$ reduction) showing bleached (altered) zone (at left end) within $15 \mathrm{~cm}$ of edge of heater hole. 


\title{
Deformation of Fractures Under Normal Stress
}

\author{
L. Myer, L. J. Pyrak-Nolte, and N. G. W. Cook
}

\section{Introduction}

When the stress state in a rock mass is perturbed, fractures, which may be envisioned as two surfaces in partial contact, experience deformation. Deformations of the areas of contact and the voids between them affect the mechanical, hydrologic and geophysical properties of the rock mass as a whole. The magnitude of the effect on physical properties is of course related to how much deformation occurs for a particular change in stress. One way to quantify this stress-deformation relationship is to measure the specific stiffness of the fracture. The specific stiffness relates the change in average fracture deformation to the change in average stress applied to the fracture surfaces.

This report describes results of a laboratory investigation of the deformation of natural fractures in crystalline rock subjected to normal stress. Deformations of single fractures were measured for stresses up to $85 \mathrm{MPa}$. Experiments were performed under water saturated and elevated temperature conditions as well as under dry room temperature conditions. Specific stiffness values were obtained from the deformation-stress data.

\section{Experimeatal Procedures}

The experimental configuration is shown in Figure 1. Samples were approximately $52 \mathrm{~mm}$ in diameter by $77 \mathrm{~mm}$ long. Each contained a single fracture located midway between the ends and oriented orthogonal to the long axis of the sample.

Three annular collars were attached to the sample as illustrated in Figure 1. The inside surface of a collar did not touch the rock surface; each collar was secured to the 
rock by three pointed set screws. Care was taken to assure that the collars were parallel and equispaced.

Four precision linear variable differential transformers (LVDT's) (rated repeatability of $4.0 \times 10^{-6}$ inch) were attached in pairs on diametrically opposite sides of the sample as shown in Figure 1. The assembly was placed in a rest frame and axial load applied to the sample. Displacements of the intact rock as measured by the two upper LVDT's were subtracted from the displacements measured by the two lower LVDT's to isolate the average displacement of the fracture. Performance of the measurement system was checked by duplicating the experiment using a solid aluminum cylinder in place of the fractured rock.

To perform a test on a saturated fracture the sample was enclosed in a rubber sheath, evacuated, and then saturated under a head of about one meter of water. With the addition of a sample sheath, the experimental configuration was exactly as illustrated in Figure 1; the set screws in the collars were driven through the sheath to rest against the rock.

For measuremenits at elevated temperature, the sample was wrapped with strip heaters and insulation. Temperature was monitored by a thermocouple strapped to the rock. The system was allowed to equilibrate at constant temperature before measurements were made.

\section{Deformation Measurements}

Fracture deformations for two complete loading/unloading cycles for one sample (E30) are shown in Figure 2. Though nonlinear there is essentially no difference in deformation between loading cycles and very little hysteresis. Deformation of the asperities and voids within the fracture must therefore have been elastic. As will be discussed below, nonlinearily reflects the changing geometry of the areas of asperity contact as load increased. 
Other investigators (Bandis et al., 1983; Raven and Gale, 1985) have observed significant hysteresis in the initial loading cycle for natural fractures. However, they also observed that the amount of hysteresis and hence the difference in deformation between cycles decreased with the number of cycles. Sample E30 had been loaded to $85 \mathrm{MPa}$ on several occasions for different tests prior to when the measurements in Figure 2 were made. Thus the observed behavior was consistent with previous studies by other investigators.

Other effects of repeated loading were observed in a later test, performed after the fracture had been cycled on several different occasions. Figure 3 shows the data of this subsequent test (April Test) in addition to first loading cycle data (February Test) replotted from Figure 2. Though the deformations in either loading cycle are essentially reversible, more deformation occurred in the April Test and the rate of change of displacement with stress, i.e., compliance of the fracture, is also greater. It is also interesting to note that at high stresses the deformations of the early test appear to asymptote to a constant rate of deformation while the deformations of the later test asymptote to a constant value. It is believed the differences in behavior between the February Test and April Test are due to the breakage of asperities.

Fracture deformations versus applied normal stress for three different fractures are shown in Figure 4. Though the magnitude of total deformation varies for the different samples, all samples exhibited decreasing rates of deformation with increasing stress. As will be discussed in the next section, it is believed that this behavior reflects changes in the area of asperity contact between the surfaces.

The inverse of the tangent slopes to the deformation versus stress curve is defined as the specific stiffness of the fracture. Values of specific stifness for the three fracture deformation curves in Figure 4 were determined graphically and plotted in Figure 5.

Specific stiffness increases rapidly with stress up to about $10 \mathrm{MPa}$ and then increases at a decreasing rate. Though the trend is less for sample E30. the specific 
stiffness for each fracture appears to approach a constant value.

Specific stiffnesses obtained from the April Test on E30 exhibit different trends with stress. As seen in Figure 6, specific stiffness increases at about the same rate as the February Test up to about, $20 \mathrm{MPa}$. Thereafter stiffness of the April Test approaches a more constant value up to about $50 \mathrm{MPa}$ and then accelerates to very high values at high stress.

Fracture deformation data for sample E30 (April Test) under room temperature dry and elevated temperature wet and dry conditions are plotted in Figure 7. The water saturated test was performed under head of about one meter of water at a temperature of about $95^{\circ} \mathrm{C}$. The temperature of the hot dry test was about $100^{\circ} \mathrm{C}$. As can be seen in the figure neither the presence of water nor temperatures up to $100^{\circ} \mathrm{C}$ had any significant effeci upon the magnitude of fracture deformations or fracture stiffness.

\section{Discussion}

The fracture deformation behavior described above can be explained assuming only changes in fracture geometry and elastic deformation of the voids and asperities. If deformations are elastic, the observed norlinearily and change in specific stiffness with load must be due to nonlinear elastic properties of the rock comprising the fracture surfaces and/or changes in the fracture void geometry.

Changing fracture void geometry as load is increased has been independently confirmed for samples E30 and E32 from tests in which a low melting point metal was injected into the fracture (Pyrak et al., 1985). After the metal solicified, separation of the fracture revealed a cast of the void space. Injections performed with the fractures under different normal stresses clearly showed an increase in contact area with increasing normal stress. For E32, the injection tests also indicated that the rate of increase in contact area decreased at high stress. In addition, at high stress levels, the amount of void space was still significant in all fractures. 
Based on these observations it is believed that the observed rapid increases in specific stiffness at low normal stresses were primarily due to increasing numbers of asperities coming into contact. Higher specific stiffness values for E32 than E30 suggest a higher contact area for E32 and this was confirmed by metal injection tests.

At higher loads the more nearly constant specific stiffness values reflected elastic void deformation and a diminished rate of increase in contact area. The rate of void closure would depend upon the elastic properties of the rock, the distribution, size, and aspect ratio of the voids. The lower stiffness of E35 in comparison to the other samples (Figure 5) was probably due to the presence of more, larger voids. Similarly asperity breakage between the February and April test of E30 created larger voids of higher aspect ratio than had been present before, and, consequently, higher rates of deformation with increasing load.

Elastic void closure can not continue indefinitely. As more sûress is applied voids will eventually close with a corresponding increase in contact area and stiffness. The rapid increase in stiffness of the April Test of E30 at high stress reflects the limiting condition in which so many voids have closed that there is no further fracture deformation in excess of the intact rock deformation.

The observed mechanical behavior of these fractures have important implications with respect to both hydrologic and seismic behavior of fractures. The relationship between fracture deformations and hydraulic conductivity is discussed in detail in Report No. 7 "Fracture Permeability Under Normal Stress." The influence of fracture stiffness on the propagation of seismic waves through a fractured rock mass is discussed in detail in Report No. 5 "Seismological Modeling Methods in Fracture Studies." When substituted in to the seismic numerical models, fracture specific stiffness values obtained in this study were found to be too high to be representative of reasonable field behavior. It is believed that the reason for this discrepancy is that the scale of the laboratory measurements is not representative of field conditions. 


\section{Conclusions}

Fracture deformation measurements as a function of normal stress were completed for three natural granitic fractures. Results from all three fractures illustrate the important influence of geometry, i.e., size and distribution of asperities and voids in the fracture, on mechanical behavior. Three stages of fracture deformation were suggested. In the first stage at low loads contact area increases rapidly with load. The second stage is characterized by elastic deformation of voids. As these voids close in the third stage the specific stiffness of the fracture becomes unbounded.

Deformation measurements from this study have been integrated into studies of both hydrologic and seismic behavior of fractures. The seismic studies have indicated that the mechanical behavior of fractures is scale dependent.

Further work on mechanical deformation behavior of fractures will center on understanding effects of geometry and scale. Theoretical work will be carried out to evaluate effects of the form of statistical distribution function assumed for asperities. Laboratory work will continue with mechanical measurements of samples of different sizes. 


\section{References}

Bandis, S.C., Lumsden, A.C., and Barton, N.R., 1983, Fundamentals of rock joint deformation: Int. J. Rock Mech. and Min. Sci. \& Geomech. Abstr., v. 20, no. 6., p. 249-268.

Pyrak, L.J., Myer, L.R., and Cook, N.G.W., 1985, Determination of fracture void geometry and contact area at different effective stress: Trans. Am. Geophys. Union, v. 66, no. 46, p. 903.

Raven, K.G., and Gale, J.E., 1985, Water flow in a natural rock fracture as a function of stress and sample size: Int. J. Rock Mech. and Min. Sci. \& Geomech. Abstr., v. 22, no. 4, p. 251-261. 


\section{Figure Captions}

Figure 1. Schematic illustration of experimental set-up.

Figure 2. Comparison of fracture deformations for two sequential loading/unloading cycles.

Figure 3. Comparison of deformation test performed in April with earlier test. Sample had been subjected to repeated loading in interim.

Figure 4. Fracture deformations as a function of normal stress on fracture for three samples.

Figure 5. Specific stiffness for the three deformation tests shown in Figure 4.

Figure 6. Comparison of specific stiffness from April Test ọn E30 with earlier test.

Figure 7. Comparison of fracture deformations for sample E30 under room temperature, $100^{\circ} \mathrm{C}$ dry, and $95^{\circ} \mathrm{C}$ saturated conditions. 


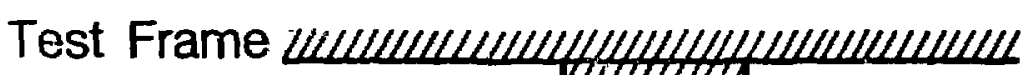

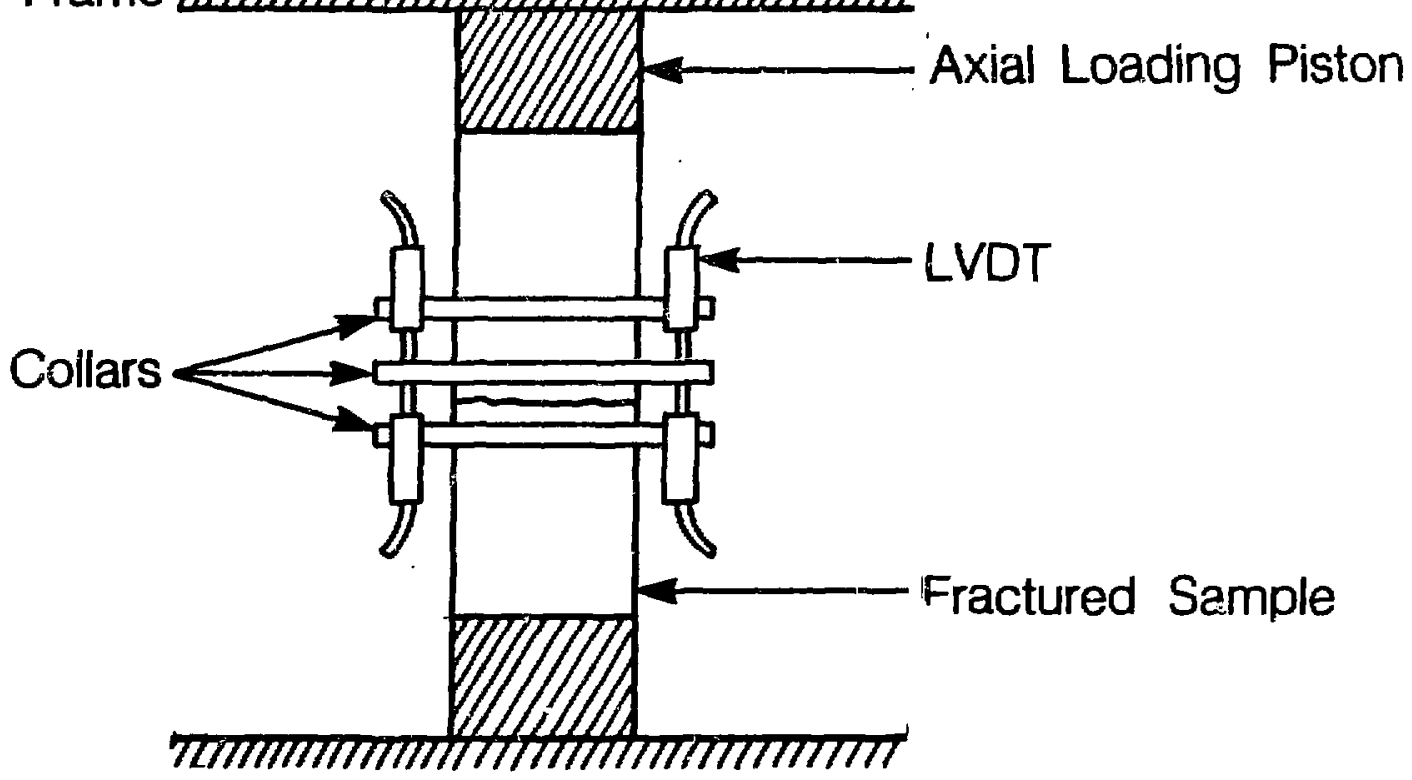

XBL 869-11043

Figure 1. Schematic illustration of experimental set-up. 


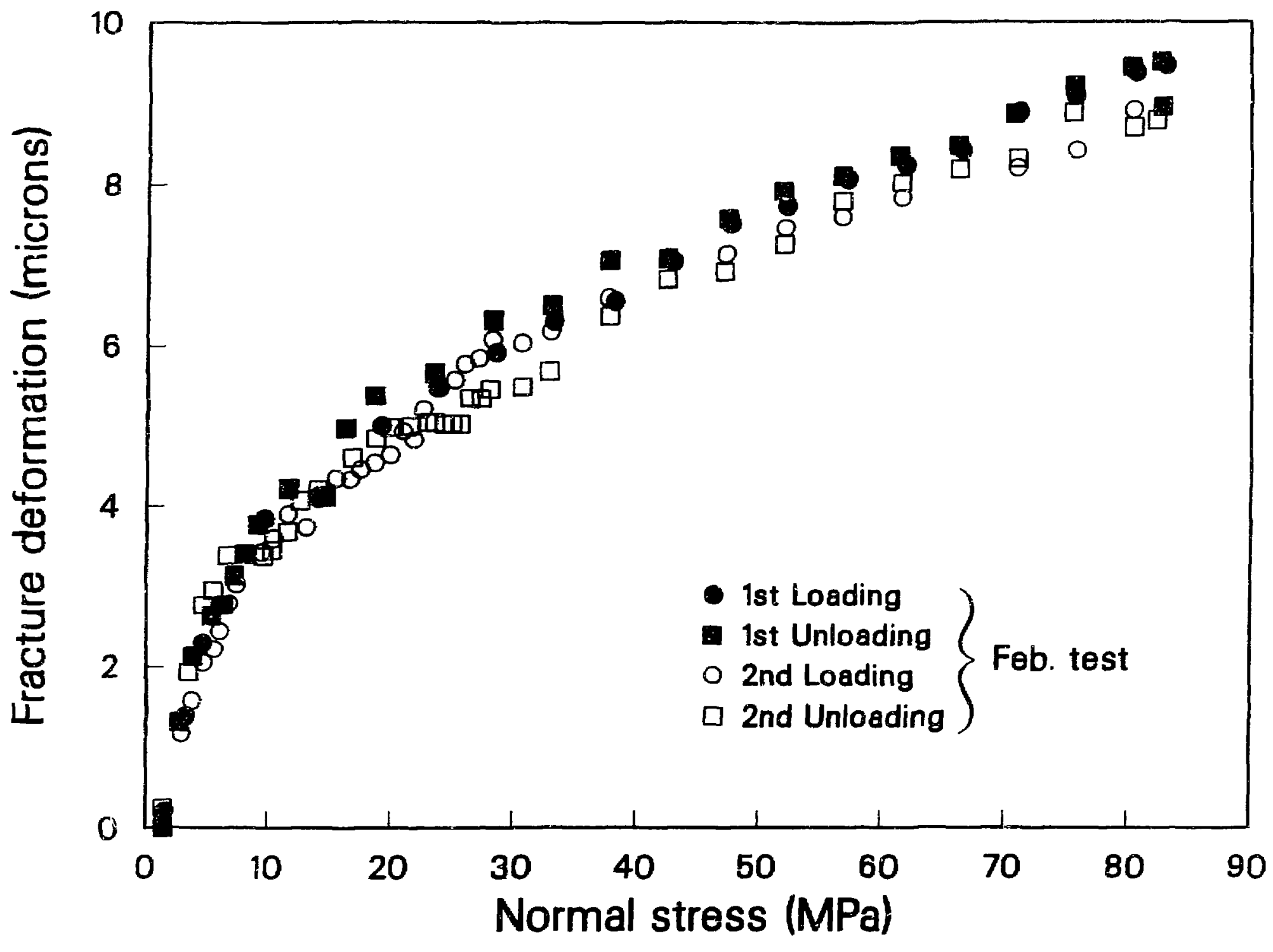

XCG 8610-12155

Figure 2. Comparison of fracture deformations for two sequential loadinf/unloading cycles. 


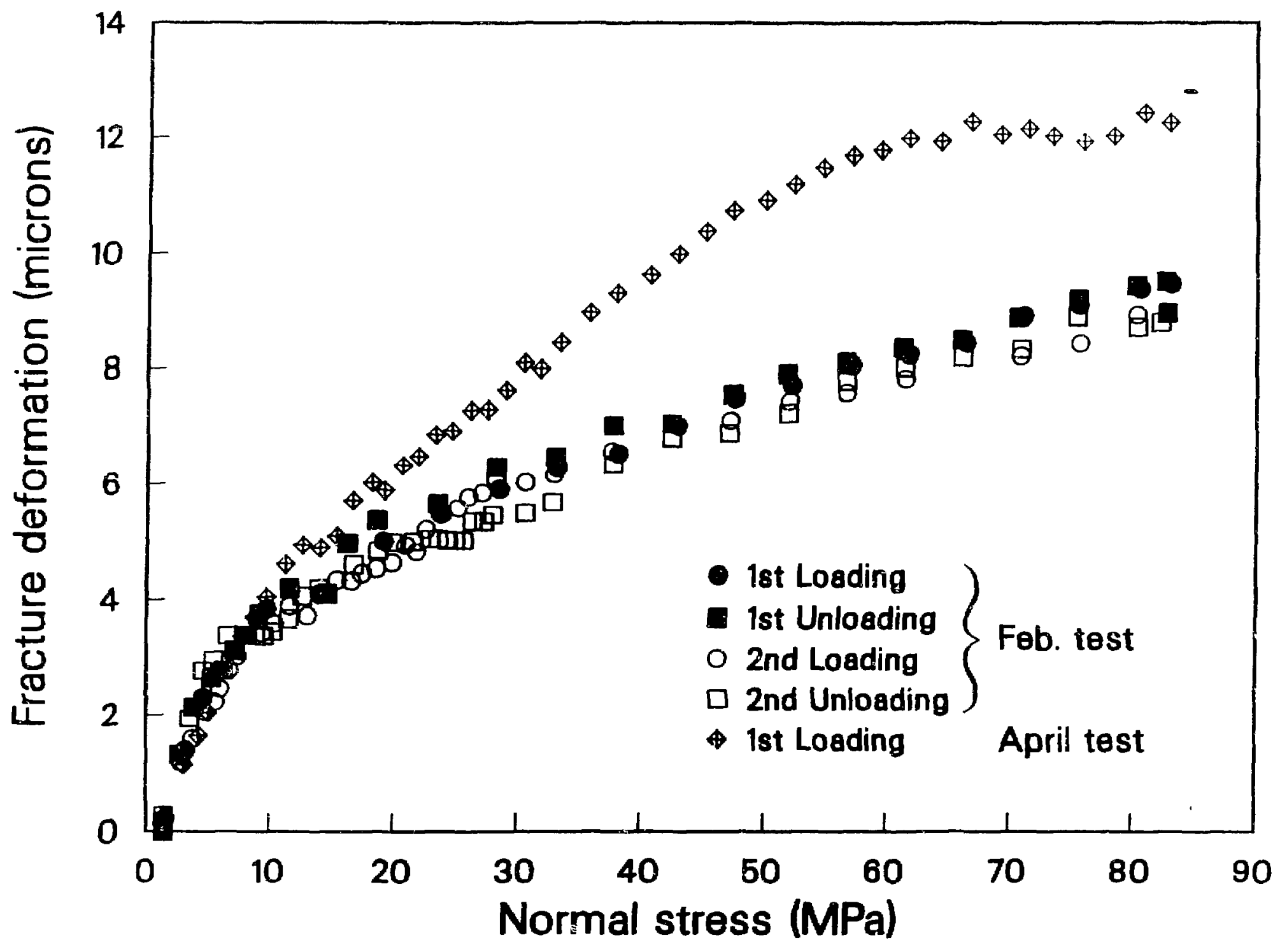

XCG 8610-12156

Figure 3. Comparison of deformation test performin in April with earlier test. Sample had been subjected to repeated loading in interim. 


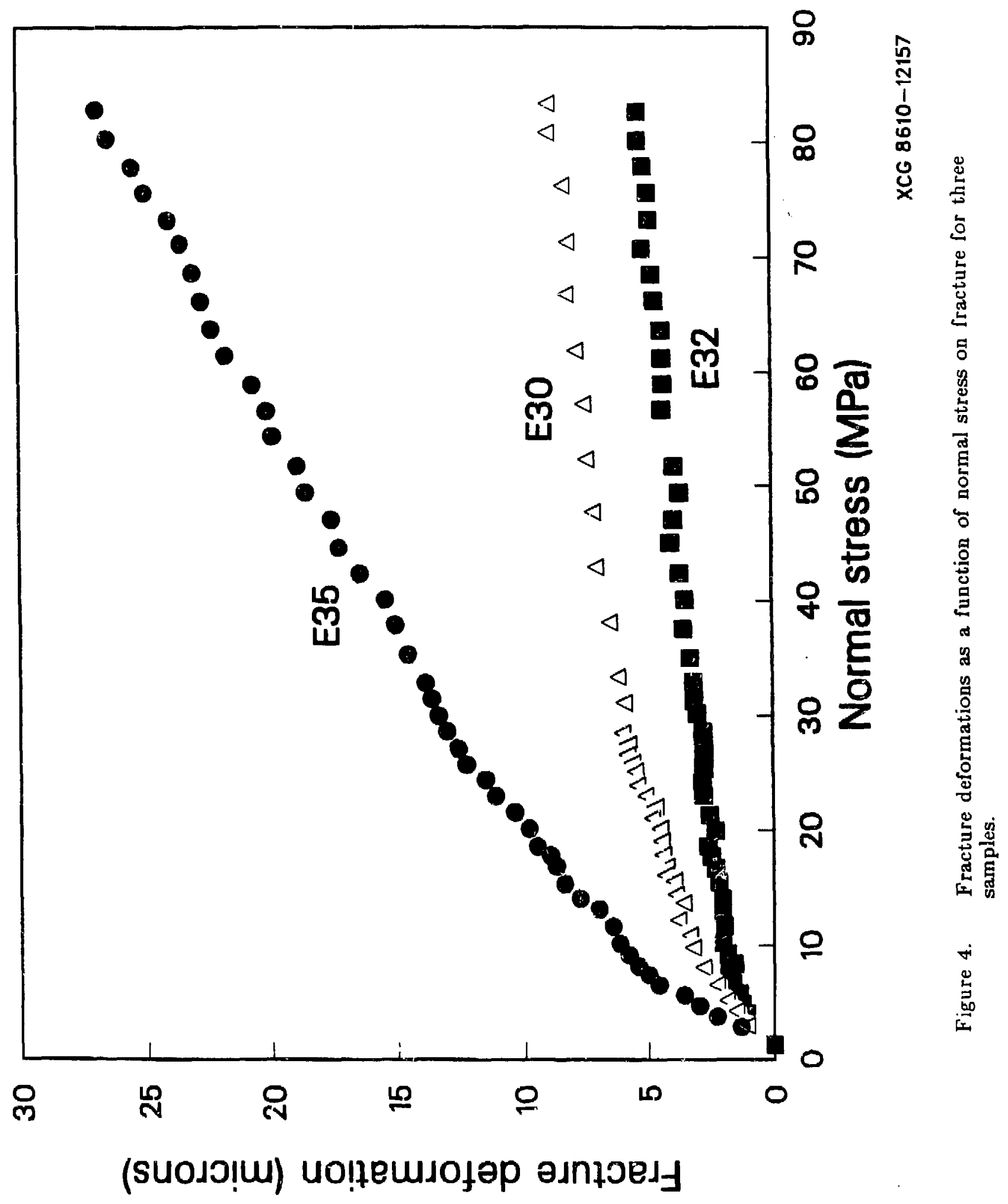




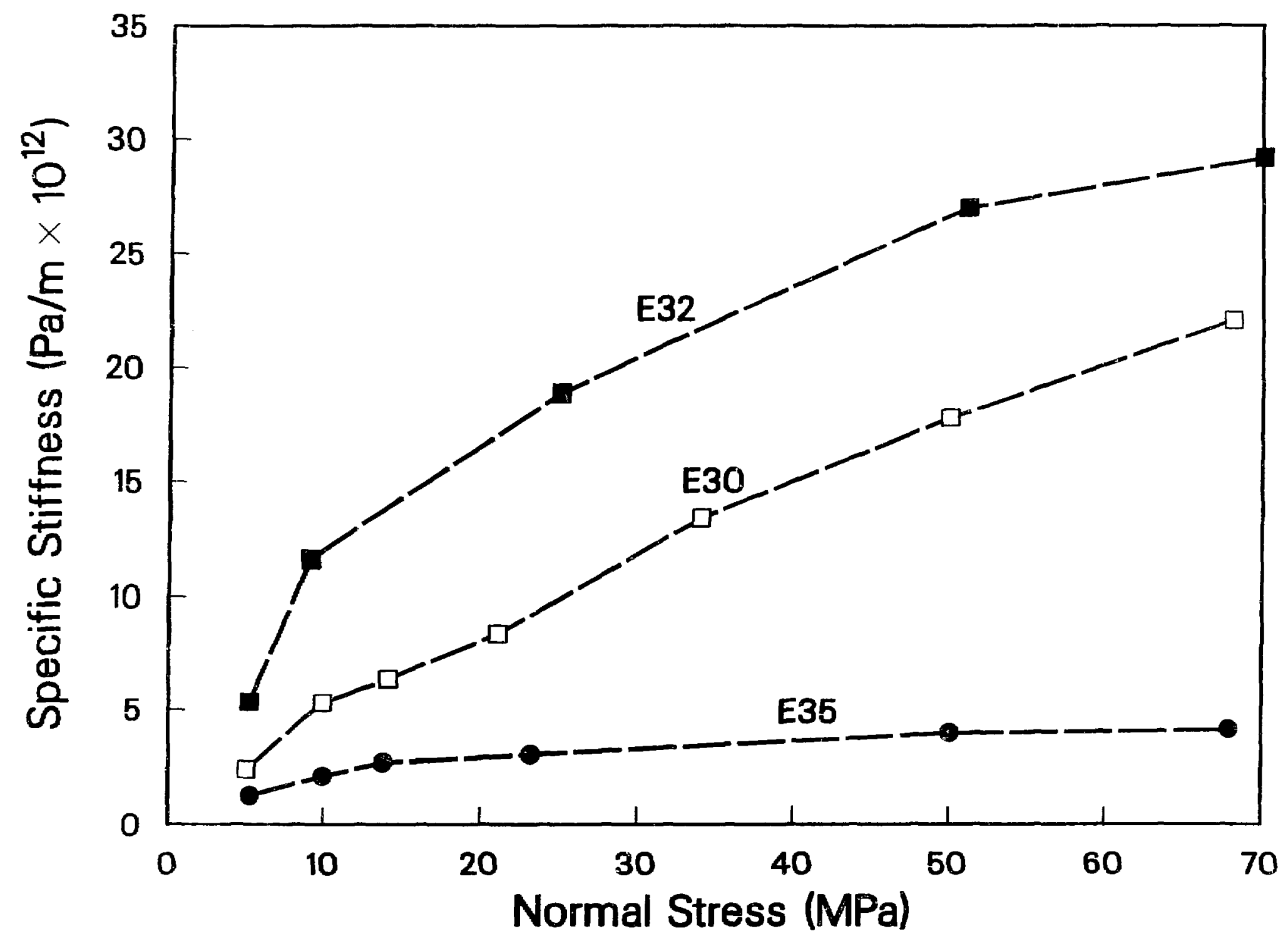

XCG $8610-12159$

Figure 5. Specific stiffness for the three deformation tests shown in Figure 4. 


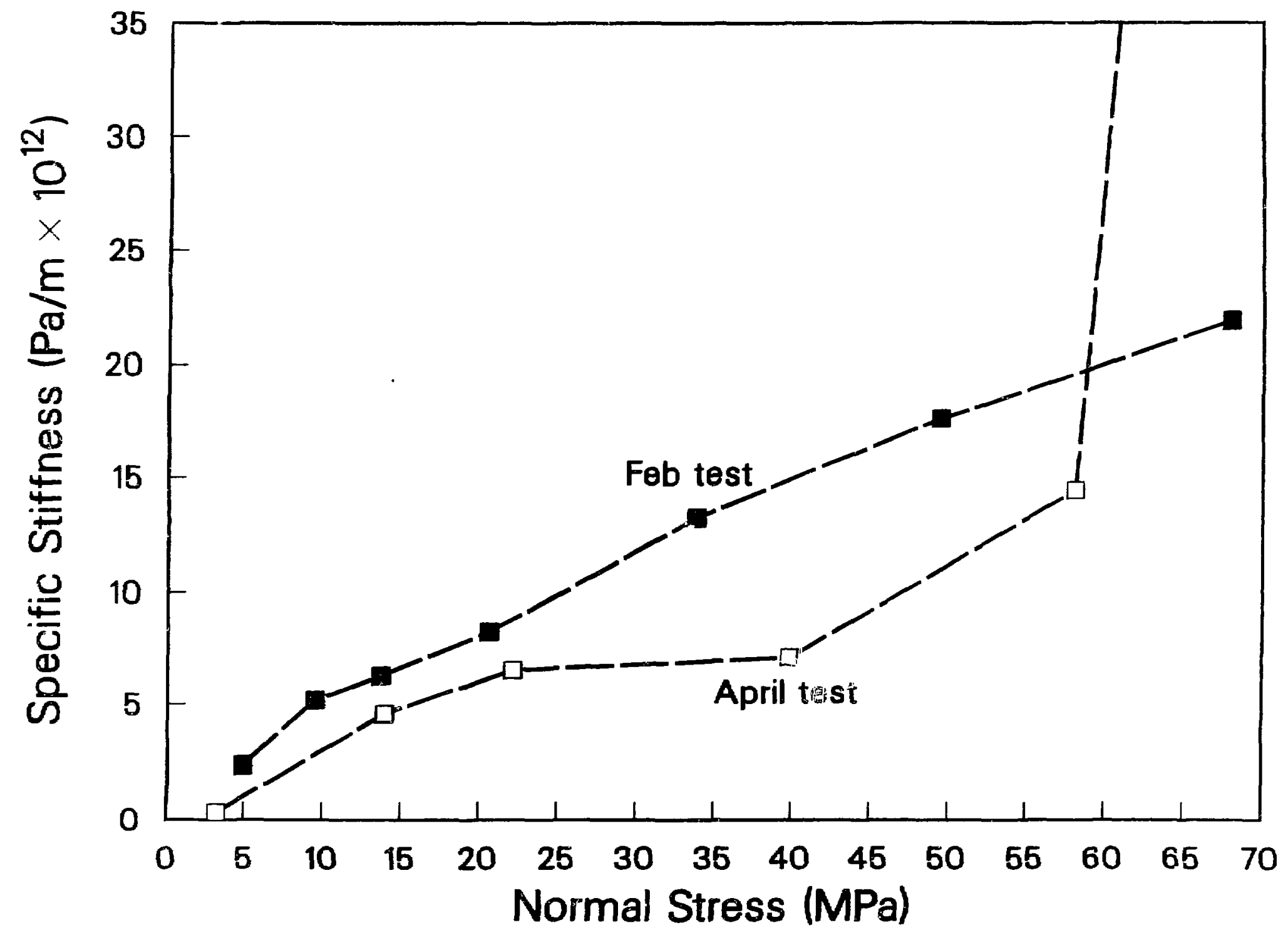

XCG 8610-12160

Figure 6. Comparison of specific stiffness from April Test on E30 with earlier test. 


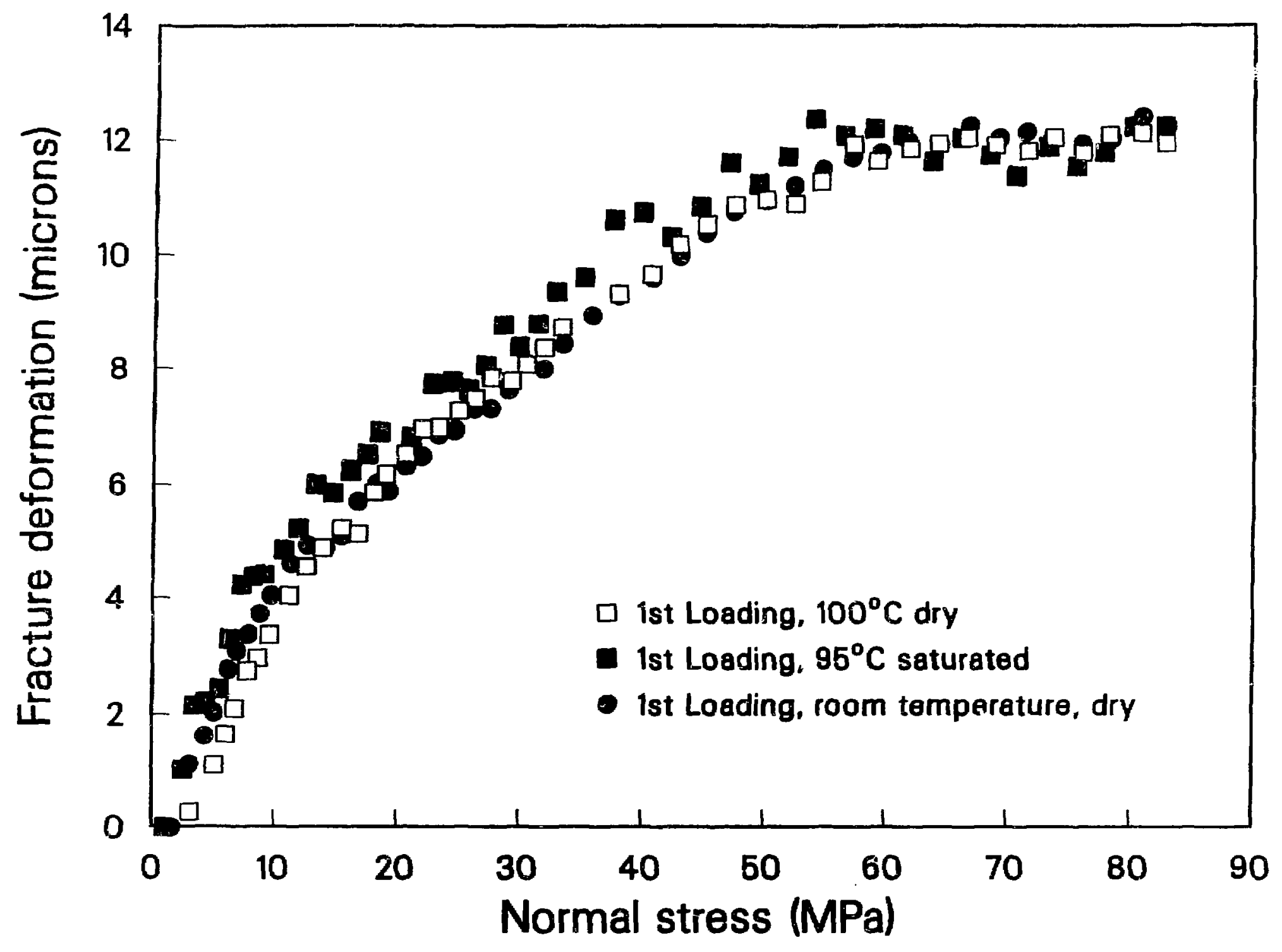

XCG $8610-12158$

Figure 7. Comparison of fracture deformations for sample E30 under room temperature, $100^{\circ} \mathrm{C} d r y$, and $95^{\circ} \mathrm{C}$ saturated conditions. 


\title{
Fracture Permeability Under Normal Stress
}

\author{
L. J. Pyrak-Nolte, N. G. W. Cook, and L. R. Myer
}

\section{Introduction}

Understanding fluid flow through fractures is a central issue to many geolugical problems. Geological isolation of nuclear waste, petroleum recovery, and aquifer contamination are just a few examples where the knowledge of the fundamentals of fluid flow through single rock fractures is necessary to predict behavior of fluid movements in fractured rock masses.

Several investigations of fluid flow through single fractures have been carried out in the laboratory under varying conditions. Iwai (1976) studied flow as a function of stress through single induced fractures, attaining maximum stresses of only $20 \mathrm{MPa}$. Engelder and Scholz (1981) studied fluid flow along fractures for effective stresses up to $200 \mathrm{MPa}$, using artificial fractures in the experiment. Raven and Gale (1985) studied the effect of stress on radial fluid flow through natural fractures for samples of various sizes, but the maximum pressure was only $30 \mathrm{MPa}$. The current investigation studied the effect of uniaxial effective stress on fluid flow through a natural fracture in a low permeability granitic rock. Flow measurements in conjunction with fracture displacement measurements were used to develop an empirical relationship between flow and fracture closure.

\section{Experimental Procedure}

Three samples of quartz monzite (Stripa granite) measuring $52 \mathrm{~mm}$ in diameter by $77 \mathrm{~mm}$ in height were used in the flow and displacement experiments. Each sample contained a fracture orthogonal to the axis of the core. The core was obtained from extensometer holes in the Stripa in silu heater experiments. It was carefully drilled and 
logged, so that the fractures were preserved and their exact location in the field could be traced (Olkiewicz, et al., 1979).

A linear flow technique (quadrant flow) was developed to measure fluid flow. This technique was employed because of sample size. If a radial flow method had been used, the central borehole would have been very small and the results would have reflected loss of energy predominately due to flow adjacent to the borehole rather than the effect of the whole fracture.

The fracture was assembled and two diametrically opposed quadrants were sealed with silicone sealant. A rubber gasket was stretched thinly over the specimen and a nylon manifold was secured around the sample with hose clamps (Figure 1). Removing the tension from the gaskets caused the rubber jacket to relax and seal the system. Inlet and outlet ports were cut in the gasket after assembly. Flow occurred between the two open quadrants which are diametrically opposed (Figure 2). The apparatus was placed in the load frame of a servo-controlled stiff-testing machine to maintain the desired effective stress. An upstream head of $0.4 \mathrm{MPa}$ was applied, and flow measurements were made for one complete loading and unloading cycle and an additional loading cycl: up to a maximum effective stress of $85 \mathrm{MPa}$.

The experimental setup for the displacement measurements is described in the fracture deformation report and will not be described here.

\section{Results}

In Figure 3, flow data (flow per unit head drop, Q) for sample E30 for all loadings and unloadings are shown. Though the magnitude of the flow varies between loading and unloading cycles, the trend of a rapid decrease in flow at low stresses and a much more gradual decrease in flow at higher stresses was observed to be independent of the load cycle for all of the specimens. This behavior has also been observed by many other investigators (e.g., Iwai, 1976; Engelder and Scholz, 1981; Raven and Gale, 1985). 
In Figure 4 fluid flow data for three fractures is compared. Data for E30 and E32 were obtained from the first unloading cycle. Data presented for E35 were obtained from the first loading cycle because this was the most complete data set. For E30 and E32 the data show a rapid decrease in flow as stress is increased to about $20 \mathrm{MPa}$. Above this stress the flow appears to asymptote to a constant value. Though the trend is less pronounced for sample E35, a decrease in flow at higher stresses is still apparent. The small but finite flow in samples E30 and E32 even at $85 \mathrm{MPa}$ is significant in that it suggests that How approaches an irreducible level at high stresses. Fracture displacement data for these fractures (Figure 5) show that the fractures continue to close even at the highest stresses. At high stresses, fracture flow is not strongly affected by the average mechanical deformation of the fracture.

In Figure 6 the flow test data is plotted in the conventional format of logarithm of average fracture closure versus logarithm of flow. The.effect of the irreducible flow is seen as a departure from linearity in this plot. The slope of the linear portion of the curves is also not $1 / 3$, as would be expected if the flow followed the commonly accepted "cubic law" relationship. However, it is interesting to note that the slopes are very similar to those obtained by Raven and Gale (1985) for other natural fractures.

To analyze the fracture closure versus fluid flow data a model consisting of a general power relationship between fracture closure and fluid flow as well as a constant term representing the irreducible flow was proposed. Th? relationship between flow and average fracture closure is given by:

$$
\mathrm{Q}=\mathrm{Q}_{\infty}+\mathrm{C}\left(\mathrm{d}_{\max }-\mathrm{d}\right)^{\mathrm{n}}
$$

where

$$
\begin{aligned}
& \mathrm{Q}=\text { mesured value of flow (flow per unit head drop) } \\
& \mathrm{Q}_{\infty}=\text { irreducible flow } \\
& \mathrm{C}=\text { fitted constant } \\
& \mathrm{d}_{\max }=\text { maximum value of closure }
\end{aligned}
$$


$\mathrm{d}=$ measured value of closure

n $=$ power relation.

A linear least-squares fitting routine applied to the logarithm of the quantities in Equation (1) (Press et al., 1986) was used to determine $Q_{\infty}, d_{\max }, C$ and $n$. Table 1 lists the measured values of closure at a stress of $85 \mathrm{MPa}$ and the values of the fitted maximum closure, $d_{\max }$. The fitted values of $d_{\max }$ are reasonable compared to the mechanically measured values at $85 \mathrm{MPa}$. From the displacement data (Figure 5), it can be seen that the fitted values of maximum closure may be reached if the stress could be increaseed indefinitely, so that complete closure of all the voids occurs. This is evident from the slope of the displacement versus stress curves. For example, it is plausible that E32, the tight fracture, would close to a maximum of $6.6 \mu \mathrm{m}$ if sufficient stresses were applied, whereas E35, the loose fracture, which is still closing at $85 \mathrm{MPa}$ could close an additional $20 \mu \mathrm{m}$.

When values of irreducible flow, $Q_{\infty}$, are subtracted from th-flow data, the result, as shown in Figure 7, is a power law relationship between flow and average closure. However, as indicated by the values of $n$ in Figure 7 , the relationship differs greatly from a cubic law representation.

\section{Discussion}

The large values observed for the exponent in Equation (1) may be explained by the changes in fracture void geometry occurring as stress is increased. The apertures and aspect ratios of the fracture voids are heterogeneous. As stress is applied, the high aspect ratio vioids close much more rapidly than the averaged measured value of fracture closure. This rapid closure of some voids is reflected in the rapid increase of displacement, and the sharp decrease in flow for low stresses. The high aspect ratio fracture voids eventually become barriers to flow as the stress is increased and the high aspect ratio voids become completely closed; the only voids that remain open are small equidimensional pipes. The barriers to fow are not randomly distributed, but have 


\section{Table 1}

Values of experimentally determined closure at $85 \mathrm{MPa}$ and maximum closure, $\mathrm{d}_{\max }$, determined from the flow equation (1).

\begin{tabular}{|ccc|}
\hline Specimen & Closure at $85 \mathrm{MPa}$ & $\mathrm{d}_{\max }$ \\
\hline $\mathrm{E} 32$ & $4.5 \mu \mathrm{m}$ & $6.6 \mu \mathrm{m}$ \\
$\mathrm{E} 30$ & $9.5 \mu \mathrm{m}$ & $12.5 \mu \mathrm{m}$ \\
$\mathrm{E} 35$ & $28.1 \mu \mathrm{m}$ & $46.0 \mu \mathrm{m}$ \\
\hline
\end{tabular}

correlated geometrical arrangements. In Figure 8 from Pyrak et al. (1985), the barriers (black) increase as stress was applied from $3 \mathrm{MPa}$ to $85 \mathrm{MPa}$, while the flow paths (white) become more tortuous as it flowed pass the barriers. The difference in the number and distribution of the barriers as the stress is increased is evidence vat some of the high aspect ratio voids have closed completely. The irreducible flow is a result of low aspect ratio fracture voids that cannot be closed.

\section{Conclusions}

Fluid flow through a natural fracture is controlled by the distribution and number of high aspect ratio fracture voids. As stress is applied, the high aspect ratio voids close first and become barriers to flow. These barriers are not simple point contacts but have geometrical arrangements and are proximate to one another. This result is evident in the displacement data in which there is a rapid increase in displacement at low stresses (which is the closure of high aspect ratio voids) and at high stresses, a more gradual increase in closure (the remaining displacement due to low aspect ratio voids). The barriers are also evident in contact area measurements made by Pyrak et al. (1985). Further work needs to be done to explore the distribution of barriers and their formation as stress is increased or decreased. 


\section{References}

Engelder, T. and Scholz, C.H., 1981, Fluid flow along very smooth joints at effective pressures up to 200 Megapascals, In Mechanical Behavior of Crustal Rocks: $A m$. Geophys. Union Monogr. 24, p. 147-152.

Iwai, K., 1976, Fundamentals of fluid flow through a single fracture: Ph.D. thesis, 280 p., Univ. of Calif., Berkeley.

Olkiewicz, A., Gale, J.E., Thorpe, R., Paulsson, B., 1979, Geology and fracture systems at Stripa, Lawrence Berkeley Laboratory Report LBL-8907, SAC-21, Univ. of Calif., Berkeley.

Press, W.H., Flannery, B.P., Teukolsky, S.A., and Vettering, W.T., 1986, Numerical Recipes: p. 509, Cambridge University Press, New York.

Pyrak, L.J., Myer, L.R., and Cook, N.G.W., 1985, Determination of fracture void geometry and contact area at different effective stress: Trans., Am. Geophys. Union, v. 66 , no. 46, p. 903.

Raven, K.G. and Gale, J.E., 1985, Water flow in a natural rock fracture as a function stress and sample size: Int. J. Rock Mech. and Min. Sci. \& Geomech. Abstr., v. 22 , no. 4, p. 251-261. 


\section{Figure Captions}

Figure 1. Experimental apparatus for quadrant flow measurements.

Figure 2. Flow path in quadrant flow technique.

Figure 3. Flow per unit head drop as a function of effective stress level for sample E30 for sequential loading/unloading cycles.

Figure 4. Comparison of flow per unit head drop as a function of effective stress for samples E35, E30 and E32.

Figure 5. Fracture displacements as a function of normal stress for samples E35, E30 and E32.

Figure 6. Fracture closure versus flow per unit head drop for samples E35, E30 and E32.

Figure 7. Fracture closure versus flow per unit head drop after subtraction of irreducible flow for samples E35, E30 and E32.

Figure 8. Photograph of fracture surfaces under $85 \mathrm{MPa}$ stress showing actual fow paths (white) and barriers to flow (black). 


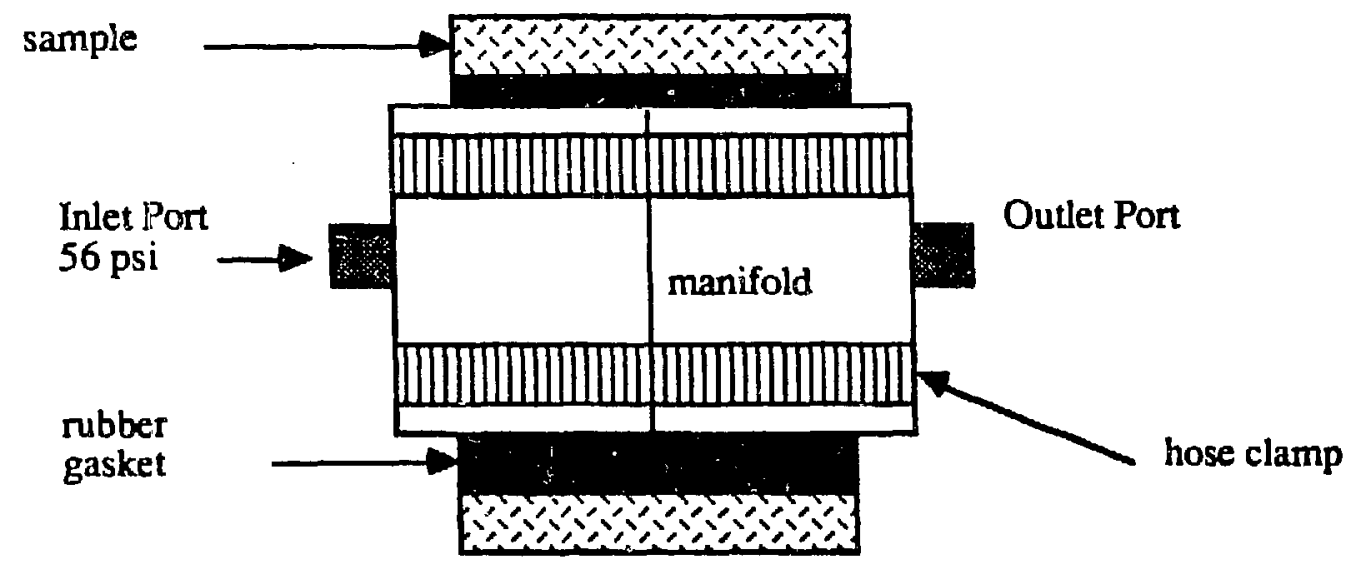

- XBL 8610-3880 -

Figure 1. Experimental apparatus for quadrant flow measurements. 


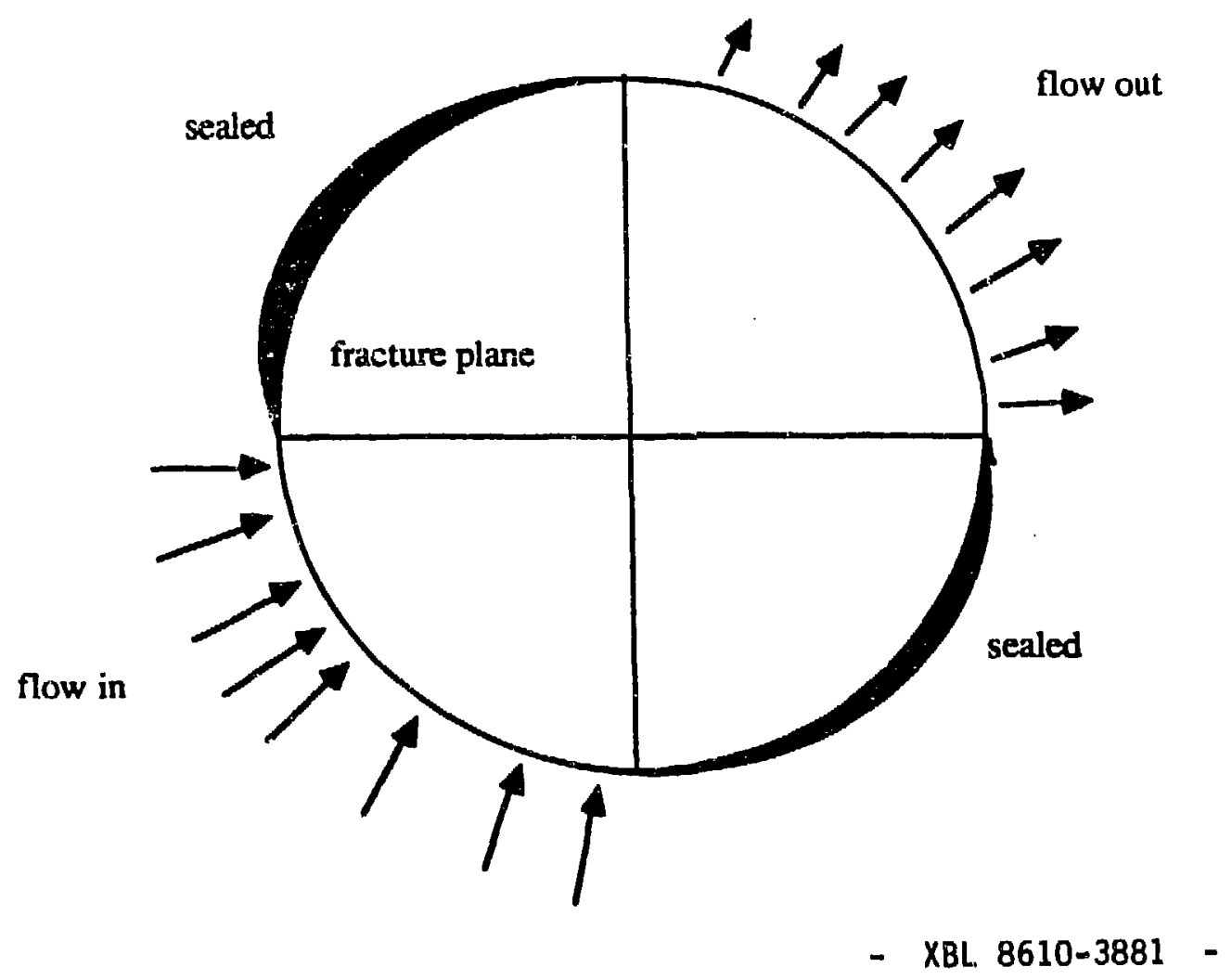

Figure 2. Flow path in quadrant flow technique. 


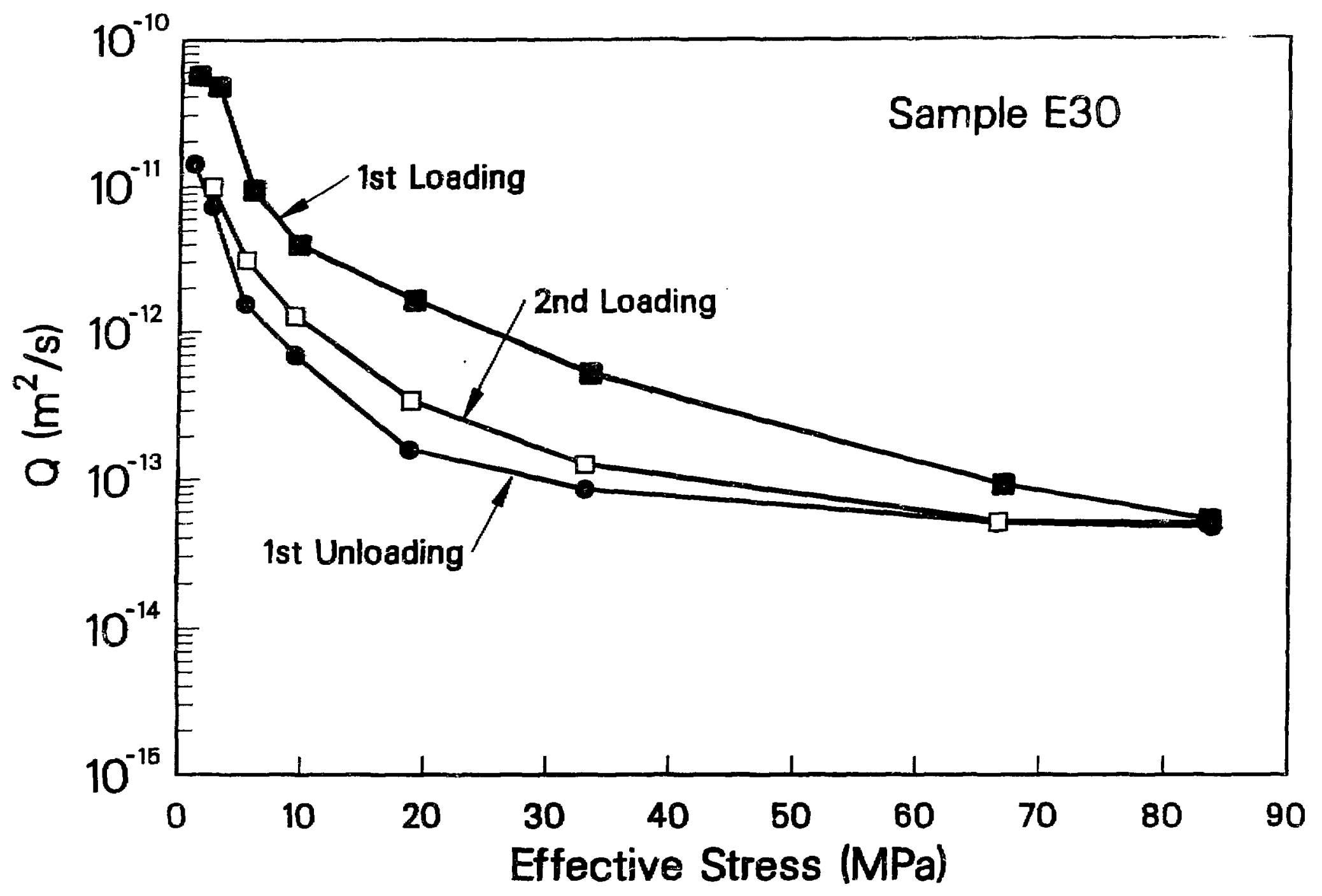

XCG 8610-12169

Figure 3. Flow per unit head drop as a function of effective stress level for sample E30 for sequential loading/unloading cycles. 


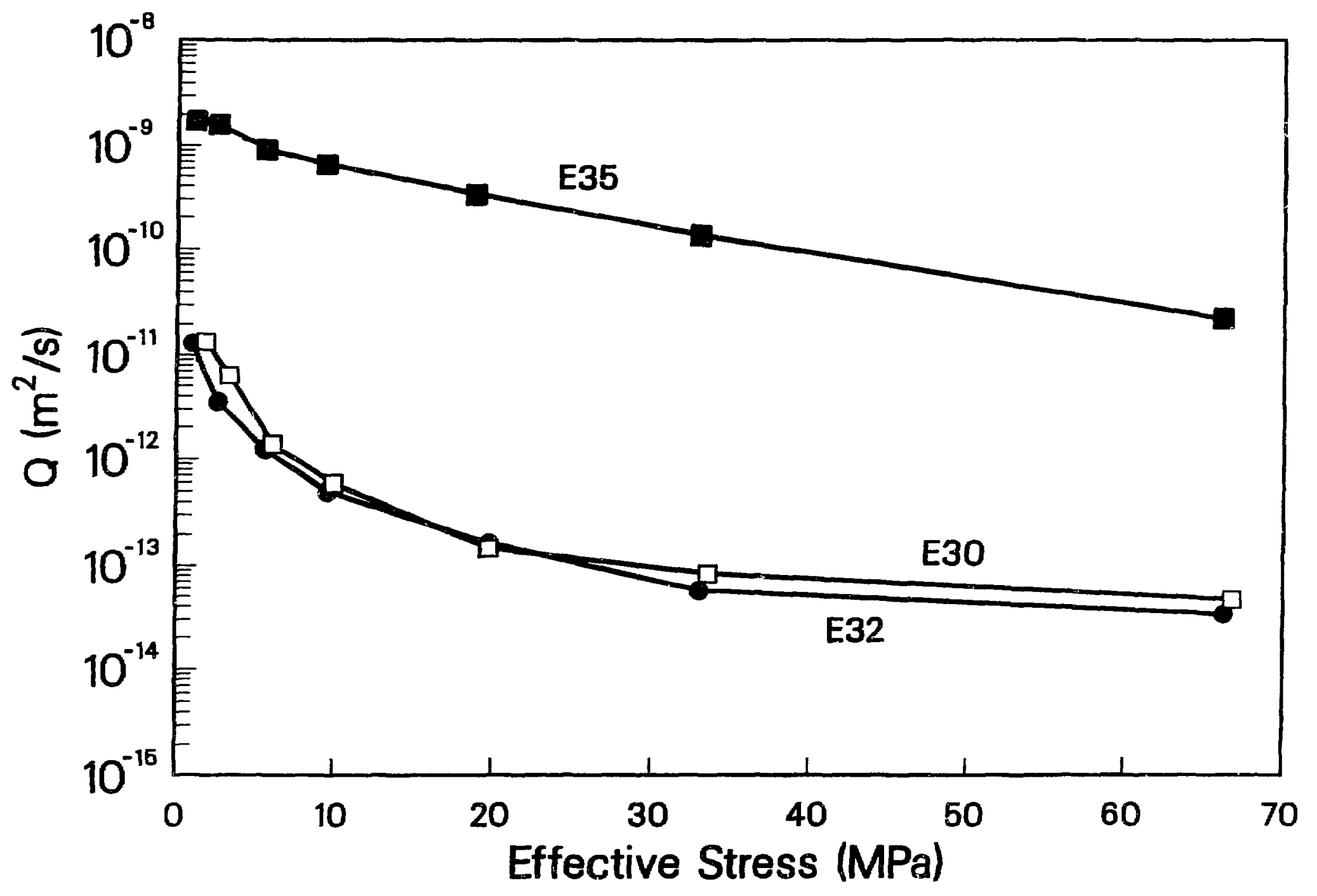

Figure 4. Comparison of flow per unit head drop as a function of effective stress for samples E35, E30 and E32. 


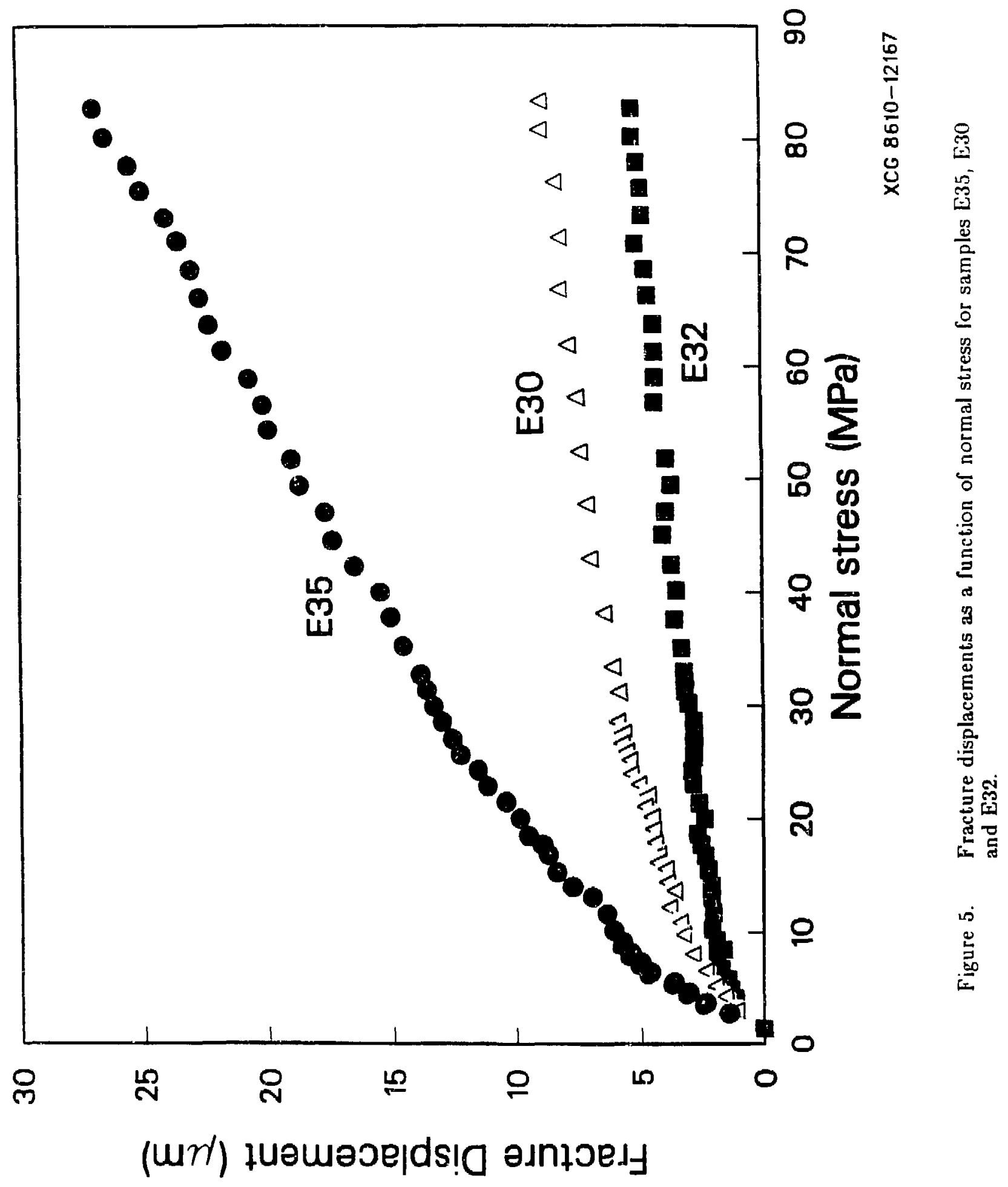




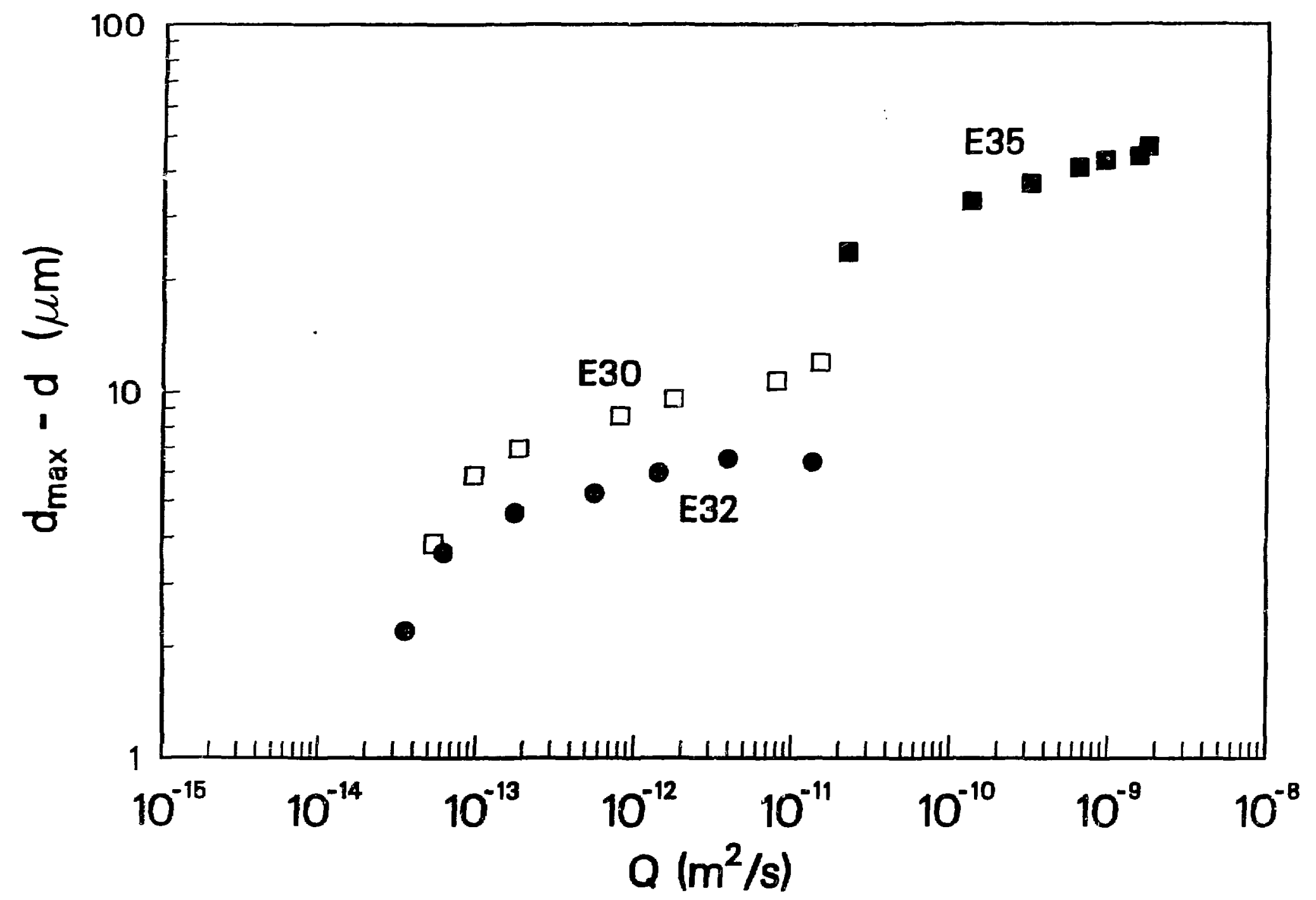

XCG $8610-12166$

Figure 6. Fracture closure versus flow per unit head drop for samples E35, E30 and E32. 


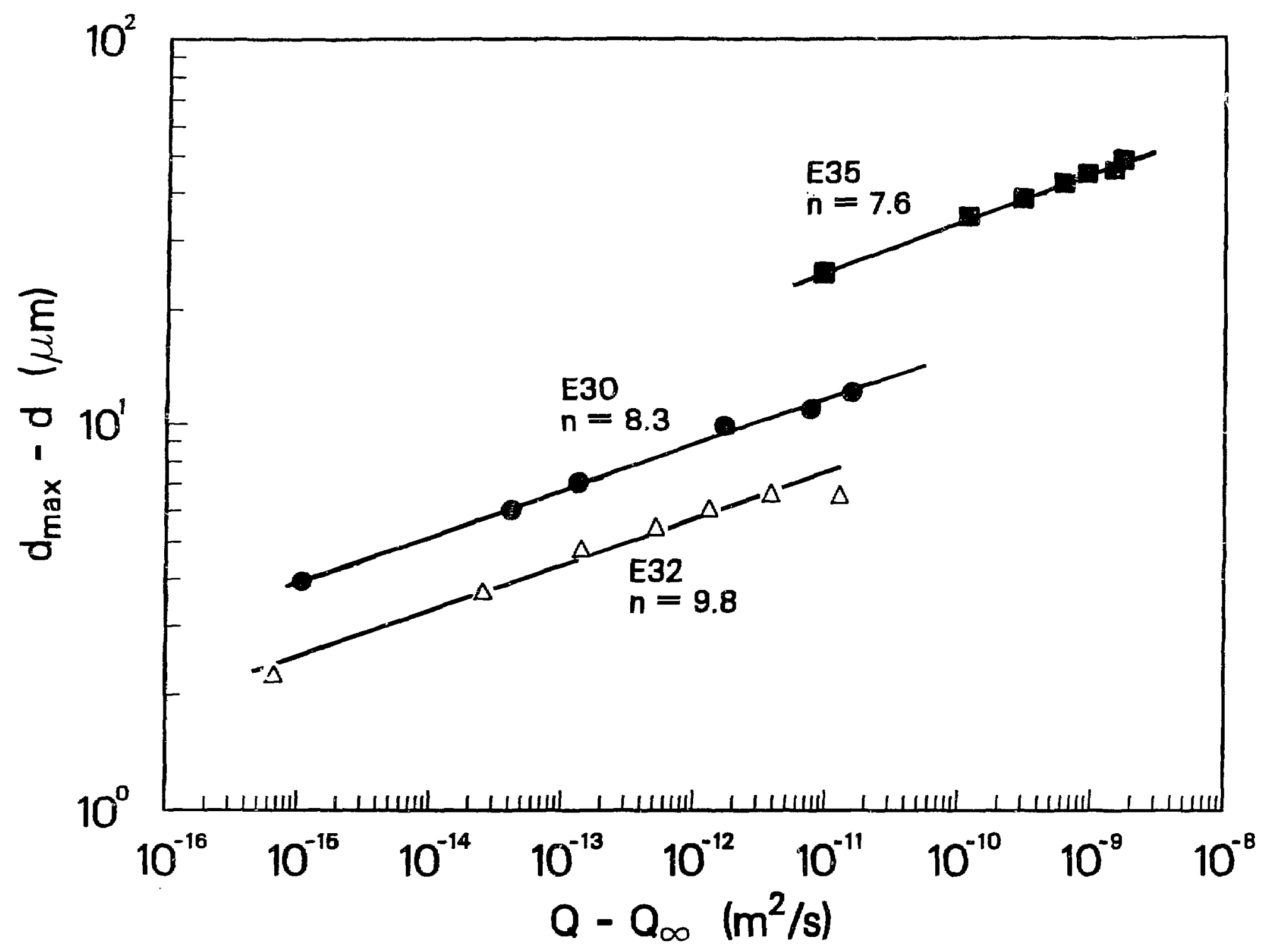

Figure 7. Fracture closure versus flow per unit head drop after subtraction of irreducible flow for samples E35, E30 and E32. 


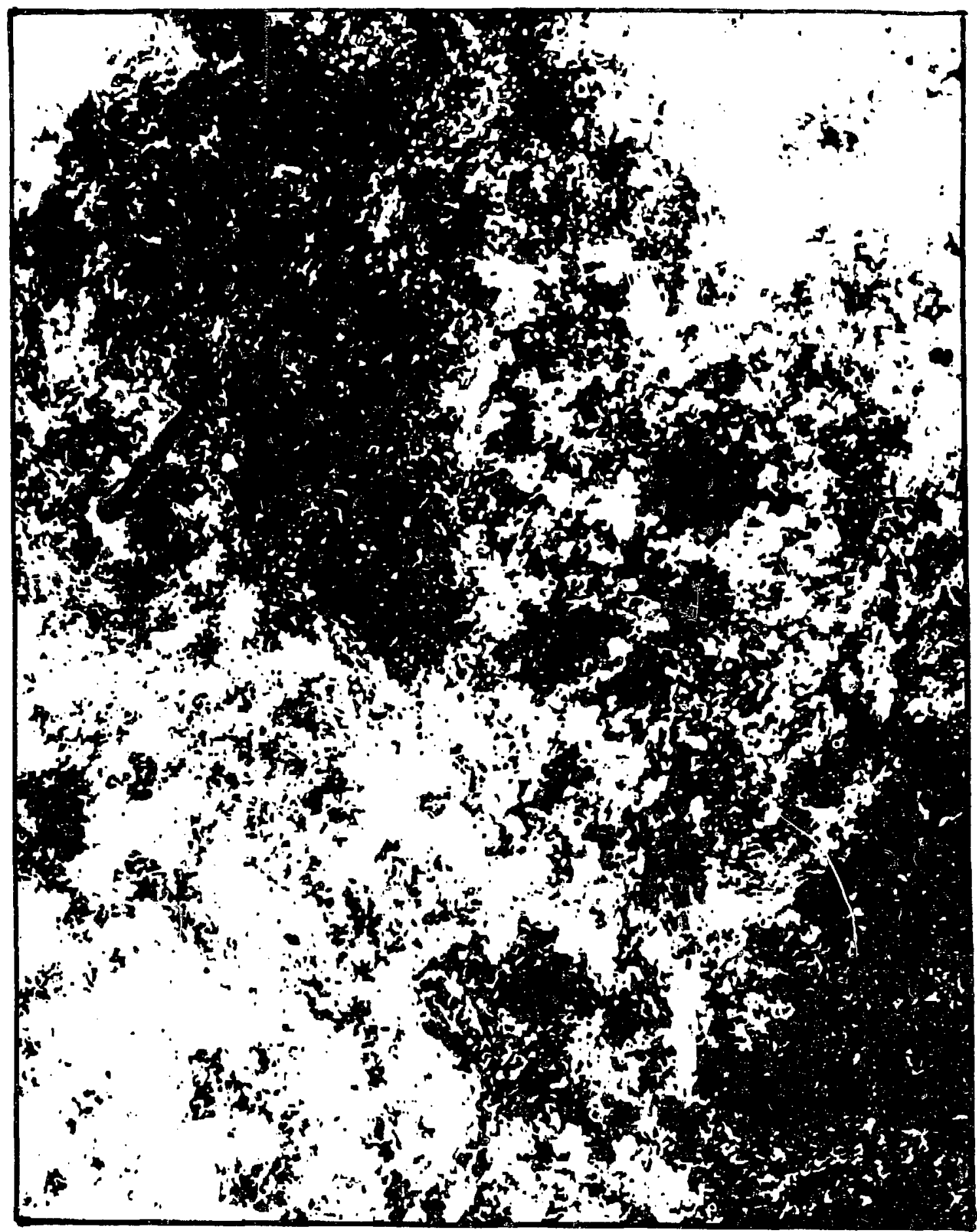

Approximate Scale

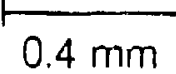

XBL $8610 \cdot 12621$

Figure 8. Thotograph of fracture surfaces unuter sis Ml'a stress showing actual fow paths (white) and barriers to flow (black). 


\title{
Channel Model of Flow Through Fractured Media
}

\author{
Y. W. Tsang* and C.F. Tsang**
}

\section{Introduction}

Recent concerns in the geological isolation of nuclear waste and in deep injection of liquid toxic waste have stimulated much interest in the study of fluid flow and solute transport through tight rocks. Flow through such low permeability rocks predominantly occurs in interconnecting fractures. The flow through each fracture is most commonly treated as the flow through a pair of smooth parallel plates separated by a constant aperture, and thus the fluid flowrate varies as the cube of the constant separation. However, a real fracture in rock masses has rough-walled surfaces, and, unlike parallel plates, portions of the fracture may be blocked by filling material or closed when subjected to normal stress.

Theorectical studies (Tsang, 1984) have shown that only at low applied stress, when the fracture is essentially open, does the paralle!-plate idealization of a rock fracture adequately describe fluid flow. Because of the contact areas between fracture surfaces and constrictions of the fracture subject to stress, flow through a single fracture takes place in a few channels which are tortuous, have variable aperture along their length, and which may or may not intersect each other.

Evidence that flow takes place in channels also occurs in field and laboratory experiments. In the field experiments of solute migration in single fractures in the Stripa mine, Sweden (Abelin et al., 1983, 1985; Neretnieks, 1985), the observation that the

- Research sponsored by DOE-OBES.

* Research sponsored by DOE-OCRWM. 
amount and time of tracer returns at two near-by sampling points were very different, and that many of the neighboring collection holes registered no tracer (non-sorbing) return at all lends support to the channel nature of fluid flow within a single fracture.

The laboratory experiments of Pyrak et ai., (1985) and the field experiment cairied out in a single fracture in Cornwall (Bourke et al., 1985; P. J. Bourke, personal communication, 1986) also demonstrated that flow in a single fracture took place in a limited number of channels.

\section{Tracer Transport in the Channel Model}

On the basis of theoretical and experimental observations referred to above, we have studied fluid flow and solute transport in a tight fractured medium in terms of flow through channels of variable apertures. The channel llow model is conceptually different from current approaches to the problem of How through a fractured medium, which can be broadly classified into two approaches. One approach is to treat the fractured medium as an equivalent porous medium which is appropriate when the fractured medium contains many int3r-connecting fractures. The other approach is a discrete representation of the fiacture for a medium which is tight and fracture intersections are few. The basic assumption in the latter approach is that the single fracture is the basic unit for the fractured medium, an ' $: \mathrm{z}^{+}$esch fracture is represented by a pair of paralle: plates with $n$ constant aperture. Inwever, the studies on single fracture as discussed earier have shown the inadequacy of the parallel-plate description of a single fracture. Ir. the discussion of channel flow which followis we shall abandon the single fracture as the basic unit to model a fractured medium.

Instead we hypothesize that the fluid flow and solute transport through a tight rock medium is b; reans of a limited number of tortuous and intersecting channels. These channels have variable apertures along their lengths. Figure 1a shows schematically the channeling effect in a single fracture. Figure 2 shows schematically the 
channeling effect in a number of three-dimensional intersecting fractures. Each channel in Figure 1a or 2 is represented schematically in Figure $1 \mathrm{~b}$. It is defined by the aperture density distribution $n(b)$ along its length. The channel width is assumed to be a constant of the same order as the correlation length, $\lambda$, since, by definition, the correlation length is the spatial range within which the apertures have similar values. The channel length does not equal the linear length between two points, but it is not expected to vary more than a factor of two to three from the actual linear length. For a given aperture density distribution and correlation length, different realizations of statiscally equivalent channels may be generated (Tsang and Tsang, 1986) using geostatistical method.

When a pressure head difference is applied between two points, the flow paths between these two points may be represented by a number of channels, which may intersect each other at various points (Fig. 3a). Figure 3b shows two channels with one crossover. Under steady state flow conditions, the flow through the two intersecting channels is hypothesized to be approximated by the flow through three independent, statistically equivalent, non-intersecting channels. With every crossover, there is the added possibility of a different flow path. In practice, the actual configuration of the channels between input and exit measurement points is not known. One is only able to obtain transient pressure and tracer concentration data. Thus, as far as the interpretation of the pressure and tracer transport measurements are concerned, the system of $\mathrm{M}$ independent, statistically equivalent channels such as schematically shown in Figure 3c may be an adequate and approximate representation of the realistic configuration shown in Fig. 3a. Tracer concentration breakthrough curves may be calculated for transport through a system of $\mathrm{M}$ independent channels as shown in Figure 3c.

For a step function input of tracer, Figures $4 \mathrm{a}$ through $4 \mathrm{~d}$ show the tracer concentration breakthrough curves as a function of time for $M=32,16,11$ and 8 , respectively. We note a rather steep rise in the concentration curves in the early times, then some 
"stair-step" structure, due to the finite delay for the solute carried in the next channel to breakthrough. The early arrivals correspond to flow in fast channels, those with few very small aperture constrictions. The steep rise therefore indicates that a large proportion of the total flow is in fast channels. In Figures (5a) through (5d) we reproduce the breakthrough curves from laboratory experiments (Moreno et al, 1985) performed on a single fracture in a $18.5 \mathrm{~cm}$ core. Caref $u$ l examination of Figures 4 and 5 indicates that the prominent features in the theoretical curves based on the channel model (Fig. 4) are also evident in Figure 5. These features (such as the steep rise in tracer returns and the stair-step structures) are not found in the conventional advection-dispersion curves. We are aware of the fact that there are data measurement error in the laboratory breakthrough data, hence raising a question mark over the claim that the stair-step structure in the experimental breakthrough curve arises from the channel nature of the flow. Discussions with Eriksen (private communication, 1986) who performed the experiments as shown in Fig. 5 about the precision of the measurements led us to believe that the stairstep structures are not merely data scatter. Presently, a new set of laboratory experiments are being carried out by Eriksen to ascertain the presence of these stair-step structures. The experiments are performed with a square pulse tracer concentration input of time duration $\Delta t$. In this case, a step structure which occurs on the rising part of the breakthrough curve will reappear in the falling part of the breakthrough curve at a time duration $\Delta t$ later. The one to one correspondence separated by $\Delta t$ will differentiate between real stair-step structure and experimental scatter.

When normal stress across a fracture is increased, the reduction in channel apertures affects the tracer breakthrough curves. One may start with the experimental breakthrough data such as in figure 5 and interpret them in terms of our conceptual channel model. Making the assumption that all the apertures in a fracture are reduced by the linear displacement of the single fracture under stress, a new tracer breakthrough curve may be derived (Tsang and Tsang, 1986). Sample calculations indicate that even 
with a small change in the mean fracture aperture ( $6 \%$ reduction), a large change in the breakthrough curve resulted. The reason is that the small change affects significantly the constricted part of the channels, which controls the flow rates.

\section{Conclusion}

We have attempted to understand and calculate transport through fractured media in terms of flow through a system of tortuous and variable aperture channels. In this initial study, we show that calculated tracer breakthrough curves based on the channel model have features that correspond well to those in recen i data by Moreno et al.(1985). The signature of channeling in fracture is in the stair-step structure of the breakt,hrough curves and their sensitivity to stress applied across the fracture. These suggested possible laboratory experiments which may be performed in order to further investigate the channel nature of fluid flow in fractures.

Validation of the conceptual channel model by experiments is crucial, since we have made a number of simplifying assumptions in our approach, in order to side-step the issues of the very complicated geometry involved in the flow through a three-dimensional multi-fracture system. The appeal of the present approach lies in its simplicity, and the finding of our initial study indicates that to interpret fluid flow and transport in terms of a channel model may be a promising area of research. 


\section{References}

Abelin, H., I. Neretnieks, S. Tunbrant and L. Moreno, Final report on the migration in a single fracture. Experimental results and evaluation, SKB Technical Report 85-03, 1985.

Bourke, P. J., E. M. Dunance, M. J. Heath and D. P. Hodgkinson, Fracture hydrology relevant to radionuclide transport, AERE Harwell Report R11414, United Kingdom, 1985.

Moreno, L., I. Neretnieks and T. Eriksen, Analysis of some laboratory tracer runs in natural fissures, Water Resour. Res., 21(7), 951-958, 1985.

Neretnieks, I., Transport in fractured rocks, Proceedings, Memoires of the 17th International Congress of International Association of Hydrologists, Tuscon, Arizona, Vol. XVII, 301-318, 1985.

Pyrak, L. R., L. R. Myer and N. G. W. Cooke, Determination of fracture void geometry and contact area at different effective stress, Transactions, American Geophysical Union, 66(903), 1985.

Tsang, Y. W., The effect of tortuosity on fluid flow through a single fracture, Water Resour. Res., 22(9), 1209-1215, 1984. Tsang, Y. W. and C. F. Tsang, Channel model of flow through fractured media, to be published in Water Resour. Res., 1986. 
$a$

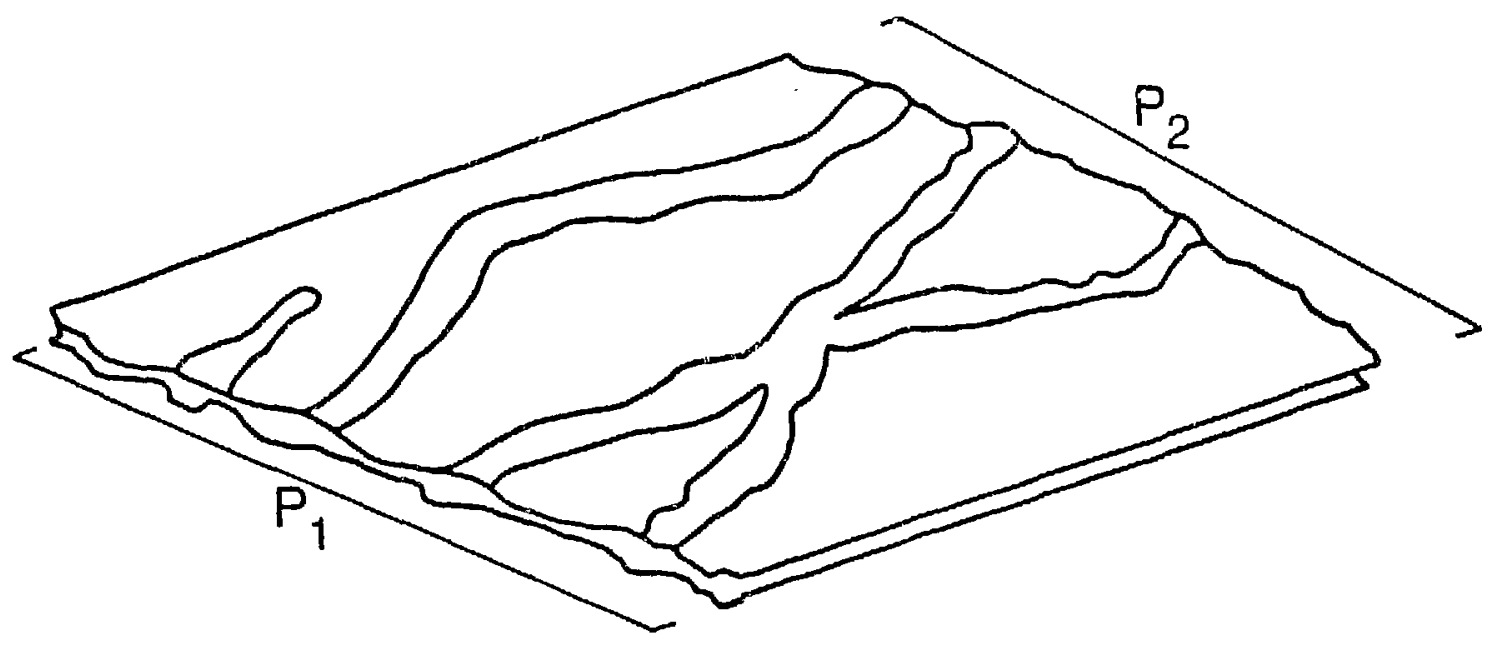

$b$

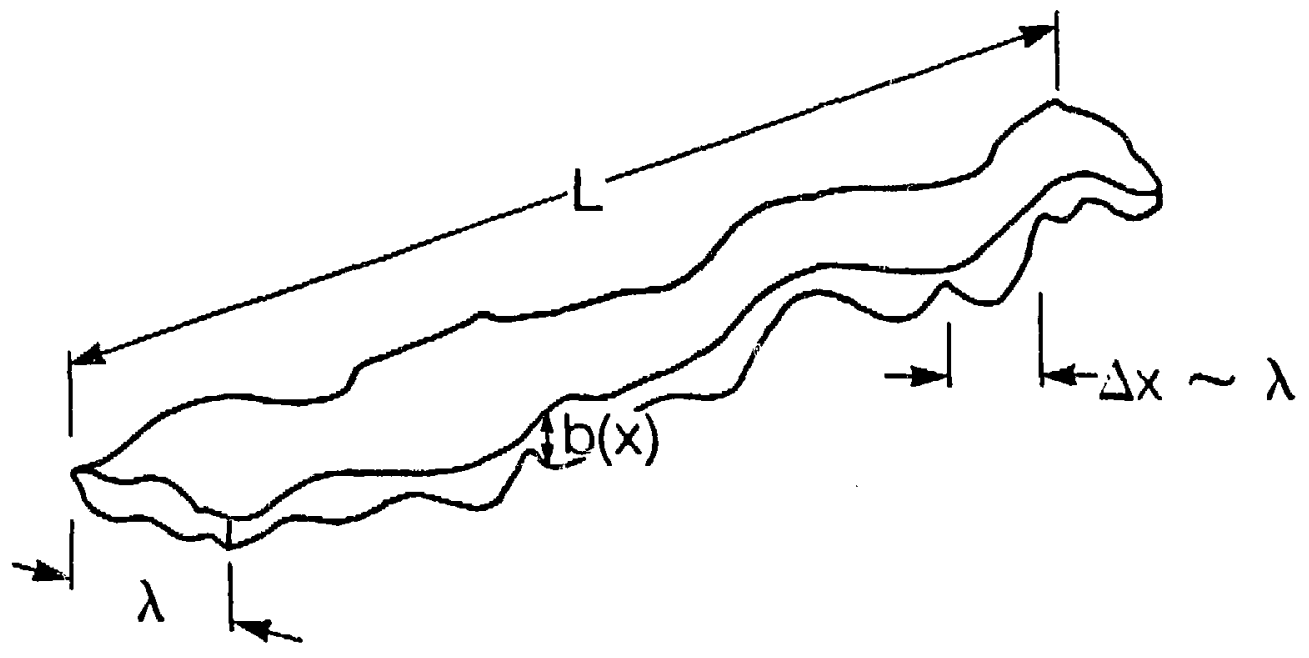

XEL 863-10710A

Figure 1. (a) Schematic diagram of the channel representation of Huid flow in a single fracture.

(b) Schematic sketch for one channel. 


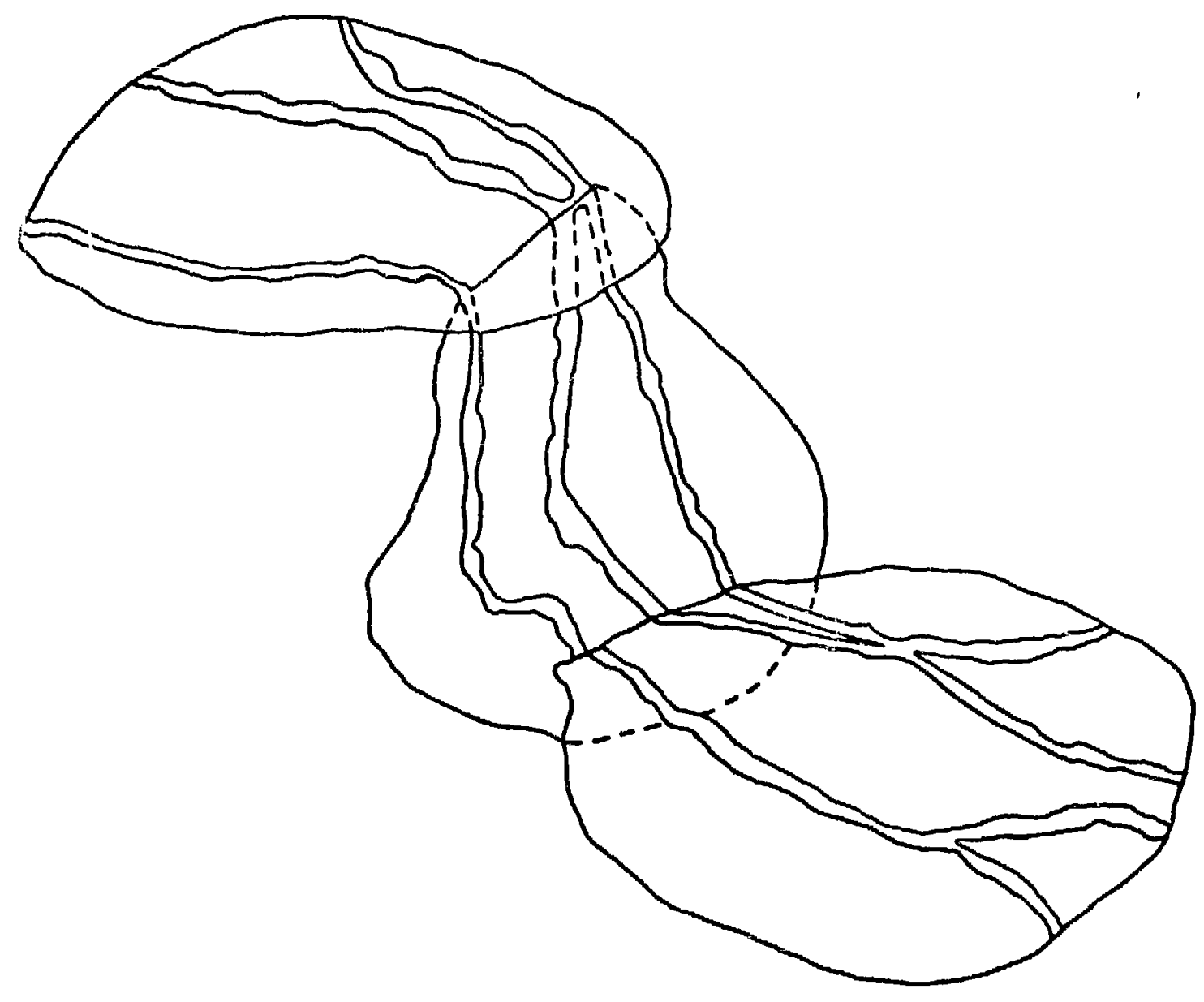

XBL 863.10711

Figure 2. Schematic diagram of the channel representation of fluid flow in a multiple fractured medium. 


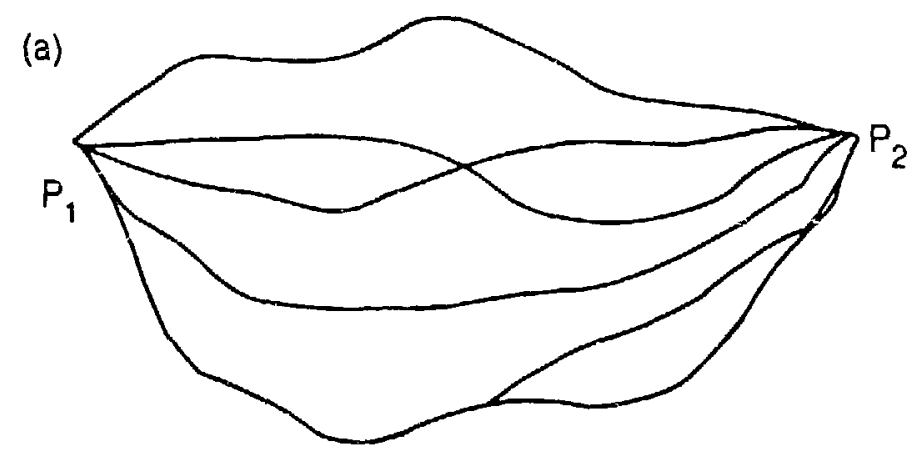

(b)

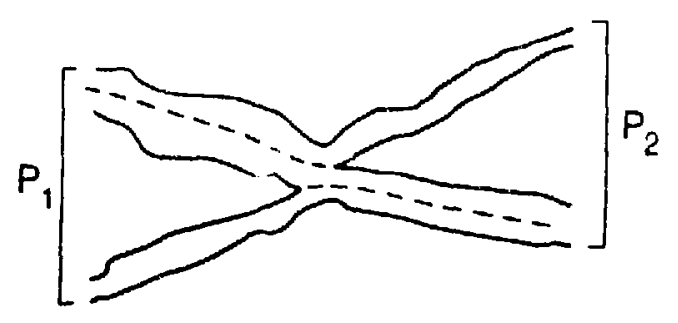

(c)

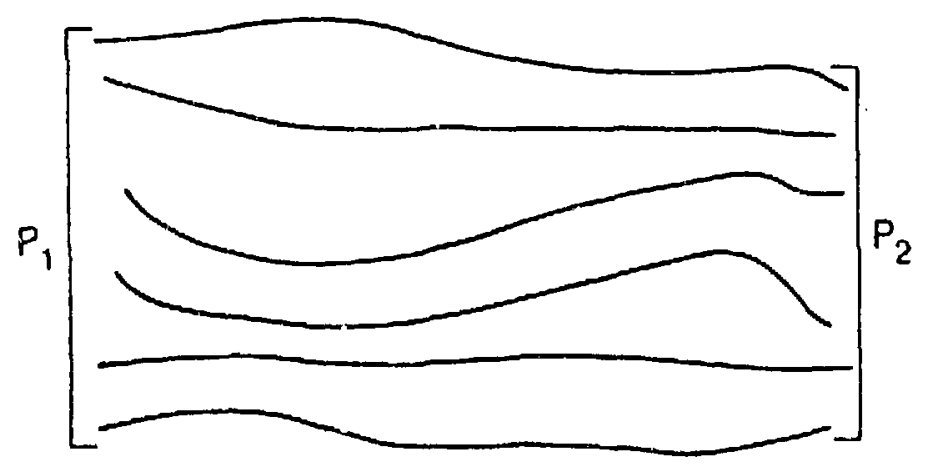

XE1 $80 \overline{3} 10712$

Figure 3. (a) A schematic diagram of lluid flow paths between two points maintained at pressures $\mathrm{P}_{1}$ and $\mathrm{P}_{2}$.

(b) A diagram of two intersecting channels.

(c) A set of independent chanuels, a conceptually equivalent representation to the flow paths shown in $3(a)$. 


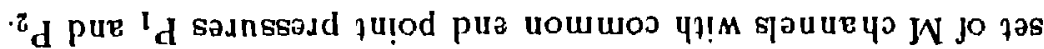

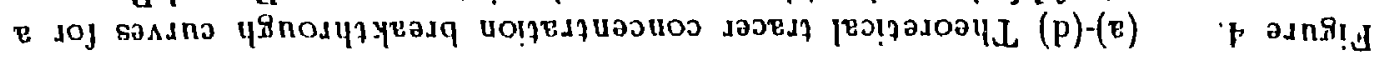
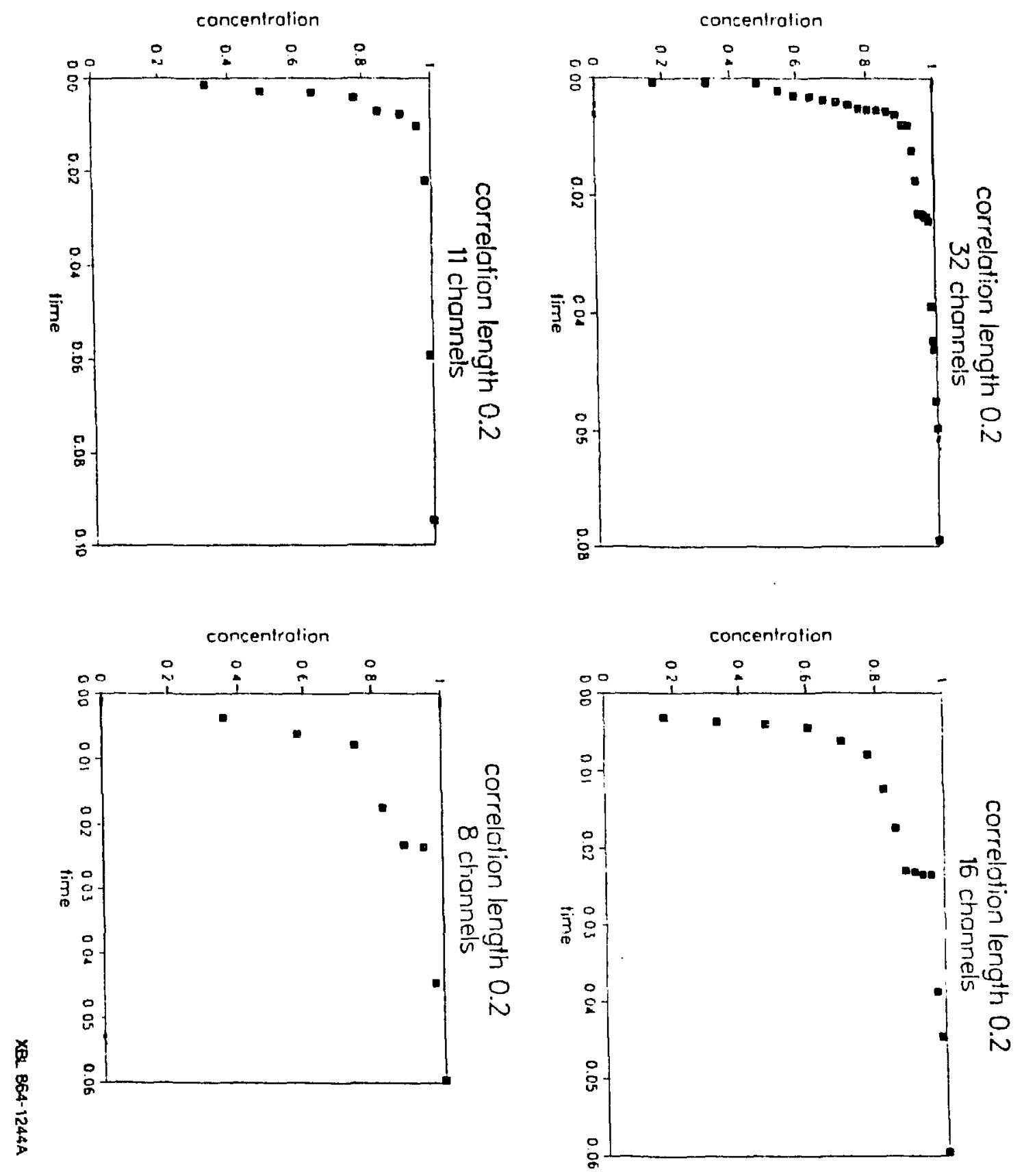

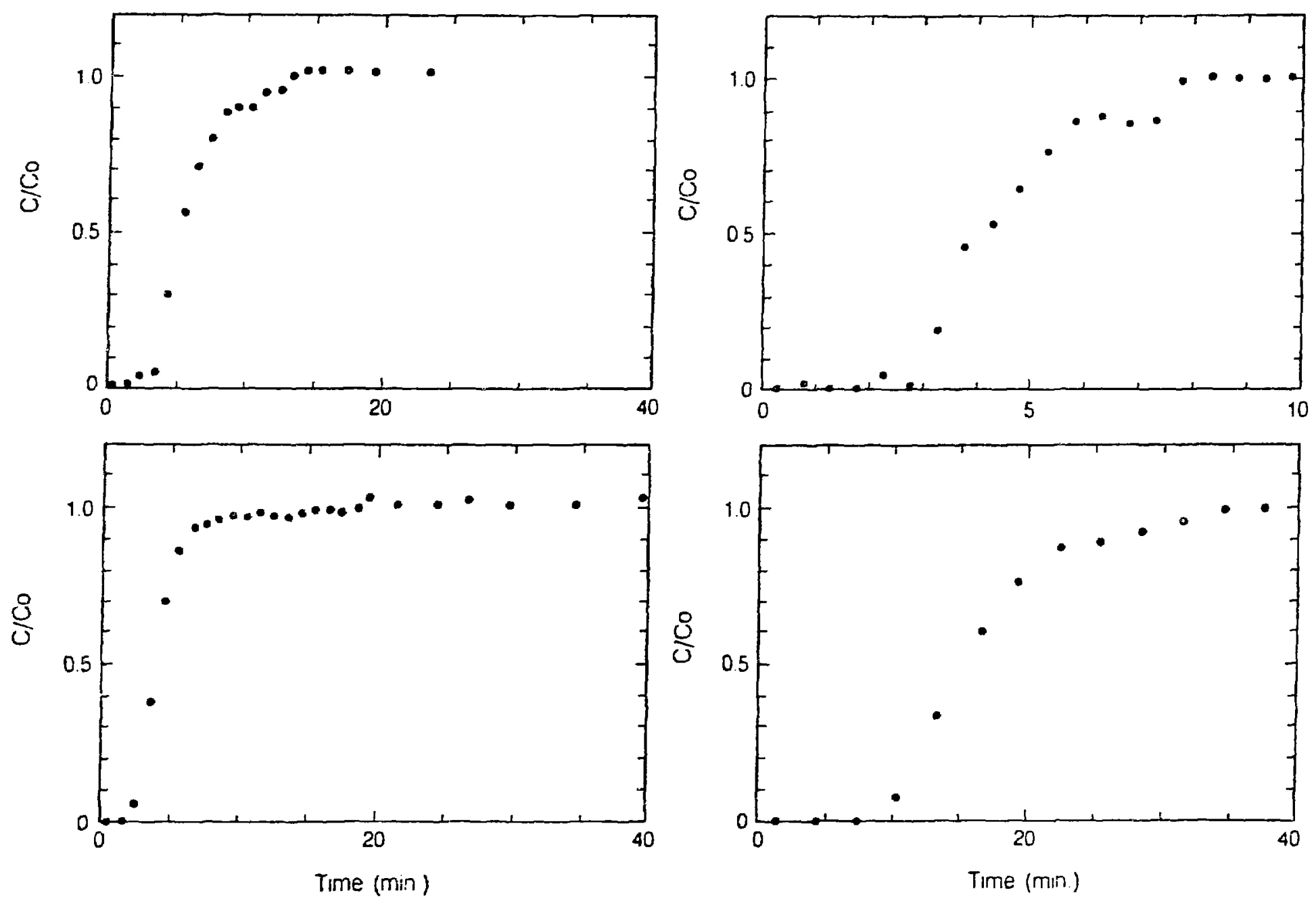

Figure 5. (a)-(d) Tracer concentration breakthrough data from laboratory measurements on a single fracture in a granitic core $18.5 \mathrm{~cm}$ in height and $10 \mathrm{~cm}$ in diameter (Moreno et al, 1985). The four curves correspond to different runs involving different injection flow rates and different tracers (NaLS or 1 ). 


\section{Solution of Navier-Stokes Equations in Fractures}

\section{K. Muralidhar and J.C.S. Long}

The science of fracture hydrology is a relatively now field. It is a separate endeavor from classical porous media ground water hydrology because analysis techniques developed for porous media do not work well for fractured rock. Basic research is needed to understand how the features of the fracture control flow in the rock. To that end, the interest is in how features of individual fractures control flow.

Fractures in general have rough sides and these sides are held apart through the contact of asperities on the surfaces. The area of contact, "contact area," is irregular, as is the aperture of the fracture, where is is open. Thus from the point-of-view of fluid mechanics, a fracture is an irregular three-dimensional channel with irregularly spaced and sized obstacles.

To characterize the geometry of such a channel is a problem in itself. Research has been initiated to quantify the geometry through the use of several laboratory and analytical techniques. Casts of the fracture can be made by injecting a low melting point metal into the fracture. The fracture can then be taken apart and both sides photographed. In such a photo, the contact area. shows up as the color of the rock and the open area shows up as the color of the metal. Both photographs and profile data can be used in a conditional geostatistical simulation which provides an estimate of the aperture as a function of location in the fracture plane. Once the geometry is defined, one proceeds to analyze fluid flow through the channel. Analysis of flow through such a channel is the subject of this work.

In general, the problem of fluid flow in an irregular geometry can be solved only if a numerical approach is adopted. Further, any such scheme must have a detinite capability to handle boundary shapes which do not coincide with 
coordinate lines. In the present study, a three dimensional grid generation procedure has been used, which maps the interior of a complex rugiun onto the interior of a rectangular parallelipiped. The central idea involves the pointwise determination of a natural coordinate system, with respect to which the boundaries of the fracture represent constant coordinate surfaces. The flow computation is performed in the newly defined region, and an inverse transformation rule extracts values of flow velocities and pressure in the geometry of interest. This two-step procedure involving grid generation followed by flow calculation is described in detail elsewhere (Muralidhar and Long, 1987). The implications of using this procedure are the following.

1. Boundary conditions of flow can be imposed exactly (without requiring the use of interpolation) on an irregular surface.

2. The grid lines in the transformed region are evenly spaced, thus making finite-difference rules algebraically simple

3. The procedure used in this work to generate a grid allows the specification of a pre-determined amount of orthogonality of the mesh lines. This is important in the control of truncation error of flow calculation. The method can be easily extended to include other mesh properties such as concentration of nodes near a region of severe velocity gradients.

4. Since the flow is dynamically invariant to mapping of geometries, the mathematical model of flow must be modified when it is solved in the regularly shaped domain, to account for the change in the measure of distance. This is accomplished by viewing the whole process of transformation as one of change of coordinates. In general, the new model has a more complicated form than the expression in Cartesian coordinates. For this reason, it is possible to interpret the approach taken here as a change from irregular, complex geometry and simple equations to regular geometry and expanded 
equations.

\section{Grid Generation}

The actual differential equations chosen to define the mapping function depend ultimately on the physical problem prevailing on the flow domain. The interest in this study is restricted to low-Reynolds number steady flow in rock fractures and the respective equations and boundary conditions are known to form an elliptic problem. The grid generated form such a system of equations has built-in smoothing properties, as is observed in related diffusion-dominated problems. Little modification is required to extend this to time-dependent cases. The ellipticity of the physical problem permits the use of a variational principle for defining the grid. The advantage of using such minimization rules is that mesh quality can be imposed as a constraint on the problem, and the desired grid pattern can be generated in a systematic way. Only one such constraint, namely orthogonality, has been used in this study. Other techniques of grid generation, which are problem dependent have been described in the proceedings of a symposium edited by Thompson (1982). The use of grid generation in the solution of problems in fluid mechanics has been described in a book edited by Hauser and Taylor (1986).

The integral statement provided by the variacional principle (Brackbill and Saltzmann, 1982), and applicable over a finite region can be converted to a system of differential equations applicable pointwise from the appropriate EulerLagrange equations of the problem. These are subsequently solved by finite differences. The boundary conditions correspond to, (a) imposing the shape of the fracture and/or (b) requiring the intersecting grid lines be orthogonal to the boundary. These constitute the Dirichlet-Neumann conditions which along with the governing differential equations guarantee a unique solution 10 the grid 
generation problem.

\section{Calculation of Fluid Flow}

The primary thrust of this work is to replace Darcy's law of fluid motion as a constitutive relationship by the complete momentum equations of flow based on Newton's second law. These are the Navier-Stokes' equations, and along with the equation of continuity, determine every state of flow, whether laminar or turbulent, for a wide class of fluids, including air and water. In this work, the flow is taken steady and incompressible. The two primary difficulties in solving this system of equations are, (1) the treatment of non-linear acceleration terms and (2) the treatment of incompressibilty. The problem of non-linearity has been circumvented in this work within the framework of finite-differences, by the use of a hybrid scheme. This employs central differencing of all first order derivatives (unless the local Peclet number exceeds a certain value, based on one-dimensional considerations). Otherside, an upwind approximation is employed. Any false diffusion generated by upwinding is expected to be insignificant since the flow has reached steady state and the Reynolds number of flow is small. The incompressibility constraint is handled by replacing it by the Poisson equation of pressure. This has the advantages that pressure values can be directly imposed as boundary conditions, and pressure is identified as a basic variable of the problem. More discussion on these issues can be found in the report referred to earlier (Muralidhar and Long, 1987). On the fracture surfaces, the momentum equations are replaced by the no-slip condilion for velocity, and simultaneously they are used to approximate wall pressure gradients. The generalized form of the Navier-Stokes' equations in a non-orthogonal coordinate system is derived by applying chain-rule relationship to the Cartesian form. 
The numerical solution of both the grid generation equations and the flow equations is carried out by finite differences. The reduced algebraic problem is solved by a pointwise iterative scheme, which does not require the formation of large matrices. For convergence, this requires a diagonally dominant system of equations, and this imposes certain restrictions on the difference approximations of the equations and boundary conditions. The use of a hybrid scheme for the acceleration terms is one of the most significant of them.

\section{Results}

The grid generation equations have been programmed for both two and three dimensional geometries and tested for a variety of problems. The special formulation for the flow field (involving a pressure equation) has been programmed in both two and three dimensions, in Cartesian coordinates. This has been extended to cover flow in complex two dimensional gecmetries. Work on the full three dimensional geometry in generalized coordinates is in progress.

Figure 1 shows grid generation in a wavy channel. The rectangular region is the transformed plane where computation of fluid flow is carried out. Figure 2 shows grid generation in a region with a circular obstacle. The transformed plane views the obstacle as a square, constructed from the grid lines. This greatly simplifies applications of boundary conditions on its surface. Figure 3 shows flow pattern in a three dimensional rectangular duct with a square obstacle. The roll pattern beyond this object is clearly seen, and is a consequence of solving the full flow equations including non-linearity. It is this flow behavior which is expected to lead to departure from Darcy's law. 


\section{References}

Brackbill, M.V. and Saltzmann, J.S., 1982, "Adaptive Zoning for Singular Problems in Two Dimensions," Journal of Computational Physics, Vol. 46, pp. 342-368.

Hauser, J. and Taylor, C., Ed., 1986, Numerical Grid Generation in Computational Fluid Mechanics, Pineridge Press, Swansea, U.K.

Muralidhar, K. and Long, J.C.S., 1987, "A Scheme for Calculating Flow in Fractured Channels Using Numerical Grid Generation in Three Dimensional Domains of Complex Shapes," LBL report, in preparation.

Thompson, J.F., Ed., 1982, "Numerical Grid Generation," Elsevier Science Publishing Co., New York. 


\section{Figure Captions}

Figure 1. Grid Generation in a Wavy Channel with Constriction.

$$
\text { Aperture }=2 \text {, Length }=6 \text {. }
$$
a. Physical Region. b. Transformed Region.

Figure 2. Grid Generation in a Square Region with a Circular Contact Area. Region Size $=6$, Obstacle Diameter $=2$.

a. Physical Region. b. Transformed Region.

Figure 3. Velocity Vector Plot in a Three Dimensional Duct with an Obstacle. Reynolds Number $=25$. 


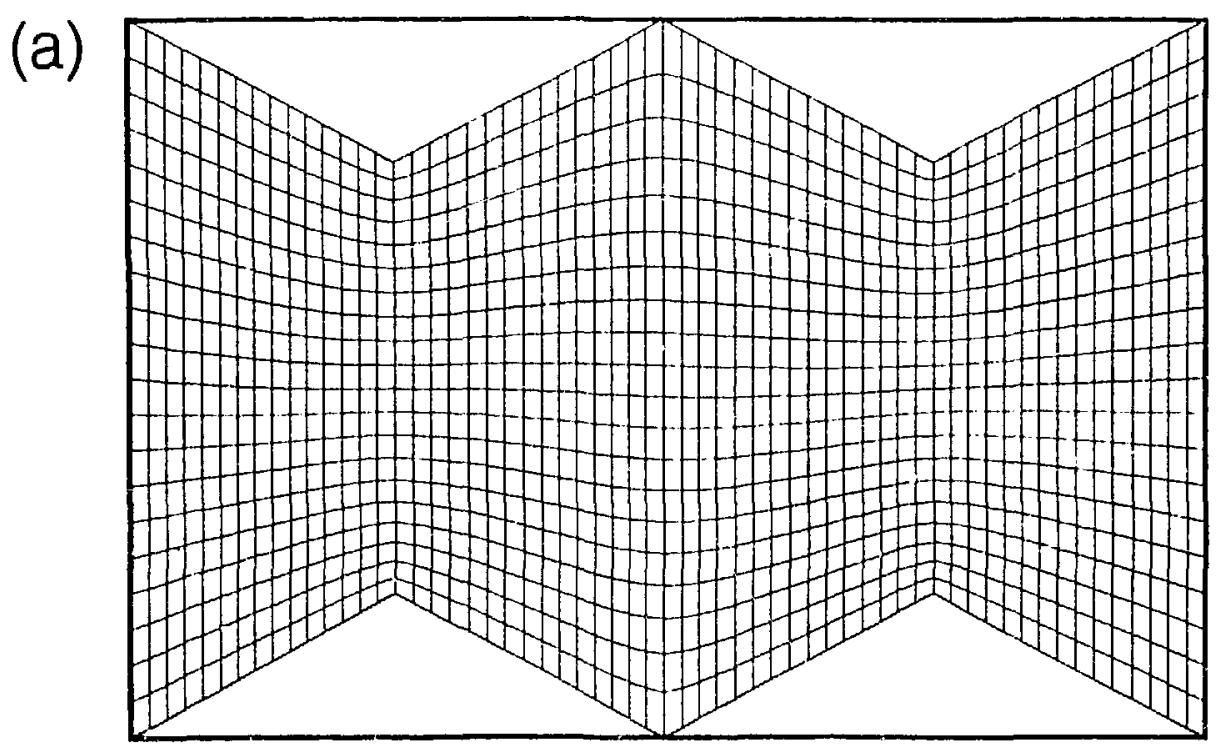

(b)

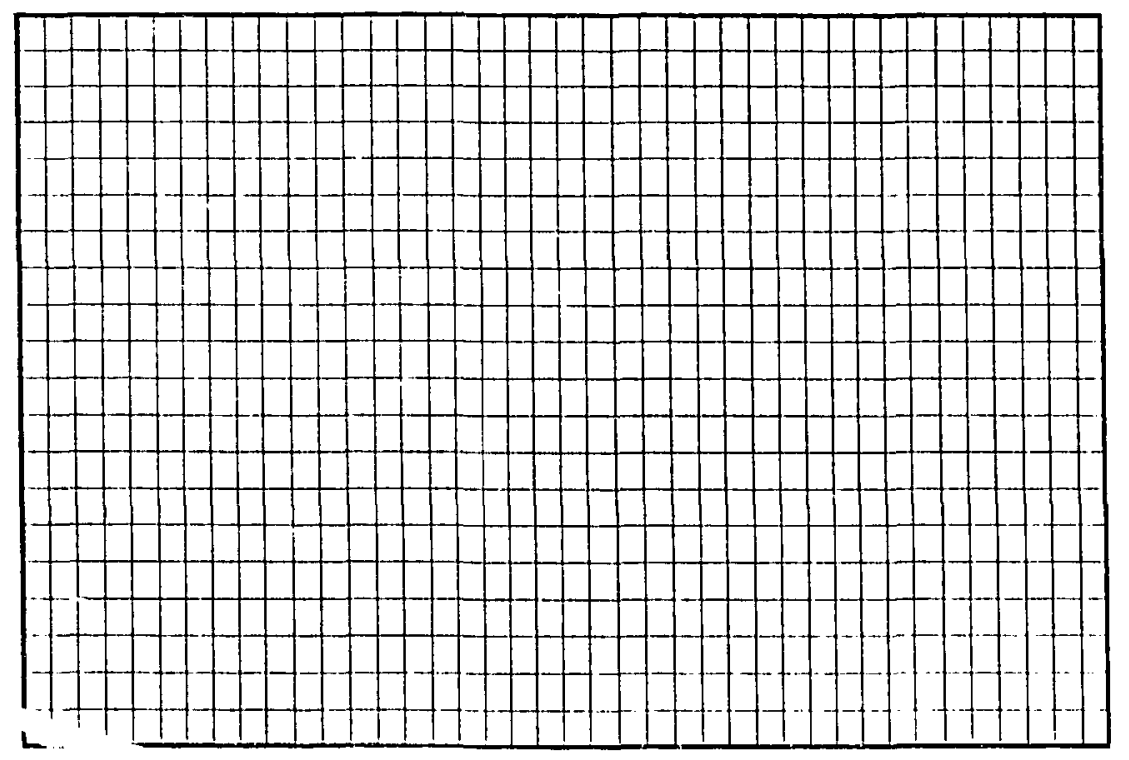

XBL $8610-3691$

Figure 1. Grid Generation in a Wavy Channel with Constriction.

Aperture $=2$, Length $=6$.

a. Physical Region. b. Transformed Region. 
(a)

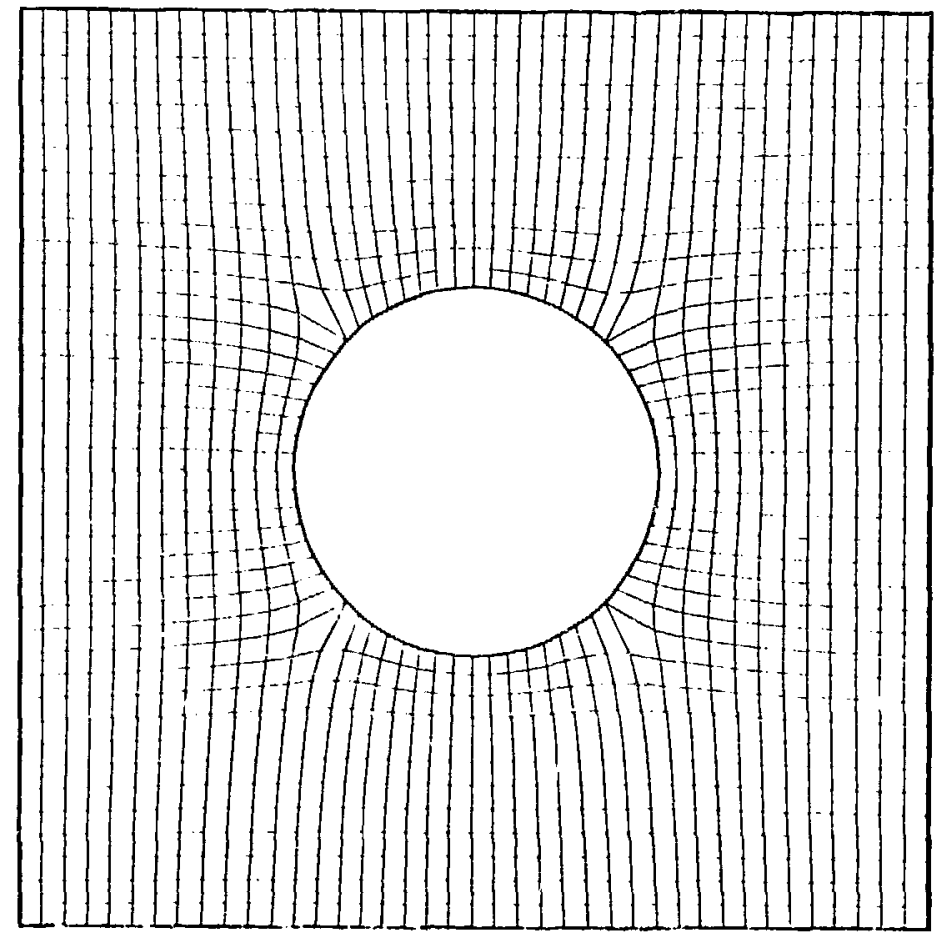

(b)

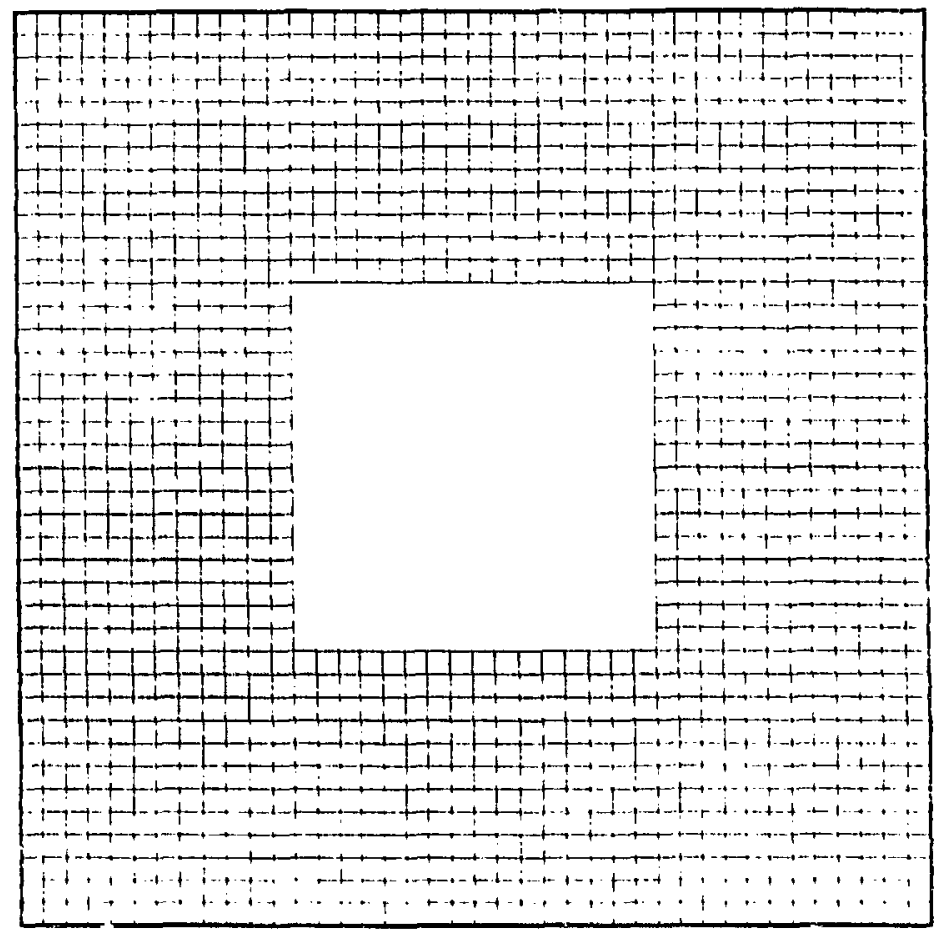

XBL $8610-3696$

Figure 2. Grid Generation in a Square Region with a Circular Contact Area. Region Size $=6$, Obstacle Diameter $=2$.

a. Physical Region. b. Transformed Region. 


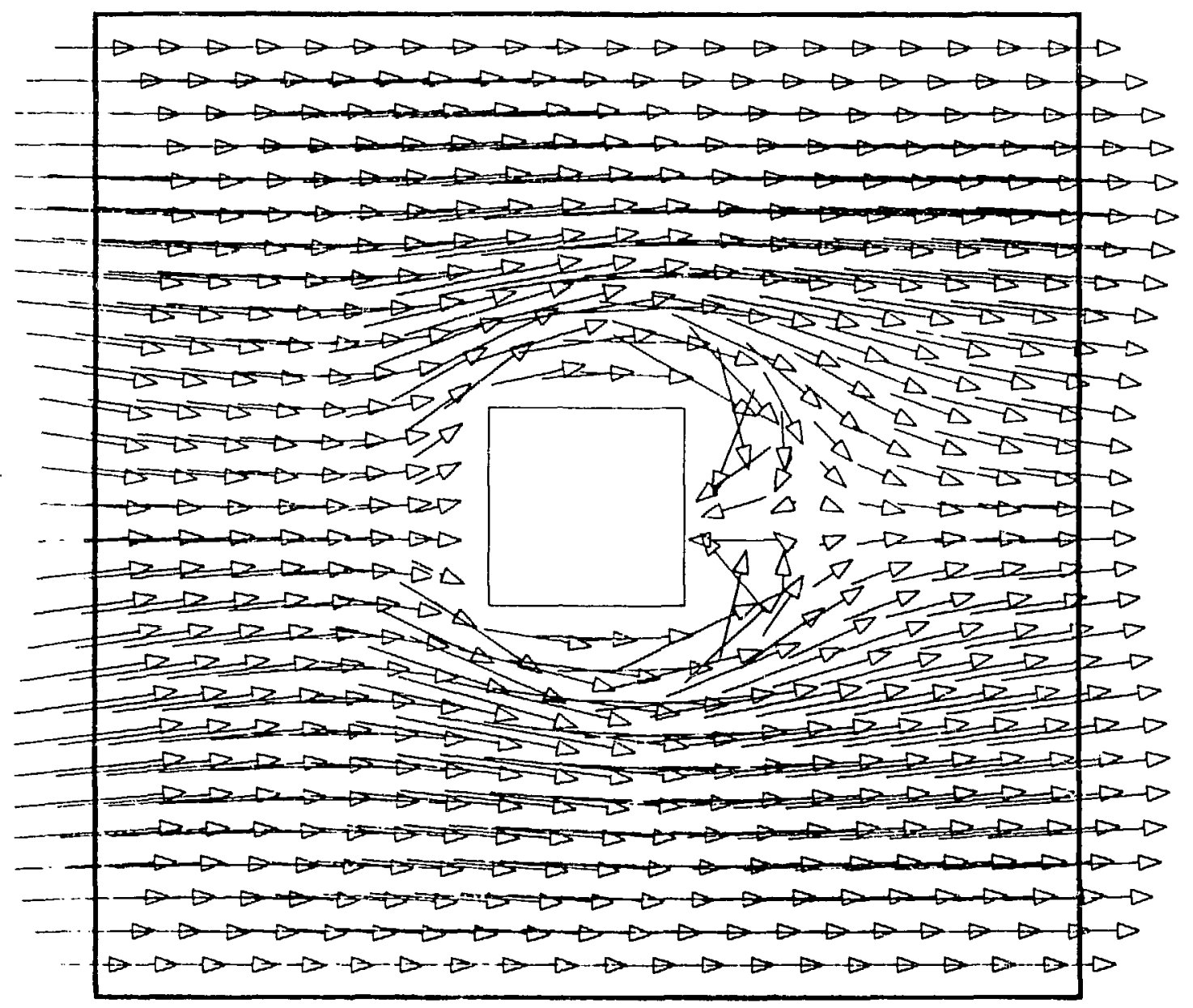

XBL $8610-3686$

Figure 3. Velocity Vector Plot in a Three Dimensional Duct with an Obstacle. Reynolds Number $=25$. 


\section{Pressure Solution Geochemistry}

John A. Apps

\section{Introduction}

When a fractured rock is stressed under waste repository conditions, the deformation is partly accommodated by sliding movement along the fractures. This movement is limited, because all natural fractures display a certain roughness due to the inhomogeneous nature of the rock and the crystal fabric. The roughness prevents further movement unless localized stresses build up to the level where cataclasis occurs and interstitial crystals are comminuted to form a "gouge".

If the rock is saturated with an aqueous phase, and the localized stresses are below the level at which cataclasis occurs, then the asperities, or points of contact may change their shape due to mechanisms involving deformation or preferential dissolution of the minerals contained within the asperities. This leads to slow progressive movements along fractures and the redistribution and recrystallization of minerals as characteristic "slickenside" textures. Such a process can drastically change the physical, hydrological and chemical properties of the rock, particularly in the near field of a nuclear waste repository, where high stress concentrations are caused by excavation of the repository access tunnels and waste package wells. Failure to account for this process seriously affects predicted release rates of radionuclides from breached radioactive waste containers.

It is generally understood that in the range of temperatures and stresses characteristic of the near field of a nuclear waste repository, the dominant process is a phenomenon known as "pressure solution". Unfortunately, a satisfactory mechanistic interpretation of this phenomenon has so far not been forthcoming, even through several phenomenological and theoretical studies have addressed this subject in the last decade. 
The purpose of this project is to accomplish the following:-

(1) Review previous theoretical and experimental studies pertaining to pressure solution.

(2) Develop an experimental design, which can identify the mechanism(s) and can quantitatively determine the rate of strain as a function of applied stres.

(3) Apply the resulting data to quantitative models, to predict the seismic stability of fractures subjected to stress in the pressure solution domain.

(4) Estimate the consequences of pressure solution on the porosity, permeability, strength and rate of deformation of the rock mass in the vicinity of a waste repository.

Since the initiation of this project during FY 1986, the following activities have been conducted or are presently underway.

(1) Review of the literature describing theoretical and experimental studies relating to pressure solution.

(2) Evaluation of a suitable experimental design to measure pressure solution.

(3) Review of the kinetics of quartz dissoiution and precipitation.

(4) Development of a consistent thermodynamic data base covering minerals most likely to participate in pressure solution phenomena.

Progress in each of these four tasks will be discussed in turn.

\section{Literature Survey}

Rocks deform through a variety of mechanisms depending on stress and temperature. The mechanisms have been reviewed by Rutier $(1976,1983)$ and McClay (1977) and include: 
(1) Cataclasis

(2) Dissolution and precipitation of minerals from an intergranular pore fluid, i.e. pressure solution.

(3) Coble Creep (interfacial phase diffusion)

(4) Nabarro-Herring creep (solid state difiusion)

(5) Intracrystalline plastic flow, e.g. dislocation creep or dislocation glide.

Pressure solution is considered by most investigators to be the dominant mechanism of rock deformation in water saturated rocks below $500^{\circ} \mathrm{C}$. Kerrich et al., (1978) have determined that pressure solution in rock grains 100-1000 microns in diameter is the most probable deformation mechanism for calcite below $300^{\circ} \mathrm{C}$ and for quartz below approximately $450^{\circ} \mathrm{C}$. Coble creep probably participates in the pressure solution phenomenon but the interfacial phase diffusion coefficient, $\mathrm{D}$ (Coble Creep), is not well known. This is a serious difficulty as will be discussed later.

Pressure solution arises from localized stress concentrations at the points of contact of individual grains in a rock which leads to enhanced aqueous solubility. The increased chemical potentials cause dissolved constituents to diffuse through the aqueous pore fluid to regions of lower localized stress, where precipitation occurs. Robin (1978) has conducted heuristic calculations of this mechanism with respect to quartz, and shown that even supersaturation with respect to amorphous silica is possible under some circumstances, as confirmed by de Boer et al., (1977). Experimentally observable compaction of quartz aggregates

due to pressure solution has been obtained within two weeks at $290^{\circ} \mathrm{C}$ by Sprunt and Nur, (1977) and at $340^{\circ} \mathrm{C}$ by de Boer (1977).

A considerable divergence of opinion appears to exist regarding the actual mechanism responsible for pressure solution. Rutter $(1976,1983)$ and other 
workers, e.g. Paterson (1973), Robin (1978), and Green (1980), conceive the interfacial contacts of mineral grains to be separated by a load bearing interfacial water so thin that it no longer possesses the properties of bulk water. Rutter (1983) believes it to be about $10 \AA$ thick. This interfacial phase, containing partially ordered water with enhanced viscosity, can resist the localized stress as to the extent that it cannot be squeezed entirely from the interface. Under these conditions, the solid phase is assumed to show enhanced solubility in the interfacial phase, (most minerals, including quartz show a positive pressure solubility coefficient) leading to dissolution at the interface and diffusion of the dissolved constituents into voids elsewhere in the system, i.e. intergranular pores, or the voids between the asperities of a fracture. Because the interfacial phase is assumed to have properties intermediate between a liquid and a solid, the interfacial diffusion coefficient is expected to lie somewhere between that in the aqueous phase, i.e. approximately $10^{-5} \mathrm{~cm}^{2} \mathrm{sec}^{-1}$ at $25^{\circ} \mathrm{C}$ and the diffusion coefficient in the solid at the same temperature i.e. $\approx 10^{-20} \mathrm{~cm}$. ${ }^{2} \mathrm{sec}$ at $25^{\circ} \mathrm{C}$. The magnitude of this interfacial diffusion coefficient is poorly known. Rutter $(1976,1983)$ estimates it to be about $10^{-5}$ smaller than that of water, i.e. $\approx 10^{-10} \mathrm{~cm}^{2}, \mathrm{sec}^{-1}$ at $25^{\circ} \mathrm{C}$, whereas Elliot (1973) believes it to be about $10^{-16} \mathrm{~cm}^{2} \cdot \mathrm{sec}^{-1}$ on the basis of independent field evidence. From experimental data (Rutter and Mainprice, (1978), Rutter (1983)) show that the activation enthalpy, $\Delta H^{*}$, lies between 8 and $10 \mathrm{kcal} . \mathrm{mol}^{-1}$, a value intermediate between that of molecular diffusion in water, $\approx 2-3 \mathrm{kcal} \cdot \mathrm{mol}^{-1}$ and molecular diffusion in a solid, $\approx 24 \mathrm{kcal}^{\mathrm{mole}} \mathbf{- 1}^{-1}$ This has recently been substantiated by Brantley et al., (1986), who estimate about 10-17 kcal.mol ${ }^{-1}$.

It is clear from Rutter's interpretation that pressure solution depends on three transport mechanisms: 
1. Surface dissolution of the mineral in the interface.

2. Diffusion of the dissolved constituents through the interfacial phase.

3. Precipitation of the mineral or secondary mineral in the voids under hydrostatic pressure.

Rutter argues that the wide temperature range over which pressure solution phenomena are observed in nature suggests a temperature insensitive process such as diffusion as the rate controlling mechanism. However, it is to be expected that with falling temperature, mass transport through an aqueous phase will transition from diffusion control to surface dissolution or precipitation rate control, especially in the case of quartz.

An entirely different interpretation is advanced by Lehner and Bataille (1984) who envisage the interface between two crystals to be occupied by an aqueous phase possessing the characteristic transport properties of water, i.e. with a ionic diffusion coefficient of $\sim 5 \mathrm{~cm}^{2} \cdot \mathrm{see}^{-1}$ and an activation energy of between 2-3 kal.mol ${ }^{-1}$. To account for enhanced solubility resulting from stress concentrations at the interface, a "local dissipation jump condition" is postulated in identifying the thermodynamic force during dissolution. This interpretation automatically leads to diffusion control through the interface at a much higher temperature than would be deduced under identical conditions by Rutter.

In neither of these two models is enhanced dissolution attributed to the generation of defects in the crystal lattice due to high localized stress concentrations at the points of contact of mineral grains. However, there is circumstantial information, strengthened by recent unpublished research by Meike (1986) that the primary cause of enhanced dissolution may be defect production in the crystalline solid in regions of high localized stress. Evidence of this comes from recent studies by Cook (1986), who shows that voids or cracks in a stressed material are the locus of stress concentrations five to ten times greater than the deviatoric 
stress. Futhermore, Meike (1986) has shown, that defect formation in calcite crystals will occur at stresses up to 10 orders of magnitude below the yield modulus.

If pressure solution phenomena can be attributed to a mechanistic cause of the type described, then assignment of a distinct region in applied stresstemperature space as attempted by Rutter (1976) is not strictly valid, as the same defect producing mechanisms responsible for dislocation glide and dislocation creep, causing deformation in high stress, high temperature domains, are also operating at lower applied stresses and temperatures. However, under milder conditions, the dominant effect is one of enhanced aqueous solubility, rather than plastic flow. Pressure solution may still be controlled by diffusion through an interfacial fluid, but the chemical potential gradients would be substantially higher than postulated by Rutter.

\section{Experimental Design}

The development of an experimental design to identify and quantify pressure solution mechanisms is fraught with serious measurement problems. Strain rates estimated to occur in natural systems due to pressure solution are so small as to be unmeasurable i.e., $10^{12}-10^{-14} \cdot \mathrm{sec}^{-1}$. (Rutter, 1983) in quartz. The practical limitation for strain measurement in the laboratory is $10^{-8}-10^{-9} \cdot \mathrm{sec}^{-1}$. At these rates, machine stiffness is critical, and temperature control must be extremely precise. Special strain gages e.g. linear variable differential transformers must be employed.

Rutter's analysis (Rutter, loc. cit.) would suggest that the strain rate due to pressure solution in a crystal aggregate and without defect creation is sensitive to grain size. His analysis suggests an inverse cubic dependence. The strain rate is also accelerated by temperature, but because of the assumed impact of diffusion control through the interfacial boundary, a relatively small temperature 
dependence is expected. Optimum strain rates calculated to be experimentally achievable in 1-10 micron grain size quartz aggregates using Rutter's model would lie in the range of $10^{-7}$ to $10^{-8} \cdot \mathrm{sec}^{-1}$ at $300-400{ }^{\circ} \mathrm{C}$; close to the experimentally measurable limits. Such an approach has recently been attempted by Brantley et. al., (1986) with aggregates of 1-2, 3-5 and 10-30 micron quartz grains at $400^{\circ} \mathrm{C}$ and $600^{\circ} \mathrm{C}$, a fiuid pressure of $1 \mathrm{kbar}$ and effective pressures of $0.4,1.0$ and $1.5 \mathrm{kbar}$. Under these conditions, they interpreted their results as indicating a diffusion controlled process responsible for compaction of the aggregate, a result not unexpected under these conditions regardless of the model assumptions. $I_{12}$ maximum strain rate was about $10^{-7} \sec ^{-1}$.

The disadvantage with an approach such as used by Brantley et al., (1986) is the difficulty in identifying and quantifying the actual mechanism involved in pressure solution, as only the bulk properties of the deforming a crystal aggregate can be measured. However, designing an experiment that allows segregation of the mechanisms is an undeniable challenge. Three issues require clarification and qiantification.

(1) the effect of hydrostatic pressure on the dissolution and precipitation kinetics of mineral phases as a function temperature.

(2) the effect of defect creation on the kinetics of mineral dissolution as a function of applied stress and temperature.

(3) the role of interfacial boundary diffusion and its magnitude as a function of temperature, pressure and interfacial width.

After careful review of alternative experimental configurations, it was decided that examination of the mechanisms should be best separated into different experiments. The first experiment would measure the kinetics of dissolution under a variety of temperatures, pressures and applied stress, essentially covering items (1) and (2), and a second experiment, which would deal with the 
role of interfacial diffusion. Quartz was chosen for examination, because its thermodynamic properties have been accurately determined (Kilday and Prosen, 1973 ) and its solubility has been repeatedly measured as a function of temperature and pressure, and is very well known (e.g. see a review by Fournier and Potter (1981)). Furthermore, several studies have been made of the kinetics of quartz dissolution and precipitation in recent years (e.g. see Rimsidt and Barnes, (1979), and Bird et al., (1986), for recent studies and reviews of the literature), which permit semiquantitative if not quantitative estimates. Of interest, and possibly germane to quartz dissolution kinetics, are the corresponding more comprehensive studies of amorphous silica precipitation and dissolution kinetics by Weres et al., (1980), and by Fleming (1986), in which consideration is given to the effect of catalysing anions, and to ionic strength due to the presence of $\mathrm{NaCl}$. Finally, but not least, quartz is a common rock forming mineral. Its behavior under stress is therefore pertinent to the subject in hand.

After due consideration of alternative experimental configurations, a preliminary design was settled upon, which is illustrated in Figures 1a and b. In this design, a single quartz crystal fabricated into a cylinder with a slot penetrating the longitudinal axis, Figure 1a, would be subjected to a confining pressure, Pc, while an aqueous fluid would be pumped through the slot at a steady rate equivalent to a pore pressure, $\mathrm{Pp}$, which would be equal to or less than the confining pressure. The rate of quartz dissolution would be measured as a function of $\mathrm{Pc}, \mathrm{Pp}$, temperature, and aqueous phase composition. The anticipated experimental condition would be $\mathrm{Pc} \leq 2.0 \mathrm{kbar}, \mathrm{Pp} \leq 2.0 \mathrm{kbar}$ and $\mathrm{T},=150-$ $500^{\circ} \mathrm{C}$. The aqueous phase solubility could range between 0.0 and $1.0 \mathrm{~N} \mathrm{NaCl}$. These conditions are somewhat more extreme than might be encountered in a waste repository, but are chosen to ensure the acquisition of experimental data in reasonable time periods. 
The experiment would involve measurement of $\mathrm{SiO}_{2}$ aq in the efluent stream under varying conditions of $\mathrm{Pc}, \mathrm{Pp}$ and $\mathrm{T}$, the rate of aqueous phase flow and operating parameters being determined by a readily measurable concentration of silica in the effluent. Calculations using preliminary estimates of silica dissolution kinetics (Apps et. al., 1975) suggest that the range of feasible operating conditions for the base case involving hydrostatic dissolution are as illustrated in Figure 2. However, these estimates are tentative.

Techniques to measure dissolved $\mathrm{SiO}_{2}$, were investigated, with the thought that continuous analysis by some colorimetric method would be most desirable. However, it was concluded that it would be more practical to collect samples using an automatic sampler, and submit these for chemical analysis by I.C.P. However, as the analytical limit is reached, it would be preferable to use a colorimetric method with less extragant demands on sample size.

When Pc $>$ Pp, stress concentrations at the corners of the slot, would lead to defect formation and enhanced dissolution. This would in turn accelerate dissolution by an undetermined amount and cause stress corrosion. It is possible that stress corrosion would aggravate the localized stress concentration, inducing a run aw ay condition. However, this must be determined. Continuous measurement of $\mathrm{SiO}_{2}$,aq under preset parameters would assess the significance of this process. In addition, it is planned to examine the extent of defect formation as a function of applied stress both on untreated samples and post test samples using the LBL $1.5 \mathrm{M}$ volt high voltage transmission electron microscopic.

By varying the operating parameters, it is hoped to model consequences of stress corrosion on quartz.

There remains the probiem of quantifying diffusion of $\mathrm{SiO}_{2}$, aq through interfacial boundaries. So far, no satisfactory experimental design has been devised that represents an improvement over refined versions of experiments already 
attempted, e.g. De Boer et. al., (1977). Sprunt and Nur (1977), Rutter (1983), Brantley et. al., (1986), This problem is under active consideration, and it is hoped that some resolution will be found shortly.

\section{Quartz Dissolution Kinetics}

Apps et. al., (1975) conducted a preliminary evaluation of the kinetics of quartz dissolution using absolute rate theory (Glasstone, et al., 1941). Subsequently, two additional studies have been published in which additional experiments were performed (Rimstidt and Barnes, (1980), Bird et al., (1986)). Significant discrepancies in the activation energies of precipitation are evident from comparison of the three cited works. Also, the latter two references do not include in their evalution, many of the papers identified the course of preparation of the preliminary report by Apps et. al., (1975). Because an accurate estimate of the dissolution kinetics of quartz is essential for the design of the planned experiments, a thorough review was considered appropriate. This has been started with incorporation of all earlier work as well as the more recent data compiled in Rimstidt (1979) and Bird and Boon (1984). Because some of the quartz dissolution measurements reported in the literature were made in alkaline and $\mathrm{NaCl}$ solutions at different pressures, an attempt will be made to ascertain whether available data permits an estimate of the dissolution rate dependency on these parameters.

\section{Thermodynamic Consistency in Mineral Precipitation}

Recent evaluation of mineral thermodynamic data based on phase equilibrium and calorimetric measurements (Berman and Jones, (1985), Helgeson et. al., (1978), and Hemley et. al., (1980)) have highlighted inconsistences in the interpretation of phase equilibria, solubility measurements, and calorimetric 
studies. A key issue is the relevance of predicted mineral "solubilities" in the aqueous phase at repository temperatures when based on thermodynamic data of solid phases. There is mounting evidence that aluminosilicates precipitating from supersaturated solution build up on their surfaces a disordered layer of product phase that establishes metastable equilibrium with the aqueous phase. This means that precipitation kinetics may be controlled by a complex two stage process involving precipitation and solid phase ordering. Because this is likely to zcur during pressure solution of quartz and in the precipitation of quartz and secondary clay minerals, this aspect is being investigated further with a survey of the solubilities and dissolution and precipitation kinetics of kaolinite, a common secondary clay mineral found precipitating in water filled fractures in many crystalline and sedimentary rocks.

To date, some twenty papers have been examined, and kaolinite solubility data compiled and entered on computer for evaluation using the EQ3 code developed by T. J. Wolery at LLNL. This work will continue during FY 1987 with the intention of identifying long term solubility trends in this mineral and the departure of predicted from actual solubilities as a function of temperature.

\section{Planned Activities of FY 1987}

During FY 1987 research will continue along the lines described above. Specifically, the following will be attempted:-

(1) Finalize the experimental designs to measure quartz dissolution kinetics under stress.

(2) Issue a request for bids for the construction of the equipment and award a contract for its construction.

(3) Complete the review and evaluation of quarts dissolution kinetics and issue a report on the subject. 
(4) Develop a design to measure diffusional transport of $\mathrm{SiO}_{2}$ aq in interfacial phases.

(5) Evaluate the effect of metastable equilibration with respect to solutions supersaturated in kaolinite and quartz.

(6) Compile a review of theoetical and experimental papers interpreting pressure solution phenomena.

Other issues may arise during the course of the research. These will be addressed and the project scope reviewed accordingly. 


\section{References}

Apps, J. A., E. L. Madsen and R. L. Hinkins, 1975, The kinetics of quartz dissolution and precipitation, Energy and Environment Division Annual Report, LBL-5299, Lawrence Berkeley Laboratory, Berkeley, CA, p. 12-15.

Berman, R. G. and Brown, T. H., 1985. An internally-consistent thermodynamic data base for minerals in the system $\mathrm{Na}_{2} \mathrm{O}-\mathrm{K}_{2} \mathrm{O}-\mathrm{CaO}-\mathrm{MgO}-\mathrm{FeO}-\mathrm{Fe}_{2} \mathrm{O}_{3}-\mathrm{Al}_{2} \mathrm{O}_{3}-\mathrm{SiO}_{2}-\mathrm{T}_{i} \mathrm{O}_{2}-\mathrm{H}_{2} \mathrm{O}-\mathrm{CO}_{2}$. Unpublished report of the Department of Geological Sciences, University of British Columbia, Vancouver, B.C., Canada, 26p plus figures, tables and bibliography.

Bird, G. and Boon, J. 1984. Silica transport during steam injection into oil sands: I. Dissolution and precipitation kinetics of quartz - New results and review of existing data. Oil Sands Research Department, Alberta Research Council, Edmonton, Alberta, Canada. File No. 1545-1-18, 22p. plus figures and tables.

Bird, G. Boon, J., and Stone, T., 1986. Silica transport during steam injection into oil sands; Part 1, Dissolution and precipitation kinetics of quartz; new results and review of existing data. Chemical Geology v. 54 p. 69-80.

Brantley, S. L., Crerar, D. A., and Evans, B., 1986. Rates and mechanisms of porosity reduction in quartz. Implications for fluid flow in rocks. Fifth International Symposium on Water-Rock Interaction, Reykjavik, Iceland, August 8-17, 1986 Extended Abstracts, p. 79-82. 
Cook, N. G. W., 1986. Personal communication.

De Boer, R. B., Nagetgaal, P. J. C., and Duyvis, E. M., 1977. Pressure solution experiments on quartz sand, Geochimica et Cosmochimica Acta, v. 41, p. 257-264.

Elliott, D., 1973. Diffusion flow laws in metamorphic rocks, Geological Society of America Bulletin, v. 84, p. 2645-2664.

Fleming, B. A., 1986. Kinetics of reaction between silicic acid and amorphous silica surfaces in $\mathrm{NaCl}$ solutions. Journal of Colloid and Interface Science, v. 110, No. 1, March 1986, p. 40-64.

Fournier, R. O., and Potter, R. W., 1982. An equation correlating the solubility of quartz in water from $25^{\circ}$ to $900^{\circ} \mathrm{C}$ at pressures up to 10,000 bars. Geochimica et Cosmochimica Acta, v. 46, p. 1969-1974.

Glasstone, S., Laidler, K. J. and Eyring, H., 1941. The Theory of Rate Processes, McGraw Hill Book Company, New York. 611p.

Green, H. W., 1980. On the thermodynamics of non hydrostatically stressed solids. Philosophical Magagine, v. 5, p. 637-47.

Helgeson, H. C. Delaney, J. M., Nesbit, H. W., and Bird, D. K., 1978. Summary and critique of the thermodynamic properties of rock-forming minerals. American Journal of Science, v. 278-A, 225 p. 
Hemley, J. J., Montoya, J. W., Marimenko, J. W., and Luce, R. W., 1980. Equilibrium in the system $\mathrm{Al}_{2} \mathrm{O}_{3}-\mathrm{SiO}_{2}-\mathrm{H}_{2} \mathrm{O}$ and some general implications for alteration mineralization processes. Economic Geology, v. 75, p. 210228.

Kerrich, R., Beckinsale, R. D., and Durham, J. J., 1978. The transition between deformation regimes dominated by intercrystalline diffusion and intracrystalline creep evaluated by oxygen isotope geochemistry. Tectonophysics, v. 38, p. $241-258$.

Kilday, M. V., and Prosen, E. J., 1973. The enthalpy of solutions of low quartz $(\alpha$-quartz) in aqueous hydrofluoric acid. Journal of Research of the National Bureau of Standards, A. Physics and Chemistry. v. 77A, p. 205215.

Lehner, F. K. and Bataille, J. 1984. Non equilibrium thermodynamies of pressure solution. Report No. 25, Division of Engineering, Brown University, Providence, R.I. 52 p.

McClay, K. R., 1977, Pressure solution and Coble creep in rocks and minerals: a review, Journal of the Geological Society of London, v. 134, pp. 57-70.

Meike, A., 1986. A study of deformation-enhanced dissolution in theory, experiment and nature, based on microstructural evidence. Unpublished Ph.D. thesis, Department of Geology and Geophysics, University of California, Berkeley, California, 166 p. 
Paterson, M. S., 1973. Non hydrostatic thermodynamics and its geologic applications. Reviews of Geophysics and Space Physics, V. 11, p. 355-89.

Rimstidt, J. D. 1979. The kinetics of silica-water reactions. Unpublished Ph.D. thesis, The Pennsylvania State University, State College, Pa.

Rimstidt, J. D. and Barnes, H. L., 1980. The kinetics of silica-water reactions. Geochimica et Cosmochimica Acta, v. 44, p. 1683-1699.

Robin, R., 1978, Pressure solution at grain-to-grain contacts, Geochimica et Cosmochimica Acta, v. 42, p. 1383-1389.

Rutter, E. H., 1976, The kinetics of rock deformation by pressure solution, Philosophical Transactions of the Royal Society of London, A., v. 283, p. 203219.

Rutter, E. H., 1983. Pressure solution in nature, theory and experiment, Journal of the Geological Society, London, v. 140, p. 725-740.

Rutter, E. H., and Mainprice, D. H., 1978. The effect of water on stress relaxation of Paulted and unfaulted sandstone. Pageoph. v. 116, Birkaüser Verlag, Basel p. 635-654.

Sprunt, E. S. and Nur, A. 1977. Destruction of porosity through pressure solution, Geophysics, v. 42, p. 726-741.

Weres, O., Yee, A., and Tsao, L., 1980. The kinetics of silica polymerization. 
Lawrence Berkeley Laboratory Report No. 7033. The Lawrence Berkeley Laboratory, University of California, Berkeley, California, $256 \mathrm{p}$. 


\section{Figure Captions}

Figure la. Schematic drawing of a single quartz crystal shaped to measure aqueous dissolution kinetics under stress.

Figure $1 \mathrm{~b}$. Schematic configuration of apparatus to measure quartz dissolution kinetics under stress.

Figure 2. Experimental constraints on the measurement of quartz dissolution kinetics under stress. 


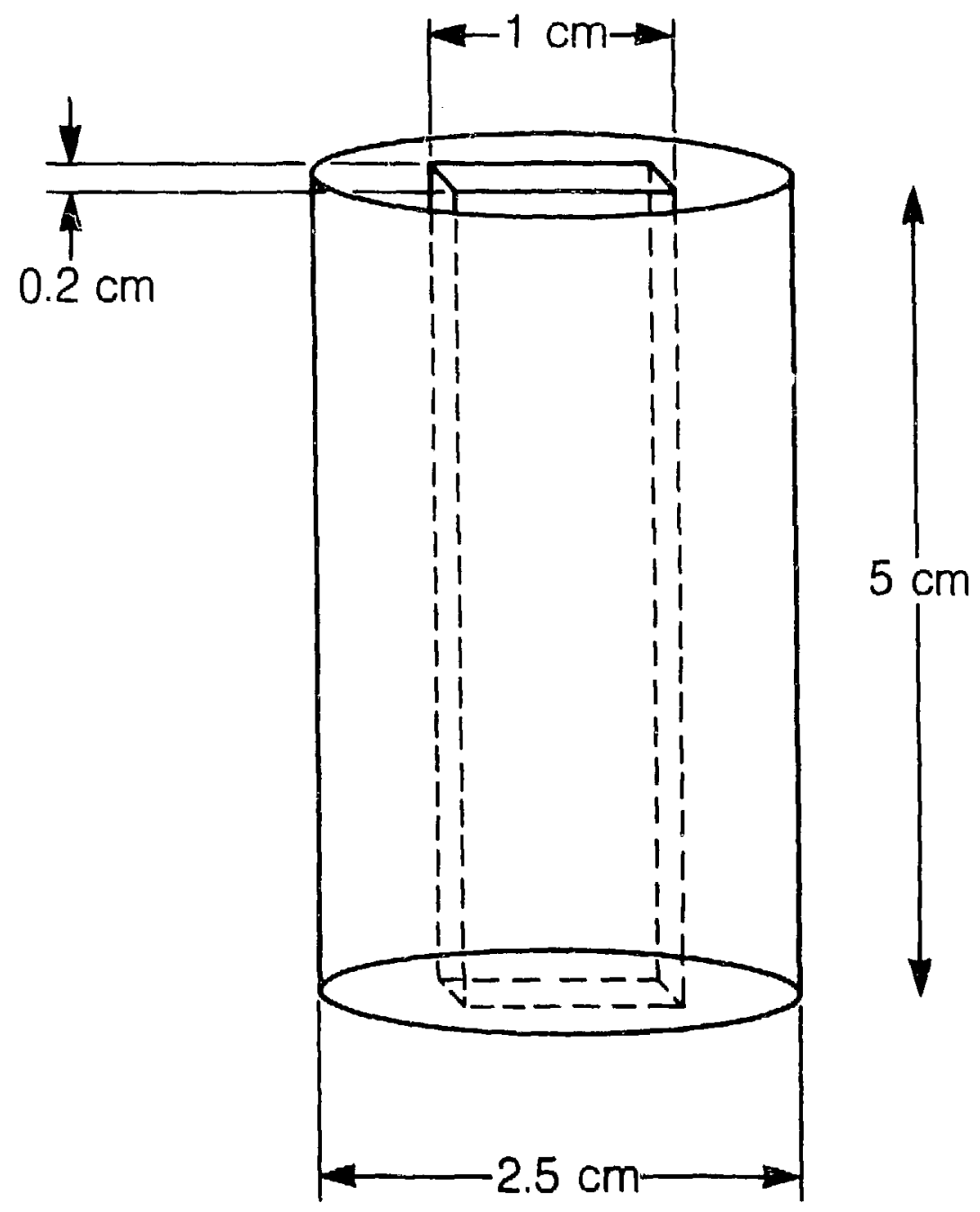

XBL $8611-12733$

Firure 12. Schematic drawing of a single quartz crystal shaped to measure aqueous dissolution kineties under stress. 
Figure 1b. Schematic configuration of apparatus to measure ciuartz dissolution kinetics under stress.

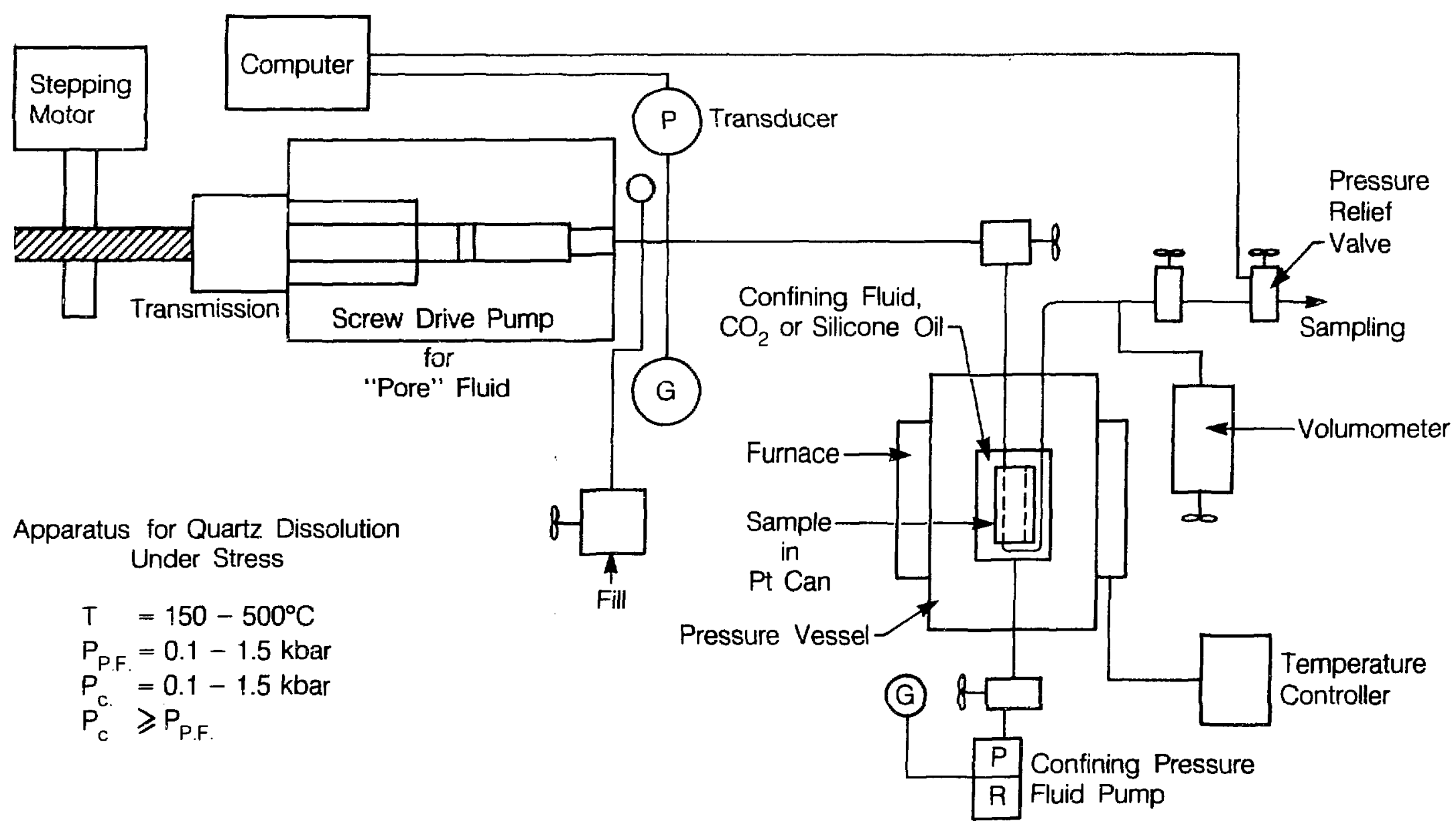




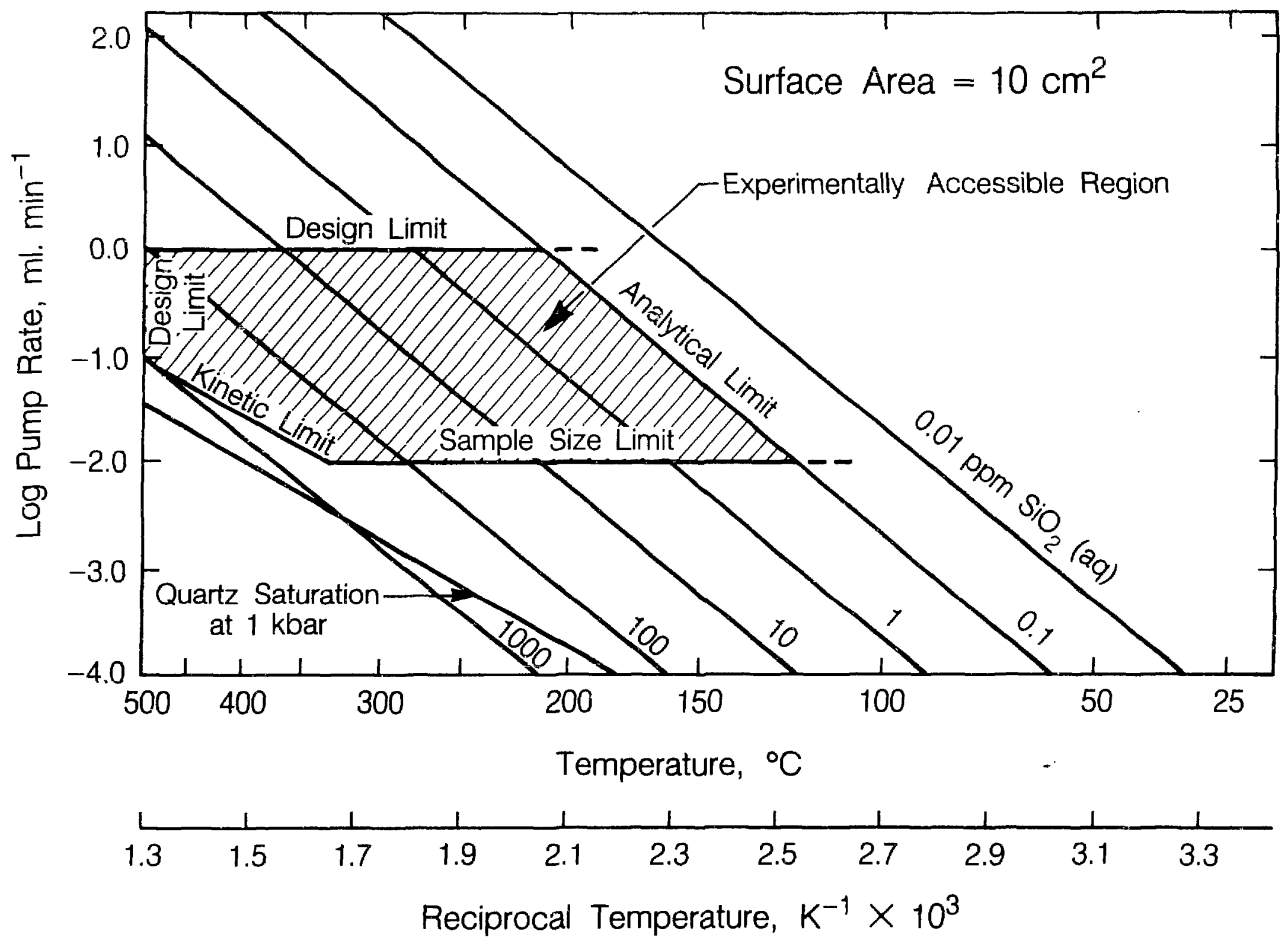

Figure 2. Experimental constraints on the measurement of quartz dissolution XBL 86:1-12732 


\section{Seismic Wave Properties of Idealized Fractures \\ D. L. Hopkins, L. R. Myer, and N. G.W. Cook}

Seismic methods are currently among the most promising geophysical techniques for characterizing the fracturing at potential repository sites. Until recently the effects of fractures on seismic waves were included implicitly in models by modifying the bulk material properties of the medium. A new theory has now permitted development of models which can explicitly account for the effect of each fracture on the velocity and attenuation of a seismic wave (see Letter Report (5), Seismological Modeling Methods in Fracture Studies).

A central concept in this new theory is that a fracture, which may be visualized as a non-welded interface, causes a discontinuity in seismic displacement as the wave crosses the fracture, while seismic stresses remain continuous. Specific stiffness defines the relationship between the applied seismic stress and the displacement discontinuity across the non-welded interface. For a prescribed stiffness, theory completely specifies the reflection, refraction, and transmission of plane waves incident upon the interface (Schoenberg, 1980).

To validate the theory, a series of controlled laboratory experiments has been performed in which seismic waves were propagated across idealized fracture 
surfaces. In addition, a new analytical model has been developed and implemented numerically to calculate the specific stiffness of a fracture.

\section{THEORY}

A non-welded interface may be envisioned as two surfaces which are in contact over a portion of their area. Between the contact areas are voids. Formally, specific stiffness is defined as the average applied stress divided by the displacement across the interface in excess of the displacement that would occur if the load were uniformly distributed across two surfaces in perfect contact (see Figure 1). Using this definition, specific stiffness has the desired properties of becoming infinite for a perfectly welded joint, and approaching zero for an interface with vanishing contact.

The seismic wave transmission coefficients are derived assuming that stresses are continuous across the joint whereas displacements are discontinuous by an amount proportional to the specific stiffness of the interface. Making the further assumption that the thickness of the interface is small compared to the incident wavelength, Schoenberg (1980) has derived the general solution to the elastodynamic problem of obliquely incident plane waves.

For normally incident waves and media of the same properties on both sides of the interface, the expressions for the magnitude of the transmission coeflicients for compressional (P) and shear (S) waves are: 


$$
\begin{aligned}
& \left|T_{P}(\omega)\right|=\frac{2\left(k_{z} / z_{P}\right)}{\sqrt{4\left(k_{z} / z_{P}\right)^{2}+\omega^{2}}}, \\
& \left|T_{S}(\omega)\right|=\frac{2\left(k_{x} / z_{S}\right)}{\sqrt{4\left(k_{x} / z_{S}\right)^{2}+\omega^{2}}},
\end{aligned}
$$

where:

$$
\begin{aligned}
& z_{P}=\rho c_{P}, \\
& z_{S}=\rho c_{S}, \\
& c_{P}=\sqrt{(\lambda+2 \mu) / \rho} \\
& c_{S}=\sqrt{\mu / \rho} \\
& \lambda=\text { Lames constant, } \\
& \mu=\text { shear modulus, } \\
& \rho=\text { density, } \\
& \omega=\text { circular frequency, and } \\
& k_{z}, k_{x}=\text { specific stiffness under normal } \\
& \quad \text { and shear stress, respectively. }
\end{aligned}
$$

Figure 2 shows the magnitude of the transmission coefficient as a function of frequency and relative stiffness for a normally incident $\mathrm{P}$-wave. 


\section{RESULTS OF EXPERIMENTS}

In a previous series of laboratory experiments, an idealized fracture surface was created by placing thin, parallel strips of lead between two steel cylinders. The experimental set-up is as shown in Figure 3. For these experiments, good agreement was found between observed attenuation and that predicted by theory for both compressional and polarized shear waves and for both dry and saturated conditions (Myer et al., 1985). The present study was designed to extend the experiments to more complex, three-dimensional geometries that better represent fracture surfaces in rock. For the current experiments, idealized fractures are created by placing thin lead discs of varying diameter between the steel cylinders.

To compare the results of the experiments to those predicted by theory, the stiffness of each idealized fracture was determined using the model described in the following section. The transmission coefficients were then calculated using the equations described in the previous section. Amplitude spectra for each signal were obtained from a Fast Fourier Transform of the received waveform as described in Myer et. al., 1985. To produce predicted spectra for each configuration of discs, the transmission coefficients were applied to the spectra obtained when the two sieel cylinders were separated by a solid disc of lead. The solid disc was the same thickness as the discs of lead used to create the idealized fractures and was used to ensure good contact between the steel cylinders.

Figures 4-5 show the predicted amplitude spectra versus the amplitude spectra of the observed signals as a function of frequency for three different arrangements of discs. The amplitude spectrum of the signal observed when the steel 


\section{Seismic Wave Properties of Idealized Fractures \\ D. L. Hopkins, L. R. Myer, and N. G. W. Cook}

Seismic methods are currently among the most promising geophysical techniques for characterizing the fracturing at potential repository sites. Until recently the effects of fractures on seismic waves were included implicitly in models by modifying the bulk material properties of the medium. A new theory has now permitted development of models which can explicitly account for the effect of each fracture on the velocity and attenuation of a seismic wave (see Letter Report (5), Seismological Modeling Methods in Fracture Studies).

A central concept in this new theory is that a fracture, which may be visualized as a non-welded interface, causes a discontinuity in seismic displacement as the wave crosses the fracture, while seismic stresses remain continuous. Specific stiffness defines the relationship between the applied seismic stress and the displacement discontinuity across the non-welded interface. For a prescribed stiffness, theory completely specifies the reflection, refraction, and transmission of plane waves incident upon the interface (Schoenberg, 1980).

To validate the theory, a series of controlled laboratory experiments has been performed in which seismic waves were propagated across idealized fracture 
nation of the deformations caused by the forces acting on all asperities in the region. For work done to date, the asperities are modeled as discs and the deforniation of the half-spaces defining the fracture is calculated using the Boussinesq solution for displacement beneath a loaded circle assuming a constant stress boundary condition (Timoshenko and Goodier, 1970).

As a first step in assessing the performance of the model we searched for an alternative method of estimating stiffness that would allow us to compare results from the model to ones obtained using an independent solution. For the particular case of an interface defined by a series of parallel strips, we were able to use the methods of linear elastic fracture mechanics and Betti's reciprocal theorem to derive the following expression for displacement that can be used to calculate stiffness:

$$
\bar{\delta}=\frac{-8 \sigma b\left(1-\nu^{2}\right)[\log \cos (\pi c / 2 b)]}{\pi E}
$$

where $\sigma$ is the applied stress, $\nu$ is Foisson's ratio, $E$ is Young's modulus, $2 c$ is the spacing between strips and $2 b$ is the center-to-center distance between strips.

The details of the calculation are given in Appendix 1. In brief, fracture mechanics allows us to calculate strain energy based on the stress intensity factor for a row of parallel slits. Betti's reciprocal theorem is then used to derive the relationship between strain energy and displacement. Once the expression for displacement is obtained, stiffiness can be calculated as explained previously.

As shown in Table 1, the fracture mechanics solution and the model yield results that agree well, with the best agreement being for those arrangements 
where the strips are relatively close together. As an additional check on the model, displacement measurements will be made in the laboratory for a variety of surfaces and compared to those predicted by the model.

In addition to calculating the stiffnesses of the idealized fractures used in the laboratory experiments, the model has been used to study the relationship between contact area, contact geometry, and stiffness. Several different arrangements of discs and strips are shown in Figure 7. Even though these configurations represent nearly identical contact areas of $25 \%$, stiffnesses vary significantly demonstrating that stiffness is not uniquely determined by either contact area or geometry.

\begin{tabular}{|c|c|c|}
\hline \multirow{2}{*}{$\begin{array}{c}\text { Ratio of strip } \\
\text { spacing : width }\end{array}$} & \multicolumn{2}{|c|}{$K_{\text {sp }}(\mathrm{MPa} / \mathrm{m})$} \\
\cline { 2 - 3 } & Model & SIF \\
\hline \hline $1: 1$ & $10.47 \mathrm{E7}$ & $10.75 \mathrm{E7}$ \\
$2: 1$ & $5.25 \mathrm{E7}$ & $5.09 \mathrm{E7}$ \\
$3: 1$ & $3.23 \mathrm{E7}$ & $3.00 \mathrm{E7}$ \\
$7: 1$ & $1.06 \mathrm{E7}$ & $0.87 \mathrm{E7}$ \\
\hline
\end{tabular}

Table 1. Comparison of specific stiffness $\left(K_{s p}\right)$ calculated using the model described in this section versus the stress-intensity factor solution (SIF) for different ratios of spacing to strip width; e.g. a ratio of 2:1 means the spacing between strips was two times the width of the strips.

\section{FUTURE WORK}

A second suite of experiments is planned to further study seismic wave attenuation and propagation across idealized fractures. Because we can control the parameters which define the fracture surface, we will explicitly study the 
effects of contact area, contact geometry, and stiffness. Experiments will also be done with relatively large discs to improve our understanding of the effect of having contact areas whose dimension is on the same order as the wavelength of the propagating wave. Initially, we will continue to work with $\mathrm{P}$ - and S-waves propagating across a single interface. Once analysis of the resulting data is completed, the experiments will be extended to study seismic wave propagation across multiple layers.

The analytical model developed to estimate stiffness will be extended so that it can be used to study surfaces that more closely reflect realistic rock fractnres. As a first step, the model will be generalized so that a distribution of heights can be assigned to the asperities. Results from the model will be compared to measurements made in the laboratory of displacements across a natural fracture as a function of applied stress. 


\section{References}

Brown, S. R. and C. H. Scholz, Closure of random elastic surfaces in contact, $J$. Geophys. Res., 90, 5531-5545, 1985.

Gangi, Anthony F., Variation of whole and fractured porous rock permeability with confining pressure, Int. J. Rock Mech. Min. Sci., 15, 249-257, 1978.

Greenwood, J. A., and J. B. P. Williamson, Contact of nominally flat surfaces, Proc. R. Soc., London, Ser. A, 295, 300-319, 1966.

Jaeger, J. C. and N. G. W. Cook, Fundamentals of Rock Mechanics, p. 124, Chapman and Hall Ltd., London, 1977.

Myer, L. R, D. L. Hopkins, and N. G. W. Cook, Effects of contact area of an interface on acoustic wave transmission characteristics, Proc. 26th U.S. Symp. on Rock Mech., 565-572, 1985.

Schoenberg, M., Elastic wave behavior across linear slip interfaces, J. Acoust. Soc. $A m ., 68,(5), 1516-1521,1980$.

Tada, Hiroshi, Paul C. Paris, and George R. Irwin, The Stress Analysis of Cracks Handbook, Del Research Corp., Hellertown, Pa., 1973.

Timoshenko, S. P. and J. N. Goodier, Theory of Elasticity, pp. 403-409, McGrawHill Book Co., New York, 1951. 


\section{APPENDIX 1}

\section{Derivation of Average Displacement Based on the Stress Intensity Factor For a Row of Parallel Slits}

From fracture mechanics we use $\boldsymbol{g}$ defined to be the change in mechanical energy per unit increase in crack surface area for one side of the crack surface. Let $U$ be the strain energy of the system, i.e. $U$ is the potential energy stored in the strained body. We can then write:

$$
2 \boldsymbol{g}=\frac{d U}{d A}
$$

where $A$ is the crack surface area and the two is present to account for both sides of the crack. Equivalently, we can write

$$
2 \int_{A} g=U
$$

From fracture mechanics we make use of the result that for plane strain and a normal uniaxial load,

$$
g=\frac{K_{I}^{2}\left(1-\nu^{2}\right)}{E}
$$

where $K_{I}$ is the stress intensity factor, $\nu$ is Poisson's ratio, and $E$ is Young's modulus.

An interface defined by a row of parallel strips can be equivalently modeled as a row of slits. The stress intensity factor for a normal stress applied to a row of parallel slits is available from handbooks (e.g. Tada et al., 1973) and is given by

$$
K_{1}=\sigma \sqrt{2 b \tan (\pi c / 2 b)}
$$

where $2 c$ is the width of the slit and $2 b$ is the center-to-center distance between slits. Plugging this value of $K$, into Equation 2 yields $g$ which in turn can be plugged into Equation 1 to yield the strain energy: 


$$
U=\frac{2\left(1-\nu^{2}\right)}{E} \int_{0}^{c} \sigma^{2} 2 b \tan (\pi x / 2 b) d x
$$

Pulling the constants outside the integral and making the substitution

$$
y=\frac{\pi x}{2 b}
$$

Equation 4 becomes:

$$
U=\frac{2\left(1-\nu^{2}\right) \sigma^{2} 4 b^{2}}{\pi E} \int_{0}^{c} \tan (y) d y
$$

Evaluating the integral gives the strain energy as:

$$
U=\frac{8 \sigma^{2} b^{2}\left(1-\nu^{2}\right)[-\log \cos (\pi c / 2 b)]}{\pi E}
$$

We now employ Betti's reciprocal theorem to relate strain energy to displacement. The method requires considering two systems of forces applied to the same elastic body. For simplicity, consider an elastic body of unit width containing a single crack or slit as illustrated in Figure 8. In the first case the body is subjecterl to a normal load $\sigma$ which results in a displacement at the crack of $\Delta_{c}$, and a total displacement away from the crack of $\delta_{e}+\delta_{c}$ where $\delta_{e}$ is the elastic displacement due to $\sigma$ and $\delta$ is the additional displacement due to the crack. In the second case the body is again subjected to a normal load $\sigma$, and in addition, the crack is closed by applying a stress of $-\sigma$ to the surfaces of the crack.

Because we are considering two systems of forces, each acting on the same elastic body, we can apply the reciprocal theorem which states that the work done by the forces of the first state acting through the displacements of the second (left-hand side of Equation 6), is equal to the work done by the forces of the second state acting through the displacements of the first (right-hand side of Equation 6). Mathematically, this translates into the following for the two systems of forces discussed above where the elastic body is taken to be of unit thickness: 


$$
\int_{0-b}^{1} \int_{e}^{b} \sigma \delta_{e} d x d y=\int_{0-b}^{1} \int_{-b}^{b} \sigma\left(\delta_{e}+\delta_{c}\right) d x d y+\int_{0-c}^{1} \int_{-c}^{c}-\sigma \Delta_{c} d x d y
$$

Note that the crack surfaces in Case 1 are stress-free boundaries so that only the external force due to $\sigma$ contributes to the left-hand side. Further, the integral on the left cancels with the first term in the first integral on the right leaving:

$$
1 \cdot \int_{-b}^{b} \sigma \delta_{c} d x=1 \cdot \int_{-c}^{c} \sigma \Delta_{c} d x
$$

However, for constant applied stress, the expression on the right-hand side is just one-half the strain energy term corresponding to a unit extension in crack length (see Jaeger and Cook, 1977); i.e.

$$
U=\frac{1}{2} \int_{0-c}^{1} \int_{c}^{c} \sigma \Delta_{c} d x d y
$$

Substituting this into Equation 7 yields:

$$
\sigma \int_{-b}^{b} \delta_{c} d x=2 U
$$

We now define $\bar{\delta}$ to be the average displacement due to the crack:

$$
\bar{\delta}=\int_{-b}^{b} \delta_{c} d x / 2 b
$$

Making the substitution in Equation 8 results in the desired expression relating the average displacement due to the crack to the strain energy:

$$
2 b \sigma \bar{\delta}=2 U
$$

or,

$$
b \sigma \bar{\delta}=U
$$

While the above derivation was for a single slit, the result generalizes to a row of 
slits so long as the appropriate stress intensity factor is used to calculate the strain energy $U$. Thus, substituting $U$ from Equation 5 we have:

$$
b \sigma \bar{\delta}=\frac{8 \sigma^{2} b^{2}\left(1-\nu^{2}\right)[-\log \cos (\pi c / 2 b)]}{\pi E} .
$$

Finally, solving for $\bar{\delta}$ yields

$$
\bar{\delta}=\frac{-8 \sigma b\left(1-\nu^{2}\right)[\log \cos (\pi c / 2 b)]}{\pi E}
$$

where $\bar{\delta}$ is the average displacement in addition to the elastic displacement due to a row of slits. 


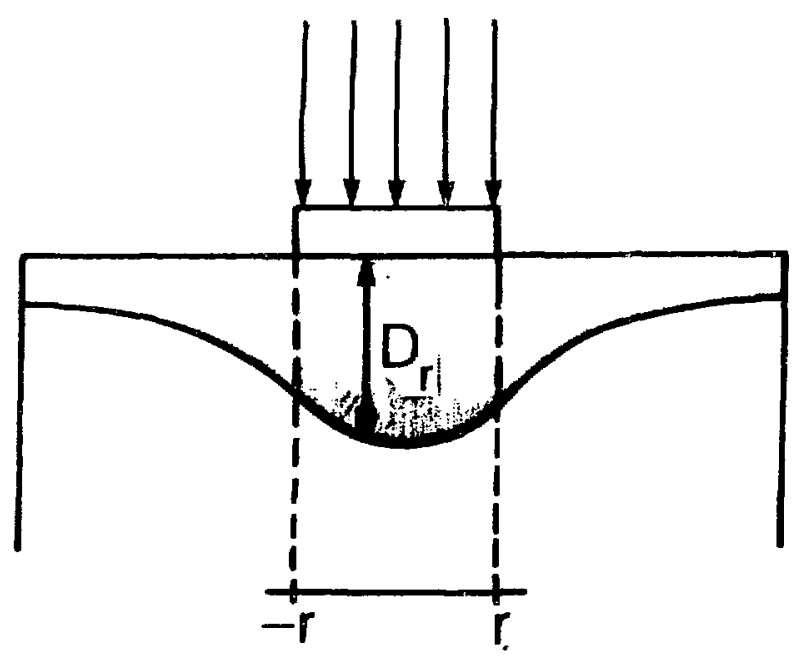

$\bar{D}=\int_{-r}^{r} D_{r} / 2 r$

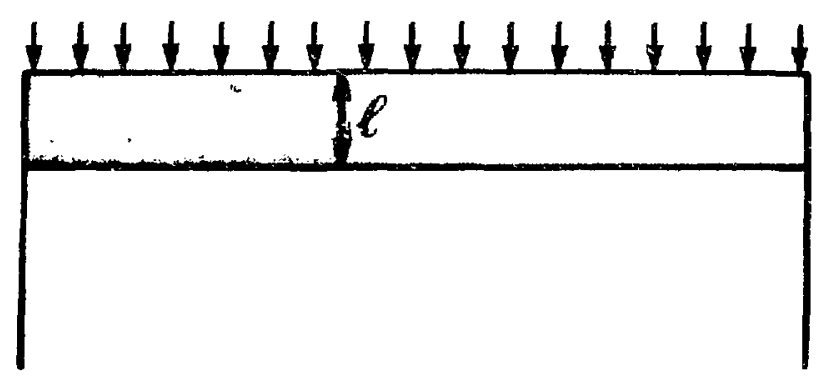

$\sigma=$ Applied Stress

$$
\mathrm{K}_{\mathrm{sp}}=\frac{\sigma}{\overline{\mathrm{D}}-\ell}
$$

Figure 1. Definition of specific stiffness $\left(K_{s p}\right)$ in terms of applied stress $(\sigma)$ and the average displacement $(\bar{D})$ in excess of the displacement that would occur if the load were uniformly distributed $(l)$. 


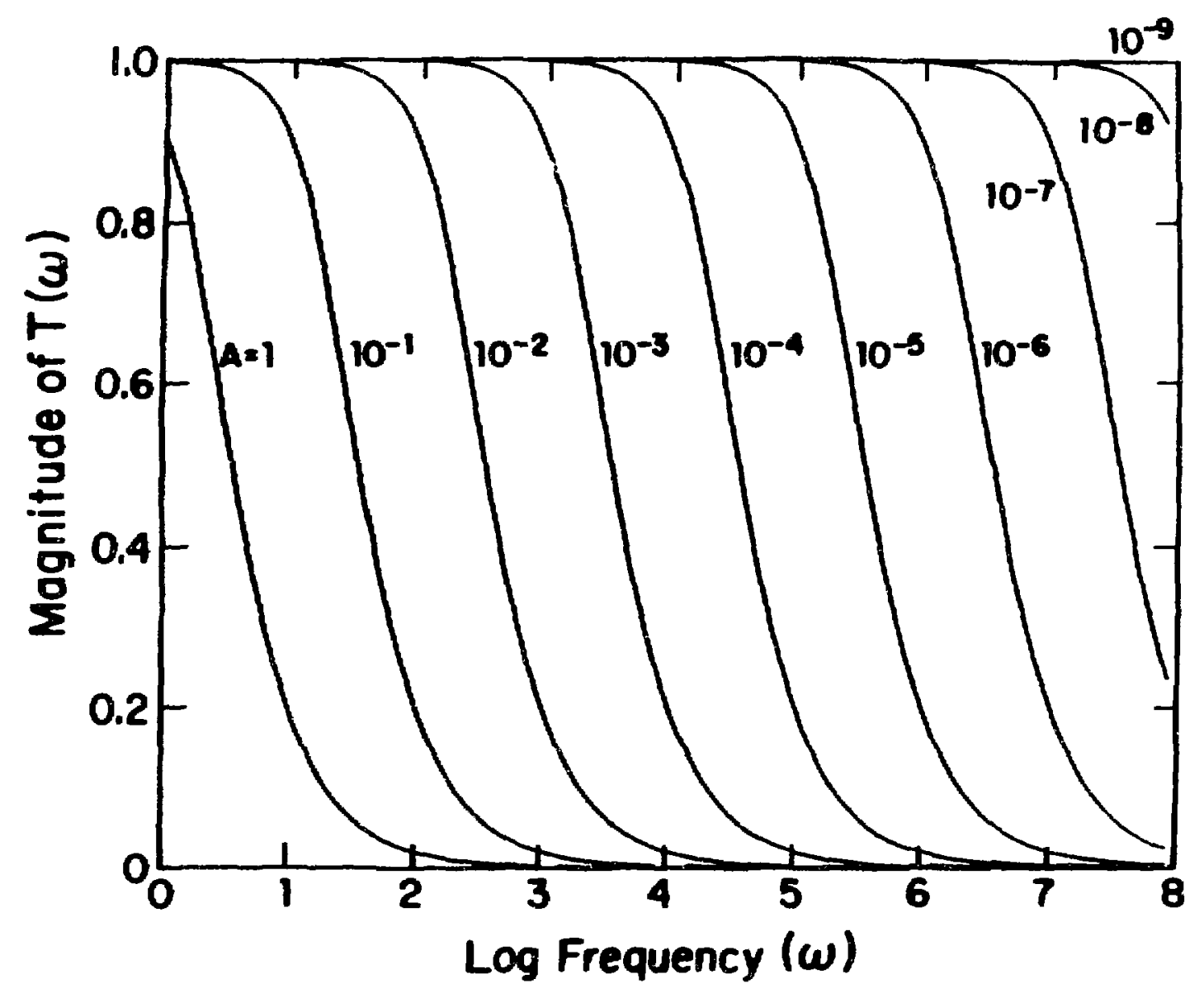

Figure 2. Magnitude of the transmission coefficient for a normally incident Pwave and media of the same properties on both sides of the interface where $A$ is the ratio of acoustic impedance to stiffness; i.e. $A=z / k$. 


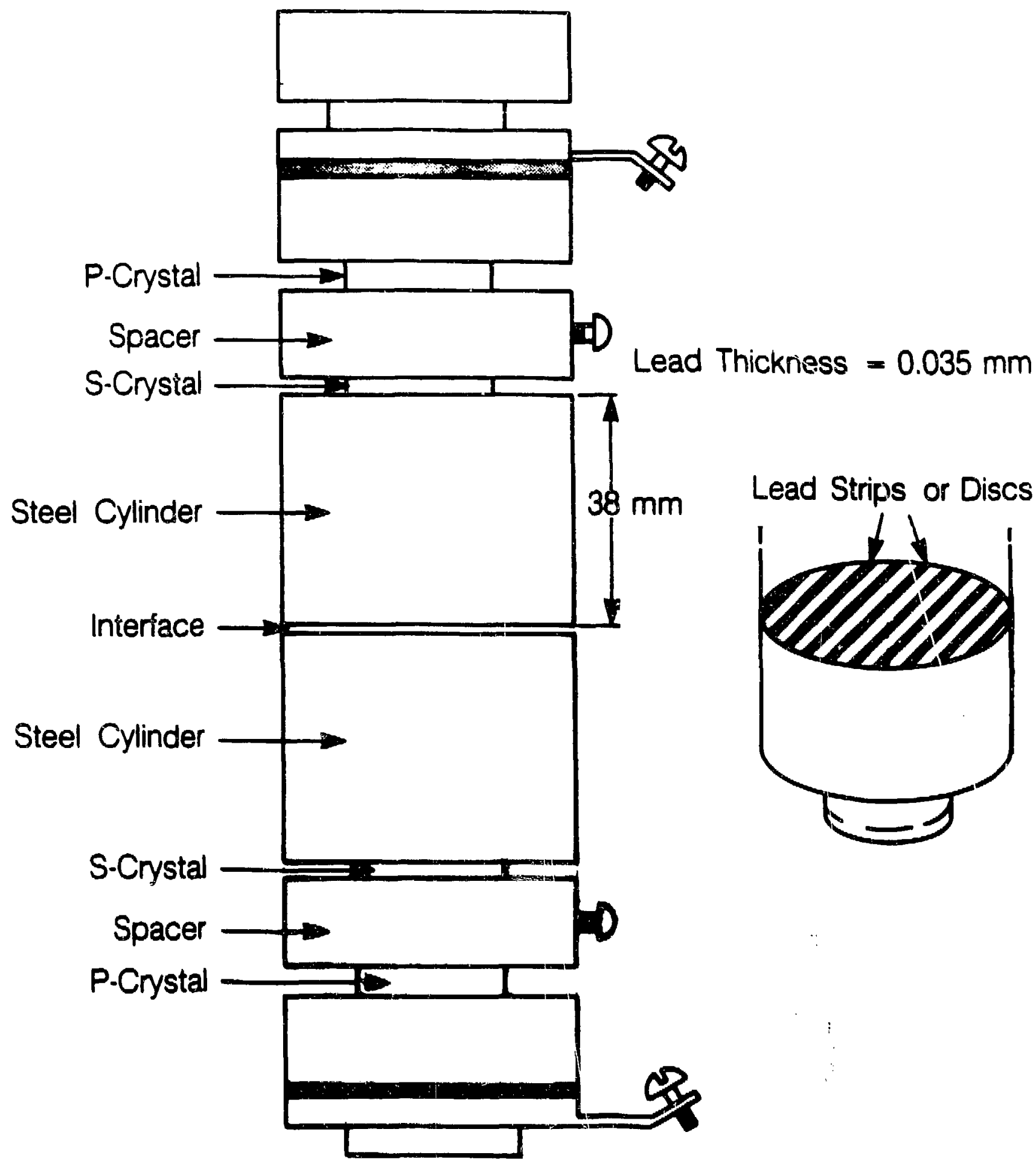

XBL $8610-12636$

Figure 3. Experimental set-up. Thin strips or discs of lead are placed between two steel cylinders to create artificial fracture surfaces. P- and S-waves are transmitted and received by two pairs of piezoelectric crystals placed at the top and bottom of the stack, respectively. 
Fourier Amplitude

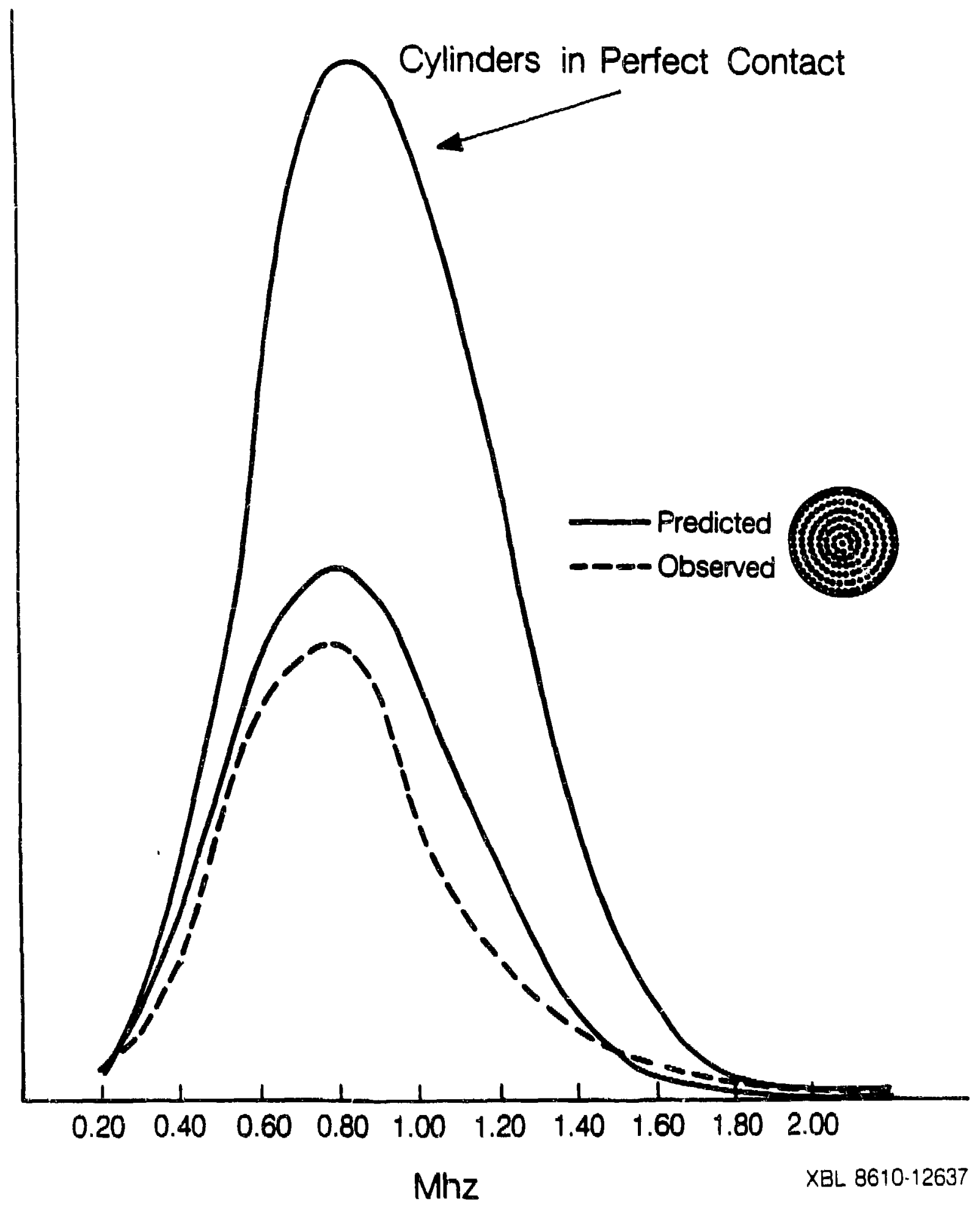

Figure 4. Fourier amplitude spectrum of the predicted signal (solid line) versus the spectrum of the observed signal (dashed line) for an arrangement of 165 discs having equal diameters of $1 \mathrm{~mm}$. 
Fourier Amplitude

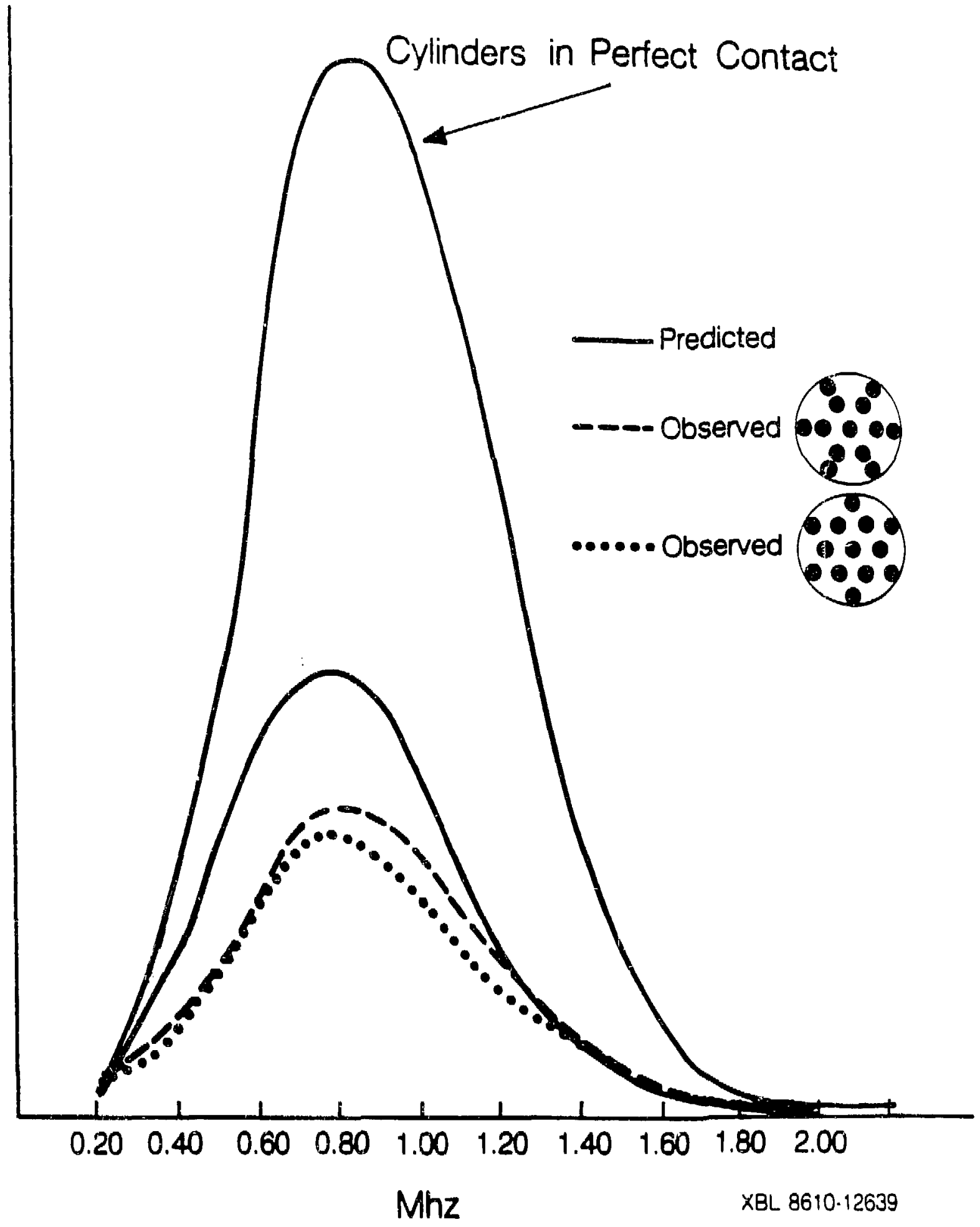

Figure 5. Fourier amplitude spectrum of the predicted signal (solid line) versus the spectrum of the observed signals (dashed and dotted lines) for two arrangements of 13 discs having equal diameters of $7 \mathrm{~mm}$. 
$6 \mathbf{a}$.

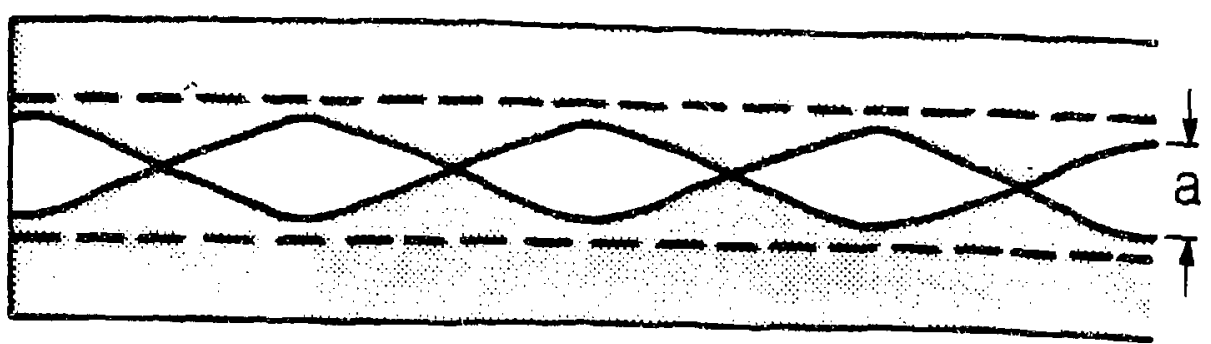

$6 \mathrm{~b}$.

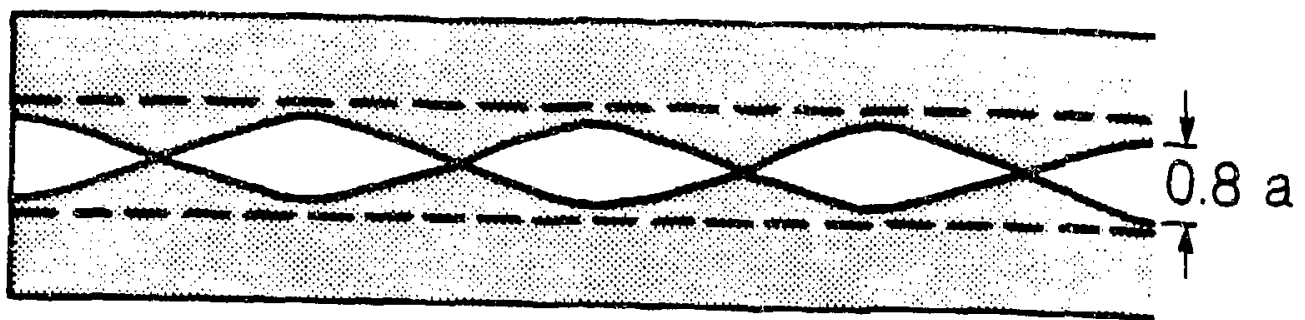

Bc.

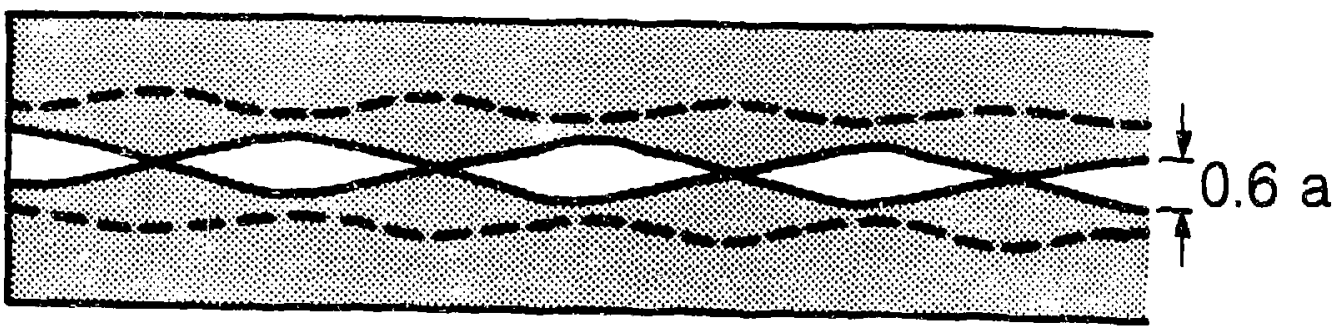

XBL $8610-12635$

Figure 6. Schematic drawing of displacement across a fracture under two different models. An idealized fracture is shown in Figure Ba under zero load. When a normal stress is applied to the fracture, the reference planes (indicated by the dotted lines) move closer together. Figures $\mathbf{6 b}$ and $\mathbf{6 c}$ illustrate the difference in displacement and aperture that results when only the deformation of the asperities is considered $(\mathbf{\theta b})$ versus that which results if the deformation of the halfplanes defining the fracture is considered in addition to the deformation of the asperities (Bc). 
Estimated

Stiffness (MPa/m) :

Contact area :

Disc diameter $(\mathrm{cm})$ :

Estimated

Stiffness (MPa/m) :

Contact area :

Disc diameter $(\mathrm{cm})$ :

Estimated

Stiffness (MPa/m) :

Contact area :

Disc diameter $(\mathrm{cm})$ :

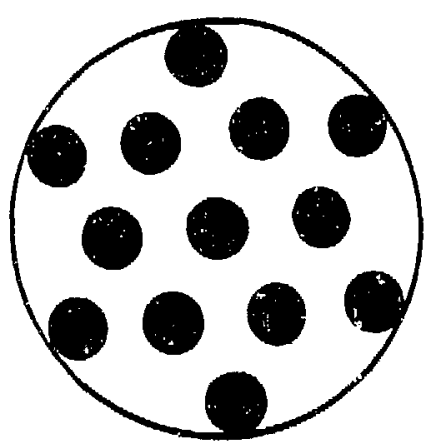

$1.31 \mathrm{E7}$

$25 \%$

0.7

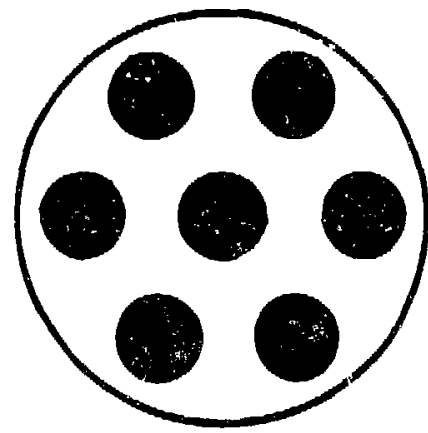

$1.18 \mathrm{E7}$

$25 \%$

1.0

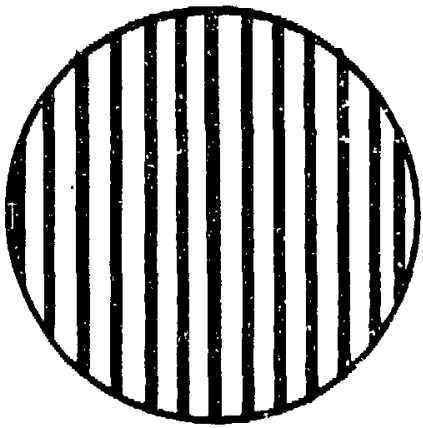

$3.23 \mathrm{E7}$

$25 \%$

strip width $=0.1$

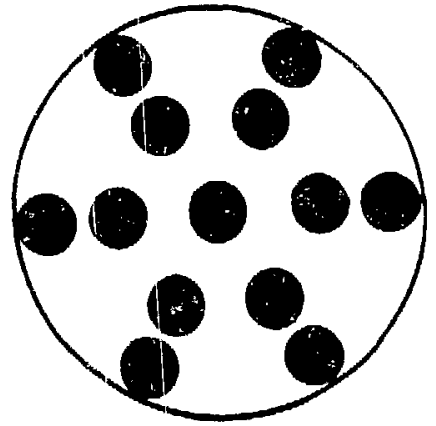

1.30 E7

$25 \%$

0.7

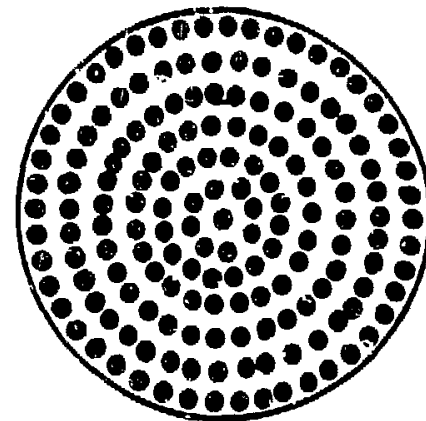

$1.65 \mathrm{E7}$

$25 \%$

0.2

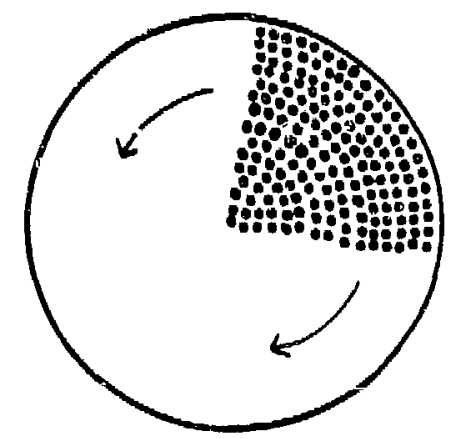

$5.43 \mathrm{E7}$

$25 \%$

0.1

Figure 7. Stiffnesses calculated for different arrangements of discs with nearly identical contact areas. 
Case I.

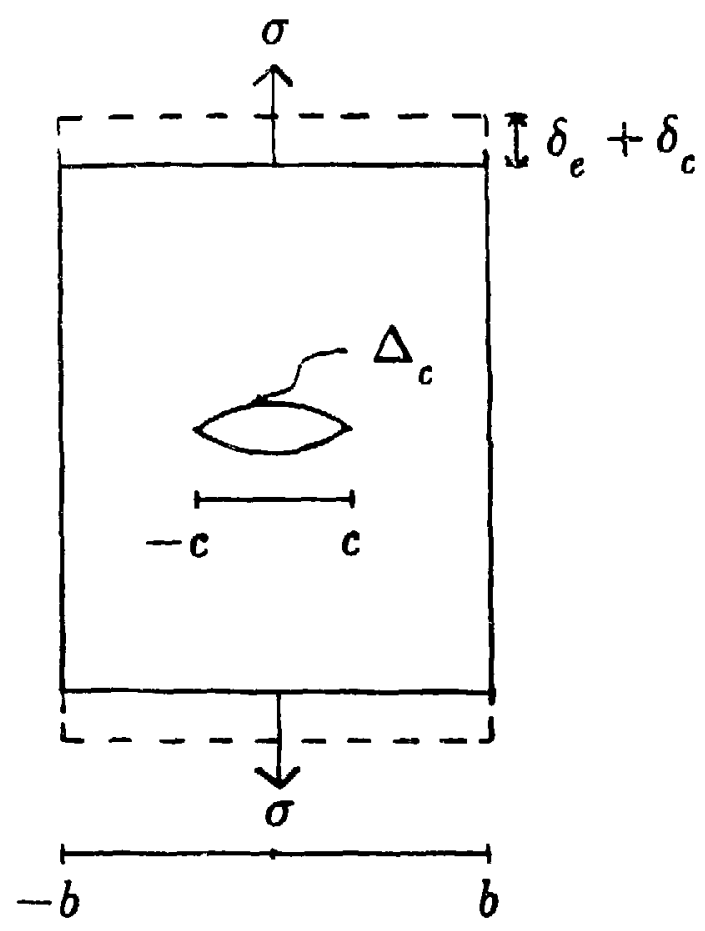

Case II.

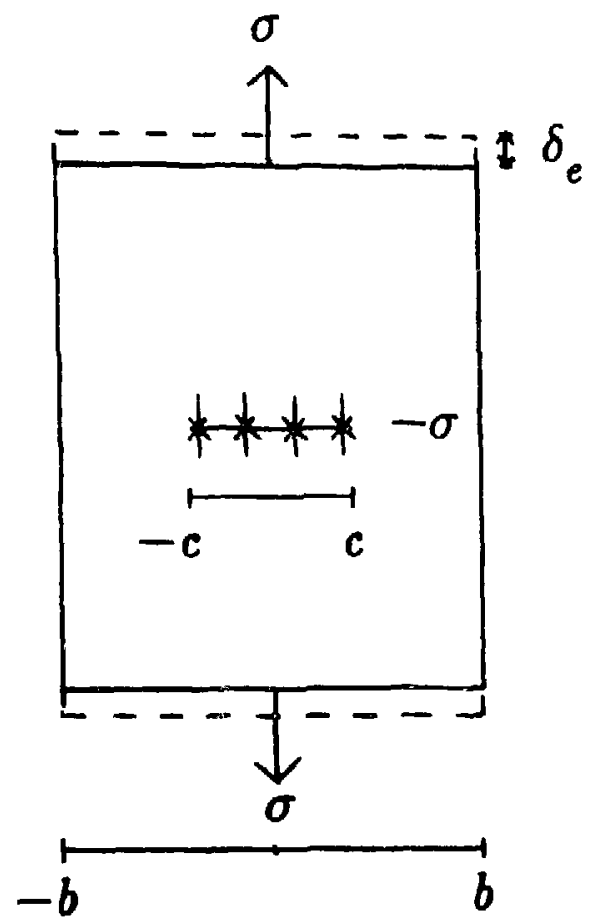

Figure 8. The work done by the forces of Case $I(\sigma)$ acting through the displacements of Case II $\left(\delta_{e}\right)$ is equal to the work done by the forces of Case II ( $\sigma$ and $-\sigma)$ acting through the displacements of Case $I\left(\Delta_{c}\right.$ and $\left.\delta_{e}+\delta_{c}\right)$. 


\title{
Modeling the Seismic Response of Fractured Media
}

\author{
E.L. Majer, and T.V. McEvilly
}

\section{Introduction}

One of the most crucial needs in the design and implementation of an underground waste isolation facility is a reliable method for the detection and characterization of fractures in zones away from boreholes or subsurface workings. The fracture network will largely determine the hydrological and geomechanical response of the host rock under thermal loading. Within underground workings we are able to examine fractures directly, however, a major problem exists in trying to extrapolate this characterization to unexposed regions. Geophysical methods represent our approach to these problems. If fractures represent elasticity anomalies seismic techniques may detect and characterize them. It then remains to relate the measured seismic properties to the overall hydrologic and geomechanical characteristics and predicted performance of the media. There have been almost no attempts to relate geophysical anomalies to the hydrologic or geomechanical parameters of fractured materials.

The techniques of Vertical Seismic Profiling (VSP) may be applicable in characterizing fractured media. Through tomographic analysis of VSP data, it may be possible to map the elastic properties indicative of fracture content and structure. Such methods use travel times, amplitudes, and particle motions of the P-, SV-, and SH-waves to estimate fracture orientation, density, and distribution. Resulting properties can then be used to construct hydrologic or geomechanical models of fracture networks to study the behavior of the rock mass. The VSP method is being evaluated as a tool for fracture definition in repository siting and performance evaluation. This research will develop the relationship between seismic response and hydrologic behavior of fractured media, and will evaluate VSP tomography as a tool for mapping the relevant properties throughout the repository volume. If successful the technique will provide a method for characterizing the overall hydrologic and geomechanical properties of the repository. 
Fracture studies using VSP have been reported (Stewart et al., 1981), and Crampin in a series of papers has pointed out the importance of using 3component data, particularly for fracture detection (Crampin, 1977, 1978, 1981, 1984a, 1984b, 1985). The phenomena of shear wave splitting and anisotropy effects on $\mathrm{S}$ and $\mathrm{P}$ waves have been discussed previously (Leary and Henyey, 1985).

Recent laboratory (Myer et al., 1985) and theoretical work (Schoenberg, 1980,1983 ) develop a model which relates apparent shear wave anisotropy to the to the stiffness of a fracture across which the displacement is not required to be continuous as a seismic wave passes. The discontinuity in displacement at the fracture is taken to be linearly related to the stress through the stiffness of the fracture surface. A fracture set can thus have a significant effect on wave propagation. Schoenberg shows that the velocity ratio for propagation perpendicular and parallel to the fracture set is a function of the spacing and the stiffness of the discontinuities. Consequently, given the fracture stiffness, with this model one can determine the average fracture spacing by measuring the velocity anisotropy.

As an example of the effect of fractures on the propagation of seismic waves in a VSP study, $\mathrm{P}$ and cross-polarized $\mathrm{S}$ vibrators were used to investigate the potential utility of shear wave anisotropy measurements in characterizing a fractured rock mass. The fractured rock was a greenstone caprock at The Geysers geothermal field in northern California and was found to exhibit $\sim 11 \%$ velocity variation between SH and SV waves generated by rotaling the vibrator orientation to two orthogonal polarizatinns for each survey level in the well. The effect of fractures on the travel times is shown in figure 1. The effect is generally consistent with equivalent anisotropy azpected from the known fracture geometry, although unexplained factors remain. In this pilot VSP study of shear waves in fractured rock at The Geysers geothermal field several interesting observations were made:

Anisotropy of shear waves evident in a $\sim 11 \%$ velocity difference and in apparent splitting of SH- and SV- polarized waves generated at a common source point and recorded by a common downhole 3-component geophone. 
There is little or no evidence of any P-wave anisotropy.

The apparent anisotropy is consistent to first order with expected effects of the known dominant fracture set in the greenstone caprock overlying the production zone.

Complexities remain, after simplest anisotropy models, in anomalous amplitudes and apparent velocities of the observed component S-waves from the two source polarizations.

The data set collected at The Geysers was limited and insufficient for detailed determination of fracture density and orientation. However, the data do suggest, as Crampin and others have pointed out, the potential application of 3component multi-source VSP data in determining subsurface fracture content and orientation. In addition, if the theory developed by Schoenberg relating SV and $\mathrm{SH}$ velocity differences to fracture stiffness is applicable, information on average fracture spacing may also be obtained. The data presented show clearly a significant anisotropic effect on the propagation of shear waves through the fractured greenstone caprock at The Geysers geothermal field. It appears that a model in which dominant fracture sets impose an effective anisotropy on the medium can explain to first order the observations.

Much work lies ahead in interpreting the data in actual field situations in terms of fracture properties. It appears promising, however, that useful information on fracture density and orientation can be obtained. Combined S- and Pwave data offer information on the nature of fracture-filling fluids. Amplitude and spectral information remain to be exploited. If the fracture stiffness model holds up, the spectrum of the reflected wavelet offers a valuable diagnostic tool in discriminating between reflections from welded interfaces and those from fracture sets. In this work we hope to develop sufficiently sophisticated modeling capabilities to account for such field observations as at The Geysers. Given this capability we will then be able to predict fracture density, orientation, and and hopefully relate these fracture charactor:tics to the hydrologic and geomechanical properties 


\section{Work to date}

The initial focus of this research has been the development of a computer model to predict how seismic waves travel through a fractured network. Whereas several numerical techniques are available for predicting fluid flow through fracture networks, the corresponding computational tools for determining how a seismic wave is affected as it is transmitted through a network of randomly located and oriented finite fractures was not available at the onset of this study. The development of such a seismic modeling tool has been a high priority for this project, and it has been accomplished. One of the other goals of this project is to integrate the results of the theorectical and laboratory studies being carried out at LBL under N.G.W. Cook and L.R. Myer investigating the seismic response of fractures into the computer modeling codes.

The first attempt was to modify our present one-dimensional and twodimensional ray tracing and synthetic seismogram models that relied upon conventional welded boundary theory to admit 'stiff' fracture surfaces with arbitrary orientation. Due to the complex geometry of fractures and the complexity involved in ray tracing through many fractures, we soon abandoned this approach. It is necessary to include the displacement discontinuity boundary conditions in the solution for the propagation of the seismic wavelet. The constitutive equations for this model come from the study of single fractures which is ongoing at LBL. The approach finally taken was to modify a code that is used for hydrologic modeling of fractured media. This code, Fracture Mesh Generator (FMG) generates any desired fracture distribution (density and sizes), and calculates the relative position of each fracture. The new program FMGRAY is used to obtain the center position of each fracture and to calculate the ray tracing coordinates. A second program was also developed, SYNHYD1. This code is the Cerveny synthetic seismngram generator, i.e., SYN'TPL with the fracture information included. This has also been modified to include the stiffness effect of fractures on the seismic waves in addition to the geomeiry information.

Using this modeling capability we can now vary fracture geometry, density and orientation in a medium and measure the seismis response. Because we used FMC to generate our fractures, we can compare the seismic response to the 
hydrologic response. Parameter studies will be designed to determine the degree to which VSP is sensitive to the interconnection of the fractures. This involves calculating the average seismic response of a fractured region. We can then study VSP sensitivity to heterogeneity in fracture stiffness. In these studies we vary the geometric properties of fractures which control the hydrology and relate these to any significant differences in the VSP-measured properties.

In addition to describing structure and fracture content we are also hoping to relate the seismic response of the rock mass to the hydrologic response. The idea is to tomographically map the variation in the P-, SV-, and SH-wave properties and relate the resulting anomalies to the actual fracture density, orientation, and spacing. An example of this approach is shown in figure 2. Shown are ray paths through a model of fractured rock. This fracture model was actually generated by modifying code that is used to model the hydrologic respone of fractured media. In this way we can compare the seismic response to the hydrologic response. In a conventional approach to ray tracing, the fractures, due to their very small width, would have little or no effect on the ray parameters. In the programs that we have developed we have incorporated the effect of fracture stifiness (Myer et al. 1985) in addition to the effect of the bulk rock properties. The fractures in figure 2 are zero thickness but have finite stiffness. The area modeled in figure 2 is $1 \mathrm{~km}$ by $1 \mathrm{~km}$. Figures 3 and 4 show the resulting waveforms from $4 \mathrm{hz}$ and $40 \mathrm{hz}$ wavelets, respectively. As can be seen the stiffness has a significant effect on the seismic energy. Shown in these figures are P-waves. We also have the capability to model SV- and SH-waves as well. The aim is to use the times, amplitudes and polarizations of the P-, SV-, and SHwaves to map fracture properties.

A significant question that remains to be answered is the scale effect of stiffness. If we use stiffnesses of fractures that have been measured in the laboratory in our kilometer size model, we see no effect on the seismic waves. To see an effect we must assume that sliffness scales as the square of the length of the fracture. We have observed in field cases effects of fractures at kilometer size scales, (Majer et al 1986). Therefore we assume that there must be a scale effect. 
Running in parallel with this effort is work designed to integrate data from actual VSP field studies we have carried out in fractured media. Data from various fractured rock types, crystalline, tuff, and metamorphic, are now being modeled to match the observed behavior on the seismic waves. Depending upon the success of this effort, we will incorporate the tomographic analysis. By applying this analysis to a map of fractures which have different network parameters in each pixel, we can then measure the seismic response of each pixel. Such a tool, once developed will have to be modified as we learn more about the physics of seismic waves in fractured rock.

In field study in a less complicated environment than The Geysers we performed a multi-offset/multi-source VSP. As in the case of The Geysers we used P- and S-wave vibrators. The zone covered in the well was from 300 feet to 1800 feet. At each offset (each being 300 feet from the well) we turned the S-wave vibrator parallel and perpendicular to the ray path connecting the well and the vibrator. In effect we had a compressional wave ( $\mathrm{P}$-wave vibrator), a SH-wave (shear-wave vibrator perpendicular to the well), and a SV-wave source (shearwave vibrator parallel to the well). The well that we used was in granite about 30 miles east of the San Andreas Fault near Lancaster, California. It was a very tight granite and relatively unfractured formation. Hydyofracturing had been carried out in the well to determine the stress information. There were some fractured regions at the bottom of the well, but we were mostly in unfractured rock, especially compared to a geothermal environment. The plan of the experiment was to vibrate at 0,45 , and 90 degrees to the fracture direction inferred from the hydrofracture data. We knew that we were unlikley to detect the short fractures from the hydrofracture, but we were interested in determining if we could detect a preferred fabric or overall microfracturing of the rock. Differences were detected in the SH- and SV-components from the different shear wave sources as a function of azimuth. The differences are subtle and difficult to demonstrate at the scale available in this report, but were on the order of 5 to 10 percent velocity anisotropy. Shown in figures 5,6 , and 7 are the 3 component data from the SH source at 0,45 , and 90 degrees, respectivly, to the fracture direction that have been rotated into the plane of propagation of the $\mathrm{P}$-wave. That is, channel 2 is the particle motion component along the ray path (P), 3 is vertical (SV), and 4 is 
horizontal (SH) to the ray path. From these figures on can at 'east see the relative amount of energy arriving at the different positions of the source and receiver. Even in this relatively isotropic environment we do see effects of fractures.

A third effort is to improve and keep up to date our synthetic seismogram capability and to integrate a more complete anisotropy theory into our codes. We have obtained Cerveny's most recent version of his code and we are now in the process of implementing this version. Once complete this will give us higher frequency response and a user friendly tool.

\section{Future Work}

If successful, the VSP method could prove to be a valuable method in siting and evaluating future repository sites. Because VSP is based on techniques that have been thoroughly tested and used in the petroleum industry (i.e. reflection profiling), the method could easily meet the accountably and QA requirements. The most important result, however, may be the link between the fracture characteristics as inferred from the seismological results and their utility in inferring the hydrological properties of the media.

Much work is still left to be done to advance the technique to a field ready state. Future work will involve more complicated models including finite fracture length, effects of multiple fractures and including anisotropy into the matrix properties.

If the seismic modeling indicates that seismic response is sensitive to the geometric parameters which control saturated flow, it will be necessary to determine how unsaturated flow is controlled by these parameters. Also, we do not expect the geophysics to tell us the location of every fracture. Rather, in each pixel we will have some average property. The use of fracture models which incorporate geostatisical simulation is also based on average pixel properties. Thus, work can be done to apply geostatistical techniques to extend the seismic pixel information and relate this extension to hydrologic properties. 
The key to this effort is to interpret the data in light of the experimental and theoretical work that LBL and others have been doing on the effect of fracture stiffness and infilling material on the velocity, amplitude, and polarization of seismic waves. This is an extension of the shear-wave splitting that many have observed in fractured media. Its attractiveness is that it offers a quantitative solution to fracture spacing and orientation. If this approach works out as well as we expect it to, it will be invaluable for defining fracture content and density, espccially for fracture sets that do not intersect the borehole. It will also point the way as to how to design and implement future studies from other boreholes and the underground workings. It is vecoming increasingly apparent to not only us, but to others, that VSP/tomographic techniques using 3-component data will be invaluable for defining fine structure. Because of this, new equipment (borehole sources and multi-element receiver strings) will soon be available to carry out much more detailed surveys at relatively low cost. In essence, in this study we are attempting to determine if seismic methods can be of aid in providing the hydrologists and engineers with useful parameters for determining the hydrologic and geomechanical performance of the repository area.

Through development of models to trace seismic waves through fracture networks we will be able to determine to what extent the geometric parameters which control saturated flow also have a seismic signature. If such a relationship is confirmed it will remain to study how geometry controls unsaturated flow through fracture networks. This in turn will show us how to refine the field technique to best measure the critical parameters. 


\section{References}

Crampin, S., 1977, A review of the effects of anisotropic layering on the propagation of seismic waves: v. 53, pp. 467-496.

Crampin, S., 1978, Seismic-wave propagation through a cracked solid: polarization as a possible dilatancy diagnostic: v. 53, pp. 467-496.

1981, A review of wave motion in anisotropic and cracked elastic-media: v. 3, pp. 343-391.

1984a, Effective anisotropic propagation through a cracked solid: Crampin, S., Hipkin, R.G., and Chesnokov, E.M., eds., Proc. of the First Internat. Workshop on Seismic Anisotropy, v. 76, pp. 135-145.

1984b, Anisotropy in exploration seismics: v. 2, pp. 19-21.

1985, Evaluation of anisotropy by shear wave splitting: v. 50, no. 1, pp. 142-152.

Leary, P.C. and T.L. Henyey, 1985, Anisotropy and fracture zones about a geothermal well from P-wave velocity profiles: v. 50, no. 1, pp. 25-36.

Majer, E.L., T.V. McEvilly, F.S. Eastwood, and L.R. Myer, 1986, Fracture Detection Using P- and S-wave VSP's at The Geyers Geothermal Field: Geophysics (in press)

Myer, L.R., D. Hopkins, and N.G.W. Cook, 1985, Effects of contact area of an interface on acoustic wave transmission characteristics: Balkenia, A.A., ed., Research and Engineering Applications in Rock Masses, South Dakota School of Mines, v. 1, pp. 565-572.

Myer, L.R., D.L. Hopkins, and N.G.W. Cook, 1985, Effects of an interface in 
partial contact on attenuation of acoustic waves: (in press).

Schoenberg, M., 1980, Elastic wave behavior across linear slip interfaces: v. 68, no. 5 , pp. 1516-1521.

Schoenberg, M., 1983, Refiection of elastic waves from neriodically stratified media with interfacial slip: v. 31, pp. 265-292.

Stewart, R.R., R.M. Turpening, and M.N. Toksoz, 1981, Study of a subsurface fracture zone by vertical seismic profiling: v. 8, pp. 1132-1135. 


\section{Figure Captions}

Figure 1. A comparison of the SH component from the SH source versus the SV component from the SV source. Notice the some 100 millisecond difference in travel times through a fractured media. The data are from a VSP study at the Geysers geothermal field in northern California

Figure 2. FMGRAY model showing fracture pattern and ray paths.

Figure 3. The synthetic seismograms from the model in figure 2 using a $4 \mathrm{hz}$ wavelet.

Figure 4. The synthetic seismograms from the model in figure 2 using a $40 \mathrm{hz}$ wavelet.

Figure 5. Three component data from Hi-Vista that have been rotated. Channel 2 is the P-wave component , 3 the SV component, and 4 the SH component. The data are from a shear wave vibrator oriented such that the base plate motion is perpendicular to the inferred fracture direction.

Figure 6. Three component data from Hi-Vista that have been rolated. Channel 2 is the P-wave component , 3 the SV component, and 4 the SH component. The data are from a shear wave vibrator oriented such that the base plate motion is 45 degrees to the inferred fracture direction.

Figure 7. Three component data from Hi-Vista that have been rotated. Channel 2 is the P-wave component, 3 the SV component, and 4 the SH component. The data are from a shear wave vibrator oriented such that the base plate motion is parallel 
to the inferred fracture direction. 


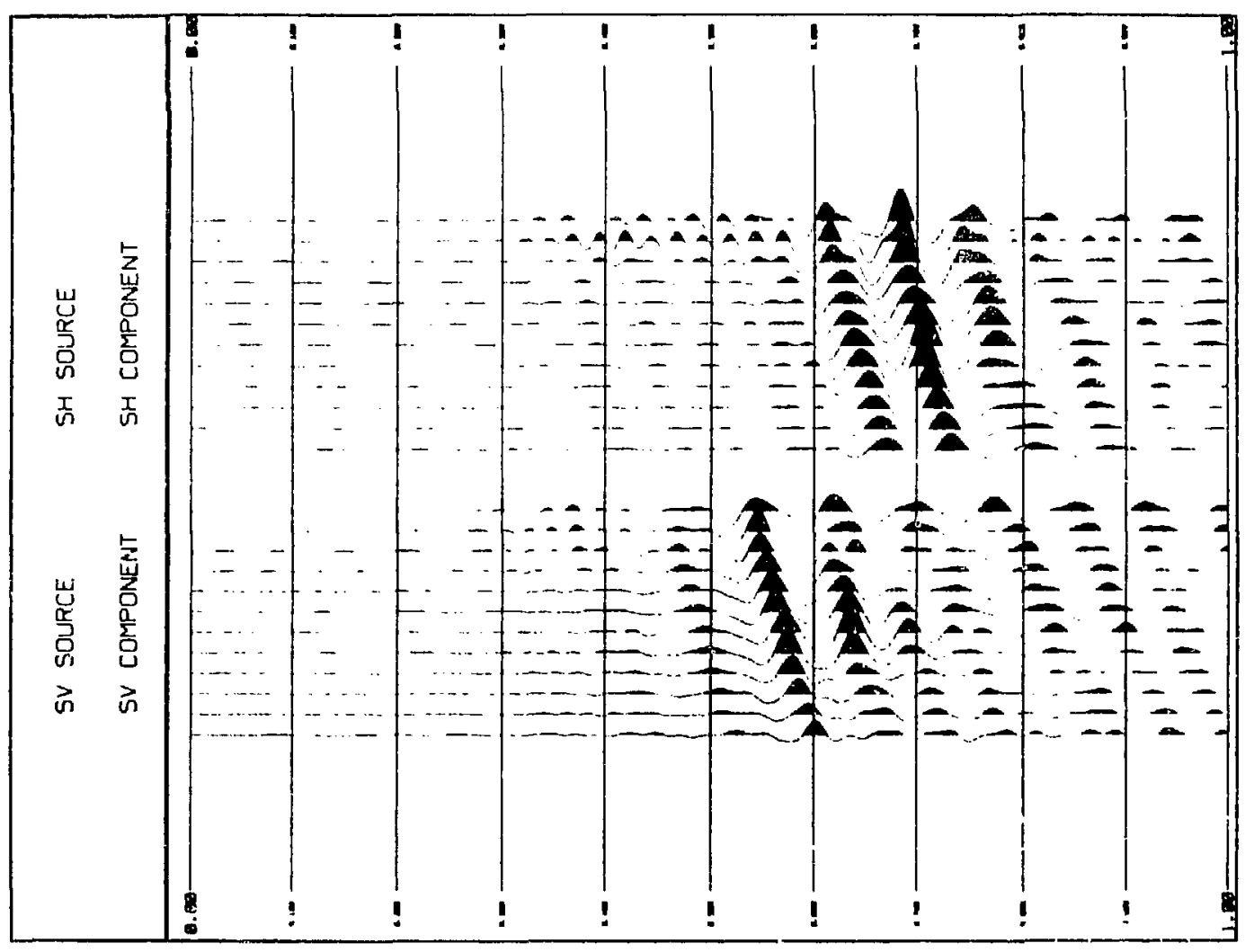

IBL $8511 \cdot 4830$

Figure 1. A comparison of the SH component from the SH source versus the SV component from the SV source. Notice the some 100 millisecond difference in travel times through a fractured media. The data are from a VSP study at the Geysers geothermal field in northern California 


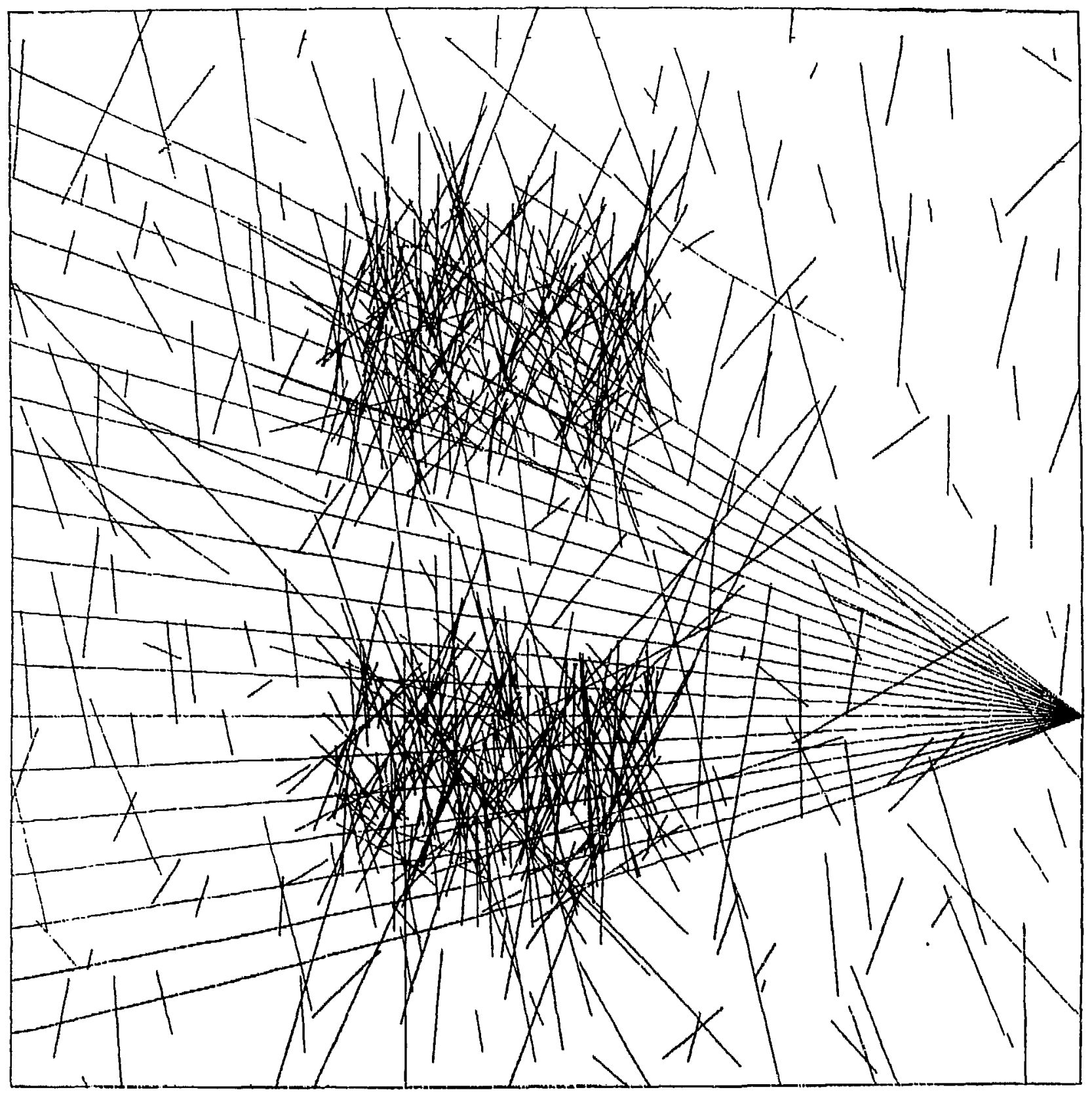

Figure 2. FMGRAY model showing fracture pattern and ray paths. 
Figure 3. The synthetic seismograms from the model in figure 2 using a $4 \mathrm{hz}$ wavelet.

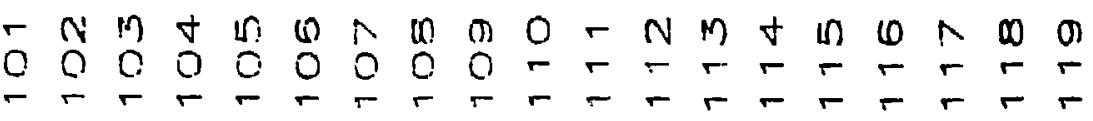

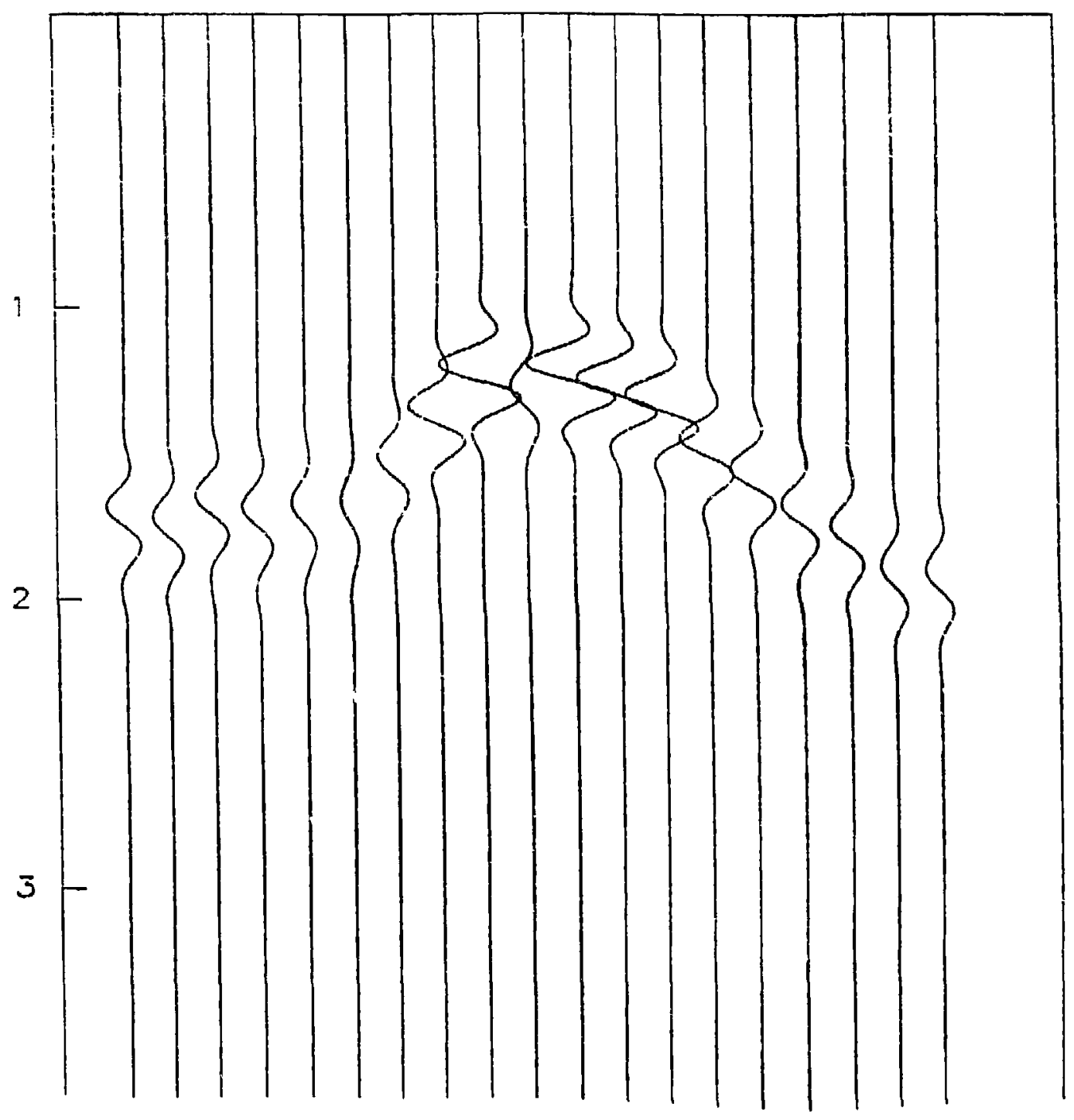


Figure 4. The synthetic seismograms from the model in figure 2 using a $40 \mathrm{hz}$ wavelet.

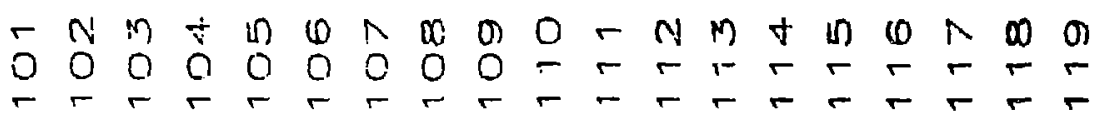

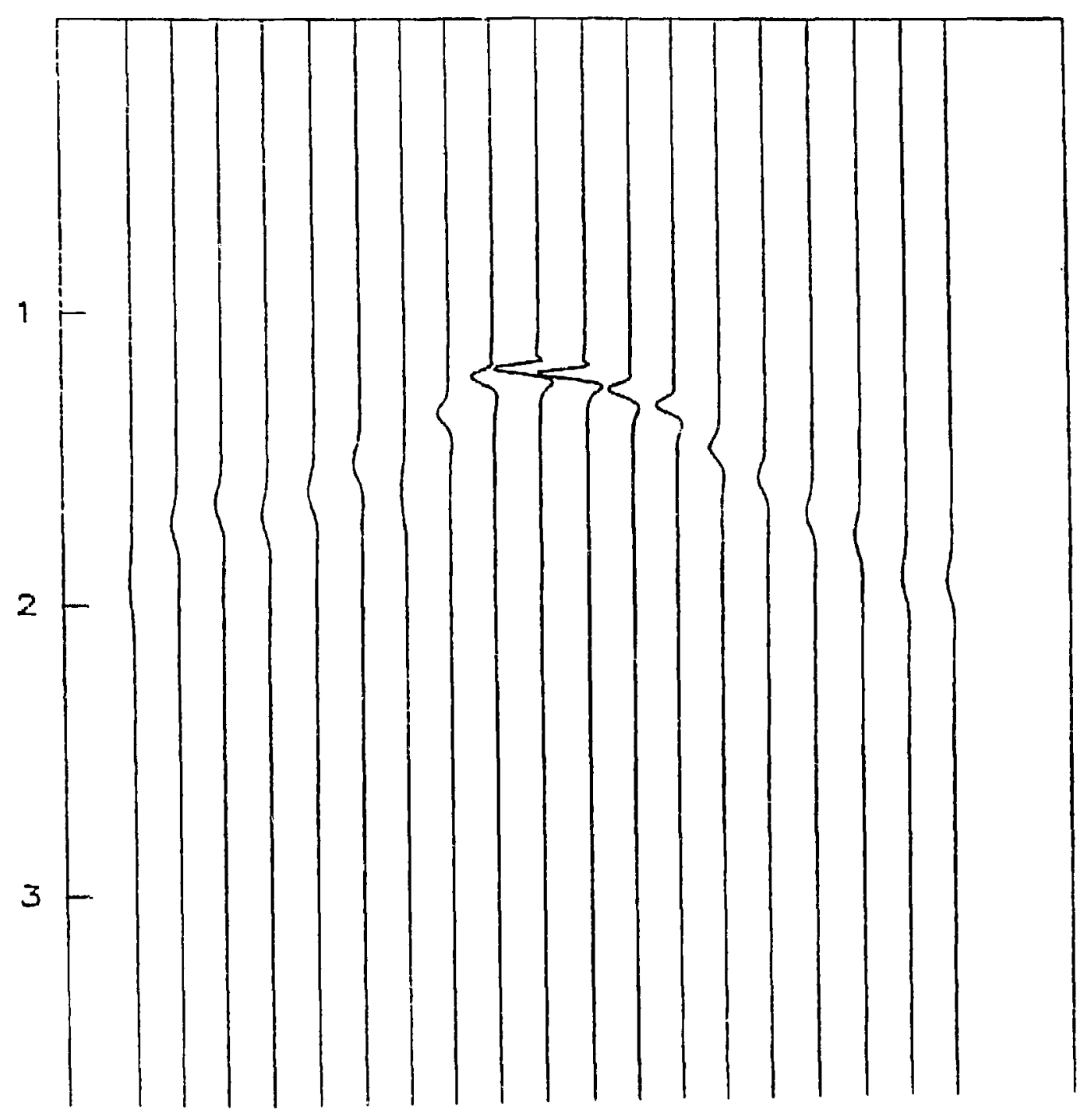




\section{HI VISTA DATA, SOUTH}

CHAN

几

$\omega$

$+$

CHAN

SHOr

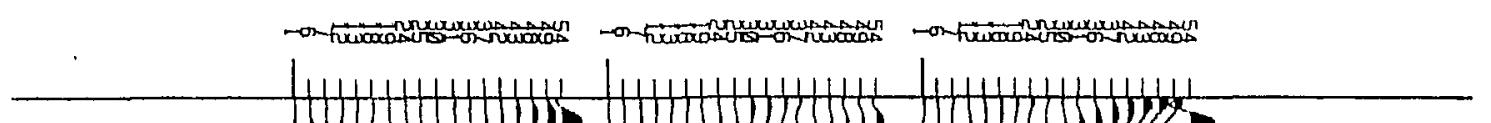

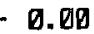

ต. 0 .

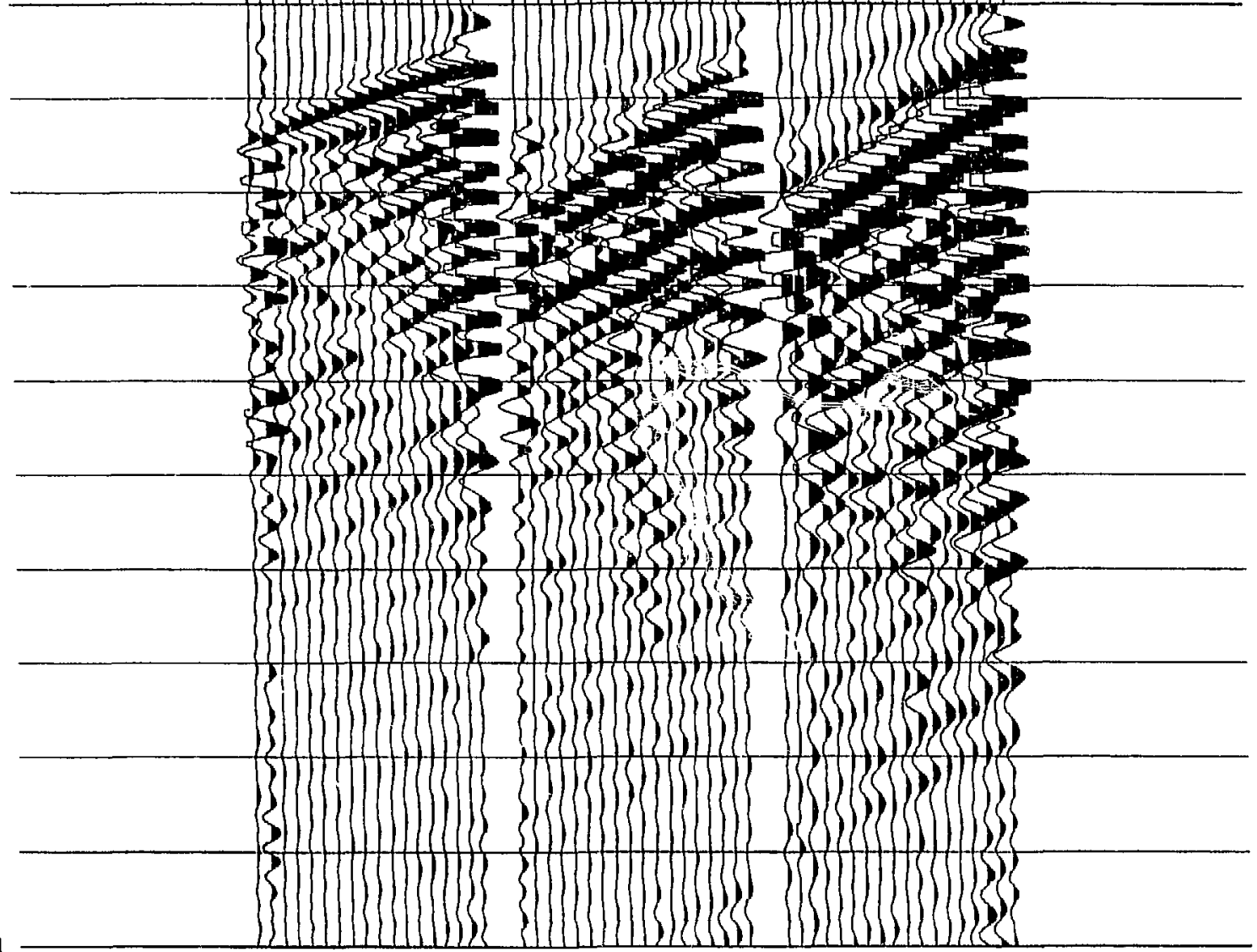

Figure 5. Three component data from Hi-Vista that have been rotated. Channel 2 is the P-wave component, 3 the SV component, and 4 the SH component. The data are from a shear wave vibrator oriented such that the base plate motion is perpendicular to the inferred fracture direction. 


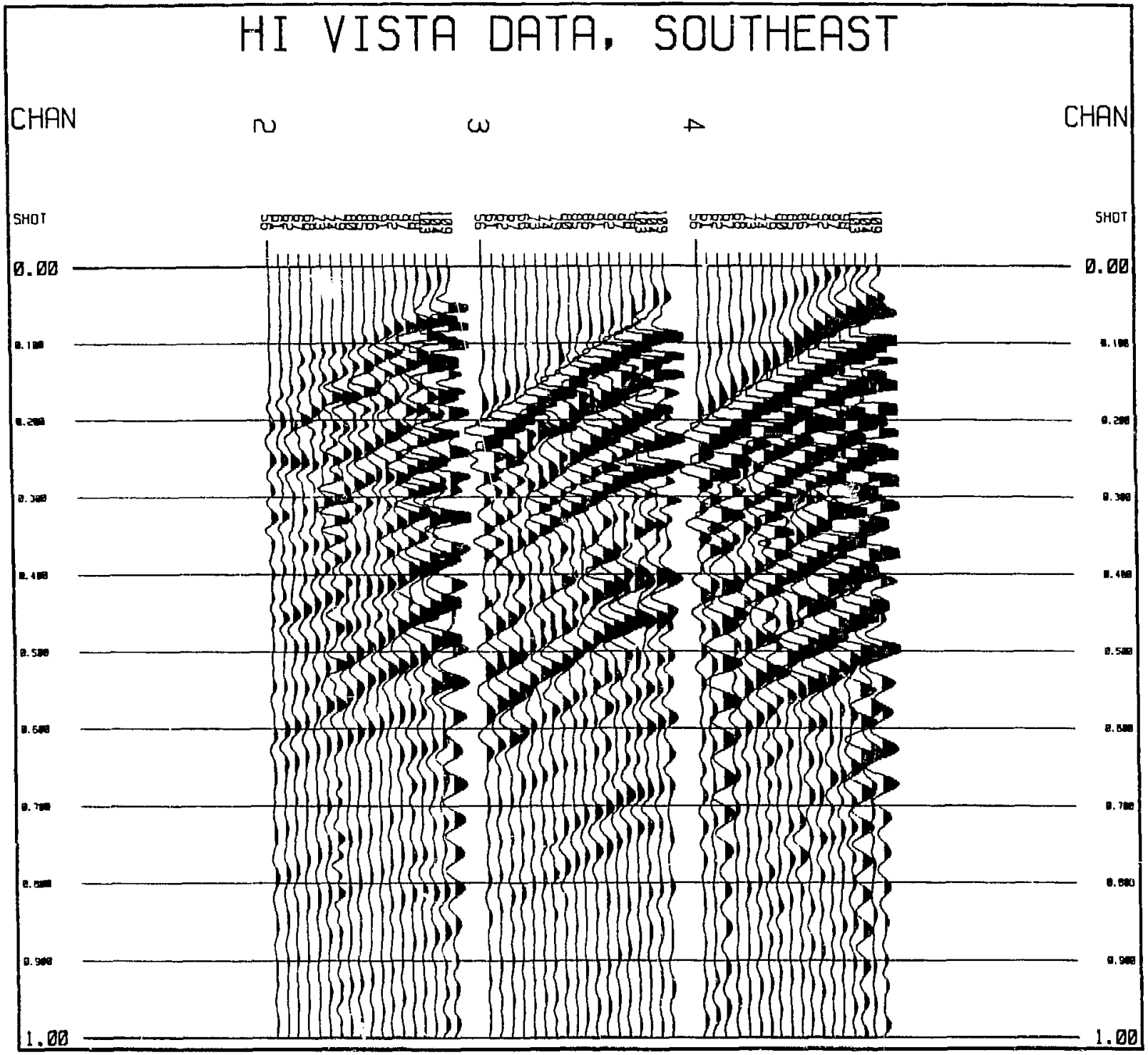

Figure 6. Three component data from Hi-Vista that have been rotated. Channel 2 is the P-wave component, 3 the SV component, and 4 the SH component. The data are from a shear wave vibrator oriented such that the base plate motion is 45 degrees to the inferred fracture direction. 


\section{HI VISTA DATA, EAST}

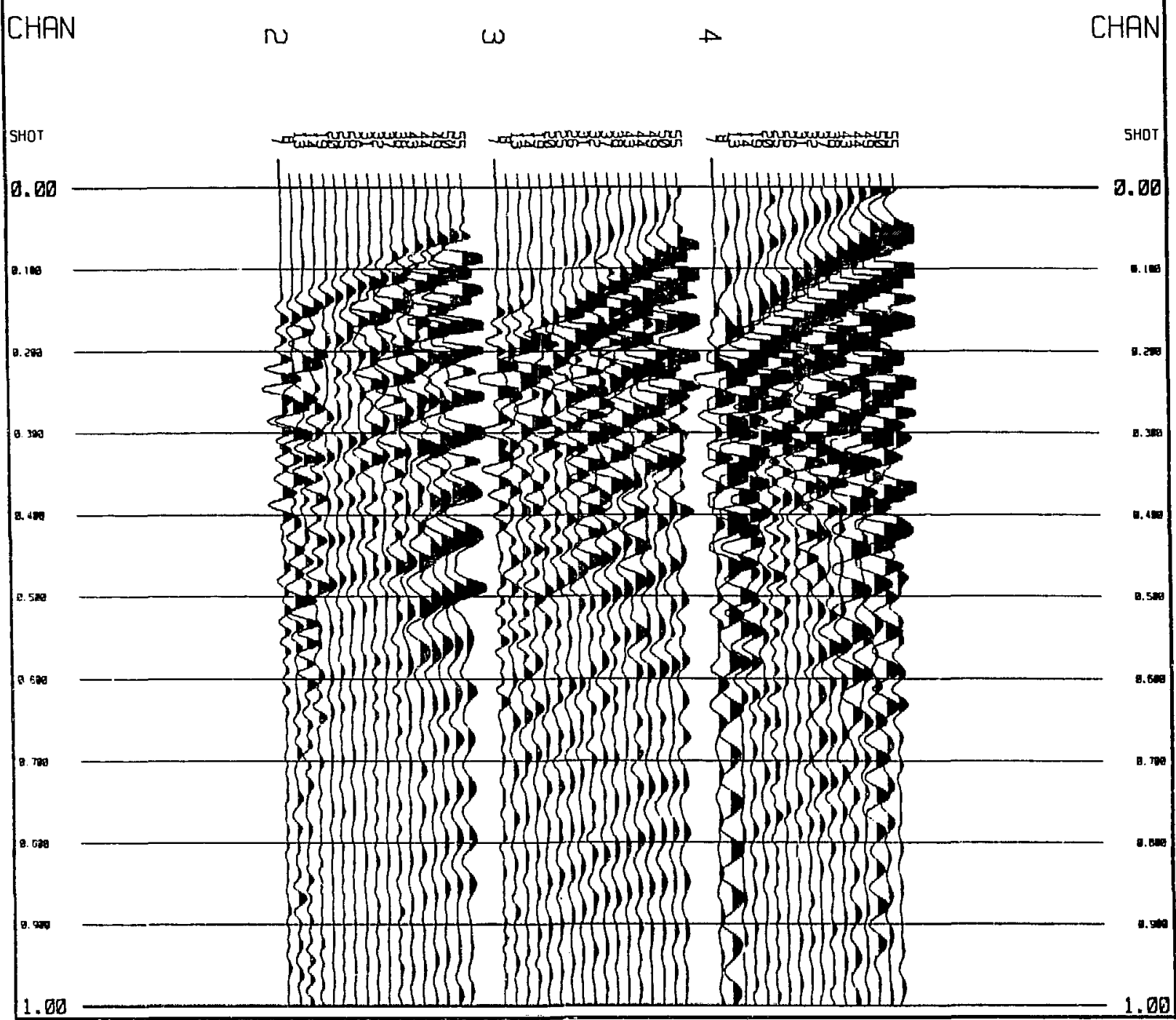

Figure 7. Three component data from Hi-Vista that have been rotated. Channel 2 is the P-wave component, 3 the SV component, and 4 the $\mathrm{SH}$ component. The data are from a shear wave vibrator oriented such that the base plate motion is parallel to the inferred fracture direction. 


\title{
Borehole Breakout Analysis
}

\author{
N. G. W. Cook and Z. Zheng
}

\section{Introduction}

Fracture of rock adjacent to the surfaces of underground excavations is of considerable interest in connection with the performance of mined geologic repositories for the disposal of nuclear wastes, the strength of deep excavations for defense, safety in underground mining, and the stability of deep boreholes for gas and oil production or scientific observation.

Boreholes are the most ubiquitous form of underground excavation. Under conditions where the magnitudes of the stresses in the rock are of the same order as the strength of the rock, it has been established that the walls of boreholes fracture, elongating the cross-section of the borehole in the direction of the minimum stress orthogonal to its axis (Gough and Bell, 1982; Hickman et al., 1985; Plumb and Hickman, 1985; Zoback et al., 1985).

Gough and Bell (1982) have analysed the process of fracture that produces wellbcre breakouts by applying a Mohr Coulomb failure criterion to the distribution of stresses given by the Kirsch solution for a circular hole in an elastic material. This solution shows maximum concentrations of compressive stress around the borehole at opposite ends of a diameter parallel to the minimum compressive stress in the rock. They propose that breakouts are produced by two pairs of shear fractures at opposite ends of the above diameter. These shear fractures are assumed to be tangent to the original circular cross-section of the borehole and inclined to the direction of minimum stress by half the Coulomb angle of internal friction for the rock plus $\pi / 4$. They argue that these tangents define the pointed, "dog ear" shape of a typical breakout cross-section, and that their 
point of intersection along the diameter parallel to the minimum principal stress defines the maximum depth of the breakout.

Zoback et al. (1985) have also analysed the process of fracture that results in breakouts, using the Kirsch solution and a Mohr Coulomb failure criterion. However, they used the stress distribution and the failure criterion to define regions adjacent to a circular borehole within which the elastic stresses exceed the strength of the rock, and then define these regions to be the shape of the initial breakout cross-section. This method leads to predictions of broad, flat-bottomed breakout cross-sections. They then show that the shape of the breakout, in terms of its depth and the angle subtended by it at the center of the borehole, can be used to estimate the ratio of the stresses in the rock orthogonal to the axis of the borehole. These authors also consider briefly the question of breakout growth. They used a numerical model based on boundary elements to evaluate the distribution of stresses in an elastic material around a hole with the crosssection given by the initial breakout analysis. The stresses in the rock adjacent to the initial, and succseding, predicted cross-sections become increasingly severe to that breakouts should propagate indefinitely. They suggest that inelastic processes must provide the stability of breakout cross-sections observed in the field.

\section{Fracture Process}

Many rocks are extremely brittle in uniaxial compression. Wawersick and Fairhurst (1970) and Wawersick and Brace (1971) measured complete stress strain curves on a variety of rocks in uniaxial and triaxial compression. In uniaxial compression, deformation is essentially elastic up to near the maximum ordinate of the stress strain curve, or the strength of the rock. Beyond this point many rocks are intrinsically unstable (Class II, Wawersick c. 1 Fairhurst, 1970), in that the stored energy in the rock at the maximum stress exceeds the energy needed to fractire the rock, while in other rocks the residual strength diminishes very rapidly with small increases in strain (Class 
I). Wawersick and Fairhurst (1970) observe that in uniaxial compression "axial fracturing generally precedes faulting and characterizes failure initiation at 50-95 percent of the compressive strength," and that the strength is governed "by local fracturing predominantly parallel to the direction of loading." Likewise, Wawersick and Brace (1971) note that "a large number of fractures are formed predominantly parallel to the direction of loading" and "Large cracks approximately parallel to the free sides of the sample Interestingly, both Gough and Bell (1982) and Hickman et al. (1985), amont others, use the term "spalling" in connection with the formation of wellbore breakouts.

Fracture by axial splitting, or spalling, parallel to the direction of maximum compressive stress has been analysed by Horii and Nemat-Nasser (1985) and Kemeny and Cook (1986), among others, using linear elastic fracture mechanics. These authors have derived complete stress strain curves for elastic materials in which fracture occurs by the growth of extensile cracks parallel to the direction of maximum principal compressive stress from inclined sliding, source cracks. These curves exhibit initial strain hardening as the extensile cracks begin to grow, followed by Class II unstable, brittle fracture as co-linear cracks interact. These complete stress strain curves are remarkably similar to the Class II curves measured by Wawersick and Fairhurst (1970) and Wawersick and Brace (1971) (Figure 1b). The analysis predicts also that extensile crack growth is inhibited very strongly by confining stress, because of the negative stress intensity factor at the tip to the extension crack produced by this stress.

Figure $1 C$ shows the incremental strain associated with the growth of extensile cracks in biaxial compression according to Kemeny and Cook (1986). Stresses and strains have been normalized with respect to the initial length of the sliding, source crack, $2 l$, and the pitch between co-linear source cracks, $2 b$, as well as the critical stress intersity factor $\mathrm{K}_{\mathrm{IC}}$, for Mode I crack propagation (Figure 1a).

In this paper we use this fracture mechanics model for extensile splitting in uniaxial conpression together with a numerical boundary element (Crouch and Starfield, 1983) 
analysis of the distribution of stresses in an elastic material to analyse the formation and stability of wellbore breakouts.

\section{Breakout Model}

When a borehole is drilled, the tangential stress in the rock around the hole is increased near the ends of a diameter parallel to the minimum stress in the rock mass, and the radial stress is diminished to zero in the case of an empty hole or, otherwise, to the fluid pressure in the hole. In the absence of drilling mud or casing, the rock in this region adjacent to the borehole is subjected essentially to a biaxial, compressive effective stress. If this stress is sufficiently great in relation to the strength of the rock given by the maximum ordinate of the stress strain curve in Figure $1 \mathrm{C}$, the rock should fail by extensile splitting subparallel to the wall of the borehole. Note that such splitting must occur quite close to the free surface of the borehole, because the radial stress increases rapidly with radial distance into the rock away from the circumference of the borehole and it has been shown that such confinement inhibits axial splitting very strongly. Also, the extensile splitting becomes intrinsically unstable just beyond the peak of this clirve because of its Class II character. As a result of the formation of the first spali by extensile splitting, a new free surface is created and the shape of the cross-section of the borehole is changed. In general, the concentration of the tangential stress in the rock adjacent to the elongated portion of the new cross-section will be even greater than it was around the initially circular cross-section, and the new free surface diminishes the radial stress in the rock adjacent to it so that another extensile fracture should form subparallel to the circumference of the elongated portion of the new cross-section. Wellbore breakout is assumed to be the result of a series of cpisodes of spalling by extensile splitting, such as described above.

To model this sequence of changes in cross-section by successive spalling, a method for systematically changing the cross-section of the borehole as a result of each episode is 
required. This has been done by dividing the rock around an initially circular borehole into a large number of small blocks defined by angular increments of $1.5^{\circ}$ and radial increments of 0.067 of a borehole radius, Figure 2. Initially, the boundary element analysis is used to determine the tangential stress around a circular borehole for values of the rock mass stresses of in terest. An annular arc of rock extending out 0.067 of the borehole radius which includes that portion of the borehole circumference within which the tangential stress exceeds the strength is then removed. The new distribution of stress in the rock around the elongated cross-section resulting from this change is now calculated using the boundary element analysis, and another layer of rock is removed from anywhere on the circumference of the now noncircular cross-section, wherever the tangential stress exceeds the compressive strength. The final breakout shape of the borehole is allowed to evolve by a succession of such episodes until the tangential stress is everywhere less than the strength of the rock.

Once the final breakout cross-section has been found the stability of this crosssection is verified in two ways. First, the tangential stress around the circumference of the breakout must be everywhere less than the compressive, or tensile, strength of the rock. Second, in the rock outside the borehole, failure by extensile splitting should not occur because this is inhibited so strongly by confining stress, but shear failure may occur. Therefore, the distribution of the stresses everywhere in the rock outside the breakout cross-section is compared with a Mohr Coulomb criterion for the triaxial strength of the rock. If the distribution of elastic stresses is everywhere less than that needed to produce failure either by extensile splitting or Mohr Coulomb shear, the breakout cross-section should indeed be stable. The rock will then be in an elastic condition everywhere so that the stress analysis using boundary elements in an elastic material is valid.

The episodes by which an initially circular borehole develops a stable breakout cross-section, as determined by the numerical simulation, is illustrated by the sequence 
of cross-sections shown in Figure 2. Clearly, the key to this process is the nature of the stress redistribution that results from the changing cross-sectional shape. For a vertical borehole where the horizontal stresses orthogonal to the hole axes are $30.3 \mathrm{MPa}$ and 15.17 $\mathrm{MPa}$, respectively, and the compressive strength is $69 \mathrm{MPa}$, the changes in the principal stresses at critical positions ahead of the circumference of the borehole and at a distance of 0.133 of a borehole radius, or just over 1 element into the rock, are illustrated in Figure 3, where the abscissa values correspond to successive cycles of spalling identified by the cross-sections in Figure 2. In general, the magnitudes of both principal stresses near the boundary of the breakout cross-section diminish to very small values as a result of the change in cross-sectional shape. Stresses near the tip of the elongated cross-sections differ from this trend. Here two effects occur, the difference between the principal stresses diminishes while the minimum compressive stress increases in value. Both these effects contribute to a stable state of stress. Detailed contours of the sums and differences between the principal stresses in the region near the tip are shown in Figure 4. It can be seen that the mean stresses are sufficiently high that the rock in this region is far from failure in terms of a Mohr Coulomb criterion.

\section{Results}

Using the methodology described above, stable wellbore breakout shapes have been determined for a range of ratios between the principal stresses in the rock mass orthogonal to the axis of a borehole and range of the magnitudes of these stresses relative to the strength of the rock, as is illustrated in Figure 5. The region on the top left of this figure, bounded by the almost circular arc, represents conditions where the tangential stress around a circular borehole is not sufficient to result in spalling arid produce breakouts. To the right of this are shown stable breakout shapes corresponding to a variety of stress conditions. These results were determined by applying the stresses first to the rock mass and then excavating the borehole. To some axtent this represents what 
occurs when a borehole is drilled, although the full stress concentrations around the hole must actually develop progressively as the hole is drilled beyond the plane where the cross-section is being considered.

In laboratory tests of wellbore breakouts it is much easier to increase the stresses in a specimen of rock in which a pre-drilled borehole exists (Haimson and Herrick, 1985). We have used a similar methodology to that described above to simulate wellbore breakouts under these conditions of progressively increasing stress. The stresses in the rock are increased in small, regular steps from critical values necessary to initiate fracture at the ends of a diameter parallel to the direction of the minimum principal stress in the rock to the desired final values. After each stress increase, the tangential stress around the circumference of the breakout cross-section is compared with the strength of the rock. Wherever the tangential stress exceeds this strength, a thin layer of rock is removed to change the cross-section. This sequence is repeated until the desired values of the rock mass stresses have been reached. The stability of the final breakout crosssection is established by showing that the tangential stresses around the entire circumference are less than the strength of the rock and that the elastic stresses everywhere in the rock outside the breakout are less than those necessary to cause shear failure according to a Mohr Coulomb criterion.

Stable wellbore breakout cross-sections for these conditions of progressively increasing stress on the rock mass are shown in Figure 6 for some of the same ratios between the principal stresses and ratios of the difference between those stresses and the strength of the rock as used in Figure 5.

The difference between stable breakout cross-sections for the conditions of a borehole instantly made in a rock mass subjected to pre-existing stresses (Figure 5) and cross-sections for a borehole in a rock mass where the stresses are progressively increased to their final values (Figure 6 ) is remarkable. The amount of breakout ineeded to develop a stable cross-section in the former case is much larger than in the latter case. 
However, the differences between the principal stresses a short distance in to the rock from the breakout for the case of steadily increasing stress, although less than those needed to cause failure, are, nevertheless, greater than for the larger breakouts associated with drilling into a pre-existing state of stress. The real case of drilling into rock with a pre-existing stress probably lies somewhere between the two cases.

Laboratory tests in which the stresses in a rock specimen containing a pre-existing hole are progressively increased probably result in breakout cross-sections significantly smaller than those that would form as a result of drilling into pre-stressed rock. Indeed, Mastin (1984) and Haimson and Herrick (1985), who conducted such tests, observed small breakouts, and found that the calculated tangential stress needed to produce them was almost twice the uniaxial compressive strength of the rock. The latter observation may be yet another manifestation of the well recognized, but not well understood, phenomenon of size effects; the compressive strength of small samples of rock is much greater than that of large samples (Hoek and Brown, 1983).

Breakout cross-sections predicted by the methodology described above have a very pointed shape in the direction of the minimum principal stress orthogonal to the borehole axis. The shapes in Figure 6 resemble those shown by Haimson and Herrick (1985) and Mastin (1984) for laboratory tests. Indeed, one of the detailed cross-sections given by Mastin, reproduced as Figure 7, shows successive spalling subparallel to the circumference of the cross-section. Zoback et al. (1985) point out that breakouts may be much wider and shallower than those predicted by Gough and Bell (1982) from their shear failure model. Nevertheless, careful study of the cross-sections measured by Zoback et al. (1985) at Monticello, South Carolina, Auburn, New York and the Nevada Test Site show that nine out of thirteen examples exhibit distinct points, although the breakouts are quite shallow. The breakout angle given by their theory is very similar to that predicted by the above model for many stress conditions, because the tangential stresses given by the Kirsch solution correspond to the first cycle of breakout spalling 
used in this model.

Wellbore breakouts have been observed in many of the boreholes in the Hanford B.alts in Washington (Kim et al., 1986). Some of these have been measured using a seismic televiewer or a downhole television camera. A photograph from the latter is shown in Figure 8. Comparing the shape of this breakout with those in Figure 5, it can be seen that the cross-section of this breakout is similar to that corresponding to a ratio between the horizontal stresses of about 2 and a ratio of the difference between these stresses and the uniaxial compressive strengt' of about 0.2 . The current best estimates of the horizontal stresses in this region at the depth of this breakout are $60.6 \mathrm{Mpa}$ and $34.5 \mathrm{MPa}$ (Kim et al., 1986), which is only a little less than two. From the ratio of the stress differences to the compressive strength a value of about $130 \mathrm{Mpa}$ can be inferred for the in situ compressive strength. This is half the uniaxial compressive strength for this basalt determined from laboratory tests on small specimens taken from cores from this borehole at the same depth as the breakout (Kim, 1985). The disparity may reflect a real difference between strength determined in laboratory tests and in situ strength. However, it should be pointed out that the absolute values of the stresses are not the real item of interest. It is the magnitude of the stresses relative to the strength of the rock that is of real concern, and a correct analysis of breakout shapes shouid provide this information directly.

\section{Discussion}

A methodology has been developed to generate wellbore breakout cross-sections in elastic brittle rocks using numerical simulation. There are two particularly interesting results. First, it is shown that the breakout cross-section results in a redistribution of the stresses in an elastic rock so that these stresses became everywhere less than both the biaxial compressive strength and the shear strength given by a Mohr Coulomb criterion so the breakout cross-section must be stable. Second, it is shown that the 
resulting cross-section depends upon the stress path. Breakouts are much smaller if they result from a gradual increase in stress than if a hole is created instantly in rock already subjected to stress, yet both cross-sections resuit in stress distributions that clo not exceed the strength of the rock.

The predicted breakout cross-section should be exact for truely brittle rocks. Many softer rocks exhibit some degree of Class I, stable strain softening. It is likely that in such rock the residual strength of the rock at strains in excess of that corresponding to peak strength may prevent complete removal of the rock by spalling as assumed in the above model. Indeed, Plumb and Hickman (1985) have detected regions of enhanced electrical conductivity at the base of breakouts which could correspond to porosity caused by incomplete spalling and dilatation of the rock in this region. Perhaps rock such as this could be removed by scavenging with high pressure water jets to reveal the breakout cross-section predicted by the elastic brittle spalling model.

Finally, because $\mathrm{K}_{\mathrm{IC}}$ depends on the velocity of crack propagation (Atkinson, 1983) the ordinate values of the complete stress strain curves illustrated in Figure 1 actually depend on crack velocity. Therefore spalling may be a time dependent phenomenon, as has been observed in the laboratory by Mastin (1984) and in the field by Plumb and Hickman (1985). Spalling may develop over quite long periods of time in the field and begin at stresses significantly less than the short term uniaxial compressive strength determined in conventional laboratory tests. 


\section{References}

Atkinson, B.K., 1984, Subcritical crack growth in geological materials: J. Geophys. Res., v. 89 , no. B6, p. $4077-4114$.

Crouch, S.L. and Starfield, A.M., 1983, Boundary Element Methods in Solid Mechanics: London, George Allen \& Unwin.

Gough, D.I. and Bell, J.S., 1982, Stress orientations from borehole wall fractures with examples from Colorado, east Texas, and northern Canada: Canadian J. Earlh Sci., v. 19 , p. $1358-1370$.

Haimson, B.C. and Herrick, C.G., 1985, In situ stress evaluation from borehole breakouts experimental studies: 26th U.S. Symposium on Rock Mechanics, p. 1207-1218

Hickman, S.H., Healy, J.H., and Zoback, M.S., 1985, In situ stress, natural fracture distribution, and borehole elongation in the Auburn geothermal well, Auburn, New York: J. Geophys. Res., v. 90, no. B7, p. 5497-5512.

Hoek, E. and Brown, E.T., 1980, Underground Excavations in Rock: Institute of Mining and Metallurgy, London.

Horii, H. and Nemat-Nasser, S., 1985, Compression-induced growth in brittle solids: Axial splitting and shear failure: J. Geophys. Res., v. 90, no. E4, p. 3105-3125

Kemeny, J. and Cook, N.G.W., 1986, Crack models for the failure of rock in compression: To appear, Proceedings of the Second International Conference on Constitutive Laws for Engineering Materials.

Kim, K., 1985, Personal communication.

Kim, K., Dischler, S.A., Aggson, J.R., and Hardy, M.P., 1986, Characterization of the State of In Situ Stress by Hydraulic Fracturing for a Nuclear Waste Repository in Basalt: Rockwell International RHO-BW-SA-551 P.

Mastin, L., 1984, The Development of Borehole Breakouts in Sandstone: M.S. Thesis, Stanford University, Stanford.

Plumb, R.A. and Hickman, S.H., 1985, Stress-induced borehole elongation: A comparison between the four-arm dipmeter and the borehole televiewer in the Auburn geothermal well: J. Geophys. Res., v. 90, no. B7, p. 5513-5521.

Wawersik, W.R. and Brace, W.F., 1971, Post-failure behavior of a granite and diabase: Rock Mechanics, v. 3, p. 61-85.

Wawersik, W.R. and Fairhurst, C., 1970, A study of brittle rock fracture in laboratory compressicn experiments: Int. J. Rock Mech. and Min. Sci., v. 7, p. 561-575.

Zoback, M.D., Moos, D., and Mastin, L., 1985, Wellbore breakouts and in situ stress: $J$. Geophys. Res., v. 900, no. Bi, p. 5523-5530. 


\section{Figure Captiona}

Figure 1. a) Fracture mechanics model for extensile splitting.

b) Complete stress strain curves in biaxial compression (Wawersik and Brace, 1971).

c) Stress incremental strain curve for failure in biaxial compression by extensile splitting parallel to the direction of the compressive atress.

Figure 2. Cross-sections through one quadraat of a borehole showing the steps by which a stable breakout cross-section evolves.

Figure 3. Changes in the principal stresses at selected positions (a-f) around a borehole as the cross-section changes from circular to that of the stable breakout. (Numbers on the abscissa correspond to the 24 cycles shown in Figure 2.)

Figure 4. Contours of the sum and difference of the principal stresses in the region of greatest stress concentration around a breakout.

Figure 5. Simulated stable breakout cross-sections for different ratios of the horizontal stresses and of the difference between these stresses and the biaxial compressive strength; for the case where a borehole is created instantly in a rock with preexisting stresses.

Figure 6. Simulated stable breakout cross-sections for ranges of stress and strength similar to those of Figure 5 but for the case where the stresses are gradually increased around a preexisting borehole.

Figure 7. Microfractures around a breakout in a laboratory specimen of limestone (Mastin, 1983).

Figure 8. A television camera photograph of a breakout cross-section in the Hanford basalt (Kim, Pers. Comm. 1985). 


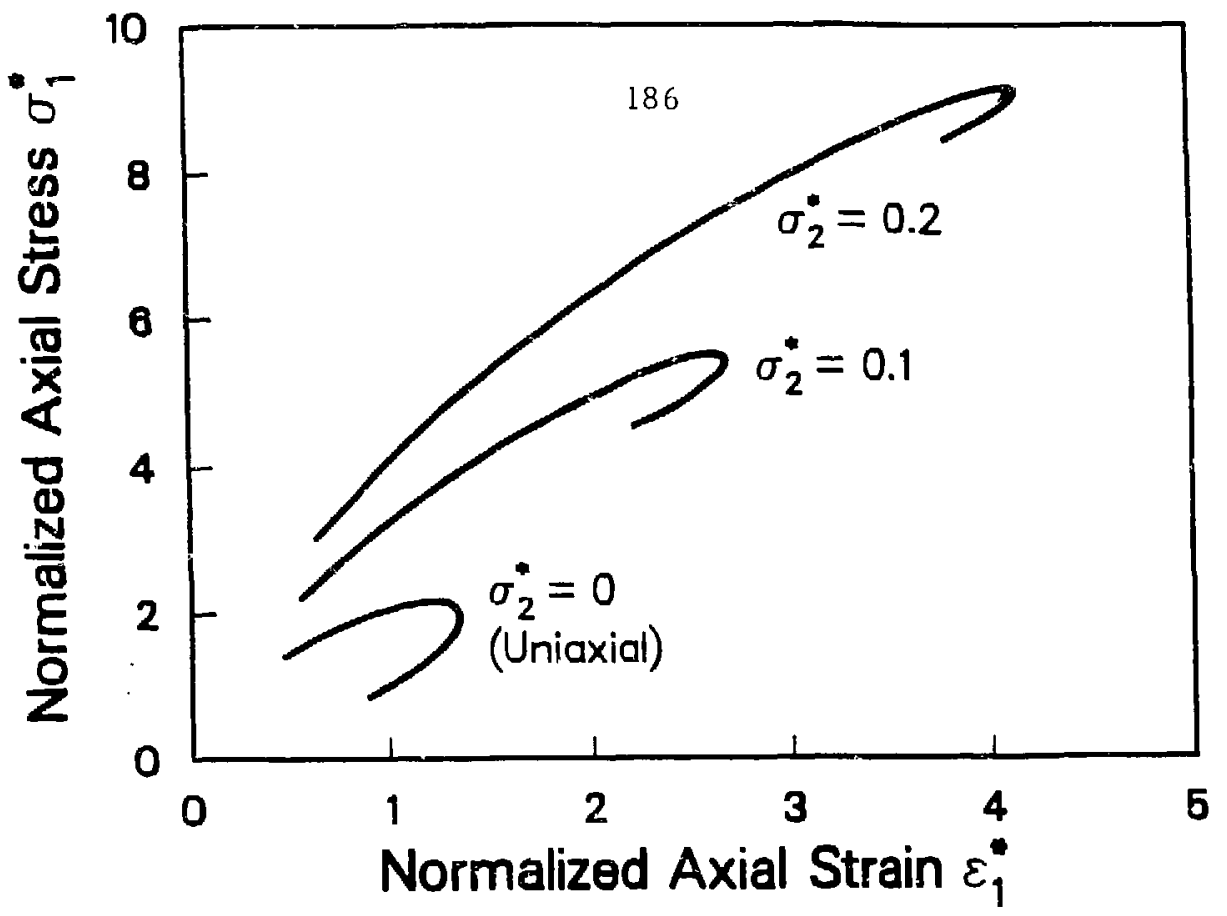

$$
\left(\sigma^{*}=\frac{\sigma l_{0}}{\mathrm{~K}_{\mathrm{IC}} \sqrt{\mathrm{b}}} \quad \varepsilon^{*}=\frac{\varepsilon w E \sqrt{b}}{\mathrm{~K}_{\mathrm{IC}} l}\right)
$$

a

$x \operatorname{CG~} 8610-12216$

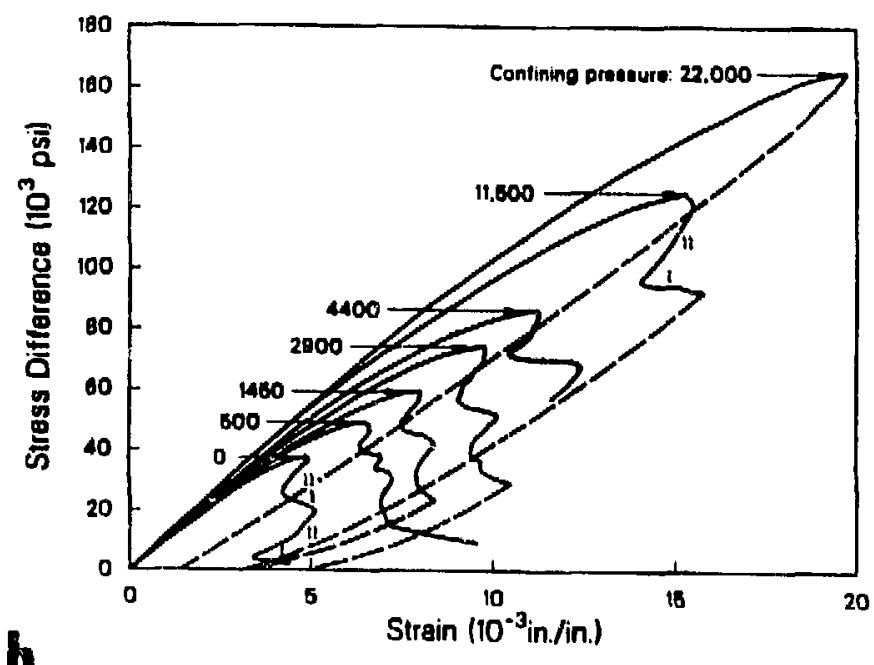

15e $1018-12213$

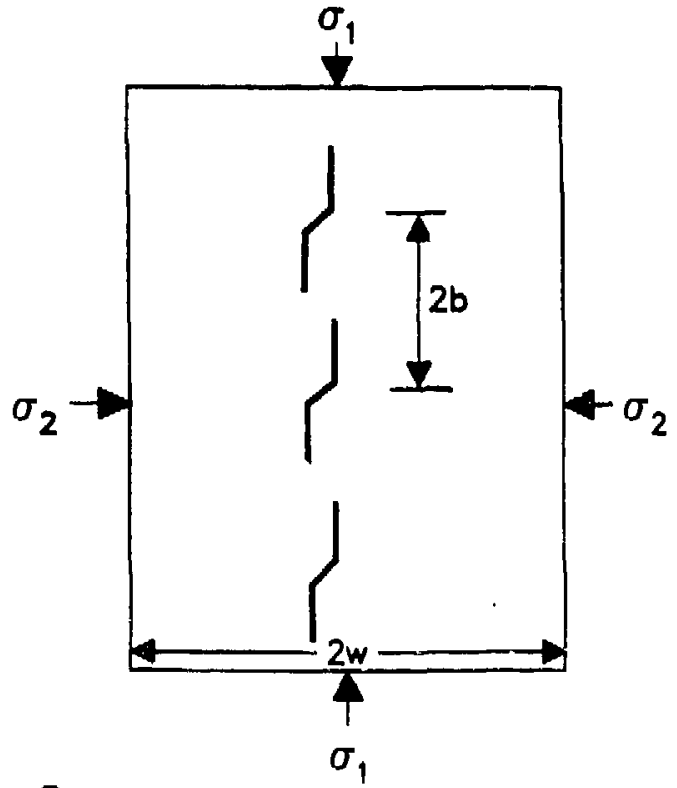

C

XCG $8610-12217$

Figure 1. a) Fracture mechanics model for extensile splitting.

b) Complete stress strain curves in biaxial compression (Wawersik and Brace, 1971).

c) Stress incremeutal strain curve for failure in biaxial compression by extensile splitting parallel to the direction of the compressive stress. 


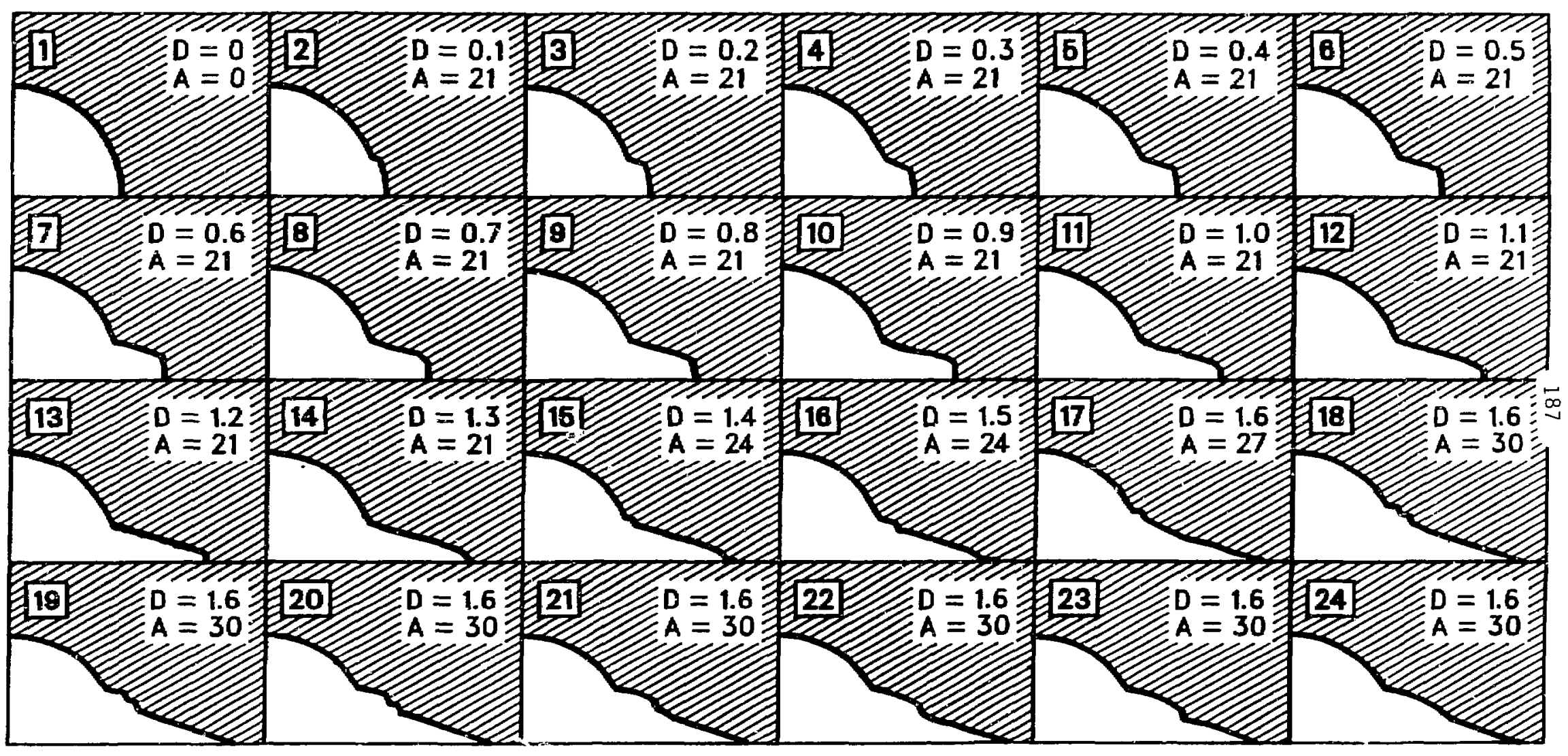

$D=$ Breakout Depth
$A=$ Breakout Angle
$1=$ Cycle No.

XCG 8610-12179

Figure 2. Cross-sections through one quadrant of a borehole showing the steps by which a stable breakout cross-section evolves. 

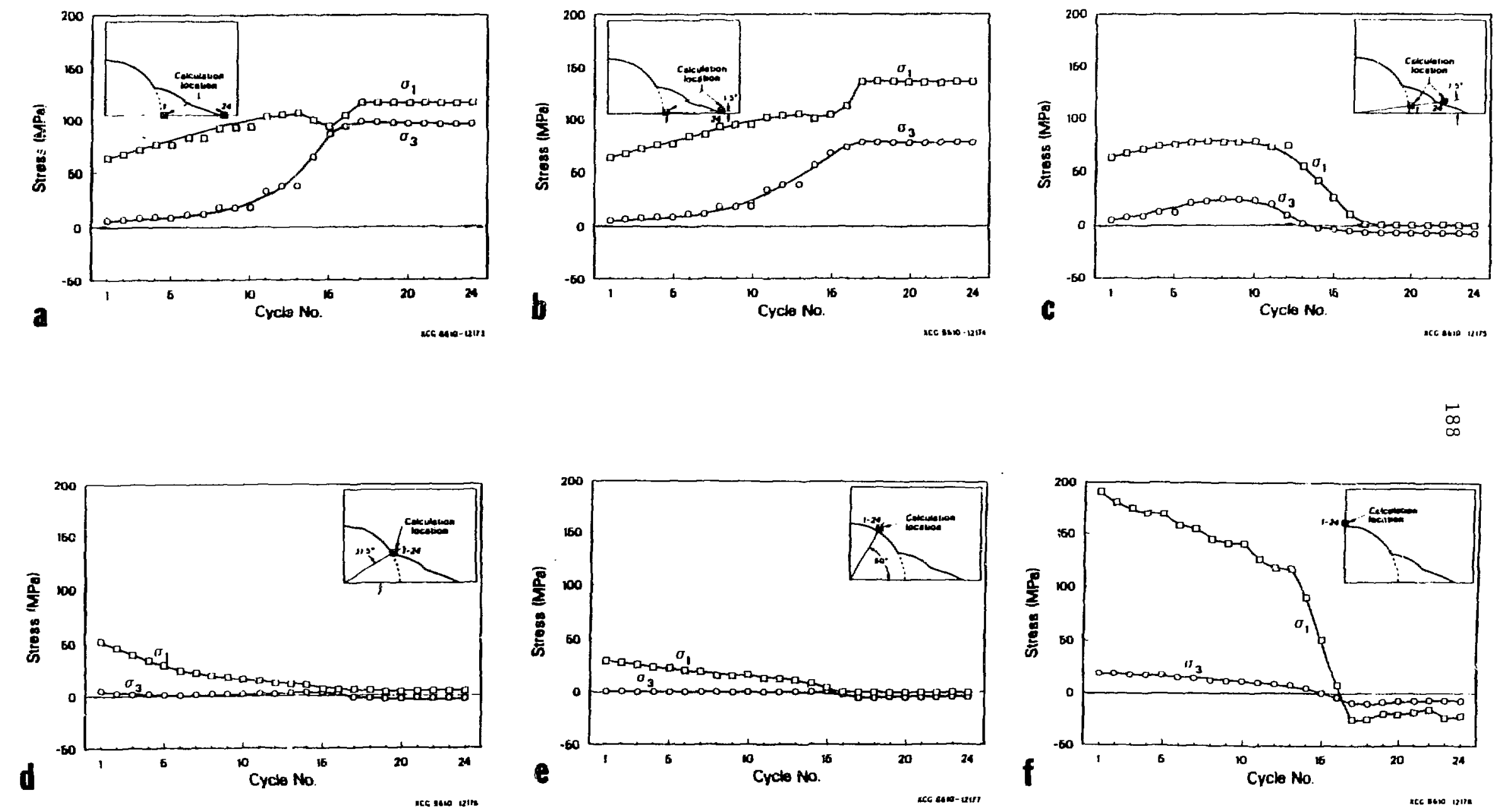

Figure 3. Changes in the principal stresses at selected positions (a-f) around a borehole as the cross-section changes from circular to that of the stable breakout. (Numbers on the abscissa correspond to the 24 cycles show in Figure 2.) 


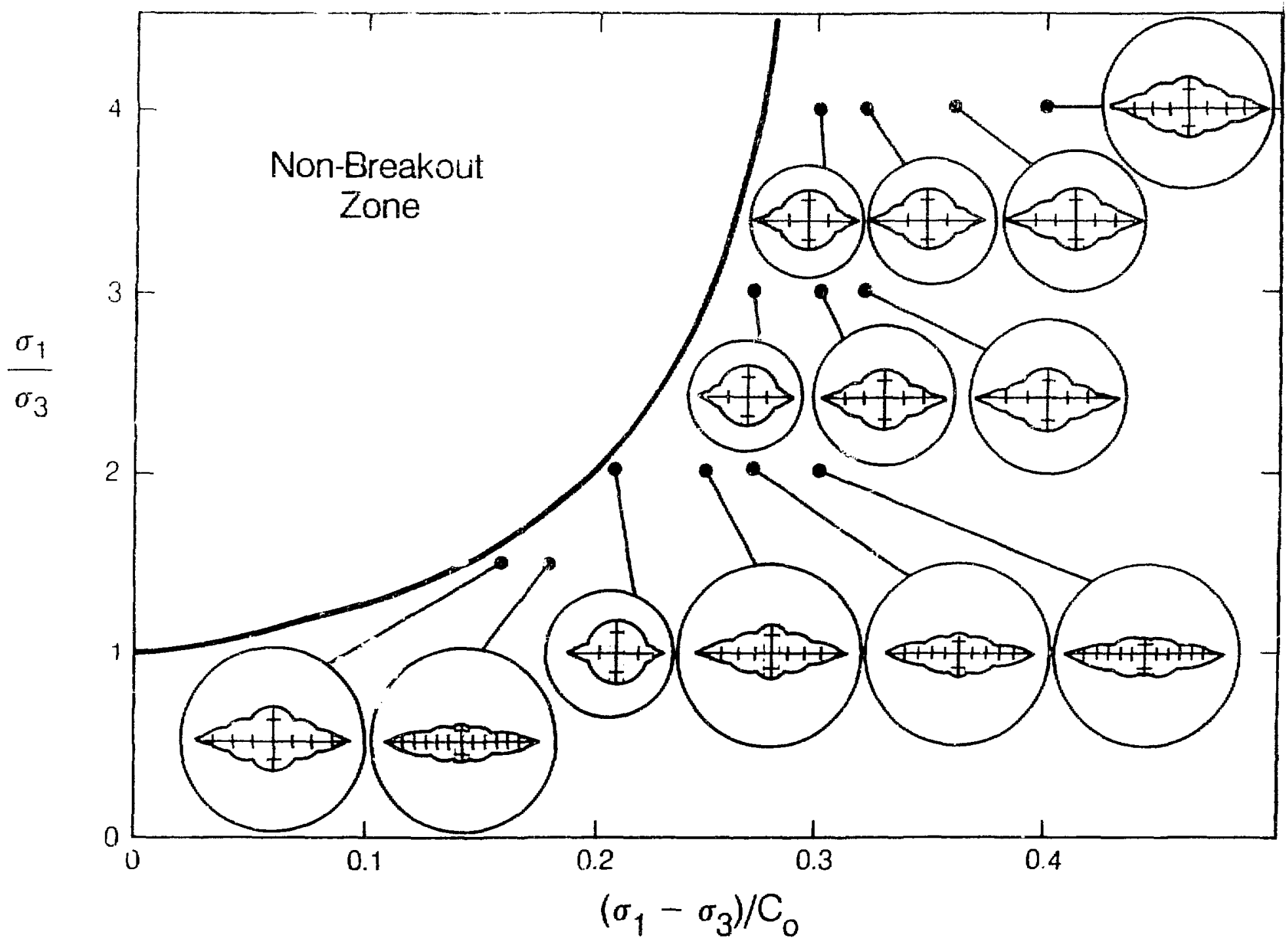

Figure 5. Simulated stable breakout cross-sections for different ratios of the horizontal stresses and of the difference between these stresses and the biaxial compressive strength; for the case where a borehole is created instantly in a rock with preexisting stresses. 


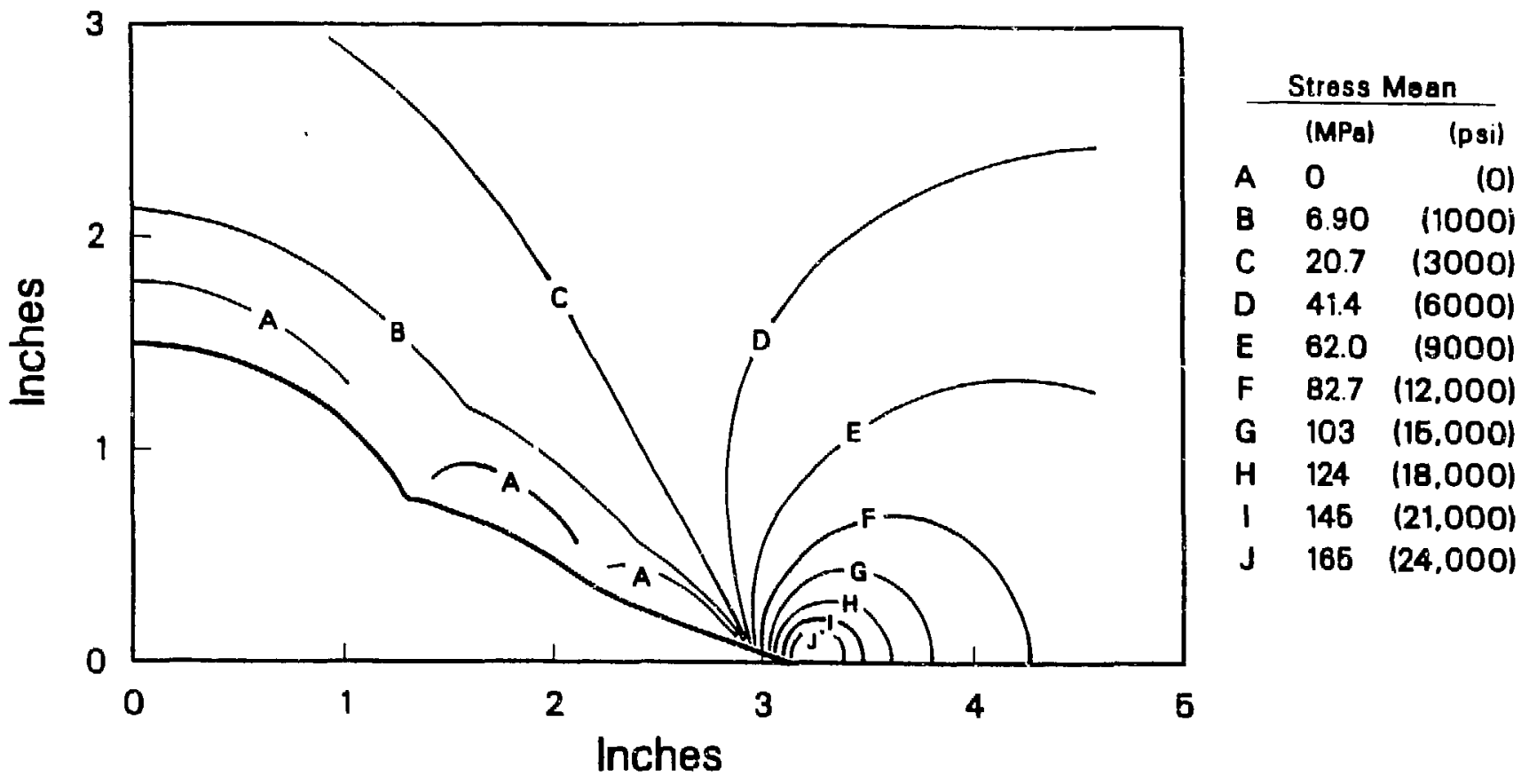

XCG $8610-12172$

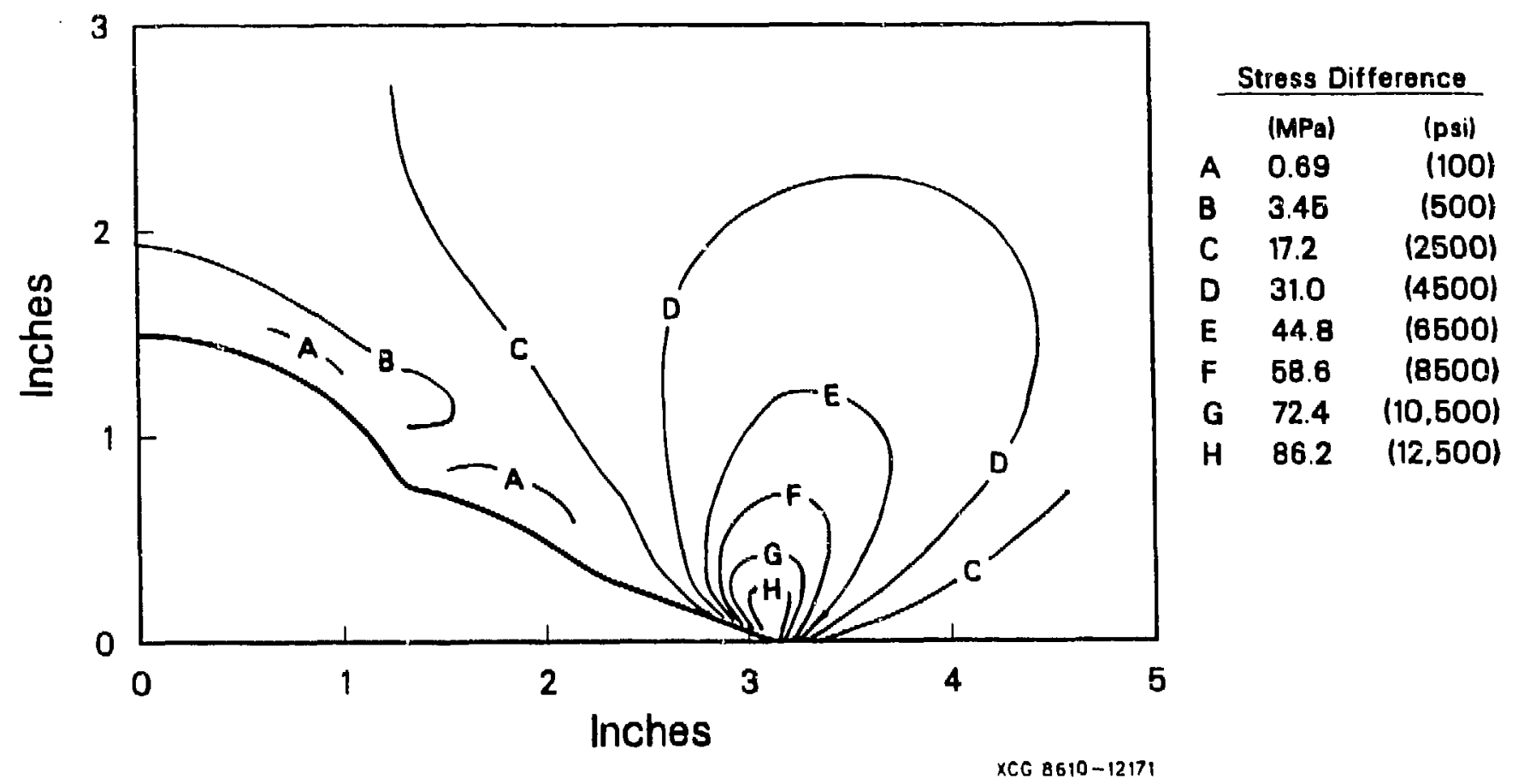

Figure 4. Contours of the sum and difference of the principal stresses in the region of greatest stress concentration around a breakout. 


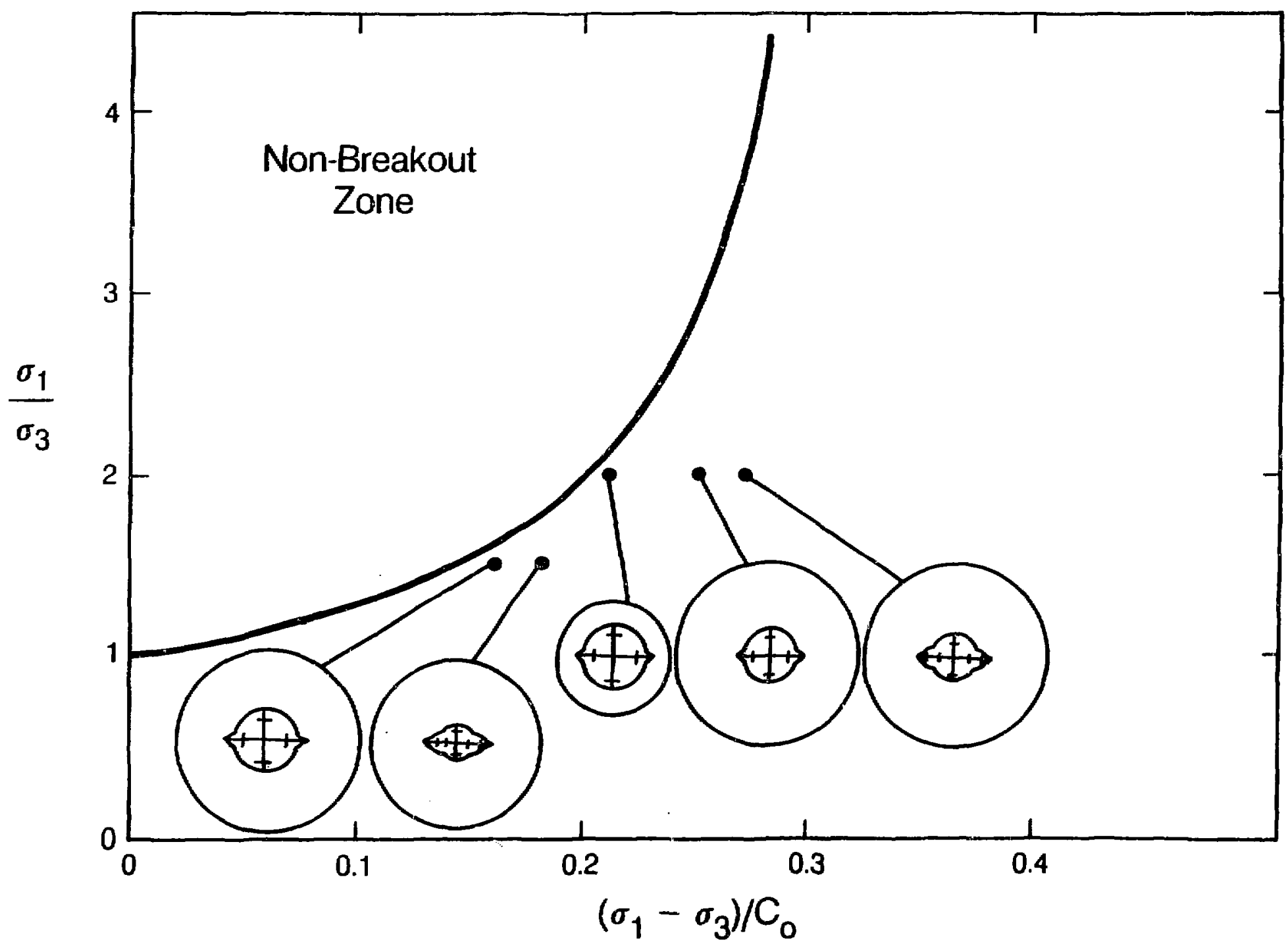

Figure 6. Simulated stable breakout cross-sections for ranges of stress and strength similar to those of Figure 5 but for the case where the stresses are gradually increased around a preexisting borehole. 


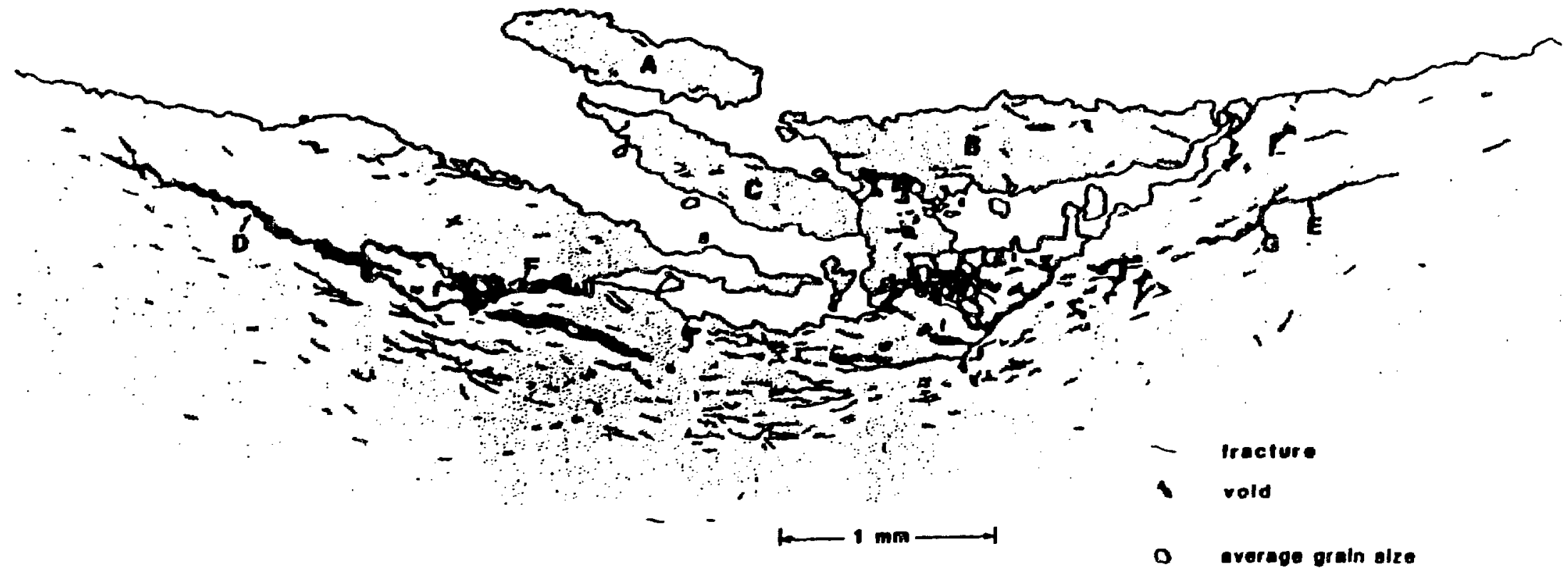

Figure 7. Microfractures around a breakout in a laboratory specimen of limestone (Mastin, 1983). 


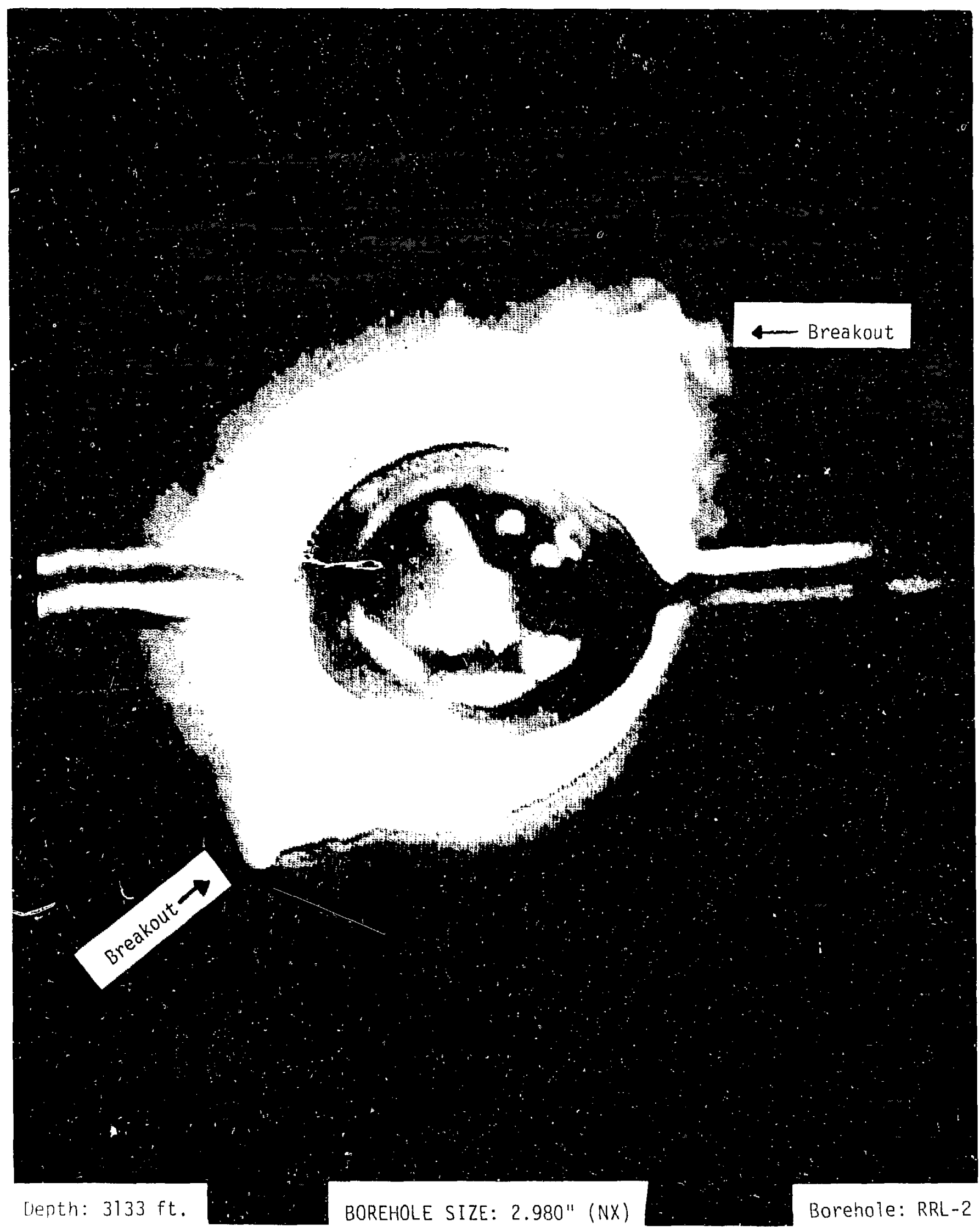

Figure 8. A television camera photograph of a breakout cross-section in the llanford basalt (Kim, Pers. Comm. 1985). 


\title{
Frictional Stability of Fractures and Faults in Rock
}

\author{
John M. Kemeny and Neville G. W. Cook
}

Fractures are persistent features in the crustal rocks of the Earth, and occur at length scales from microns to kilometers. Fractures in rocks include joints, faults, microcracks, and other planar features across which the displacement field is discontinuous, and fractures are known to significantly alter the mechanical, hydrological, thermal, chemical, and electrical properties of a rock mass. In this paper, we are concerned with the shear deformation and stability of fractures and faults, which have important implications for the stability of rock masses, earthquake faults, and the process of earthquake rupture. Laboratory experiments in the past twenty years have revealed much about the shear deformation of joints and faults. The shear stress required to cause a pre-existing surface to slip, referred to as the frictional strength, $\tau^{r}$, is found to be a strong function of the normal stress, $\sigma$, across the fault surface. The coefficient of friction, $\mu$, which relates $\tau^{f}$ to $\sigma$, depends on the material type and surface features, and is usually assumed to be linear, even though in some situations it is found to be a function of $\sigma$ (Jaeger and Cook, 1979). The shear stress-shear displacement behavior of a fault under shear is found to exhibit many important properties. Under a constant value of $\sigma$, the stress displacement behavior of a fault is found to exhibit initial linear behavior, followed by a small region where the shear stress increases nonlinearly with displacement, termed slip strengthening, and a large region where the shear stress degrades with ongoing slip, termed slip weakening (Palrner and Rice, 1973). Slip weakening is a requirement for the unstable release of energy along a fault, and stability is governed by the in teraction of the slope of the slip weakening curve with the unloading stiffness of the ground surrounding the fault (Stewart, 1979). Other important parameters with regards to slip weakening are the distance over which slip weakening occurs, referred to as $d_{r}$, and the stress drop during slip weakening (Okubo and Dieterich, 1984). Dilatation is also often 
associated with slip strengthening and slip weakening behavior (Goodman, 1976). Another important feature of faults in rock is their behavior when the rock mass is subjected to a constant strain rate. Tests on faults at a constant strain rate show regular oscillations between stable and unstable behavior, termed stick-slip (Cook, 1981), and also $\mu$ is found to be dependent on the velocity of sliding between the fault surfaces (Dieterich, 1981).

The micromechanical origin of these experimental results is presently an active area of research in theoretical rock mechanics. Many of the analytic models for friction and frictional stability of rock faults are based on the fact that when two rough surfaces are placed in contact, certain areas will interlock or become welded, and these areas are referred to as asperities, while other areas may slip relatively easy or noi even be in contact. When shear is applied to such a surface, slip will occur first in the areas of weak contact or voids, resulting in high stresses in the asperities to support the in-plane shear stresses. Models that use Herzian contact theory for asperity contact include the work of Archard (1957), Greenwood and Williamson (1966), and Swan (1983). Other models involve the brittle failure of wedge shaped asperities as given by Byerlee (1967), or the plastic yielding of asperities as analysed by Bowden and Tabor (1954). Patton (1966) and Ladanyi and Archambault (1970) consider the movement along, as well as the brittle failure of wedged shaped asperities, in order to account for the normal dilatation associated with shearing.

In all of the above models for friction, slip is assumed to occur simultaneously over the whole fault surface. Assuming elastic behavior of the asperities and surrounding ground, the shear stress will not be uniform across each asperity, nor will the average shear stress be of equal value in each of the different asperities. Thus, failure of the shear plane will occur in a complicated, progressive pattern with failure first occurring along the outside of each asperity where stress concentrations exist, and the asperities with the highest stresses breaking first. This progressive failure of slip surfaces has been observed experimentally by Mogi (1985) and Okubo and Dieterich (1984). Also, Mavco (1981), Tse and Rice (1986), and others have emphasized the importance of heterogeneity in frictional slip properties, with 
regards to the mechanics of earthquake rupture.

The asperity model discussed above assumes that slip occurs along a single, continuous surface, which is not the case in some patterns of faulting. For instance, strike slip faults can consist of a network of major faults, and each of these major faults can consist of groups of fractures with en echelon patterns (Qidong and Piezhen, 1984). Even though the geometry of some earthquake faults can be complex and discontinuous, recent seismic and geodetic inversion studies have revealed that earthquakes tend to occur by the progressive failure of patch-like regions along faults (Hartzell and Heaton, 1986; Segall and Harris, 1986), and this has led Kanamori (1986), Aki (1984), and others to propose asperity models for strike slip and subduction type earthquake faults, similar to the asperity models for joint surfaces in contact. The size of the asperities along earthquake faults that result in great earthquakes by their failure can be tremendous, for instance $200 \mathrm{~km}$ in Alaskan earthquakes (Kanamori, 1986), and over $500 \mathrm{~km}$ for earthquakes in Chile (Comte et al., 1986).

In this paper, we develop theory for the mechanical behavior of a slip plane containing asperitıes, and apply this theory to the behavior-of joints and raults in rock. The asperities are modelled by collinear or coplanar distributions of cracks in an elastic matrix, and where the asperity is the object between cracks. The stress distributions in the asperities, and the criteria for the progressive failure of the asperities, are calculated using the theory of linear elastic fracture mechanics (Rice, 1968). The important finding in this work is that nonlinear constitutive laws arise from the linear theory due to the progressive changes in the geometry of the asperities as the slip surface is sheared, and these nonlinear laws correlate with laboratory and field results. These nonlinear constitutive laws, in conjunction with the unloading behavior of the surrounding ground, give conditions for instability, and the amount of energy released during instabilities. We look initially at some very simple distributions of asperities, in order to understand the basic underlying principles. For instance, in two dimensions we consider the behavior of a fault plane with a row of equal spaced, equal sized asperities, and in three dimensions we consider the behavior of a fault plane with 
isolated elliptical asperities. In both these cases, slip weakening behavior is exhibited, giving regimes of both stable (aseismic) and unstable (seismic) behavior depending on the applied boundary conditions. Also, both of these cases result in a single instability. It turns out that for distributions of asperities with unequal sizes or spacings, multiple instabilities can occur, and the theory for these cases has proven extremely insightful. For instance, we consider a fault plane containing two-dimensional asperities with two sets of asperity spacings. Two instabilities occur in this model, and the relative magnitude of the energy releases give criteria for the occurrence of foreshocks and aftershocks. Also, if the asperity spacings are not symmetric, then we find that the asperities can fail from one side towards the other, rather than simultaneously from both sides. The energy released during such an event depends on the way in which the asperity fails and also on the spacings between asperities.

The above models are preliminary in the sense that the asperity configurations are to simple to correiate with actual laboratory or field data. The mechanics of these simple models, however, have lead to useful insights, and also results from these models have been derived in analytic form, giving the explicit dependence on the critical energy release rate, applied stresses and strains, and material constants. Based on these simple models, we have developed models containing more complicated and realistic distributions of asperities. An important phenomena that turns up in the more complicated models is the overall deforma'tion sequence or global behavior due to a number of instability events. It turns out that the global behavior can be stable even when the individual events are highly unstable, and this explains, for instance, why earthquake faults do not go unstable over their whole length at once. We consider several cases where multiple instabilities occur. First, we consider a fault plane consisting of a distribution of equal sized asperities, where the spacing between asperities is slightly larger in one location. The asperities near this location will break first, breaking out in a crack-like manner into the field of unbroken asperities. We also consider the behavior of fractal distributions of isolated three-dimensional asperities (Mandelbrot, 1984). In both of these cases, multiple instabilities occur due to the breaking of individual asperities 
that are highly unstable, whereas the global behavior can be stable under certain boundary conditions.

The developinent of nonlinear constitutive laws based on changing microstructure is supported by recent work in other fields. For instance, Hallbauer et al. (1971) conduct triaxial compressive tcsts on rocks, and by sawing open samples at various places along the stress strain curve, show that strain bardening is associated with the growth of microcracks, and strain softening is associated with the interaction and coalescence of microcracks into a fault plane. Also, tests on plexiglass with crack-like slots under triaxial compression show that nonlinear stress strain behavior is due to the growth and interaction of cracks in an otherwise elastic material, rather than inherent nonlinear bebavior of the material surrounding the cracks (Horii and Nemat-Nasser, 1985). Recently, it has been shown using theoretical models that by allowing cracks to propagate in an elastic matrix, and assuming only the principles of linear elastic fracture mechanics, nonlinear stress strain curves that compare well with the laboratory data can be derived (Costin, 1985; Kemeny and Cook, 1986a, 1987). All of these studies support the opinion that one of the most important parameters governing constitutive laws for rocks is the changing geometry of the microstructure. This also forms the basis of the field of damage mectanics for rocks and concrete, where the controlling variable is the changing microstructure (Krajcinovic, 1985).

\section{Rock Fracture Mechanics}

The basis for the analysis presented in this paper is linear elastic fracture mechanics (Rice, 1968). The crack tip stress intensity factor is a measure of the magnitudes of the stresses occurring near the tip of a crack in a linear elastic solid. It is common in crack mechanics to distinguish three types of stress intensity factors, $K_{1}, K_{I I}$, and $K_{111}$, which relate to the three types of cracking modes, mode I (opening mode), mode II (sliding mode), and mode III (tearing mode). The stresses near the crack tip then have the following form (Rudnicki, 1980): 


$$
\sigma_{\mathrm{ij}}=\mathrm{K}_{\mathrm{L}}(2 \pi \mathrm{r})^{-1 / 2} \mathrm{f}_{\mathrm{ij}}^{\mathrm{L}}(\theta)+\text { nonsingular terms }
$$

where $r$ is the radial distance from the crack tip, $\theta$ is the angle measured from the plane of the crack, $i$ and $j$ take on the values $1,2,3$, and $L$ takes on the values I, II, III for the three cracking modes. All the details of the loading and crack geometry are contained in the $\mathrm{K}$ terms. Equation (1) shows that the singular part of the stress field dut to the crack is embedded in the $r^{-1 / 2}$ term that contains $K$ as a multiplicative constant, and therefore the solution with only this first term is valid in some neighborhood close to the crack tip.

Much of the usefulness of stress intensity factors for rock fracture mechanics lies in their exact relation to the strain energy in an elastic solid. The energy release rate, $G$, is defined as:

$$
\mathrm{G}=\frac{\partial \mathrm{U}_{3}}{\partial \mathrm{c}}
$$

where $U_{e}$ is the elastic strain energy of the solid that contains a crack, and $2 c$ is the crack length. It has been shown in two dimensions by Irwin (1957), and in three dimensions by Budiansky and O' onnell (1976) that the following relationship holds between $G$ and the stress intensity factors:

$$
\mathrm{G}=\frac{\mathrm{K}_{\mathrm{I}}^{2}}{\mathrm{E}^{\prime}}+\frac{\mathrm{K}_{\mathrm{II}^{2}}^{2}}{\mathrm{E}^{\prime}}+\frac{\mathrm{K}_{\mathrm{II}}^{2}}{\mathrm{E}}(1+\nu)
$$

where $E^{\prime}=E$ for plane stress and $E^{\prime}=E /\left(1-\nu^{2}\right)$ for plane strain, and where $E$ is Young's modulus and $\nu$ is Poisson's ratio. By integrating $\mathrm{G}$ from zero to a given crack length, the total additional elastic strain energy due to a crack can be calculated. For a twodimensional solid containing a single crack of length 2c, the additional strain energy due to the crack is given by:

$$
\mathrm{U}_{\mathrm{e}}=2 \int_{0}^{\mathrm{c}} \frac{\mathrm{K}_{\mathrm{I}}^{2}}{\mathrm{E}^{\prime}}+\frac{\mathrm{K}_{\mathrm{II}}^{2}}{\mathrm{E}^{\prime}}+\frac{\mathrm{K}_{\mathrm{III}}^{2}}{\mathrm{E}}(1+\nu) \mathrm{dc}
$$

The strain energy due to a solid containing multiple cracks, and for three-dimensional bodies with cracks, is given in Kemeny (1986). 
Crack extension occurs when the energy release rate, G, becomes equal to a critical value of the energy release rate, $G_{c}$, i.e.:

$$
\mathrm{G}=\mathrm{G}_{\mathrm{c}}
$$

$G_{c}$ represents the energy required for the breakdown process at the crack tip, and is a material property (not necessarily constant, see Ouchterlony, 1983), while $G$ is related to the stress istensity factors and is a function of crack geometry and the applied stresses and strains.

Finally, we note that the elastic solution for the stresses given in equation (1) predicts infinite stresses directly at the crack tip, which is unrealistic, since material will actually yield or fail in a nonlinear fashion at some finite value of stress. However, if the region where the nonlinear behavior occurs is small relative to the region where the $\mathrm{K}$ terms dominate, then the stress field predicted by (1) is still valid. This forms the basis for the use of linear elastic fracture mechanics (LEFM) in rock fracture mechanics.

\section{Effective Shear Stiffness of a Fault Surface}

Here we develop theory for the mechanics of a fault plane containing a fixed distribution of asperities. Nonlinear constitutive relations are developed in the next section from this theory by letting the asperity distribution change in response to applied stresses and strains. We consider a linear elastic, isotropic, and homogeneous body containing a single discontinuity, where the discontinuity represents a joint or fault, and consists of a specific configuration of asperities. The specific geometry of asperities is modelled using the appropriate two- or three-dimensional configuration of cracks, where the asperities represent the areas between the cracks. A fixed, unidirectional shear displacement is applied at a distance $b$ from the fault plane, which would, in the absence of the discontinuity, result in a uniform shear stress, $\tau^{\infty}$, throughout the sample. Also, by Amoton's law, the crack faces subjected to a normal stress, $\sigma$, can sustain a frictional stress, $\tau^{\mathfrak{l}}=\mu \sigma$, where $\mu$ is assumed here to be linear. Under these conditions, the crack faces are subjected to only mode Il 
loading in two dimensions and modes II and III loading in three dimensions, and the crack tip stress intensity factors are proportional to $\tau$, where $\tau=\tau^{\infty}-\tau^{f}$ (Rice, 1984). The relative shear displacements between the two ends of the body consists of two components, the elastic displacement which would occur in the absence of the fault plane, and the additional displacement due to the asperity configuration along the fault plane. We are primarily interested in the additional relative shear displacements due to the fault plane, termed $\delta$, since $\delta$ is sensitive to changes in the geometry of the asperities, whereas the displacement due the solid is not. It is always a trivial exercise to obtain the total displacements by adding in the displacements of the solid material. Also, we will consider the average of $\delta$ over the length of the fault, termed $\bar{\delta}$. $\bar{\delta}$ turns out to have some very iniportant properties that enable constitutive relationships to be derived. First of all, since $\bar{\delta}$ is the additional sverage displacement to the asperity configuration, $\bar{\delta}$ is the same directly at the fault surface and for any plane parallel to it regardless of distance. Also, using energy theorems, various relationships between $\bar{\delta}$ and $\tau$ can be determined.

Initial loading results in no $\bar{\delta}$ until the frictional resistance of the crack surfaces is overcome. Once $\tau^{\infty}$ exceeds $\tau^{\mathfrak{f}}$, a body containing a configuration of asperities will show linear $\tau-\bar{\delta}$ behavior up to the point where asperities begin to fall, referred to as the effective shear stiffness, $k_{s}$, i.e.:

$$
k_{\mathrm{s}}=\tau / \bar{\delta}
$$

$k_{s}$ depends on the asperity configuration, the elastic contants for the solid material, and the coefficient of friction. As the asperities fall, additional load must be carried by the remaining asperities, and this causes the effective shear stiffness to decrease, decreasing to zero as all the asperities on the slip surface have been broken. Using Betti's reciprocal theorem (Sokolnikof, 1954), it has been shown (Kemeny, 1986) that there is a unique relationship between $k_{s}$ and the strain energy due to the configuration of cracks, and thus, using equation (4), between $k_{\mathrm{s}}$ and the crack tip stress intensity factors. For a two-dimensional (riañe strain) body containing some configuration of asperities, $k_{\mathrm{s}}$ is given by the following 
relationship with the mode II stress intensity factor:

$$
\frac{1}{k_{8}}=\frac{2\left(1-\nu^{2}\right)}{\tau^{2} \mathrm{wE}} \int_{\mathrm{I}} \mathrm{K}_{\mathrm{I}}^{2} \mathrm{dI}
$$

where the integral is over the distribution of cracks and $w$ is the width of the body. For three-dimensional cracks, a relationship for $k_{B}$ in terms of the modes II and III stress intensity factors is given in Kemeny (1986).

\section{Constitutive Relations}

In this section a procedure is presented for calculating nonlinear constitutive relations for joints and faults based on the progressive failure of asperities along the slip surface. It turns out that this procedure has a useful graphical interpretation, which will be demonstrated. We first note that the effective shear stifness, $k_{8}$, for a slip plane with a given configuration of asperities plots as a straight line on a $\tau-\bar{\delta}$ diagram, as shown in Figure 1 a. As asperities progressively fail due to an increase in the load or displacement, the geometry of the asperities along the slip plane will change, and at any given instant of time, the slip plane will have a different effective shear stifiness. The sequence of changes in $k_{B}$ for $a$ hypothetical deformation sequence is shown in Figure 1a. At the start, the body contains an initial configuration of asperities, and the linear behavior for this initial configuration of asperities is shown in Figure 1a by the effective stiffness with the highest slope. As the discontinuity is deformed, the asperities will progressively fail, and for any of these later asperity configurations, the effective stiffness will be lower, as also shown in Figure 1a.

Along each of the lines representing an effective shear stiffness for an asperity configuration, there will be a critical value of the shear stress where asperity failure begins, as shown in Figure 1b. The critical value of the shear stress when asperity failure begins is referred to as the critical stress, $\tau_{c}$, and the critical stress is calculated by inverting the formula for the stress intensity factor for the given apserity configuration when $G=G_{c}$. As the asperities fail, the effective shear stiffness will always decrease, but the critical stress can 
either increase or decrease, depending on whether the stress intensity factor decreases or increases with the changing asperity geometry. The stress displacement path that the body will follow during deformation is the locus of critical points over the sequence of changes in $\mathrm{k}_{\mathrm{s}}$ during loading, as shown in Figure 1c. Slip strengthening is the result of an increasing $\tau_{\mathrm{c}}$ as the effective stiffness decreases, and slip weakening is a result of a decreasing $\tau_{c}$ as the effective stiffness decreases. Figure 1c shows clearly how nonlinear stress displacement curves are produced from the linear model witb progressive asperity failure. We also note that this approach applies for any configuration of asperities in both two and three dimensions.

The stiess displacement curve as derived above is independent of the stability of the system, and instability will occur at the point where the slope of the stress displacement curve becomes less than the unloading stiffness of the surrounding material, $k_{u}$. The unloading stiffness for the boundary conditions assumed in this analysis, i.e., a fixed shear displacement at a distance $h$ from the fault plane, is given by the following formula (Stewart, 1981):

$$
k_{u}=\frac{-h(1+\nu)}{E}
$$

As $h$ approaches infinity, $k_{u}$ approaches a horizontal line, which represents the boundary conditions of applied stresses, and all slip weakening slopes will be unstable for this condition. As $h$ approaches zero, $k_{u}$ approaches a vertical line, which represents the boundary conditions of applied displacements, and only those slip weakening slopes that loop back towards the origin will be unstable. In general, the unloading stiffness for ground conditions will fall somewhere in between horizontal and vertical ( $\mathrm{Li}$ and Rice, 1983).

The deformation sequence for the asperity model developed above is summarized in Figure 2. This model predicts initial linear loading up to the point where the first asperity starts to fail, nonlinear behavior (slip weakening or slip strengthening) as the asperities progressively fail and follow the stress displacement curve, and instability when the slope of the stress displacement curve exceeds the unloading stiffness. The energy released by the 
unstable event can be calculated from the stress displacement bebavior and the unloading stiffness, and is indicated by the shaded region in Figure 2. This energy can be released as seismic energy, go into additional asperity failure at other locations, or other mechanisms (Rice, 1983).

As a first example of derived stress displacement relations for a given distribution of asperities, we consider a two-dimensional (plane strain) distribution of equal spaced, equal sized asperities, as shown in Figure 3a. the effective stiffness for this configuration is based on the stress intensity factor solution for a row of equal length cracks under uniform shear (Sih, 1975). Using this stress incensity factor solution, along with equation (7), the effective shear stiffness for this configuration, as derived by Kemeny (1986), is given by:

$$
\frac{1}{k_{s}}=\frac{-8 b\left(1-\nu^{2}\right)}{\pi E} \text { in } \cos (\pi l / 2 b) \text {. }
$$

$k_{b}$ here is a function of the crack length, 1 , and the spacing between cracks $b$, which is related to the asperity size, $m$, by $m=b-l$, and $k_{a}$ goes to zero as the size of the asperities goes to zero. The graphical procedure for calculating the stress displacement behavior due to asperity failure, as outlined previously, is equivalent to simultaneously solving $\mathrm{k}_{\mathrm{B}}$ and the critical stress, $\tau_{\mathrm{e}}$, for various values of $\mathrm{l} / \mathrm{b}$. The critical stress for the configuration of cracks in Figure $3 a$ is given by:

$$
\tau_{c}=\left[\frac{G_{E} E}{\left(1-\nu^{2}\right) 2 b \tan (\pi l / 2 b)}\right]^{1 / 2}
$$

Solving equation (10) for $1 / b$ and using this to eliminate $l / b$ in equation (9), a single formula for the stress displacement curve is determined for the configuration in Figure 3a:

$$
\bar{\delta}=\frac{-8 \tau \mathrm{b}\left(1-\nu^{2}\right)}{\pi \mathrm{E}} \ln \cos \left[\tan ^{-1} \frac{\mathrm{G}_{\mathrm{c}} \mathrm{E}}{\tau^{2} 2 \mathrm{~b}\left(1-\nu^{2}\right)}\right]
$$

The dimensionless form of equation (11) is plotted in Figure $3 \mathrm{~b}$. In this model, all the asperities fail simultaneously, since the stress intensity factors are identical at all of the 
crack tips. This is unrealistic, since imperfections will always exist in any real material, and failure will initiate at the imperfections. We consider more realistic models in the following sections. The stress displacement curve for this model shows slip weakening behavior, and this curve loops back toward the origin as the asperities become small, resulting in a single instability due to the interaction with the surrounding ground. As discussed before, a slip weakening curve past the point of vertical tangency is unstable under any boundary conditions. As the asperities become small, they become isolated from each other (noninteracting), and the limiting case of a row of isolated asperities is also shown in Figure $3 \mathrm{~b}$, calculated by taking the limit of equation (11) for small asperity size. The isolated asperity is always in the region past the vertical tangency point, and thus a two-dimensional, isolated asperity is unstable under any boundary conditions. We show later that a distribution of asperity sizes can be used to stabilize a discontinuity consisting of isolated asperities.

As a second example, we consider the stress displacement relationship for a threedimensional isolated asperity under unidirectional shear, as shown in Figure 4a. This geometry is considerably mcis complicated than the two-dimensional counterpart discussed above, since for a three-dimensional asperity subjected to a unidirectional shear, the energy release rate, $G$, is not necessarily constant around the contour of the asperity. For example, for a penny shaped (circular) asperity under unidirectional snear, $G$ at the location in line with the shear is larger by a factor of $1 /(1-\nu)$ the value of $\mathrm{G}$ at the location perpendicular to the shear. Referring to the Figure 4a, the asperity will first start to fail at point $\mathbf{A}$, and it will fail into a shape such that $G$ is constant around the contour of the asperity. This shape can be approximated by an ellipse, with major and minor axes $2 \mathrm{a}$ and $2 \mathrm{~b}$, respectively. The elliptical asperity will then continue to fail in the form of ever decreasing sized ellipses with the same ratio of $\mathrm{a} / \mathrm{b}$.

It was shown by Kemeny (1986) that for the special ratio of the major and minor axes of the ellipse given by $b=a(1-\nu)$, the values of $G$ at points $A$ and $B$ are identical, and approximately equal over all other parts of the contour of the asperity. The effective shear 
stiffness for the isolated elliptical asperity is based on the stress intensity factor solution for the external elliptical crack (Kassir and Sih, 1968). The reiationship between $k_{b}$ and the stress intensity factors for a three-dimensional crack with an elliptical contour is given as (Kemeny, 1986):

$$
\frac{1}{k_{\mathrm{s}}}=\frac{8 \mathrm{E}(\mathrm{k})}{\pi \mathrm{w}^{2}} \int_{0}^{2} \mathrm{a} \mathrm{G} d \mathrm{~d}
$$

where $E(k)$ is the complete elliptical integral of the first kind (Abramowitz and Stegun, 1964), and $k$ is the parameter of the ellipse given by $k^{2}=1-b^{2} / a^{2}$. Using equation (12) along with the stress intensity factors for the external elliptical crack with the special ratio of $a / b$, the effective shear stiffness for the elliptical asperity is given by:

$$
\frac{1}{\mathrm{k}_{\mathrm{B}}}=\frac{2 \mathrm{rE}(\mathrm{k})(1-\mathrm{a})\left(1-\nu^{2}\right)}{\mathrm{E}(1-\nu)^{2} \mathrm{a}}
$$

where $2 \mathrm{a}$ is the major axis of the elliptical asperity, and $\mathrm{r}$ is the radius of the body containing the asperity. Using equation (13) along with the procedure for calculating stress displacement curves as outlined previously, the stress displacement curve for the isolated elliptical asperity is given by:

$$
\bar{\delta}=\frac{2 \tau \mathrm{rE}(\mathrm{k})\left(1-\nu^{2}\right)\left[1-\left(\frac{\tau^{2} \pi \mathrm{r}\left(1-\nu^{2}\right)}{4 \mathrm{E}(1-\nu)^{2} \mathrm{G}_{\mathrm{c}}}\right)^{1 / 3}\right]}{\mathrm{E}(1-\nu)^{2}\left(\frac{\tau^{2} \pi \mathrm{r}\left(1-\nu^{2}\right)}{4 \mathrm{E}(1-\nu)^{2} \mathrm{G}_{\mathrm{c}}}\right)^{1 / 3}} .
$$

The dimensionless form of equation (14) is shown in Figure 4b. Like the isolated twodimensional asperity, the slope of the slip weakening curve for the isolated elliptical asperity is always positive, indicating instability under all boundary conditions. The solution in equation (14) is useful in analysing the effects of distributions of elliptical asperities of various sizes, as considered later. 


\section{Multiple Instabilitieg}

In the previous section we considered asperity configurations that resulted in a single instability, and the development of constitutive relationships for cases where multiple instabilities occur follows directly from that approach. Multiple instabilities occur in our models due to a distribution of asperities of varying sizes that do not fail simultaneously.

We first consider the case of a fault plane consisting of an array of asperities of two different sizes, but equal spacing between asperities, as shown in Figure 5a (two dimensions, plane strain). The stress intensity factor solution for this configuration is based on the solution for a row of equal length cracks with two sets of spacings, where the spacings represent the asperities. Even though the stress intensity factor solution for this configuration exists in analytic form (Rooke and Cartwright, 1976), the formulas are complicated, and therefore the integral in equation (7) for the effective stiffness must be evaluated numerically. For this case, the tips of the cracks adjacent to the smaller asperities bave the bighest stress intensity factors and will start to propagate first, and will continue to propagate until the smaller asperities have been sheared off. The stress displacement curve due to the failure of the smaller asperities is shown in Figure 5b. This curve exhibits slip weakening behavior, and possesses a vertical tangent like the simpler models in the previous section. Now, however, once the smaller asperities have failed, the system becomes a row of equal sized asperities with equal spacings, as in the configuration shown in Figure 3a. The effective shear stiffness for this new configuration of asperities is also shown in Figure $5 b$. We see that the slope of the slip weakening curve for the failure of the smaller asperities approaches this stiffness as the smaller asperity size approaches zero. If we assume a stiff system where the unloading stiffness is nearly vertical, then instability will occur in the original system near the point of vertical tangency. During instability, the stress will drop, with little increase in displacement, until it intersects the line representing the effective stiffness for the system without the smaller asperities. The energy released by the instability is shown by the first shaded region in Figure 5b. The stress on the new configuration without the smaller asperities may 
be well below that necessary to cause the remaining asperities to start to fail. Upon further loading, the system will follow the linear loading governed by the effective shear stiffness for the new system until it intersects the slip weakening curve for this system, at which point the remaining asperities will start to fail. Also plotted in Figure 5b is the stress displacement curve for the failure of the remaining asperities, which also shows an instability, as in Figure 3b.

The curves in Figure $5 b$ are each similar to the one in Figure $3 b$, except now two instabilities occur, the first instability due to the failure of the smaller asperitics, and the second instability as the remaining equal spaced asperities fail, as in Figure 3b. Our results show how these two instabilities are intimately tied together by the stiffness changes that occur during deformation. Thus, multiple stick-slip events are produced, not by crack healing, stress corrosion cracking, or other geochemical methods, but by the heterogeneity of the fault surface alone. Also important to note are the relative magnitudes of the energy releases between the first and second instabilities. If the first instability releases more energy, then it can be considered a main event, with the second instability an aftershock. If the second isntability produces more energy, then the first instability is a foreshock, followed by the main event. For the curves shown in Figure 5b, the two instabilities have energy releases of roughly equal orders of magnitude. However, as will be shown in the next section, for nonsymmetric configurations with unequal spacings between asperities, far less energy may be released. Also, it was assumed in the shaded areas of Figure $5 \mathrm{~b}$ that the surrounding ground is very stiff, so that the unloading stiffness is nearly vertical, which may not be the case.

We now consider the case of a fault plane consisting of an array of asperities of two different sizes and two different spacings between asperities, as shown in Figure 6a (two dimensions, plane strain). This configuration is based on the stress intensity solution for a row of cracks made up of two crack sizes and two spacings between cracks (Rooke and Cartwright, 1976). Because of the symmetry of the previous configuration, the asperities in the 
previous configuration failed from both sides simultaneously. In this configuration, the stress intensity factor will always be largest on the crack tip of the larger crack that is adjacent to the smaller asperity, and therefore this tip will start to propagate first, and will continue to propagate until it engulfs the smaller asperity. Thus, due to the asymmetry of the spacings adjacent to an asperity, the asperity will fail from one side towards the other, rather than from both sides simultaneously. Since slipped zones adjacent to asperities on fault surfaces will never be exactly the same size, it is important to investigate the consequences, in terms of the amount of energy released, of the above scenario. We look at the stress displacement behavior due to the breaking of the smaller asperities, where the spacings to the adjacent asperities is slightly larger on one side. The important parameter is the ratio, $\chi$, of the length of the larger spacing, with the size of the asperity. In Figure 6b, we plot slip weakening curves for $\chi=0.5$ and 0.25 , and compare these with the case where the asperity breaks from both sides simultaneously. The energy released due to unstable asperity failure (assuming stiff boundary conditions) for each case are shown by shaded regions in Figure 6b. Figure $6 \mathrm{~b}$ shows that the highest energy is released for the asperity with equal spacings on both sides, and very small amounts of energy are released when the spacing is large in relation to the size of the asperity.

\section{Regular Asperity Configuration Containing an Imperfection}

We are now in a position to analyse the effects of more complicated distributions of asperities. A realistic configuration in two dimensions would be to analyse the effects of the asperity distribution with equal asperity sizes and spacings, but containing an imperfection, say, a slightly larger spacing in one location. Based on the previous sets of results, we can speculate that asperity failure will initiate at the imperfection due to a higher stress intensity factor there due to the larger spacing, and will propagate out in a crack-like manner in to the field of unbroken asperities. Each of the asperities should fail from the side with the larger spacing, as in the previous example, and multiple instabilities should occur due to 
the unstable failure of each of the asperities, depending on the imposed boundary conditions. This configuration also has the advantage that it is a reasonable model for actual events that occur in the laboratory and along earthquake faults, and thus the results can be compared with actual data. For example, Okubo and Dietrich (1984) conducted friction experiments on a sawcut in a $2 \mathrm{~m} \times 2 \mathrm{~m}$ Granite specinen, where strain gauges were placed close to the shear surface to detect the onset and propagation of slip. Their results showed that slip does not occur uniformly across the shear plane, but rather, slip starts at the 'weakest link,' and propagates outward in a crack-like manner, as in this model. An important consideration here is the overall deformation sequence or global behavior due to a number of instability events. It turns out that the global behavior can be stable even when the individual events are highly unstable, and this has important implications for earthquake mechanics. Some important problems to analyse with regards to this model are, how does the behavior with a flaw compare with the configuration with no flaws, or with a configuration with flaws in other locations. In other words, does the addition of a flaw change the basic character of the result, and if so, is the position of the flaw, or the number of llaws also important parameters.

We consider a fault plane consisting of a regular array of asperities with a slightly larger spacing at the center, as shown in Figure 7a. The stress displacement behavior due to asperity failure can be calculated as outlined in the previous section, and thus the stress in tensity factor at each of the crack tips, and the effective shear stiffness, must be known for each of the configurations during deformation. Solutions for the stress intensity factors do not exist in analytic form for this configuration, and therefore they must be calculated numerically. The effective shear stiffness for the configuration of asperities can also be determined from these numerical calculations. We have developed a numerical model to calculate nonlinear stress displacement curves due to progressive asperity failure, based on the displacement discontinuity boundary element method by Crouch (1976). Results for the configuration in Figure $7 \mathrm{a}$ are presented in Figure $7 \mathrm{~b}$. Figure $7 \mathrm{~b}$ consists of several 
individual curves, each curve representing the stress displacement behavior as the large crack propagates through each set of asperities. Also, as in the previous section, the individual stress displacement curves are separated by the linear effective stiffnesses for the new configuration after each set of asperities has failed. The breaking of each set of asperities is highly unstable, with each of the individual stress displacement curves looping back towards the origin, the slope approaching the effective stiffness for the new system after asperity failure occurs. The energy released by each of the individual instabilities, assuming a steep unloading stiffness, are shown by the shaded regions.

The global stress strain behavior for this sequence of events is also shown in Figure $7 \mathrm{~b}$. For this example, the global stress strain behavior exhibits slip weakening, but the global stress strain behavior does not loop back towards the origin as does the individual stress displacement curves. Thus the global behavior is stable under displacement controlled boundary conditions. Work is continuing on this model and will be discussed in a future report.

\section{Conclusions}

In this report we have analysed the shear response of a fault plane consisting of asperities, by considering the asperities as the regions between cracks, and utilizing the theory of linear elastic fracture mechanics. The constitutive behavior that we derive is based on the elastic stiffness changes that occur during the progressive failure of the asperities. It is found that the progressive failure of the asperities gives the nonlinear response that is measured in the laboratory, and also, the occurrence of both stable and unstable response is consistent with the behavior of earthquake faults. We have made many simplifying assumptions in deriving constitutive behavior as presented in this report. For instance, we analyse the behavior of very simple distributions of asperities, under simple boundary conditions, and we assume that the stress state due to the asperities can adequately be described using linear elastic theory. Also, the cracks are placed in collinear or coplanar arrays, and the propagation of these cracks produces no dilatation normal to the crack surface. However, the 
fact that the shear response from our models is consistent with both laboratory and field results indicates that one of the most important effects in fault behavior is the change in stiffness due to the changing microstructure along the shear plane. This can be appreciated by considering the size of asperities that fail along a fault zone. For instance, the 1960 Chilean earthquake is believed to have ruptured over a length of over $800 \mathrm{~km}$. The knowledge of what causes these large asperities to go unstable is therefore of great importance to the field of earthquake prediction. On a smaller scale, the seismic events that occur along preexisting joints and faults due to underground excavation can be analysed by the same theory.

The analyses in this report started with some very simple asperity configurations, and based on these simple models, we were able to consider more realistic configurations, such as a regular distribution of asperities containing an imperfection, as described in the last section. This last model exhibited cornplex behavior that compared well with laboratory and field data. We are also starting to look at another approach, which is to analyse the effects of very nonregular distributions of asperities, utilizing the results for the single elliptical asperity as given in equations (13) and (14). We choose a distribution of asperities that is suritable for the geometry of slip surfaces, as determined from laboratory samples of fault surfaces, and along earthquake faults. Brown and Scholz (1985) found that the surface roughness for joints tested in the laboratory can be described with the use of 'fractals.' In the most basic terms, a fractal geometry is one that is continuous but nowhere differentiable (Mandelbrot, 1983), and a fractal geometry is found to exhibit the property of 'self similarity.' Brown and Scholz (1985) use two fractal functions, the fractional Brown function and the Weirstrauss-Mandelbrot function, to describe a power law relationship between asperity amplitude and frequency along joint surfaces. This same approach has been used by Scholz et al. (1986) for surface traces of earthquake faults. Since asperity height is not taken into account in the asperity models presented here, another form for the fractal relationship is pursued. Mandelbrot (1983) finds a fractal relationship between the diameter of islands, $\lambda$, 
and the number of islands having a size greater than or equal to $\lambda$, referred to by $\operatorname{Nr}(\lambda)$. Thus we assume that a similar relationship exists between asperity size and number greater than along a joint surface, and analyse the consequences of such a relationship, for various values of $D$. Work is continuing on this subject and will be described in a later report. 


\section{References}

Abramowitz, M., and Stegun, 1. A., 1964, Handbook of Mathematical Functions: Dover, New York.

Aki, K., 1984, Asperities, barriers, characteristic earthquakes, and strong motion prediction: J. Geophys. Res., v. 89, p. 5867-5872.

Archard, J. F., 1957, Elastic deformation and the laws of friction: Proc. Roy. Soc. London, Ser. A243, 190-205.

Barton, N., and Choubey, V., 1977, The shear strength of rock joints in theory and practice: Rock Mech., v. 10, p. 1-54.

Bowden, F. P., and Tabor, D., 1954, Friction and Lubrication of Solids: Oxford University Press.

Brown, S. R., and Scholz, C. H., 1985, Broad bandwidth study of the topography of natural rock surfaces: J. Geophys. Res., v. 90, p. 12,575-12,582.

Budiansky, B., and O'Connell, R. J., 1976, Elastic moduli of a cracked solid: Int. J. Solids Struct., v. 12, p. 81-97.

Byerlee, J. D., 1967, Theory of friction based on brittle fracture: J. Appl. Phys., v. 38, p. 2928-2934.

Cook, N. G. W., 1981, Stiff testing machines, stick slip sliding, and the stability of rock deformation: In The Mechanical Behavior of Crustal Rocks, Am. Geophys. Union Monogr. 24.

Costin, L. S., 1985, Damage mechanics in the post failure regime: Mech. of Mats., v. 4, p. 149-160.

Crouch, S. L., 1976, Solution of plane elasticity problems by the displacement discontinuity method: Int. J. Num. Meth. Eng., v. 10, p. 301-343.

Dieterich, J. H., 1981, Constitutive properties of faults with simulated gouge: In The Mechanical Behavior of Crusta: Rocks, Am. Geophys. Union Monogr. 24 .

Goodman, R. E., 1976, Methods of Geologic Engineering in Discontinuous Rocks: West Publishing Co., St. Paul, Minnesota.

Greenwood, J. A., and Williamson, J. B., 1966, Contact of nominally flat surfaces: Proc. Roy. Soc. London, Ser. A295, p. 300-319.

Hallbauer, D. K., Wagrer, H., and Cook, N. G. W., 1973, Some observations concerning the microscopic and mechanical behavior of quartzite specimens in stiff, triaxial compression tests: Int. J. Rock Mech. Min. Sci, v. 10, p. 713-726.

Hartzell, S. H., and Heaton, T. H., 1986, Rupture history of the 1984 Morgan Hill, California, earthquake from the inversion of strong motion records: Bull. Seis. Soc. Ali., v. 76 , p. 649-674. 
Horii, H., and Nemat-Nasser, S.. 1985, Compression induced microcrack growth in brittle solids: Axial splitting and shear failure: J. Geophys. Res., v. 90, p. 3105-3125.

Irwin, G. R., 1957, Analysis of stresses and strains near the ends of a crack traversing a plate: J. Appl. Mech., v. 24, p. 361-364.

Jaeger, J. C., and Cook, N. G. W., 1979, Fundamentals of Rock Mechanics: Chapman and Hall, London.

Kanamori, H., 1986, Rupture process of subduction-zone earthquakes: Ann. Rev. Earth Planet. Sci., v. 14, p. 293-322.

Kassir, M. K., and Sih, G. C., 1968, External elliptic crack in elastic solid: Int. J. Fract. Mech., v. 4, p. 347-356.

Kemeny, J. M., 1986, Fricrional stability of heterogeneous surfaces in contact: The mc anics of faulting and earthquake rupture: Ph.D thesis, Univ. of Calif., Berkeley.

Kemeny, J. M., and Cook, N. G. W., 1986a, Frictional stability of heterogeneous surfaces in contact: Proc. 27th U. S. Rack Mech. Symp., Iniversity, Alabama, p. 40-46.

Kemeny, J. M., and Cook, N. G. W., 1986b, Effective moduli, nonlinear deformation, and strength of a cracked elastic solid: Int. J. Rock Mech. Min. Sci., v. 23, p. 107-118.

Kemeny, J. M., and Cook, N. G. W., 1987, Crack models for the failure of rock in cornpression: To appear, Proceedings of the Second International Conference on Constitutive Laws for Engineering Materials, Tucson, Arizona.

Krajcinovic, D., 1985, Continuous damage mechanics revisited: Basic concepts and definitions: J. Appl. Mech., v. 52, p. 829-834.

Ladanyi, B, and Archambault, G., 1970, Simulation of shear behavior of a jointed rock mass: Proc. 11th Symp. on Rock Mech., p. 105-124.

Li, V. C., and Rice, J. R., 1983, Preseismic rupture progression and great earthquake instabilities at plate boundaries: J. Geophys. Res., +. 88, p. 4231-4246.

Mandelbrot, B. B., 1983, The Fractal Geometry of Nature: W. H. Freeman and Co., San Francisco.

Mavco, G. M., 1981, Mechanics of motion on major faults: Ann. Rev. Earth Planet. Sci, v. 9, p. 81-111.

Mogi, K., 1985, Earthquake Prediction: Academic Press, Tokyo.

Okubo, P. G., and Dieterich, J. H, 1984, Effects of physical fault properties on frictional instabilities produced on simulated faults: J. Geophys. Res., v. 89, p.5817-5827.

Okubo, P. G., and Dieterich, J. H., 1986, State variable fault constitutive relations for dynamic slip: In Earthquake Source Mechanics, Am. Geophys. Union Monogr. 37 (Maurice Eving 6), Washington, D.C.

Ouchterlony, F., 1983, Fracture toughness testing of rock: In Rock Fracture Mechanics, Springer-Verlag. 
Palmer, A. C., and Rice, J. R., 1973, The growth of slip surfaces in the progressive failure of overconsolidated clay: Proc. Roy. Soc. London, Ser. A332, p. 527-548.

Patton, F. D., 1966, Multiple modes of shear failure in rock: Proc. 1st Cong. ISRM, Lisbon, v. 1 , p. $509-513$.

Qidong, D., and Piezhen, Z., 1984, Research on the geometry of shear fracture zones: J. Geaphys. Res., v. 89 , p. $5699-5710$.

Rice, J. R., 1968, Mathematical analysis in the mechanics of fracture: In H. Liebowitz, ed., Fracture: An Advanced Treatise (Vol. II), p. 191-311.

Rice, J. R., 1980, The mechanics of earthquake rupture: In A. M. Dziewonski, and E. Boschi, eds., Physics of the Earth's Interior, Italian Physical Society, North Holland, Amsterdam, p. 555-649.

Rice, J. R., 1983, Constitutive relations for fault slip and earthquake instabilities: PAGEOPH., v. 121, p. 443-475.

Rice, J. R., 1984, Comments on "On the stability of shear cracks and the calculation of compressive strength" (J. K. Dienes, ed.): J. Geophys. Res., v. 89, p. 2505-2507.

Rooke, D. P., and Cartwright, D. J., 1976, Compendium of Stress Intensity Factors: The Hillington Press, Middx.

Rudnicki, J. W., 1980, Fracture mechanics applied to the Earth's crust: Ann. Rev. Earth Sci., v. 8, p. 489-525.

Rudnicki, J. W., Hirashima, K., and Achenbach, J. D., 1984, Amplificatinn of moment and strain energy release due to interaction of different size fault slip zones: J. Geophys. Res., v. 89, p. 5828-5834.

Scholz, C. H., and Aviles, C. A., 1986, The fractal geometry of faults and faulting: In Earthquake Source Mechanics, Am. Geophys. Union Monogr. 37 (Maurice Ewing 6), Washington, D.C.

Segall, P., and Harris, R., 1986, Slip defecit on the San Andreas fault at Parkfield, California, as revealed by inversion of geodetic data: Science, v. 233, p. 1409-1413.

Sih, G. C., 16 ?, Handbook of Stress Intensity Factors: Institute of Fracture and Solid Mechanics, Lehigh University, Bethlehem.

Sokolnikoff, I. S., 1956, Mathematical Theory of Elasticity (2nd edn.): McGraw-Hill, New York.

Stewart, W. D., 1981, Stiffness methods for anticipating earthquakes: Bull. Seis. Soc. Am., v. 71, p. 363-370.

Swan, G., 1983, Determination of stiffness and other joint properties from roughness measurements: Rock Mech. and Rock Eng., v. 16, p. 19-38.

Sun, Z., Gerrard, C., and Stephansson, O., 1985, Rock joint compliance tests for compression and shear loads: Int. J. Rock Mech Min. Sci. \& Geomech. Abstr., v. 22, p. 197-213. 
Tse, S. T., and Rice, J. R., 1986, Crustal earthquake instability in relation to the depth varjation of frictional slip properties: J. Geophys. Res., v. 91, p. 9452-9472.

Wawersik, W. R., and Brace, W. F., 1971, Post-failure behavior of a granite and diabase: Rock Mech., v. 3, p. 61-85. 
a)

b)

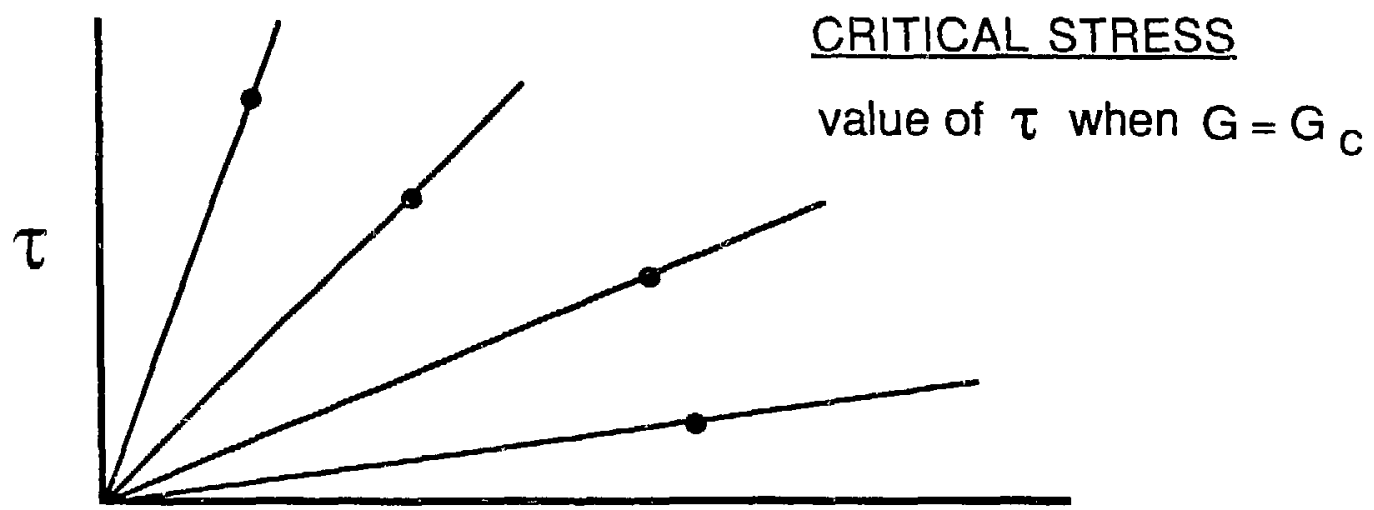

$\bar{\delta}$

c)

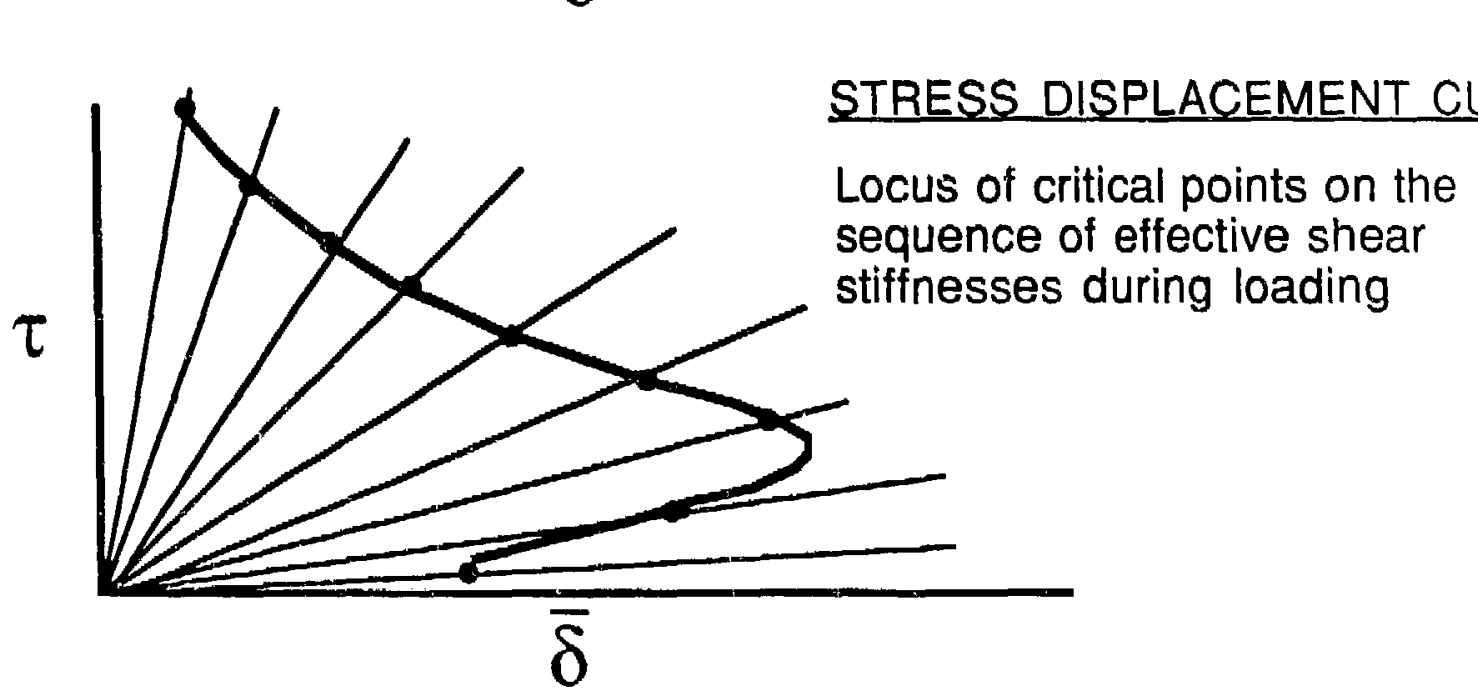

Figure 1. Graphical procedure for calculating nonlinear constitutive laws due to the progressive failure of asperities along faults.

\section{EFFECTIVE SHEAR STIFFNESS}

$k_{S}=\tau / \bar{\delta}$

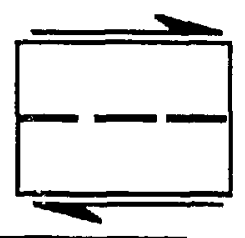

\section{$\bar{\delta}$ (average displacement due to fault)}

c) 


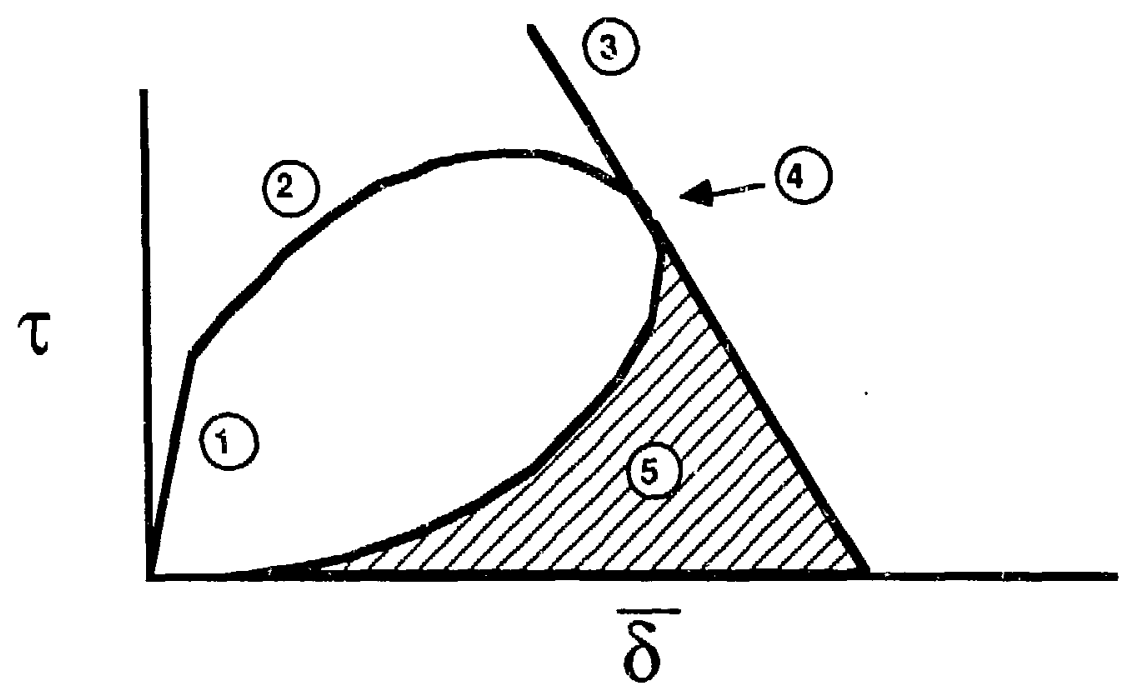

1 - linear loading due to initial asperity configuration

2 - nonlinear behavior due to progressive asperity failure

3 - unloading stiffness

4 - instability point

5 - energy release during instability

Figure 2. Summary of the deformation sequence for the asperity models in this report. 
a)

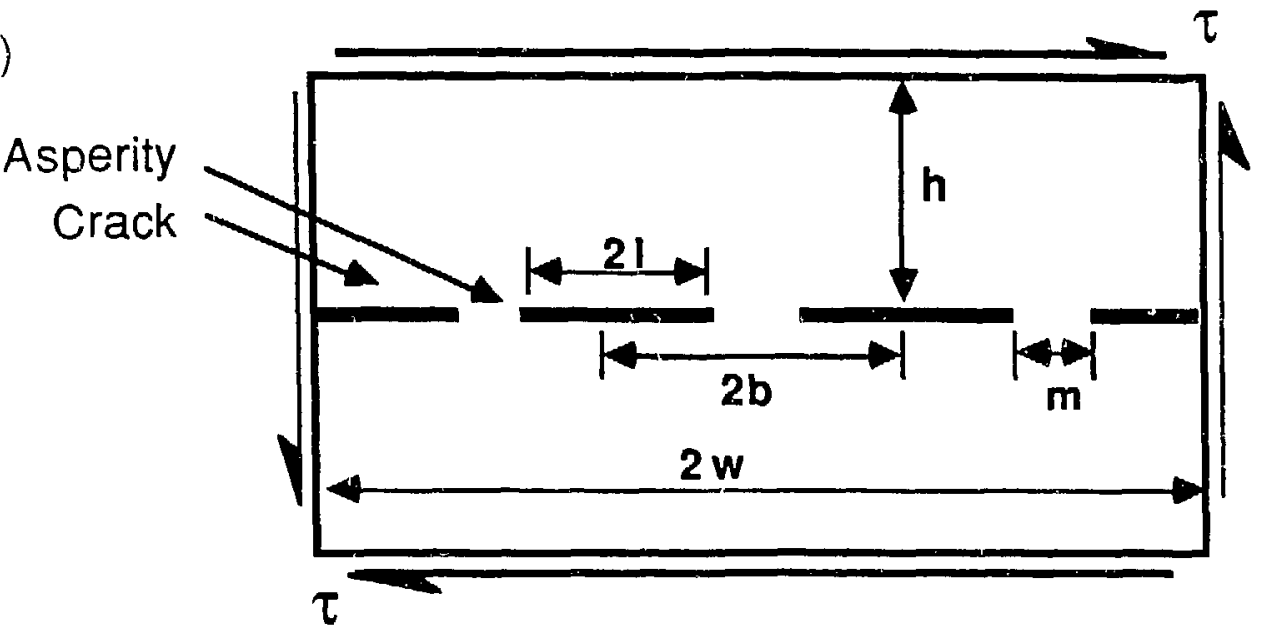

b)

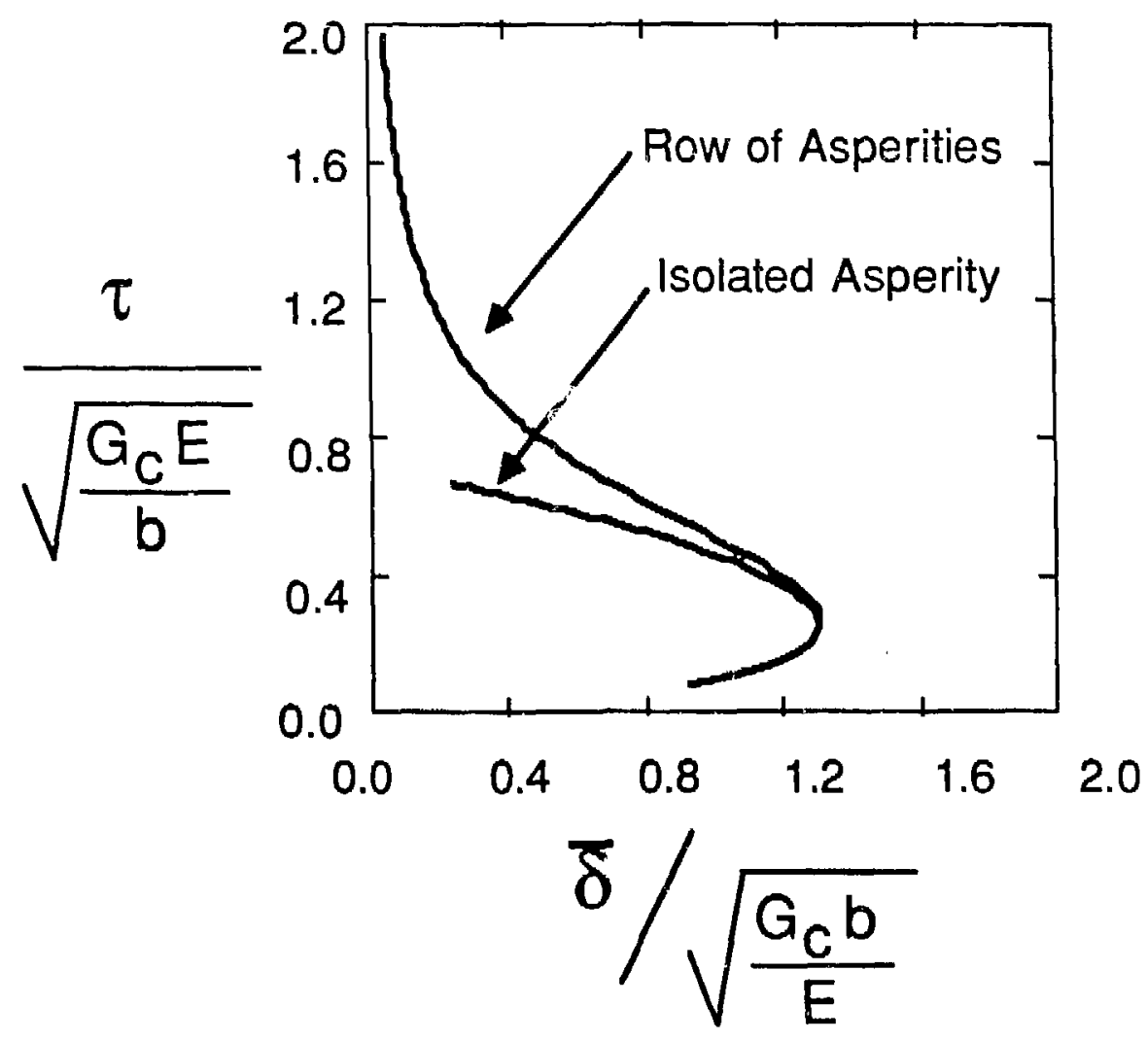

Figure 3. a) Fault model consisting of a two dimensional (plane strain) distribution of equal spaced, equal sized asperities. b) Non-dimensionalized stress displacement behavior for this model and also for the limiting case of a row of isolated (non-interacting) asperities. (Assumed $v=0.2$ ) 
a)

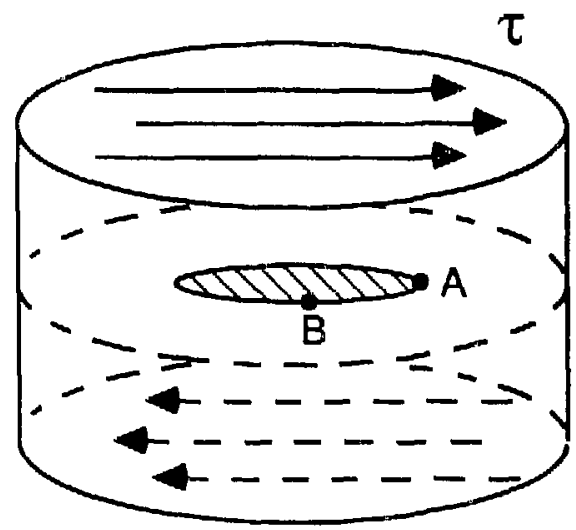

\section{Elliptical Asperity}

$\tau$

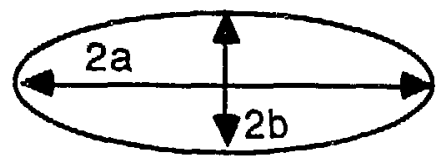

b)

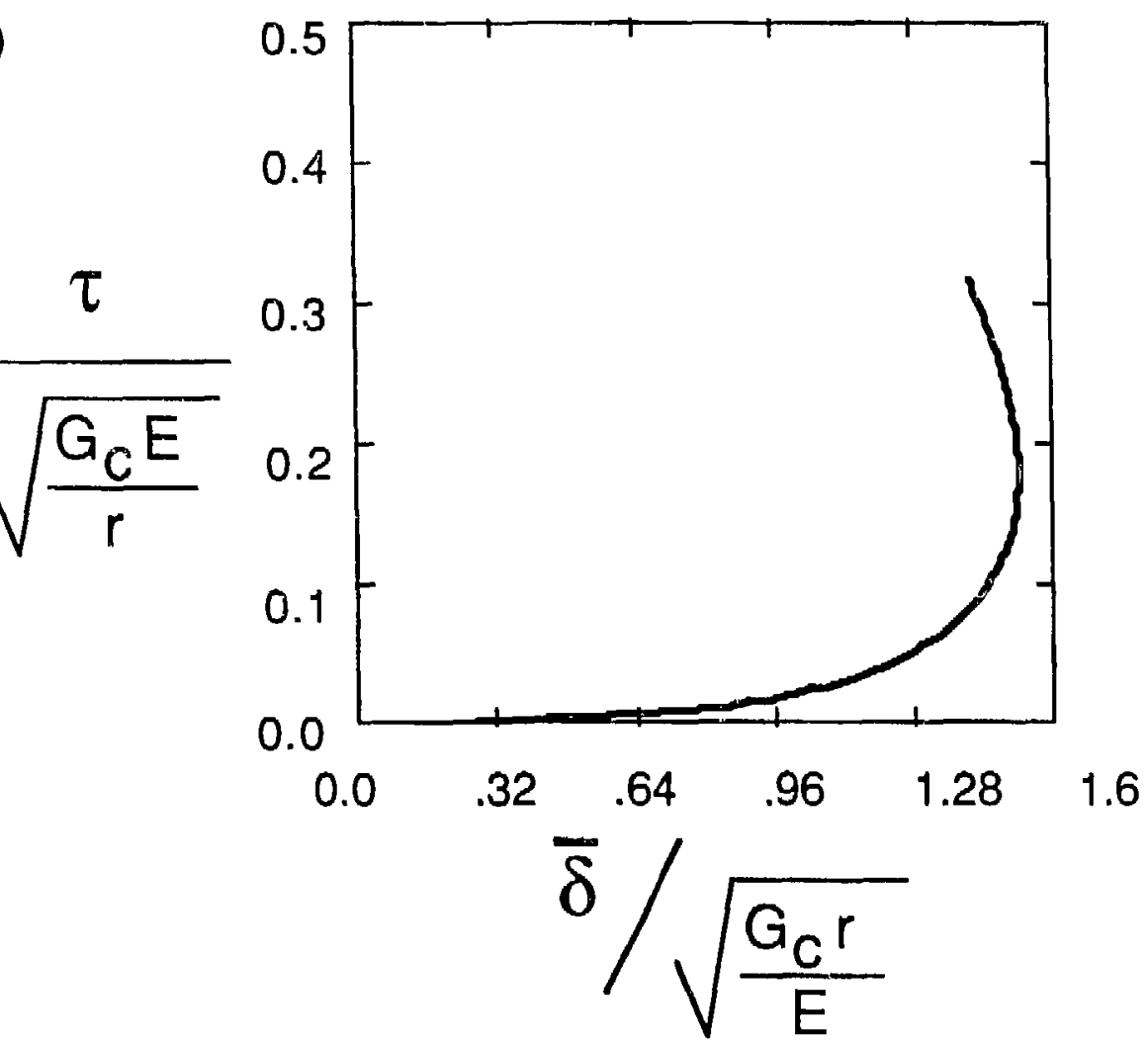

Figure 4. a) Fault model consisting of a three dimensional, isolated, elliptical asperity, inside a right circular cylinder of radius $r$.

b) Non-dimensionalized stress displacement behavior for this model. (Assumed $v=0.2$ ) 
a)

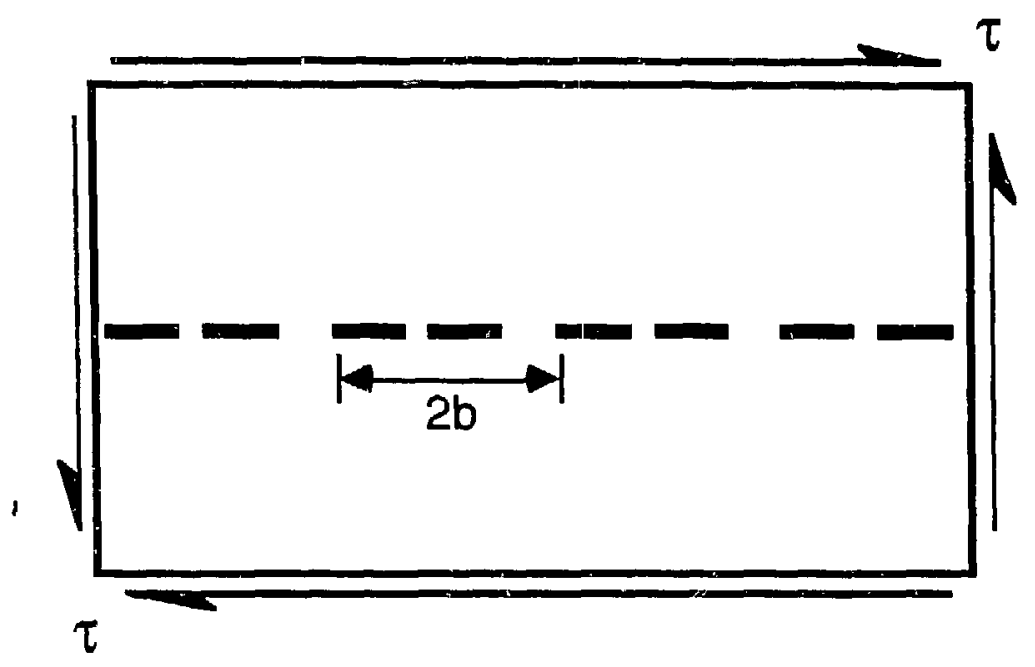

b)

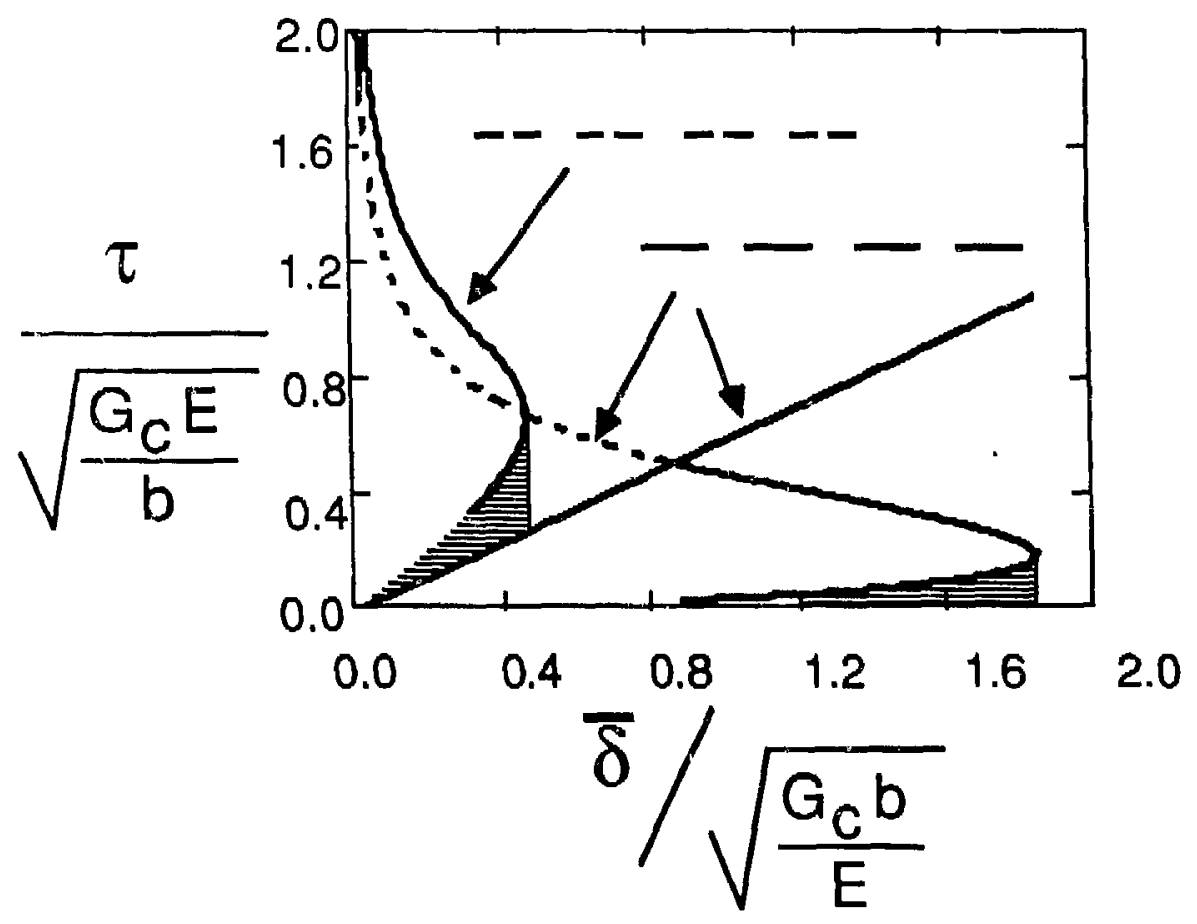

Figure 5. a) Fault model consisting of a row of equal spaced asperities with a periodic arrangement of two asperity sizes. b) Non-dimensionalized stress displacement behavior for the progressive failure of the smaller asperities, and for the remaining equal spaced asperities. (Assumed $v=0.2$ ) 
a)

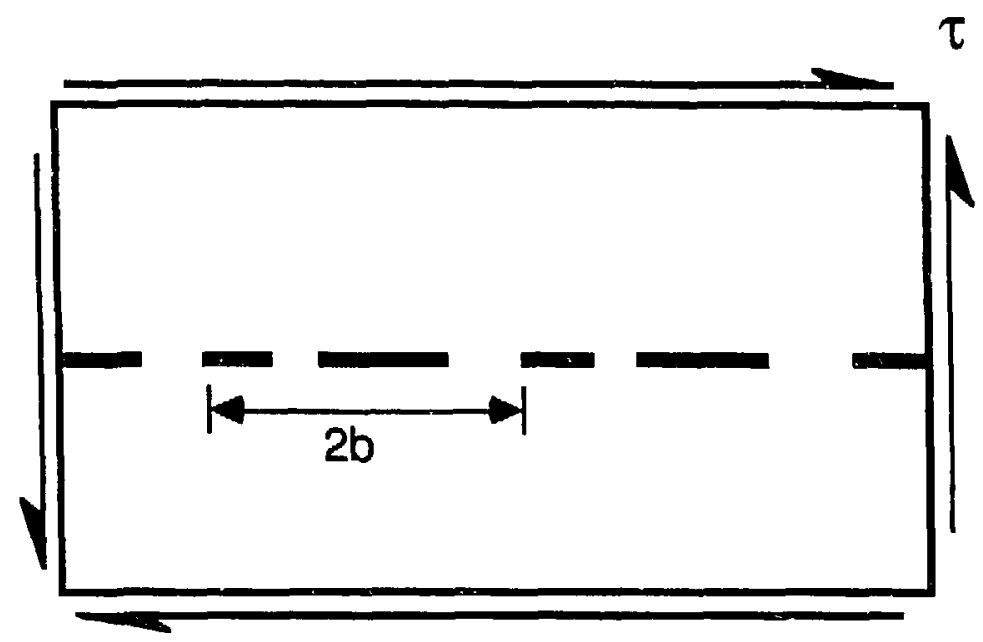

$\tau$

b)

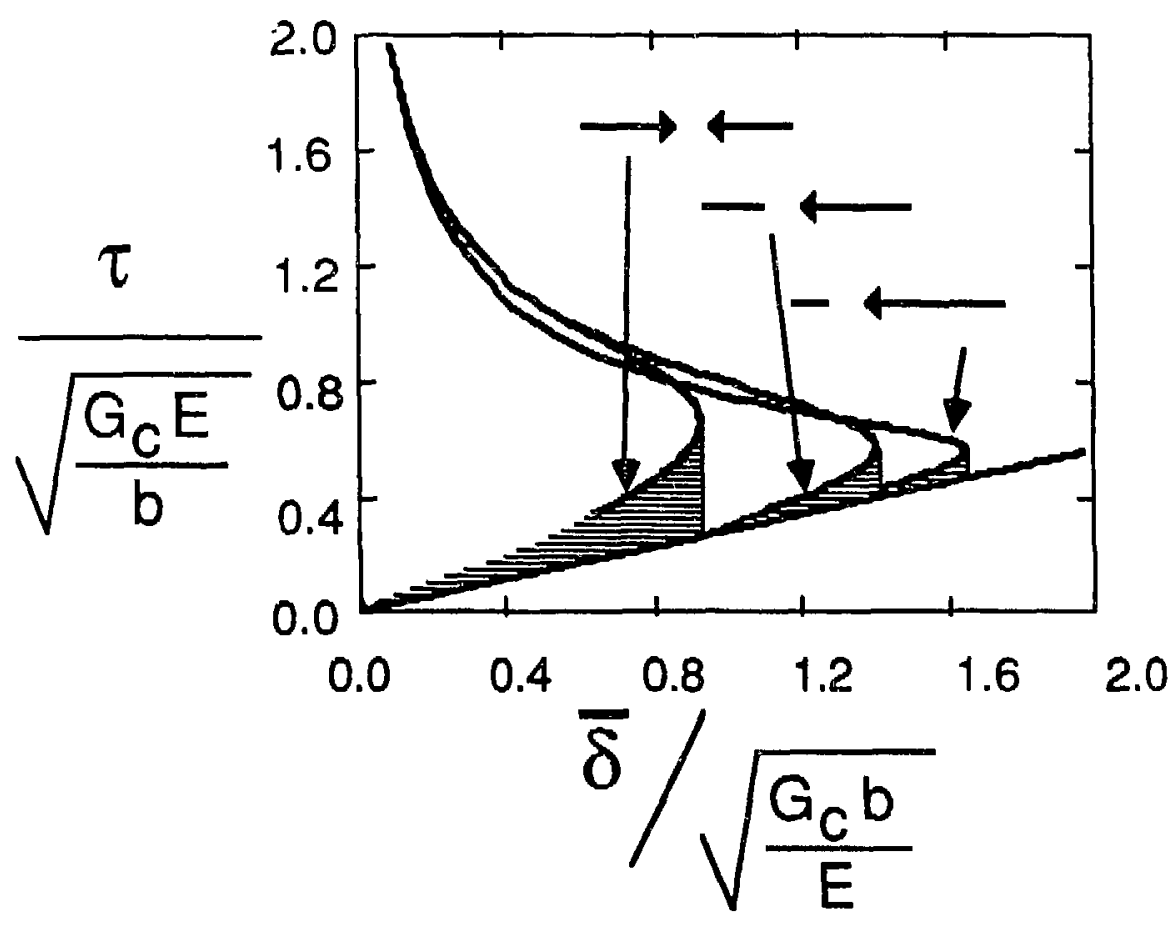

Figure 6. a) Fault model consisting of a periodic arrangement of two asperity sizes and two asperity spacings. b) Non-dimensionalized stress displacement behavior due to the progressive failure of the smaller set of asperities, for different values of $\chi$. (Assumed $v=0.2$ ) 
a)

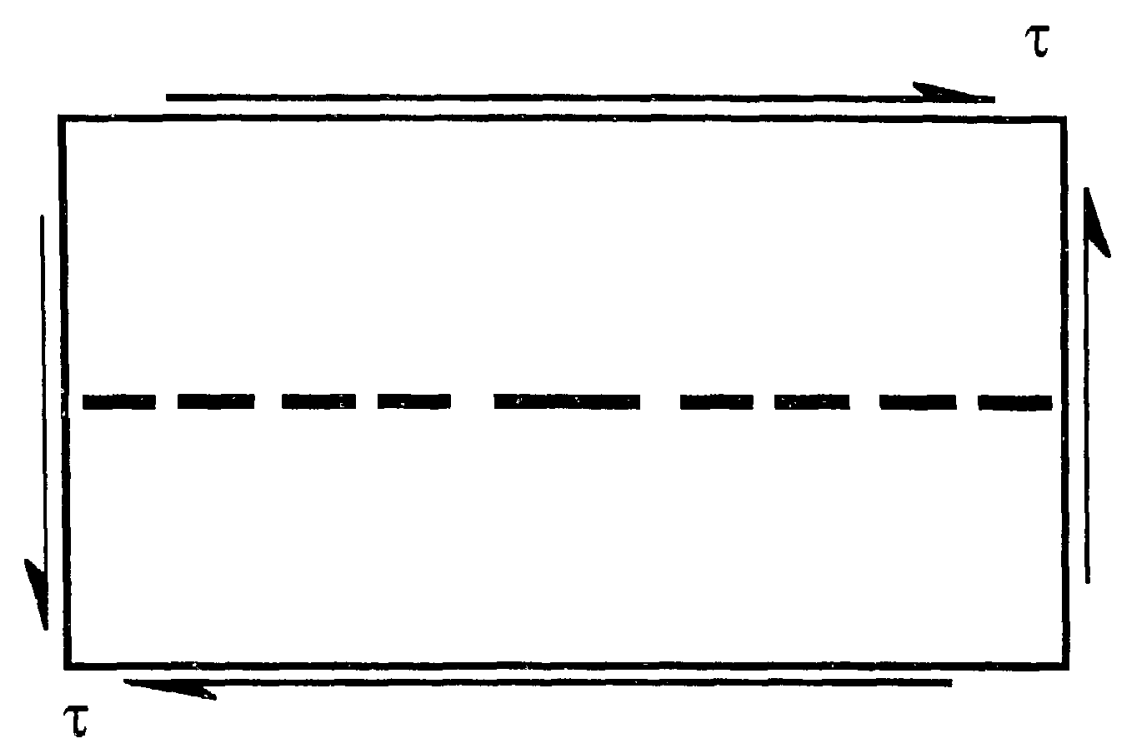

b)

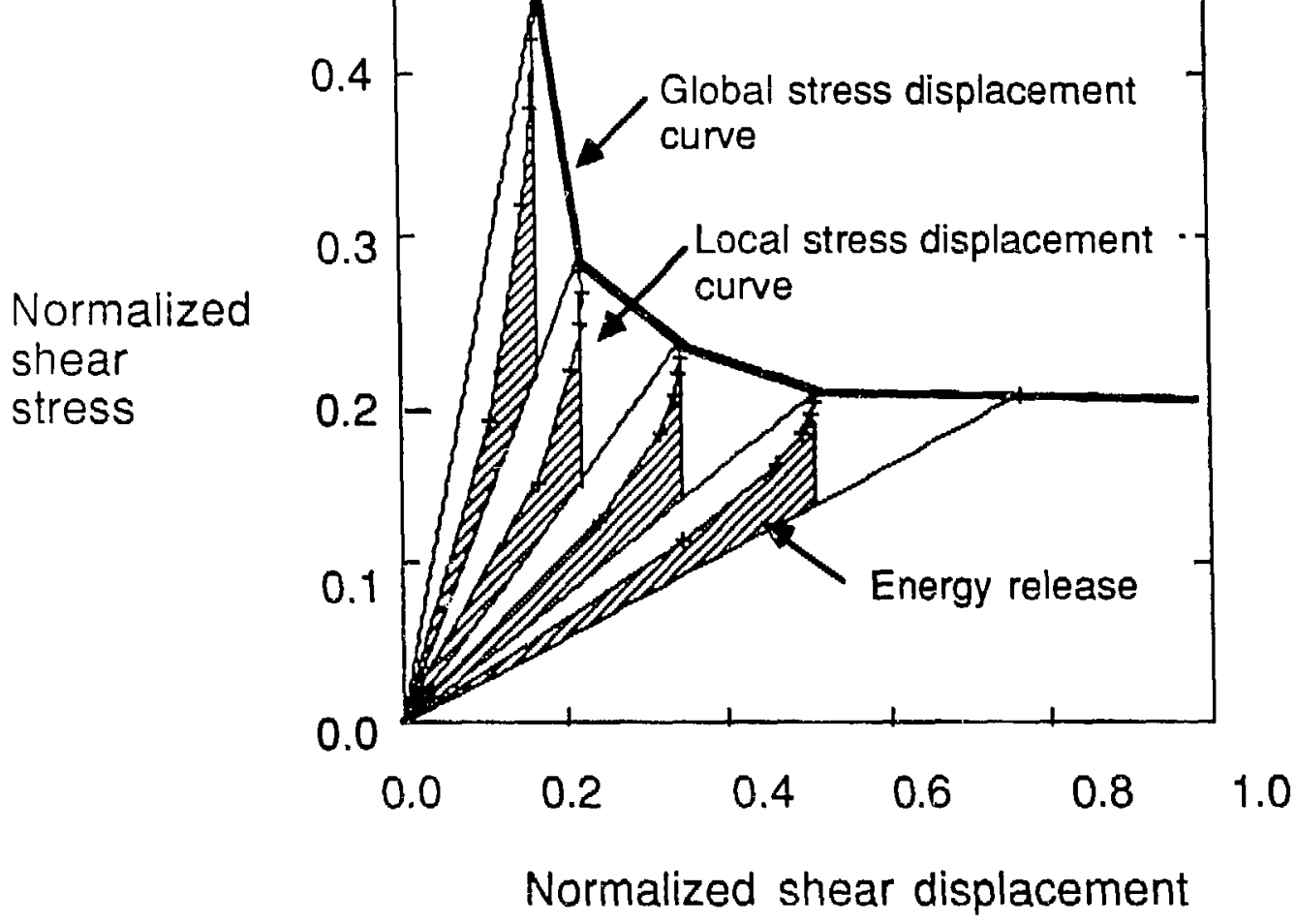

Figure 7. a) Fault model consisting of a row of equal spaced, equal sized asperities containing a slightly largar asperity spacing at the center. b) Non-dimensionalized stress displacement behavior showing both individual and global behavior. (Assumed $v=0.2$ ) 
This report was done with support from the Department of Energy. Any conclusions or opinions expressed in this report represent solely those of the author(s) and not necessarily those of The Regents of the University of California, the Lawrence Berkeley Laboratory or the Department of Energy.

Reference to a company or product name docs not imply approval or recommendation of the product by the University of California or the U.S. Department of Energy to the exclusion of others that may be suitable. 